\title{
Thrombin generation and fibrin formation in dilutional coagulopathy : towards improved peri-operative transfusion protocols
}

Citation for published version (APA):

Schols, S. E. M. (2010). Thrombin generation and fibrin formation in dilutional coagulopathy : towards improved peri-operative transfusion protocols. [Doctoral Thesis, Maastricht University]. Datawyse / Universitaire Pers Maastricht. https://doi.org/10.26481/dis.20100219ses

Document status and date:

Published: 01/01/2010

DOI:

10.26481/dis.20100219ses

Document Version:

Publisher's PDF, also known as Version of record

Please check the document version of this publication:

- A submitted manuscript is the version of the article upon submission and before peer-review. There can be important differences between the submitted version and the official published version of record.

People interested in the research are advised to contact the author for the final version of the publication, or visit the DOI to the publisher's website.

- The final author version and the galley proof are versions of the publication after peer review.

- The final published version features the final layout of the paper including the volume, issue and page numbers.

Link to publication

\footnotetext{
General rights rights.

- You may freely distribute the URL identifying the publication in the public portal. please follow below link for the End User Agreement:

www.umlib.nl/taverne-license

Take down policy

If you believe that this document breaches copyright please contact us at:

repository@maastrichtuniversity.nl

providing details and we will investigate your claim.
}

Copyright and moral rights for the publications made accessible in the public portal are retained by the authors and/or other copyright owners and it is a condition of accessing publications that users recognise and abide by the legal requirements associated with these

- Users may download and print one copy of any publication from the public portal for the purpose of private study or research.

- You may not further distribute the material or use it for any profit-making activity or commercial gain

If the publication is distributed under the terms of Article $25 \mathrm{fa}$ of the Dutch Copyright Act, indicated by the "Taverne" license above, 


\section{Thrombin generation and fibrin formation in dilutional coagulopathy \\ towards improved peri-operative transfusion protocols}


Thrombin generation and fibrin formation in dilutional coagulopathy towards improved peri-operative transfusion protocols

Thesis Universiteit Maastricht ISBN

(c) S.E.M. Schols, Maastricht 2010

Printed by Datawyse Universitaire Pers Maastricht 


\title{
Thrombin generation and fibrin formation in dilutional coagulopathy \\ towards improved peri-operative transfusion protocols
}

\author{
PROEFSCHRIFT \\ ter verkrijging van de graad van doctor \\ aan de Universiteit Maastricht, \\ op gezag van de Rector Magnificus, \\ Prof. mr. G.P.M.F. Mols, \\ volgens het besluit van het College van Decanen, \\ in het openbaar te verdedigen \\ op vrijdag 19 februari 2010 om 12:00 uur
}

door

Saskia Elise Maria Schols

Geboren op 1 maart 1982 te Heerlen 


\section{Promotor}

Prof. dr. H. ten Cate

\section{Copromotoren}

Dr. J.W.M. Heemskerk

Dr. E.C.M. van Pampus

\section{Beoordelingscommissie}

Prof. dr. J.W. Cohen Tervaert (voorzitter)

Dr. H.C.J. Eikenboom (Leids Universitair Medisch Centrum)

Prof. dr. T. Hackeng

Prof. dr. K. van Hoorelbeke (Katholieke Universiteit Leuven, België)

Prof. dr. H. Schouten

Financial support by the Netherlands Heart Foundation for the publication of this thesis is gratefully acknowledged.

CSL Behring is gratefully acknowldged for their major role in the succesful production of this thesis. 
Amor omnia vincit (liefde overwint alles)

Voor mama en papa 



\section{Contents}

$\begin{array}{lll}\text { Chapter } 1 \quad \text { General introduction } & 9\end{array}$

Chapter 2 Correction of coagulation in dilutional coagulopathy: 25 use of kinetic and capacitive coagulation assays to improve hemostasis

Chapter 3 Effects of plasma dilution on tissue factor-induced thrombin generation and thromboelastography: partly compensating role of platelets

Chapter 4 Increased thrombin generation and fibrinogen level after therapeutic plasma transfusion: relation to bleeding

Chapter $5 \quad$ Impaired thrombin generation and fibrin clot formation in patients with dilutional coagulopathy during major surgery

Chapter $6 \quad$ Novel role of glycoprotein Ib-V-IX and von Willebrand factor in platelet-dependent fibrin fiber formation at low shear flow

Chapter $7 \quad$ General discussion

Samenvatting

Addendum: Trombo-elastografie: Een hulpmiddel bij massaal bloedverlies?

Curriculum vitae

Publications

Dankwoord 



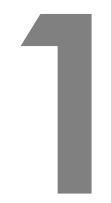

General introduction 
Hemostasis or stopped bleeding is a process that depends on numerous interactions between a damaged vessel wall, platelets and the coagulation system. Under conditions of major blood loss due to surgery or severe trauma, the normal hemostatic process becomes jeopardised and this contributes to ongoing blood loss. This major bleeding problem requires acute pro-hemostatic interventions. Surprisingly, in contrast to the extensive studies performed on other bleeding diseases, very little is known about the efficacy of current interventions. This thesis focuses on the impaired hemostatic process due to massive blood loss and subsequent massive transfusion, leading to insufficient coagulation which is referred to as acquired dilutional coagulopathy. Before describing the clinical problem, general background information is given of mechanisms contributing to normal hemostasis.

\section{Platelet activation and thrombus formation}

With an intact, healthy vessel wall, platelets are kept in a resting state and the coagulation cascade remains inactivated. However, upon vascular damage, the blood is exposed to components of the extracellular matrix, particularly von Willebrand factor (VWF) and collagen, to which platelets avidly adhere via their receptors glycoprotein (GP)Ib-V-IX and GPVI, respectively. ${ }^{1-3}$ These interactions are most prominent at high, arterial shear rates. Both receptors initiate complex signalling pathways, by which platelets change their shape, form pseudopods and express active integrins on their surface. ${ }^{4-6}$ Together with GPIb-V-IX, the activated integrin $\alpha \mathrm{llb} \beta_{3}$ is responsible for platelet-platelet interactions via VWF and fibrin(ogen), and the formation of a platelet aggregate. ${ }^{7,8}$ Factors that are involved in aggregate stability are, for instance, the secretion of autocrine platelet-activating products and signalling pathways evoked by platelet-platelet contacts, all of which prevent integrin inactivation and platelet disaggregation. ${ }^{9-11} \mathrm{~A}$ subpopulation of highly activated platelets exhibits the so-called procoagulant response, consisting of exposure of negatively charged phosphatidylserine at the outer cell surface, where coagulation factors can bind and form complexes, which stimulates the generation of thrombin. ${ }^{12-14}$ Thrombin is a serine protease that mediates the formation of fibrin fibers from fibrinogen. The result of all these reactions is a stable fibrin-containing thrombus with various types of activated platelets, which stops the bleeding and repairs the vascular damage (Figure 1.1).

By using genetically modified mice, numerous platelet signalling proteins have been identified, all of which play a role in thrombus formation. ${ }^{15,16}$ However, in spite of a vast amount of research, the final steps in this process are still not well resolved. For instance, it is unclear how and where fibrin strands are formed in a growing 


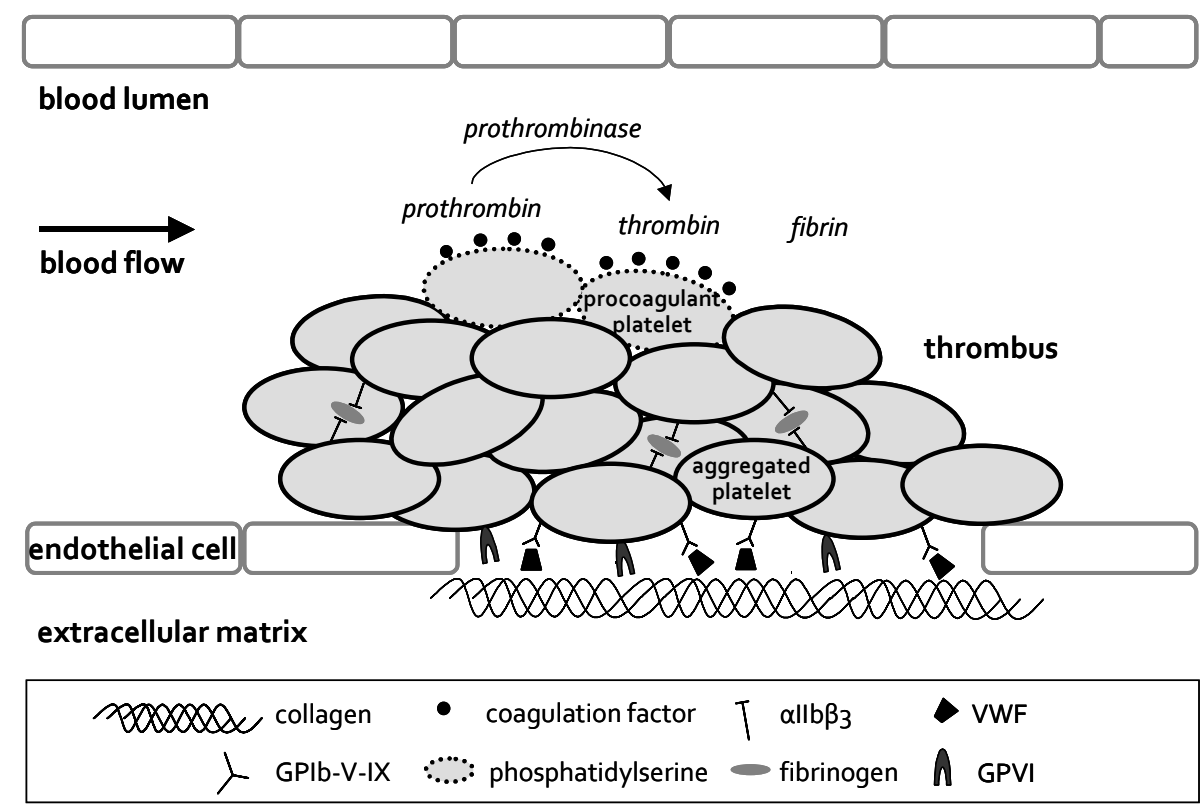

Figure 1.1: Scheme of thrombus formation after vessel wall damage. Vascular damage results in exposure of extracellular matrix components, such as von Willebrand factor (VWF) and collagen, at which platelets adhere in particular through GPIb-V-IX and GPVI, respectively. Platelets aggregate via interaction of integrin $\alpha$ llb $\beta_{3}$ with fibrinogen, while patches of platelets expose procoagulant phosphatidylserine (PS), at which coagulation factors are assembled and activated. Activation of the prothrombinase complex results in the formation of thrombin, which converts fibrinogen into fibrin monomers.

thrombus, even though in vivo data with mice suggest that this already happens in an early stage of thrombus formation. ${ }^{17}$ Given the central role of platelets in thrombus formation, one can anticipate that they might also drive the formation of fibrin fibers, but this is not documented.

\section{Activation of the coagulation cascade}

In addition to platelet activation, vascular damage simultaneously leads to the availability of triggers of the coagulation cascade. The coagulation process in plasma is known to be initiated by the so-called extrinsic and intrinsic pathways. For the purpose of this introduction, figure 1.2 gives a simplified overview of these pathways. Exposure and activation of tissue factor (extrinsic pathway), in a way involving cysteine reshuffling by protein disulfide isomerase, lead to the formation of a complex with factor VII(a) thereby stimulating the activation of factors IX and X. ${ }^{18-20}$ Recent in vivo experimental thrombosis studies and in vitro flow studies indicate that also the intrinsic pathway plays an important role in thrombus formation. ${ }^{21-23}$ It is 
currently believed that the exposure of vascular collagen leads to consecutive activation of the factors IX, XI and XII. The activated factor IX, in turn, contributes to the activation of factor $X$. Factors VIIla and IXa form the tenase complex on the surface of procoagulant platelets, which mediates the cleavage of factor $X$ into active factor Xa. Also on procoagulant platelets the prothrombinase complex is formed, which consists of factors $\mathrm{Va}$ and $\mathrm{Xa}$, and mediates the conversion of prothrombin into thrombin. There is no doubt that thrombin plays a central role in the coagulation cascade, as it triggers multiple positive feed forward loops, e.g. by activating factors $\mathrm{V}$, VIII and $\mathrm{XI}$, which eventually results in an explosive burst of thrombin generation. $^{24-26}$

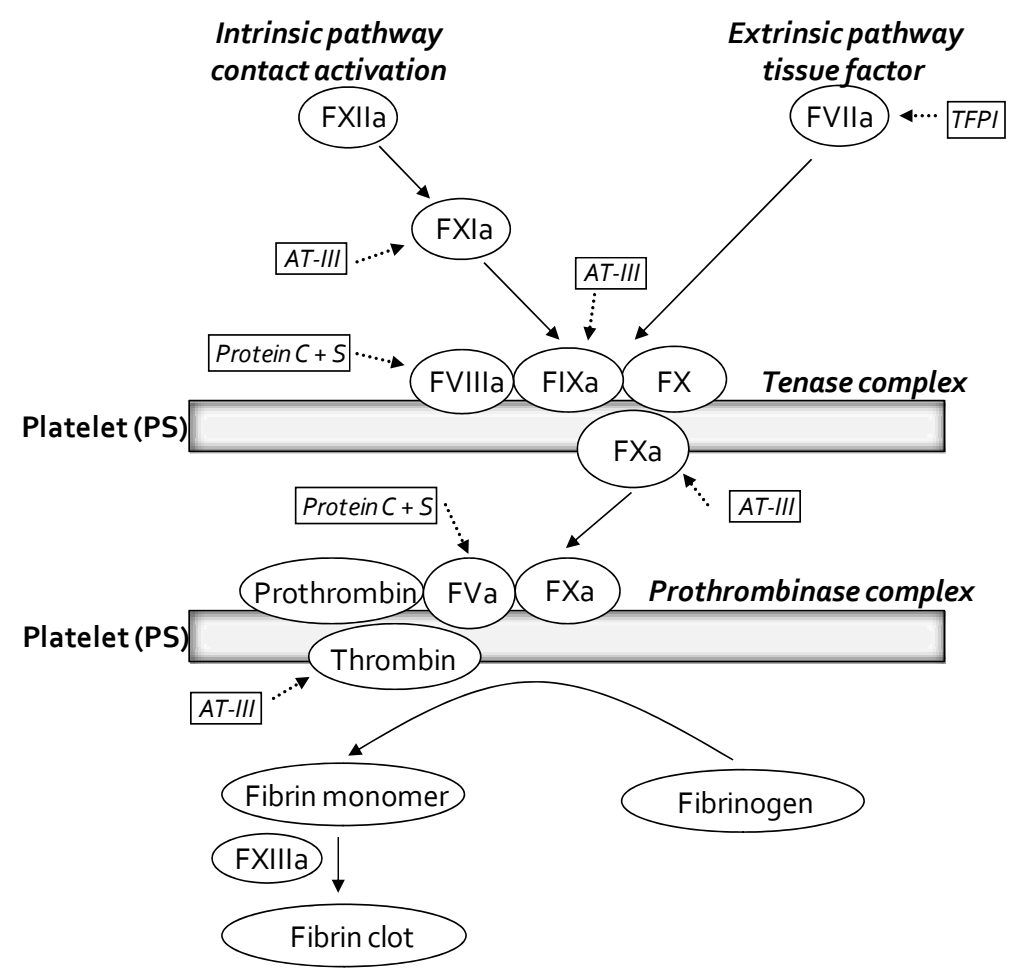

Figure 1.2: Simplified overview of the coagulation cascade. The coagulation process is triggered by two pathways, the extrinsic pathway (by tissue factor) and the intrinsic pathway (contact activation), both of which lead to activation of factor X into factor $\mathrm{Xa}$ (FXa) and factor IX into factor IXa. The tenase complex, consisting of activated factors VIII and IX, is highly activated on the surface of activated platelets exposing phosphatidylserine (PS). Similarly, PS-exposing platelets strongly support prothrombinase activity, where activated factors $\mathrm{V}$ and $X$ convert prothrombin into thrombin. As a consequence of thrombin generation, fibrinogen is cleaved to fibrin monomers. Factor XIIla polymerizes the monomers into a dense fibrin clot. In addition, thrombin has a positive feedback by activating several coagulation factors as well as platelets (not shown). Thrombin and other coagulation factors are rapidly inactivated by anticoagulation pathways (dotted lines and italic text), while the fibrin clot is degraded at a slower rate. 
Thrombin cleaves fibrinogen into fibrin monomers. It further activates factor XIII, which is a transglutaminase that cross-links the fibrin monomers to a dense fibrin network. In addition, thrombin activates platelets via specific receptors, thereby contributing to the development of platelet procoagulant activity. ${ }^{27}$

Next to these procoagulant functions, thrombin also has anticoagulant effects: thrombin secondarily inhibits its own formation by interaction with vascular thrombomodulin. The binding to this receptor protein leads to activation of anticoagulant protein $\mathrm{C}$. Together with protein $\mathrm{S}$, activated protein $\mathrm{C}$ mediates the inactivation of factors $\mathrm{Va}$ and VIIla, as a consequence of which the tenase and prothrombinase reactions are fading out. ${ }^{28,29}$ Furthermore, thrombin catalyzes the formation of plasmin, which degrades the fibrin clot. However, at higher concentrations, it activates the thrombin-activated-fibrinolysis inhibitor (TAFI), thereby preventing activation of the fibrinolysis pathway. Importantly, the life-time of thrombin in plasma is limited to several seconds, since it is rapidly inactivated by binding to antithrombin and thrombomodulin. ${ }^{30}$ Given these multiple roles of thrombin, it may not be a surprise that the assessment of thrombin generation is believed to disclose a hyper- or hypocoagulable phenotype. .1-33 $^{1-3}$

In human plasma, these pro- and anticoagulant factors are not present in similar amounts. This is obvious from estimates of the molar concentrations in normal plasma (Table 1.1). Most abundant are those proteins that are active in the final stages of the coagulation cascade (in micromolar concentrations), i.e. fibrinogen, prothrombin and antithrombin. Present in sub-micromolar concentrations are proteins of the intrinsic pathway, as well as factors $\mathrm{V}, \mathrm{VII}$, and VIII and tissue factor pathway inhibitor (TFPI). Other coagulation proteins circulate at even lower concentrations, below or well below $100 \mathrm{nM}$. Both prothrombin and fibrinogen are considered to play a central and concentration-dependent role in the generation of thrombin and fibrin, respectively. ${ }^{34-36}$ Hence, one may expect that plasma dilution influences this role.

\section{Peri-operative dilutional coagulopathy}

During the time that it takes to stop massive bleeding by surgical means, patients who experience massive blood loss are routinely infused with a variety of fluids to maintain their blood volume in order to prevent hemorrhagic shock. However, these infusions of fluids, which lack coagulation factors, dilute the patient's coagulation factors and in turn reduce the hemostatic potential. This may lead to persistent bleeding. The platelet count is also reduced during the infusion process, thereby further impairing the hemostatic process. This condition is referred to as dilutional coagulopathy. ${ }^{37,38}$ 
Table 1.1: Concentration ranges of pro- and anticoagulant factors in normal human plasma. Abbreviations: HMW kininogen, high molecular weight kininogen; TFPI, tissue factor pathway inhibitor. Data from Blombäck et al. ${ }^{67}$

\begin{tabular}{|l|l|l|l|}
\hline Plasma factor & $\begin{array}{l}\text { Weight concentration } \\
(\mathrm{mg} / \mathrm{l})\end{array}$ & $\begin{array}{l}\text { Molecular weight } \\
(\mathrm{g} / \mathrm{mol})\end{array}$ & $\begin{array}{l}\text { Molar concentration } \\
(\mathrm{nM})\end{array}$ \\
\hline Fibrinogen & $2080-3120$ & 340,000 & $6100-9200$ \\
Prothrombin & $80-120$ & 68,700 & $1150-1750$ \\
Factor V & $5 \cdot 5-8.43$ & 330,000 & $17-25$ \\
Factor VII & $0.4-0.6$ & 48,000 & $8-13$ \\
Factor VIII & $0.08-0.12$ & 330,000 & $0.24-0.36$ \\
Factor IX & $3 \cdot 5-5 \cdot 3$ & 55,400 & $64-96$ \\
Factor X & $8-12$ & 59,000 & $135-200$ \\
Factor XI & $3 \cdot 7-5 \cdot 6$ & 160,000 & $23-35$ \\
Factor XII & $24-36$ & 80,000 & $296-444$ \\
Factor XIII & $24-36$ & 320,000 & $75-115$ \\
Prekallikrein & $34-52$ & 86,000 & $400-600$ \\
HMW kininogen & $72-108$ & 120,000 & $600-900$ \\
Antithrombin & $130-195$ & 65,000 & $2000-3000$ \\
TFPI & $0.08-0.12$ & 40,000 & $2-3$ \\
Protein C & $3 \cdot 6-5 \cdot 4$ & 57,000 & $65-95$ \\
Protein S & $18-27$ & 75,000 & $240-360$ \\
Protein Z & $2.2-3 \cdot 2$ & 50,000 & $45-65$ \\
VWF & $64-96$ & $10 \times 10^{6}$ & $<8$ \\
(mono/multi) & & & \\
\hline
\end{tabular}

Massive blood loss is commonly defined as the loss of one blood volume within 24 hours or the loss of $50 \%$ of the blood volume within three hours in more acute situations. ${ }^{39}$ Massive blood loss is relatively rare, but has a high mortality and therefore is of major clinical importance. Currently, the hemostatic state is monitored by routine coagulation tests, i.e. the partial thromboplastin time (aPTT), the prothrombin time (PT) and the derived international normalized ratio (INR). However, these coagulation tests only inform on the lag time till a fibrin clot is formed. In addition, these tests are known to be insensitive for conditions of dilution. Therefore, better diagnostic tests are required to monitor the capacity of the hemostatic state during dilution to detect insufficient coagulation. Consequently, this will help to increase our still limited understanding of the underlying mechanism of coagulation during dilution.

The extent of peri-operative coagulopathy varies from case to case and is particularly dependent on the type of surgery, the rapidity of blood loss, presence of shock or consumption of platelets and coagulation factors. In cardiovascular interventions such as coronary artery bypass graft surgery, plasma dilution is limited 
to the infusion of priming fluids for connection to an extracorporeal perfusion system. However, the extracorporeal circulation frequently causes platelet dysfunction and hyperfibrinolysis, which increases the risk of bleeding complications. ${ }^{40-42} \mathrm{~A}$ number or major surgical interventions are accompanied by the loss of large volumes of blood and, hence, by more extensive fluid transfusions.

As indicated in Figure 1.3, patients with massive blood loss are at risk to enter a vicious circle. The reason is that major blood loss requires the transfusion of crystalloids and colloids to prevent hypovolemia, and the transfusion of erythrocyte concentrates to prevent impaired oxygen delivery to vital organs. ${ }^{43,44}$ Inevitably, these infusions lead to a reduction in plasma coagulation factors and platelets, an

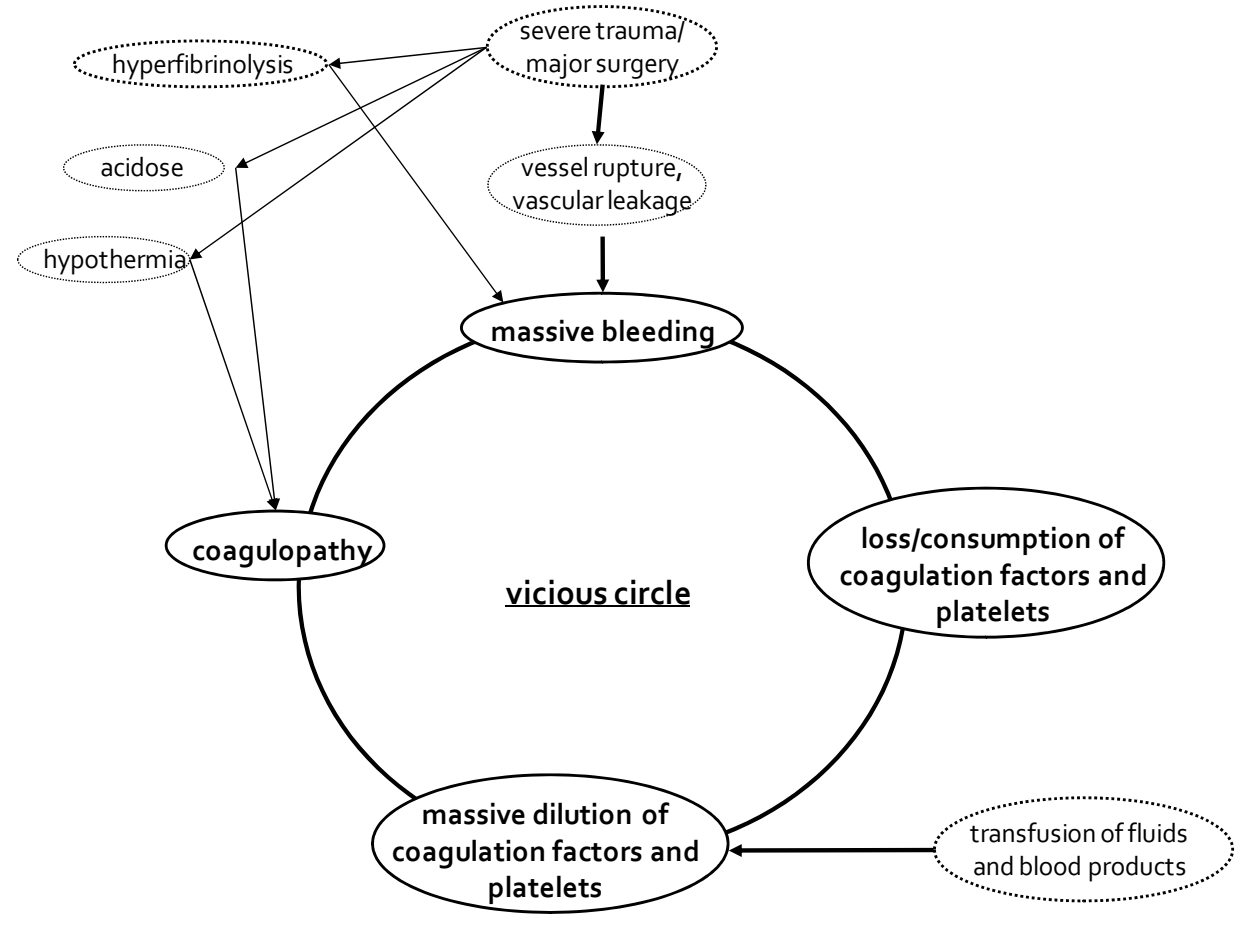

Figure 1.3: Vicious circle of massive bleeding, massive transfusion and coagulopathy. Extensive vessel rupture and vascular leakage upon major surgery and trauma can lead to massive bleeding, where blood cells and coagulation factors are lost and consumed. Massive transfusion of fluids and blood products will result in further dilution of coagulation factors, which enforces the coagulopathy and increases bleeding. This worsens the clinical condition of the patient. Factors enhancing these complications include hyperfibrinolysis, acidosis and hypothermia. 
effect that is amplified if there is concurrent consumption of coagulation factors and platelets. ${ }^{45}$ Even the transfusion of fresh frozen plasma (FFP) and platelet concentrates can worsen the situation, since coagulation factors in these blood products are diluted with citrate when given to the patient. ${ }^{46}$ The appearance of coagulopathy in combination with acidosis (low blood $\mathrm{pH}$ ) and hypothermia (low temperature, e.g. in trauma) is referred to as the "lethal triad", and consequently will further worsen the patient's condition and facilitate the development of hemorrhagic shock. ${ }^{37}$ In the well-controlled environment of the hospital, contrary to the less manageable situation of acute trauma, specific transfusion protocols are used to prevent this scenario. However, the clinical situation of trauma is outside the scope of this thesis.

\section{Massive transfusion practice and blood volume replacement}

In major surgery, transfusion interventions start with infusing fluids (crystalloids and colloids) and later red cell concentrates in order to prevent tissue hypoperfusion (Figure 1.4). The total volume of colloids that can be infused is limited, as these infusions may interfere with fibrin clot formation. ${ }^{47}$ Red cell concentrates are given, once the hematocrit is reduced to $21-24 \% .{ }^{4} \mathrm{In}$ addition to tissue oxygenation, red cells contribute to thrombus formation by causing margination of platelets towards the vessel wall. When more than 0.5 blood volume is replaced or blood loss is very rapid, the coagulation state is monitored with conventional coagulation tests, i.e. the aPTT and the PT. Once these (insensitive) tests give values $>1.5 \times$ normal, FFP is transfused to stop bleeding or reduce the risk of bleeding. ${ }^{49}$ However, the administration of large amounts of FFP contributes to further dilution and has the risk of adverse effects of citrate toxicity, immune reactions and infections. ${ }^{50}$ On the other hand, in case of trauma, there is evidence that earlier and more intensive transfusion of FFP results in better prevention of massive hemorrhage, ${ }^{51,52}$ although not all studies support this finding. ${ }^{53,54}$

At a replacement of $>1.5$ blood volumes, platelets usually become limited, and platelet transfusion starts to maintain a count of $>50 \times 10^{9} / 1 .{ }^{55}$ In recent years, control of the fibrinogen level has got particular attention; several reports describe a plasma concentration of $1.0 \mathrm{~g} / \mathrm{l}$ as a critical lower margin. $43,55,56,57$ If FFP transfusions fail to reach this level, commercial fibrinogen concentrates can be used. Another important aspect is the control of anticoagulant treatment. For instance, heparin that is administered before (cardio)vascular surgery, needs to be neutralized with protamin at a later stage to prevent bleeding problems. Indeed, insufficient heparin neutralization is a common cause of peri-operative bleeding. ${ }^{58}$ Furthermore, patients taking a vitamin $\mathrm{K}$ antagonist (coumarins) are also at increased risk of bleeding. ${ }^{59} \mathrm{To}$ 


\begin{tabular}{|ccccccc|}
\hline \multicolumn{2}{|c}{ Intervention: crystalloids } & colloids & RCC & FFP & platelets & fibrinogen \\
\hline $\begin{array}{c}\text { Trigger point for } \\
\text { intervention: }\end{array}$ & at start & $\begin{array}{c}>1.5 \mathrm{lstart} \\
\text { fluids }\end{array}$ & $\begin{array}{c}\mathrm{Ht}: \\
21-24 \%\end{array}$ & $\begin{array}{c}>1.5 \times \mathrm{PT} / \mathrm{aPTT} \\
\text { Fibr. }<1.0 \mathrm{~g} / \mathrm{l}\end{array}$ & $\begin{array}{c}<0-100 \times \\
10\end{array}$ & $<1.0 \mathrm{~g} / \mathrm{l}$ \\
\hline
\end{tabular}

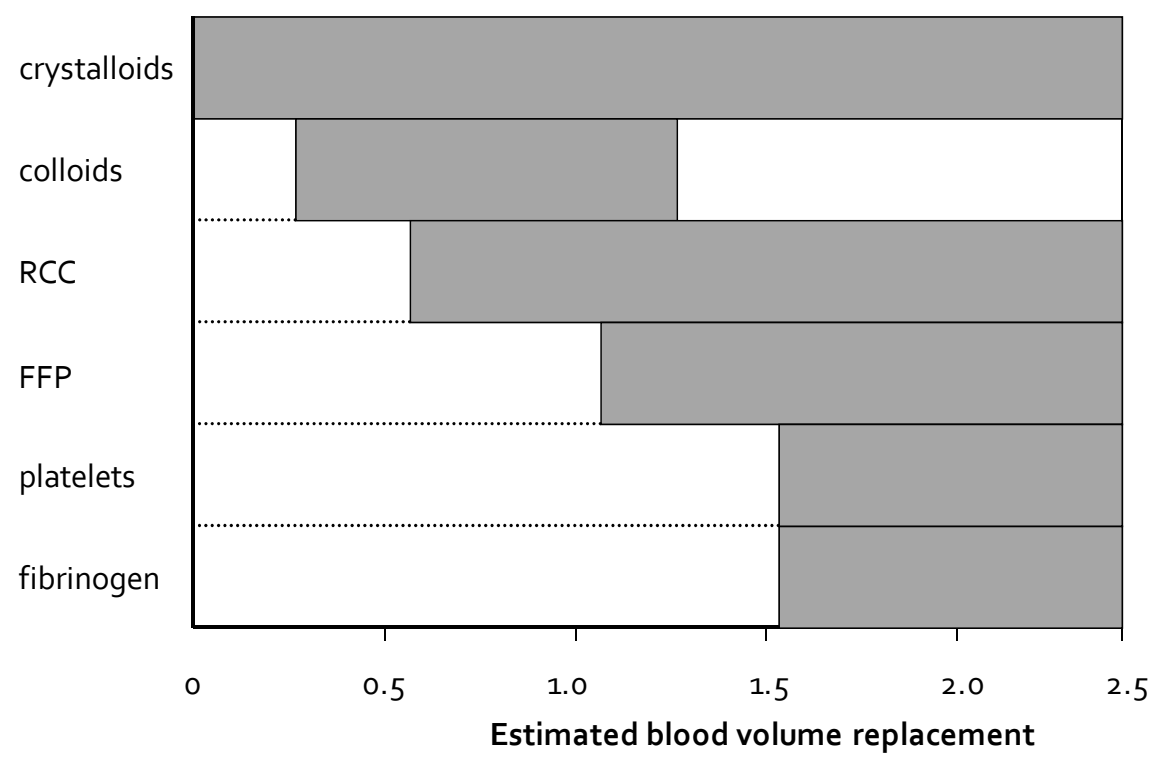

Figure 1.4: Treatment options in major surgery and trauma to prevent hypovolemia, tissue hypo-oxygenation and bleeding. Initial transfusion of crystalloid and colloid fluids and blood products lead to dilution of blood and replacement of the blood volume. Red cell concentrates (RCC) are transfused at a hematocrit below 21-24\%. FFP is given, when clotting times are more than $1.5 \times$ prolonged (replacement of about 1.0 blood volume). Platelets are transfused to maintain a count above $50 \times 10^{9} / \mathrm{l}$. Incidentally, if fibrinogen falls below $1.0 \mathrm{~g} / \mathrm{l}$, this factor is given separately. A blood volume of 1.0 is equal to an averaged amount of 5 litre of blood.

prevent bleeding problems, it is important to accurately monitor the effect of the anticoagulant treatment on the hemostatic state and subsequently adjust the dosage. In case of elective surgery, coumarin treatment has to be stopped at least 24 hours before the procedure.

\section{Use of factor concentrates and novel coagulation tests}

Recently, there is a growing interest in the potential use of factor concentrates in stead of FFP for the treatment of dilutional coagulopathy. Major advantages are that in this way procoagulant factors can be administered in smaller volumes, and adverse inflammatory effects of plasma transfusion can be reduced. Currently, concentrates of fibrinogen, prothrombin complex or recombinant factor VIla are given based on 
expert opinion and personal experience rather than as a result of clinical randomized controlled studies. ${ }^{60-62}$ To monitor the effect of factor concentrates on the hemostatic state, better coagulation tests are required that are capable of providing information on the maximal capacity of coagulation and need to surpass the limited sensitivity of the routine coagulation tests. Interestingly, the traditional method of rotational thromboelastography has experienced a revival, particularly to measure the efficacy of fibrinogen-type interventions in restoring fibrin clot formation. ${ }^{63-65} \mathrm{An}$ advantage is that it is a point-of-care method, which uses whole-blood while it can be performed near the patient and gives quick information on the clot-forming process. Another capacitive test which is increasingly used to assess coagulation deficiencies is the thrombin generation assay, as this process is also considered to reflect the capacity of the hemostatic system. ${ }^{32,66}$ At the outset of the current research, we hypothesized that particularly the combination of capacitive measurements of thrombin generation and fibrin clot formation might be more beneficial than routine coagulation tests to monitor dilutional coagulopathy and assess a potentially increased risk of bleeding.

\section{Outline of this thesis}

This thesis focuses on unravelling the mechanisms of impaired hemostasis in dilutional coagulopathy to eventually improve current transfusion practices. The introductory chapter 1 provides background information and clarifies the clinical problem of coagulopathy upon dilution. In chapter $\mathbf{2}$, an overview is given of the currently available guidelines and transfusion protocols for the control of coagulation problems in case of massive blood loss. This chapter tries to identify the impaired biochemical processes in plasma that lead to insufficient hemostasis due to massive dilution. It also discusses recent point-of-care tests used to diagnose coagulopathy, as well as the new possibilities of treatment with plasma factor concentrates to stop massive bleeding. In chapter 3, optimization is described of two capacitive-type of measurements of the coagulation process upon dilution, namely thrombin generation and fibrin clot formation in plasma. The results of in vitro addition of factor concentrates to diluted plasma are also reported here. The aim was to investigate which concentrates can normalize the outcome of the capacitive assays, and further to determine which concentrates provide new possibilities for transfusion intervention to coagulopathic patients. Chapter $\mathbf{4}$ describes an in vivo study of the effects of FFP transfusion to patients undergoing major surgery with bleeding following dilutional coagulopathy. The persistence of bleeding is compared to the outcome of measurements of thrombin generation, fibrinogen and routine coagulation tests. These findings are extended in chapter $\mathbf{5}$, where the plasmas from 
three different groups of patients are compared: patients with oral anticoagulation, patients undergoing coronary artery bypass graft surgery, and patients undergoing major general surgery. Again, measurements are performed of thrombin generation, fibrin clot formation and routine coagulation times. The goal is to establish whether capacitive coagulation assays can better monitor the patient's coagulation state than the routine coagulation tests, and whether these tests can predict an increased bleeding risk in patients. Chapter 6 describes a novel role of platelets in promoting the formation of fibrin strands under physiologic conditions of flow. The roles of platelet GPIb-V-IX and VWF are identified both in the human system and using genetically modified mice. In chapter 7 , the results of this thesis are discussed as a whole. It also tries to identify the possible clinical implications. 


\section{References}

1. De Groot PG. The role of von Willebrand factor in platelet function. Semin Thromb Hemost 2002; 28:133-138.

2. Wu D, Vanhoorelbeke $K$, Cauwenberghs $N$, Meiring $M$, Depraetere $H$, Kotze HF, Deckmyn $\mathrm{H}$. Inhibition of the von Willebrand (VWF)-collagen interaction by an antihuman VWF monoclonal antibody results in abolition of in vivo arterial platelet thrombus formation in baboons. Blood 2002; 99:3623-3628.

3. Ruggeri ZM, Mendolicchio GL. Adhesion mechanisms in platelet function. Circ Res 2007; 100:1673-1685.

4. Jackson SP. The growing complexity of platelet aggregation. Blood 2007; 109:5087-5095.

5. Heemskerk JW, Kuijpers MJ, Munnix IC, Siljander PR. Platelet collagen receptors and coagulation. A characteristic platelet response as possible target for antithrombotic treatment. Trends Cardiovasc Med 2005; 15:86-92.

6. Brass LF, Zhu L, Stalker TJ. Novel therapeutic targets at the platelet vascular interface. Arterioscler Thromb Vasc Biol 2008; 28:S43-S50.

7. Ma YQ, Qin J, Plow EF. Platelet integrin $\alpha$ llb $\beta_{3}$ : activation mechanisms. J Thromb Haemost 2007; 5:1345-1352.

8. Savage B, Sixma JJ, Ruggeri ZM. Functional self-association of von Willebrand factor during platelet adhesion under flow. Proc Natl Acad Sci U S A 2002; 99:425-430.

9. Gibbins JM. Platelet adhesion signalling and the regulation of thrombus formation. J Cell Sci 2004; 117:3415-3425.

10. Brass LF, Zhu L, Stalker TJ. Minding the gaps to promote thrombus growth and stability. J Clin Invest 2005; 115:3385-3392.

11. Cosemans JM, Iserbyt BF, Deckmyn $H$, Heemskerk JW. Multiple ways to switch platelet integrins on and off. J Thromb Haemost 2008; 6:1253-1261.

12. Lecut $C$, Schoolmeester A, Kuijpers MJ, Broers JL, van Zandvoort MA, Vanhoorel beke $K$, Deckmyn $H_{1}$, Jandrot-Perrus $M$, Heemskerk JW. Principal role of glycoprotein VI in $\alpha_{2} \beta_{1}$ and $\alpha \mathrm{llb} \beta_{3}$ activation during collagen-induced thrombus formation. Arterioscler Thromb Vasc Biol 2004; 24:1727-1733.

13. Siljander PR, Munnix IC, Smethurst PA, Deckmyn H, Lindhout T, Ouwehand WH, Farndale RW, Heemskerk JW. Platelet receptor interplay regulates collagen-induced thrombus formation in flowing human blood. Blood 2004; 103:1333-1341.

14. Munnix IC, Kuijpers MJ, Auger J, Thomassen CM, Panizzi P, van Zandvoort MA, Rosing J, Bock PE, Watson SP, Heemskerk JW. Segregation of platelet aggregatory and procoagulant microdomains in thrombus formation: regulation by transient integrin activation. Arterioscler Thromb Vasc Biol 2007; 27:2484-2490.

15. Denis CV, Wagner DD. Platelet adhesion receptors and their ligands in mouse models of thrombosis. Arterioscler Thromb Vasc Biol 2007; 27:728-739.

16. Brass LF, Stalker TJ, Zhu L, Lu B, Woulfe DS, Prevost N. Boundary events: contactdependent and contact-facilitated signaling between platelets. Semin Thromb Hemost 2004; 30:399-410.

17. Falati S, Gross P, Merrill-Skoloff G, Furie BC, Furie B. Real-time in vivo imaging of platelets, tissue factor and fibrin during arterial thrombus formation in the mouse. Nat Med 2002; 8:1175-1181. 
18. Mackman N. Role of tissue factor in hemostasis and thrombosis. Blood Cells Mol Dis 2006; 36:104-107.

19. Reinhardt C, von Bruhl ML, Manukyan D, Grahl L, Lorenz M, Altmann B, Dlugai S, Hess S, Konrad I, Orschiedt L, Mackman N, Ruddock L, Massberg S, Engelmann B. Protein disulfide isomerase acts as an injury response signal that enhances fibrin generation via tissue factor activation. J Clin Invest 2008; 118:1110-1122.

20. Cho J, Furie BC, Coughlin SR, Furie B. A critical role for extracellular protein disulfide isomerase during thrombus formation in mice. J Clin Invest 2008; 118:1123-1131.

21. Hack CE. The role of factor XII in contact system activation. Blood 1998; 92:703-704.

22. Renné T, Nieswandt B, Gailani D. The intrinsic pathway of coagulation is essential for thrombus stability in mice. Blood Cells Mol Dis 2006; 36:148-151.

23. Van der Meijden PE, Munnix IC, Auger JM, Govers-Riemslag JW, Cosemans JM, Kuijpers MJ, Spronk HM, Watson SP, Renné T, Heemskerk JW. Dual role of collagen in factor XII-dependent thrombus formation. Blood 2009; in press.

24. Mann KG, Butenas $S$, Brummel K. The dynamics of thrombin formation. Arterioscler Thromb Vasc Biol 2003; 23:17-25.

25. Pieters J, Lindhout $\mathrm{T}$, Hemker HC. In situ-generated thrombin is the only enzyme that effectively activates factor VIII and factor V in thromboplastin-activated plasma. Blood 1989; 74:1021-1024.

26. Lane DA, Bowry SK. The scientific basis for selection of measures of thrombogenicity. Nephrol Dial Transplant 1994; 9:18-28.

27. Heemskerk JW, Bevers EM, Lindhout T. Platelet activation and blood coagulation. Thromb Haemost 2002; 88:186-193.

28. Preston RJ, Tran S, Johnson JA, Ainle FN, Harmon S, White B, Smith OP, Jenkins PV, Dahl back B, O'Donnell JS. Platelet factor 4 impairs the ant icoagulant act ivity of activated protein C. J Biol Chem 2009; 284:5869-5875.

29. Tans G, Rosing J, Thomassen MC, Heeb MJ, Zwaal RF, Griffin JH. Comparison of anticoagulant and procoagulant activities of stimulated platelets and platelet-derived microparticles. Blood 1991; 77:2641-2648.

30. Lindhout $T$, Baruch $D$, Schoen $P$, Franssen J, Hemker HC. Thrombin generation and inactivation in the presence of antithrombin III and heparin. Biochemistry 1986; 25:5962-5969.

31. Vanschoonbeek K, Feijge MA, Paquay M, Rosing J, Saris W, Kluft C, Giesen PL, de Maat MP, Heemskerk JW. Variable hypocoagulant effect of fish oil intake in humans: modulation of fibrinogen level and thrombin generation. Arterioscler Thromb Vasc Biol 2004; 24:1734-1740.

32. Hemker HC, Giesen P, Al Dieri R, Regnault V, de Smedt E, Wagenvoord R, Lecompte T, Béguin S. Calibrated automated thrombin generation measurement in clotting plasma. Pathophysiol Haemost Thromb 2003; 33:4-15.

33. Van Veen JJ, Gatt A, Makris M. Thrombin generation testing in routine clinical practice: are we there yet? Br J Haematol 2008; 142:889-903.

34. Butenas S, van't Veer C, Mann KG. "Normal" thrombin generation. Blood 1999; 94:2169-2178. 
35. Zwaginga JJ, Koomans HA, Sixma JJ, Rabelink TJ. Thrombus formation and plateletvessel wall interaction in the nephrotic syndrome under flow conditions. J Clin Invest 1994; 93:204-211.

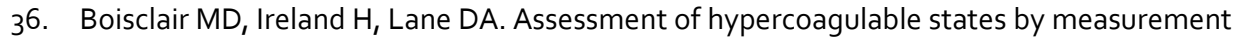
of activation fragments and peptides. Blood Rev 1990; 4:25-40.

37. Spahn DR, Rossaint R. Coagulopathy and blood component transfusion in trauma. $\mathrm{Br} \mathrm{J}$ Anaesth 2005; 95:130-139.

38. Levy JH. Massive transfusion coagulopathy. Semin Hematol 2006; 43:S59-S63.

39. Grottke $O$, Henzler D, Rossaint R. Use of blood and blood products in trauma. Best Pract Res Clin Anaesthesiol 2007; 21:257-270.

40. Karkouti K, Yau TM, Rensburg A, McCluskey SA, Callum J, Wijeysundera DN, Beattie WS. The effects of a treatment protocol for cardiac surgical patients with excessive blood loss on clinical outcomes. Vox Sang 2006; 91:148-156.

41. Mack MJ, Brown P, Houser F, Katz M, Kugelmass A, Simon A, Battaglia S, Tarkington $L$, Culler $S$, Becker $E$. On-pump versus off-pump coronary artery bypass surgery in a matched sample of women: a comparison of outcomes. Circulation 2004; 110:1-6.

42. Salmenperä MT, Levy JH, Harker LA. Hemostasis and Cardiopulmonary Bypass. In: Cardiopulmonary Bypass: Principles and Techniques of Extracorporeal Circulation (Mora, CT), Springer, New York (USA). 1995; 88-112.

43. Kozek-Langenecker S. Management of massive operative blood loss. Minerva Anestesiol 2007; 73:401-415.

44. Reding MT, Key NS. Hematologic problems in the surgical patient: bleeding and thrombosis. In: Hematology: Basic Principles and Practice (Hoffman, R, Benz, EJ, Shattil, SI, Furie, B, Cohen, HJ, Silberstein, LE, McGlave, P), Elsevier Churchill Livingstone, New York (USA). 2005; 2613-2626.

45. Rudolph R, Boyd CR. Massive transfusion: complications and their management. South Med J 1990; 83:1065-1070.

46. Zimmerman LH. Causes and consequences of critical bleeding and mechanisms of blood coagulation. Pharmacotherapy 2007; 27:S45-S56.

47. Innerhofer $P$, Fries $D$, Margreiter J, Klingler A, Kuhbacher $G$, Wachter B, Oswald E, Salner $E$, Frischhut $B$, Schobersberger W. The effects of perioperatively administered colloids and crystalloids on primary platelet-mediated hemostasis and clot formation. Anesth Analg 2002; 95:858-865.

48. Wallis JP. Red cell transfusion triggers. Transfus Apher Sci 2008; 39:151-154.

49. O'Shaughnessy DF, Atterbury C, Bolton Maggs P, Murphy M, Thomas D, Yates S, Williamson LM. Guidelines for the use of fresh-frozen plasma, cryoprecipitate and cryosupernatant. Br J Haematol 2004; 126:11-28.

50. Pealer LN, Marfin AA, Petersen LR, Lanciotti RS, Page PL, Stramer SL, Stobierski MG, Signs K, Newman B, Kapoor H, Goodman JL, Chamberland ME. Transmission of West Nile virus through blood transfusion in the United States in 2002. N Engl J Med 2003; 349:1236-1245.

51. Sperry JL, Ochoa JB, Gunn SR, Alarcon LH, Minei JP, Cuschieri J, Rosengart MR, Maier RV, Billiar TR, Peitzman AB, Moore EE. An FFP:PRBC transfusion ratio $<1: 1.5$ is associated with a lower risk of mortality after massive transfusion. J Trauma 2008; 65:986-993. 
52. Spinella PC, Perkins JG, Grathwohl KW, Beekley AC, Niles SE, McLaughlin DF, Wade CE, Holcomb JB. Effect of plasma and red blood cell transfusions on survival in patients with combat related traumatic injuries. J Trauma 2008; 64:S69-S77.

53. Moore FA, Nelson T, McKinley BA, Moore EE, Nathens AB, Rhee P, Puyana JC, Beilman GJ, Cohn SM. Is there a role for aggressive use of fresh frozen plasma in massive transfusion of civilian trauma patients? Am J Surg 2008; 196:948-958.

54. Scalea TM, Bochicchio KM, Lumpkins K, Hess JR, Dutton R, Pyle A, Bochicchio GV. Early aggressive use of fresh frozen plasma does not improve outcome in critically injured trauma patients. Ann Surg 2008; 248:578-584.

55. Stainsby D, MacLennan S, Thomas D, Isaac J, Hamilton PJ. Guidelines on the management of massive blood loss. Br J Haematol 2006; 135:634-641.

56. Erber WN. Massive blood transfusion in the elective surgical setting. Transfus Apher Sci 2002; 27:83-92.

57. Hardy JF, de Moerloose P, Samama CM. Massive transfusion and coagulopathy: pathophysiology and implications for clinical management. Can J Anaesth 2006; 53:S40-S58.

58. Crowther MA, Warkentin TE. Bleeding risk and the management of bleeding complications in patients undergoing anticoagulant therapy: focus on new anticoagulant agents. Blood 2008; 111:4871-4879.

59. Brummel KE, Paradis SG, Branda RF, Mann KG. Oral anticoagulation thresholds. Circulation 2001; 104:2311-2317.

6o. Roberts HR, Monroe DM, White GC. The use of recombinant factor VIla in the treatment of bleeding disorders. Blood 2004; 104:3858-3864.

61. Samama CM. Prothrombin complex concentrates: a brief review. Eur J Anaesthesiol 2008; 25:784-789.

62. Kreuz W, Meili E, Peter-Salonen K, Dobrkovska A, Devay J, Haertel S, Krzensk U, Egbring R. Pharmacokinetic properties of a pasteurised fibrinogen concentrate. Transfus Apher Sci 2005; 32:239-246.

63. Velik-Salchner C, Haas T, Innerhofer P, Streif W, Nussbaumer W, Klingler A, Klima G, Martinowitz $U$, Fries $D$. The effect of fibrinogen concentrate on thrombocytopenia. J Thromb Haemost 2007; 5:1019-1025.

64. Sörensen B, Johansen $P$, Christiansen $K$, Woelke $M$, Ingerslev J. Whole blood coagulation thrombelastographic profiles employing minimal tissue factor activation. J Thromb Haemost 2003; 1:551-558.

65. Ganter MT, Hofer CK. Coagulation monitoring: current techniques and clinical use of viscoelastic point-of-care coagulation devices. Anesth Analg 2008; 106:1366-1375.

66. Al Dieri R, Peyvandi F, Santagostino E, Giansily M, Mannucci PM, Schved JF, Béguin S, Hemker HC. The thrombogram in rare inherited coagulation disorders: its relation to clinical bleeding. Thromb Haemost 2002; 88:576-582.

67. Blombäck $M$, Abildgaard $U$, van den Besselaar AM, Clementson KJ, Dahlback B, Exner $T_{1}$ Francis CW, Gaffney P, Gralnick H, Hoyer LW, Johnson GJ, Kasper C, Lane DA, Lijnen HR, Lusher JM, Mannucci PM, Poller L, Rapaport SI, Saito H, Stocker K, Thomas D.

Nomenclature of quant it ies and units in thrombosis and haemostasis (recommendation 1993). Thromb Haemost 1994; 71:375-394 



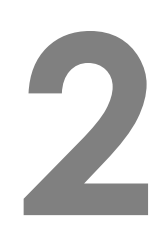

\section{Correction of coagulation in dilutional coagulopathy:}

use of kinetic and capacitive coagulation assays to improve hemostasis

Saskia E.M. Schols, Johan W. M. Heemskerk* and Elisabeth C. M. van Pampus*

Transfusion Medicine Reviews 2010; 24:44-52

Reprinted with permission

* Authors contributed equally to this paper 


\section{Abstract}

The management of dilutional coagulopathy due to fluid infusion and massive blood loss is a topic that deserves a biochemical approach. In this review paper we provide an overview of current guidelines and recommendations on diagnosis and on management of transfusion in acquired coagulopathy. We discuss the biochemical differences between kinetic clotting assays (clotting times) and new capacitive coagulation measurements that provide time-dependent information on thrombin generation and fibrin clot formation. The available evidence suggests that a combination of assay types is required for evaluating new transfusion protocols aimed to optimize hemostasis and stop bleeding. While there is current consensus on the application of fresh frozen plasma to revert coagulopathy, factor concentrates may appear to be useful in the future.

\section{Introduction}

The treatment of patients with massive blood loss by surgery or trauma has two primary goals: restoration of the blood volume to prevent hemorrhagic shock and stop of the bleeding. Usually interventions start with infusing fluids (crystalloids and colloids) and red blood cell (RBC) transfusions to prevent tissue hypoperfusion. However, as these transfusions are accompanied by plasma dilution and lowering of the hemostatic potential, they may result in increased bleeding and lead to a condition known as dilutional coagulopathy. Management of massive blood loss hence also requires correction of hemostasis. Currently, dilutional coagulopathy is assessed from conventional clotting times, i.e. prolongation of the activated partial thromboplastin time (aPTT) and the prothrombin time (PT), also expressed as international normalized ratio (INR). This implies that kinetic tests are used to detect a delay in clot formation. However, given the recent high interest in capacity coagulation measurements, which detect the integrated amount of thrombin or fibrin clot formation, a relevant question is whether these are not better suited to detect insufficient coagulation than the clotting times. Likely, coagulation capacity measurements can help to increase our still limited understanding of how the clotting system is regulated under diluted conditions. Since transfusion practices in most countries are still traditional, such new insight may lead to significant medical progress.

In the present paper, we give an overview of current definitions of massive transfusion and of transfusion regimens for patients with dilutional coagulopathy. We compare literature data evaluating the kinetics and capacity of the coagulation system under diluted conditions, by focusing on the processes of thrombin generation or fibrin clot formation. Finally, we discuss the potential of still limitedly 
used factor concentrates to restore these processes. Despite major differences between the well-controlled situation of dilution upon surgery and the uncontrollable situation in severe trauma, ${ }^{1}$ both conditions have in common a general deficiency in both coagulant and anticoagulant factors. Therefore, from the point of restoring coagulation both forms of coagulopathy are discussed together. Our perspective is more biochemical than clinical, with the supposition that biochemical understanding of the changes in coagulation processes in the blood from coagulopathic patients is necessary for strategic development of evidence-based transfusion regimes.

\section{Massive blood loss and coagulation tests to define dilutional coagulopathy}

A non-comprehensive literature overview indicates that massive blood loss is usually defined as: the loss of more than one blood volume within 24 hours; or in case of acute situations, as the loss of more than 0.5 blood volume per 3 hours or more than $150 \mathrm{ml}$ blood per minute (Table 2.1). These definitions are descriptive, rather than directive in clinical practice, given the facts that: (i) the estimations of blood loss are notoriously imprecise, (ii) the data are obtained retrospectively, (iii) inter-individual variations exists in baseline levels of coagulation factors, and (iv) age and co-morbidity may also play a variable role. For these reasons, many guidelines instead use an operative definition of massive transfusion. This is the necessary transfusion of more than 10 units of RBCs within 24 hours, or more than 4 units of red blood cells within 1 hour. For targeted therapy, it would be ideal to establish the relations between the volume of blood loss, the amount of fluid infusion, and the remaining blood cell counts and plasma levels of coagulation factors. However, in the clinical situation these relations are complicated by other factors, such as the organ involved, the type of surgery or trauma, the rapidity of blood loss, the extent of tissue hypoperfusion, and the damage of vascular endothelium. Yet the condition of coagulopathy is clinically evident as prolonged bleeding from wound surfaces after surgical control or as spontaneous bleeding from uninjured surfaces.

Published guidelines and recommendations generally agree on the type of laboratory tests to establish and confirm coagulopathy due to massive blood loss (Table 2.1). In addition to blood cell counts (platelets, hemoglobin) and clinical judgment, these are in particular the kinetic-based clotting times (aPTT, PT, INR). A recognized disadvantage of these clotting tests is their non-linearity with hemodilution and hence limited sensitivity. Separately, monitoring of the plasma fibrinogen level is recommended. The attention for fibrinogen control comes from the evidence that pre-operative fibrinogen levels greatly vary among patients and can even predict bleeding upon surgery. $^{2-4}$ In addition, recent publications 
recommend monitoring by thromboelastography (measuring elastic clot formation), which in its various forms is quite sensitive to the fibrinogen level. ${ }^{5-7}$

\section{Transfusion practice in case of massive blood loss and dilutional coagulopathy}

Table 2.2 summarizes the guidelines and recommendations of the selected papers regarding transfusion management in case of dilutional coagulopathy during surgery or trauma. All protocols are multi-factorial in nature, which likely reflects the need to restore multiple processes to stop bleeding. To secure the oxygen-carrying capacity and tissue perfusion, RBCs are transfused at hemoglobin levels below 60-90 g/l (or after $30 \%$ blood volume loss). Besides participation in a thrombus, RBCs contribute to hemostasis by facilitating the margination of platelets towards the vessel wall. The optimal hematocrit for platelet-vessel wall interaction may be as high as $35 \%$, but is in fact unknown. ${ }^{8}$

After volume resuscitation and RBC transfusions, fresh frozen plasma (FFP) is considered to be transfused, if the PT or APTT exceeds $1.5 \times$ the normal value. Some authors suggest that an earlier use of FFP may be more effective. ${ }^{9}$ There is a debate concerning the optimal transfusion ratio of FFP to RBCs. Military experience indicates that early resuscitation with units of RBCs and FFP in a 1:1 ratio increases survival (see Table 2.2). Combined transfusion of RBCs and plasma has been proposed also in non-combat cases of life-threatening severe trauma or bleeding. ${ }^{10,11}$ However, retrospective analyses are equivocal. ${ }^{12,13}$

A source of fibrinogen is given if the plasma level falls below 0.8-1 g/l (Table 2.2). Here, as an alternative or additive for FFP transfusion, cryoprecipitate is being used, which contains concentrated fibrinogen, factors VIII and XIII and von Willebrand factor. ${ }^{11,14-15}$ In European countries where cryoprecipitate is not available, fibrinogen concentrate is used instead, also as an alternative for FFP transfusion. ${ }^{5,6,16,17,18}$ FFP is also given in military trauma. ${ }^{19}$

Platelet counts are controlled independently. In case of active bleeding, transfusion of platelet concentrates is considered above counts of $50-100 \times 10^{9} / 1$ (Table 2.2). Remarkably, the use of functional platelet tests is not advocated, except for patients with platelet function deficiencies. Yet, the platelet activation status is an important parameter, since for instance, in cardiac surgery, platelet-related abnormalities are considered among the most important hemostatic abnormalities. ${ }^{20}$

Other pharmacotherapeutic interventions are considered for particular purposes, as outlined in Table 2.2: (i) prothrombin complex concentrate (prothrombin and factors VII, IX and X), e.g. in case of fluid overload; (ii) recombinant factor VIla if other interventions fail; (iii) desmopressin to elevate von Willebrand factor; (iv) anti- 
fibrinolytic agents (tranexamic acid, aminocaproic acid) in case of hyperfibrinolysis; (v) annulling prior anticoagulant treatment, e.g. protamine (heparin antidote), or specific patient-related deficiencies; (vi) $\mathrm{CaCl}_{2}$ in case of deficiency.

From the point of view of hemostasis, it is important to consider that most interventions - crystalloids, colloids, RBCs and platelet concentrates and even FFP will lead to dilution of the patient's plasma, and hence to decreased levels of coagulant and anticoagulant factors. It is therefore important to know what the effect of dilution is on coagulant activity and how factor concentrates may revert this effect.

\section{Effect of plasma dilution on the kinetics and capacity of coagulation}

The conventional aPTT and PT tests measure the kinetics of clot formation upon full activation of the intrinsic, factor XII-dependent (aPTT) or the extrinsic, factor VII-dependent (PT, INR) system, as they are carried out at optimal concentrations of procoagulant phospholipids and trigger (kaolin or tissue factor, respectively). The general use of both tests suggests that not so much the specific way of triggering, but rather the common pathway of factor $\mathrm{Xa}$ and thrombin generation is clinically relevant for assessment of the coagulant activity of diluted plasma. On the other hand, these kinetic tests are single-point measurements and hence have intrinsic limitations, as they only detect the time to formation of a threshold amount of fibrin.

In recent years, techniques have been developed to continuously measure thrombin generation in (diluted) plasma samples, such as the calibrated automated thrombogram (CAT) method. ${ }^{21,22}$ When using optimal concentrations of procoagulant phospholipids and triggers (tissue factor or kaolin) to cause full coagulation - such as in the conventional clotting tests -, these methods provide capacitive information of the thrombin generation in plasma. Similarly, at the same optimized conditions the method of rotational thromboelastography can be used for capacitive measurement of the formation of fibrin clots. Recent in vitro studies have provided important insight into the effect of dilution on the capacity of thrombin generation and fibrin clot formation. ${ }^{23-25}$ The advantage of capacitive approaches is illustrated in Figure 2.1. Four-fold dilution of plasma causes a lowering in extent of thrombin generation (in spite of the fact that both procoagulant and anticoagulant factor levels are reduced) with little effect on the delay time, such in contrast to the effect of intake of oral anticoagulation (INR 4), where also the kinetics of thrombin generation are greatly prolonged. Addition of prothrombin complex concentrate, but not of fibrinogen concentrate can revert the dilution effect. Plasma dilution results in a similar lowering in capacity of fibrin clot formation again without delay. Addition of fibrinogen concentrate rather than prothrombin complex concentrate partly restores 


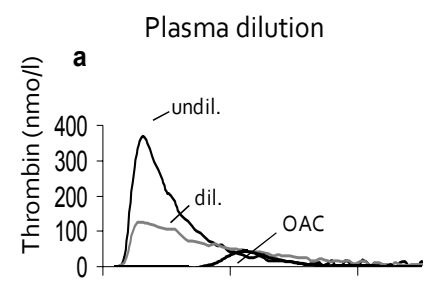

$0 \quad 10 \quad 20$

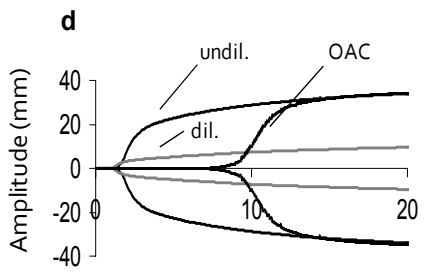

Time (min)

$$
\text { b }
$$

Fibrinogen concentrate

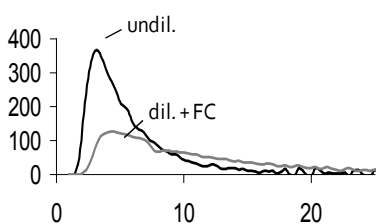

e

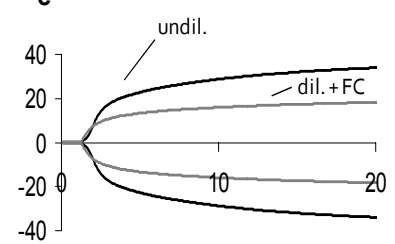

Time (min)
Prothrombin complex concentrate c

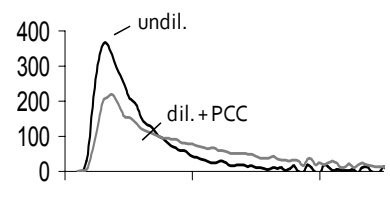

$\begin{array}{lll}0 & 10 & 20\end{array}$

f

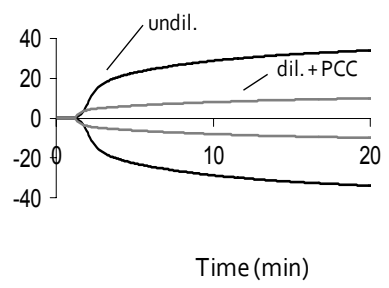

Figure 2.1: Effect of plasma dilution and factor deficiency on thrombin generation and

fibrin clot formation. Representative curves of tissue factor-induced thrombin generation (a-c) and fibrin clot formation (d-f) of undiluted normal plasma (undil.), $5 \times$ diluted plasma (dil.), and plasma from patient taking oral anticoagulants $(\mathrm{OAC}, \mathrm{INR}=4)$. $(\mathrm{b}, \mathrm{e})$ Effects in diluted plasma of supplementation of fibrinogen concentrate $(+F C) ;(c, f)$ effects of supplementation of prothrombin complex concentrate (+ PCC).

clot formation. Measurements of thrombin generation and formation of a fibrin clot (thromboelastography) - which are most sensitive to plasma levels of coagulation factors and fibrinogen, respectively $--^{22,24}$ thus provide graded information on both the kinetics and the extent of the coagulation process.

So far, these capacitive assays have been limitedly used in intervention studies to dilutional coagulopathy. Table 2.3 summarizes the results from mostly retrospective studies, where the effect of transfusion with FFP or factor concentrates is determined on coagulant activity and clinical outcome. Various papers describe the in vitro effect of recombinant factor VIIa, factor XIII and FFP on thrombin generation and fibrin clot formation. ${ }^{23,25-27}$ In general, factor VIla had a variable effect on thrombin generation (likely depending on the trigger concentration), while fibrinogen and factor XIII concentrates had no more than limited effects on thrombin generation but increased the formation and strength of fibrin clots.

Recombinant factor VIla is prescribed in the treatment of massively bleeding patients with hemophilia or other hemorrhagic disorders. ${ }^{28,29}$ Studies on the off-label treatment with recombinant factor VIlla in dilutional coagulopathy report a reduction in blood loss, and a variable effect on clotting times; capacitive coagulation assays so far have not been used (Table 2.3). This use of recombinant factor VIla is still based on the physician's discretion, and needs further research..$^{30-32}$ On the other hand, for 
bleeding patients treated with FFP, capacitive assays have been used to demonstrate overall improvement of coagulant activity after transfusion, for both thrombin generation and thromboelastography. ${ }^{33-35}$ Strikingly, the procoagulant effect of added coagulant factors here overrules the suppressing effect of added anticoagulant factors (antithrombin, protein C).

Retrospective and prospective studies have demonstrated efficacy of prothrombin complex concentrate in normalizing clotting times (INR values) and reverting bleeding due to oral anticoagulation. ${ }^{36-38}$ Capacitive coagulation test were not used. Since there were no indications for low fibrinogen levels in this patient group, the implication is that levels of thrombin generation were too low for clot formation, even at normal fibrinogen levels, and may have caused bleeding. However, also the delay in thrombin generation may increase the bleeding risk. The use of this factor complex concentrate in patients with acquired coagulopathy waits for validation in controlled studies. ${ }^{39}$

Few small-size published studies describe the use of fibrinogen concentrate in cases of acquired hypofibrinogenemia, e.g. in craniosynostosis and orthopedic surgery. Several reports describe that this intervention leads to increased fibrinogen levels and clot firmness. ${ }^{40-42}$ A rationale for the administration of fibrinogen to coagulopathic patients with bleeding is that the plasma fibrinogen level controls the mass amount of fibrin formed by thrombin and, hence, clot strength. ${ }^{43}$ This implies that low fibrinogen can contribute to bleeding, even if the capacity of thrombin generation in patients is sufficiently high. Future controlled studies need to determine whether the recommended use of fibrinogen concentrates for specific patients with persistent bleeding (Table 2.2) indeed links to improved clot formation.

\section{Future role of capacitive tests of thrombin generation and clot formation}

For optimal transfusion management to be accomplished, a diagnostic test needs to be fast, reliable, sensitive and informative about the hemostatic status of the patient. Capacitive coagulation tests potentially meet all these requirements. Thrombin generation has been used to monitor impaired coagulation in plasma from patients with inherited bleeding disorders or taking anticoagulant medication. ${ }^{21,44}$ One study with patients with peri-operative coagulopathy indicates that persistent bleeding after FFP transfusion is associated with low thrombin generation. ${ }^{33}$ Still, this assay requires further validation in prospective multi-center studies.

To measure fibrin clot formation the old method of thromboelastography, detecting the elastic properties of a clot (clot strength), has found new revival. Currently, two test systems with similar properties are in use: thromboelastography 
(TEG from Haemoscope, Niles, IL, USA) and rotational thromboelastometry (ROTEM from Pentapharm, Munich, Germany). ${ }^{45}$ These systems are being used as point-ofcare-devices to measure clot formation triggered via the intrinsic pathway (kaolin, ellagic acid) or the extrinsic pathway (tissue factor). However, the test fails to detect moderate impairments in platelet function, likely because of the very high thrombin levels reached under the assay conditions. So far, only few small-sized studies have provided evidence that thromboelastography is useful in the guidance of (fibrinogen or FFP) transfusion therapy, e.g. in cardiac surgery and in trauma. ${ }^{35,46}$ Yet, this technique has already contributed to the increased use of fibrinogen concentrates in bleeding patients. ${ }^{47}$ Larger, controlled studies are under way.

\section{Conclusions}

Biochemical analysis of the coagulant status of plasma from patients with coagulopathy suggests that the monitoring of thrombin generation and fibrin clot formation can help to predict the risk of massive bleeding. Since these two processes are differently controlled by coagulant and anticoagulant factors, current transfusion management is likely to be improved by using both capacitive coagulation assays. Transfusion with FFP has the advantage that coagulant and anticoagulant factors are given simultaneously, which is likely to moderate the risk of thrombosis. However its clinical effectiveness is limited, as it contributes to hemodilution. The possible advantages of the use of concentrated coagulation factors in the management of massive bleeding still need to be demonstrated. To improve current transfusion protocols, large multi-centre controlled trials with clinical endpoints are mandatory, particularly to validate the use of factor concentrates versus FFP. 
Correction of coagulation in coagulopathy 
Chapter 2

34 
Correction of coagulation in coagulopathy 
Chapter 2 
Correction of coagulation in coagulopathy 


\section{References}

1. Levy JH. Massive transfusion coagulopathy. Semin Hematol 2006; 43:S59-S63.

2. Singbartl K, Innerhofer P, Radvan J, Westphalen B, Fries D, Stogbauer R, van Aken H. Hemostasis and hemodilution: a quantitative mathematical guide for clinical practice. Anesth Analg 2003; 96:929-935.

3. Karlsson M, Ternstrom L, Hyllner M, Baghaei F, Nilsson S, Jeppsson A. Plasma fibrinogen level, bleeding, and transfusion after on-pump coronary artery bypass grafting surgery: a prospective observational study. Transfusion 2008; 48:2152-2158.

4. Mangus RS, Kinsella SB, Nobari MM, Fridell JA, Vianna RM, Ward ES, Nobari R, Tector AJ. Predictors of blood product use in orthotopic liver transplantation using the piggyback hepatectomy technique. Transplant Proc 2007; 39:3207-3213.

5. Kozek-Langenecker S. Management of massive operative blood loss. Minerva Anestesiol 2007; 73:401-415.

6. Heindl B, Biberthaler P. Coagulation management of severe surgical bleeding. Unfallchirurg 2008; 111:574-583.

7. Gaarder C, Naess PA, Frischknecht Christensen E, Hakala P, Handolin L, Heier HE, Ivancev $\mathrm{K}$, Johansson $\mathrm{P}$, Leppaniemi A, Lippert F, Lossius HM, Opdahl H, Pillgram-Larsen J, Roise O, Skaga NO, Soreide E, Stensballe J, Tonnessen E, Tottermann A, Ortenwall P, Ostlund A. Scandinavian Guidelines-The massively bleeding patient. Scand J Surg 2008; 97:15-36.

8. Valeri CR, Ragno G, Pivacek LE, Srey R, Hess JR, Lippert LE, Mettille F, Fahie R, O'Neill EM, Szymanski IO. A multicenter study of in vitro and in vivo values in human RBCs frozen with 40-percent (wt/vol) glycerol and stored after deglycerolization for 15 days at 4 degrees $C$ in AS-3: assessment of RBC processing in the ACP 215. Transfusion 2001; 41:933-939.

9. Hirshberg A, Dugas M, Banez El, Scott BG, Wall MJ, Mattox KL. Minimizing dilutional coagulopathy in exsanguinating hemorrhage: a computer simulation. J Trauma 2003; 54:454-463.

10. Malone $\mathrm{DL}$, Hess JR, Fingerhut $\mathrm{A}$. Massive transfusion practices around the globe and a suggestion for a common massive transfusion protocol. J Trauma 2006; 60:S91-S96.

11. O'Keeffe T, Refaai M, Tchorz K, Forestner JE, Sarode R. A massive transfusion protocol to decrease blood component use and costs. Arch Surg 2008; 143:686-69o.

12. Moore FA, Nelson T, McKinley BA, Moore EE, Nathens AB, Rhee P, Puyana JC, Beilman GJ, Cohn SM. Is there a role for aggressive use of fresh frozen plasma in massive transfusion of civilian trauma patients? Am J Surg 2008; 196:948-58.

13. Scalea TM, Bochicchio KM, Lumpkins K, Hess JR, Dutton R, Pyle A, Bochicchio GV. Early aggressive use of fresh frozen plasma does not improve outcome in critically injured trauma patients. Ann Surg 2008; 248:578-584.

14. Erber WN. Massive blood transfusion in the elective surgical setting. Transfus Apher Sci 2002; 27:83-92.

15. Spivey M, Parr MJ. Therapeutic approaches in trauma-induced coagulopathy. Minerva Anestesiol 2005; 71:281-289.

16. Perkins JG, Cap AP, Weiss BM, Reid TJ, Bolan CD. Massive transfusion and nonsurgical hemostat ic agents. Crit Care Med 2008; 36:S325-S339.

17. Busani S, Cavazzuti I, Marietta M, Pasetto A, Girardis M. Strategies to control massive abdominal bleeding. Transplant Proc 2008; 40:1212-1215. 
18. Spahn DR, Cerny V, Coats TJ, Duranteau J, Fernandez-Mondejar E, Gordini G, Stahel PF, Hunt BJ, Komadina R, Neugebauer E, OzierY, Riddez L, Schultz A, Vincent JL, Rossaint R. Management of bleeding following major trauma: a European guideline. Crit Care 2007; 11:R17.

19. Stinger HK, Spinella PC, Perkins JG, Grathwohl KW, Salinas J, Martini WZ, Hess JR, Dubick MA, Simon CD, Beekley AC, Wolf SE, Wade CE, Holcomb JB. The ratio of fibrinogen to red cells transfused affects survival in casualties receiving massive transfusions at an army combat support hospital. J Trauma 2008; 64:S79-S85.

20. Despot is G, Eby C, Lublin DM. A review of transfusion risks and optimal management of perioperat ive bleeding with cardiac surgery. Transfusion 2008; 48:2S-30S.

21. Hemker HC, Al Dieri R, De Smedt E, Beguin S. Thrombin generation, a function test of the haemostatic-thrombotic system. Thromb Haemost 2006; 96:553-561.

22. Vanschoonbeek K, Feijge MA, Van Kampen RJ, Kenis H, Hemker HC, Giesen PL, Heemskerk JW. Initiating and potentiating role of platelets in tissue factor-induced thrombin generation in the presence of plasma: subject-dependent variation in thrombogram characteristics. J Thromb Haemost 2004; 2:476-484.

23. Haas T, Fries D, Velik-Salchner C, Reif C, Klingler A, Innerhofer P. The in vitro effects of fibrinogen concentrate, factor XIII and fresh frozen plasma on impaired clot formation after $60 \%$ dilution. Anesth Analg 2008; 106:1360-1365.

24. Schols SE, Feijge MA, Lance MD, Hamulyak K, ten Cate H, Heemskerk JW, van Pampus EC. Effects of plasma dilution on tissue factor-induced thrombin generation and thromboelastography: partly compensating role of platelets. Transfusion 2008; 2384-2394.

25. Tanaka KA, Taketomi T, Szlam F, Calatzis A, Levy JH. Improved clot formation by combined administration of activated factor VII (NovoSeven) and fibrinogen (Haemocomplettan P). Anesth Analg 2008; 106:732-738.

26. Ganter MT, Schmuck S, Hamiel CR, Wischmeyer PE, Heule D, Zollinger A, Hofer CK. Monitoring recombinant factor Vlla treatment: efficacy depends on high levels of fibrinogen in a model of severe dilutional coagulopathy. J Cardiothorac Vasc Anesth 2008; 22:675-680.

27. Johansson PI, Jacobsen N, Viuff D, Olsen EH, Rojkjaer R, Andersen S, Petersen LC, Kjalke $M$. Differential clot stabilising effects of rFVIla and rFXIII-A2 in whole blood from thrombocytopenic patients and healthy volunteers. $\mathrm{Br} J$ Haematol 2008; 143:559-569.

28. Fishman PE, Drumheller BC, Dubon ME, Slesinger TL. Recombinant activated factor VII use in the emergency department. Emerg Med J 2008; 25:625-630.

29. Lusher JM, Roberts HR, Davignon G, Joist JH, Smith H, Shapiro A, Laurian Y, Kasper CK, Mannucci PM. A randomized, double-blind comparison of two dosage levels of recombinant factor VIla in the treatment of joint, muscle and mucocutaneous haemorrhages in persons with haemophilia $A$ and $B$, with and without inhibitors. rFVIla Study Group. Haemophilia 1998; 4:790-798.

30. Hardy JF, Belisle S, van der Linden P. Efficacy and safety of recombinant activated factor VII to control bleeding in nonhemophiliac patients: a review of 17 randomized controlled trials. Ann Thorac Surg 2008; 86:1038-1048.

31. Johansson PI. Off-label use of recombinant factor VIla for treatment of haemorrhage: results from randomized clinical trials. Vox Sang 2008; 95:1-7. 
32. Moltzan CJ, Anderson DA, Callum J, Fremes S, Hume H, Mazer CD, Poon MC, Rivard G, Rizoli S, Robinson S. The evidence for the use of recombinant factor VIla in massive bleeding: development of a transfusion policy framework. Transfus Med 2008; 18:112-120.

33. Schols SE, van der Meijden PE, van Oerle R, Curvers J, Heemskerk JW, van Pampus EC. Increased thrombin generation and fibrinogen level after therapeutic plasma transfusion: relation to bleeding. Thromb Haemost 2008; 99:64-70.

34. Cammerer U, Dietrich W, Rampf T, Braun SL, Richter JA. The predictive value of modified computerized thromboelastography and platelet function analysis for postoperative blood loss in rout ine cardiac surgery. Anesth Analg 2003; 96:51-57.

35. Reinhofer $M$, Brauer $M$, Franke $U$, Barz D, Marx G, Losche W. The value of rotation thromboelastometry to monitor disturbed perioperat ive haemostasis and bleeding risk in pat ients with cardiopulmonary bypass. Blood Coagul Fibrinolysis 2008; 19:212-219.

36. Bruce D, Nokes TJ. Prothrombin complex concentrate (Beriplex $P / N$ ) in severe bleeding: experience in a large tertiary hospital. Crit Care 2008; 12:R105.

37. Pabinger I, Brenner B, Kalina U, Knaub S, Nagy A, Ostermann H. Prothrombin complex concentrate (Beriplex $\mathrm{P} / \mathrm{N}$ ) for emergency anticoagulation reversal: a prospective mult inational clinical trial. J Thromb Haemost 2008; 6:622-631.

38. Yasaka M, Sakata T, Naritomi $H$, Minematsu K. Optimal dose of prothrombin complex concentrate for acute reversal of oral anticoagulation. Thromb Res 2005; 115:455-459.

39. Samama CM. Prothrombin complex concentrates: a brief review. Eur J Anaesthesiol 2008; 25:784-789.

40. Haas T, Fries D, Velik-Salchner C, Oswald E, Innerhofer P. Fibrinogen in craniosynostosis surgery. Anesth Analg 2008; 106:725-731.

41. Mittermayr M, Streif W, Haas T, Fries D, Velik-Salchner C, Klingler A, Oswald E, Bach C, Schnapka-Koepf $M$, Innerhofer P. Hemostatic changes after crystalloid or colloid fluid administration during major orthopedic surgery: the role of fibrinogen administration. Anesth Analg 2007; 105:905-917.

42. Weinkove $R$, Rangarajan $S$. Fibrinogen concentrate for acquired hypofibrinogenaemic states. Transfus Med 2008; 18:151-157.

43. Weisel JW. Structure of fibrin: impact on clot stability. J Thromb Haemost 2007; 5:S116-S124.

44. Van Veen JJ, Gatt A, Makris M. Thrombin generation testing in routine clinical practice: are we there yet? $\mathrm{Br} J$ Haematol 2008; 142:889-903.

45. Ganter MT, Hofer CK. Coagulation monitoring: current techniques and clinical use of viscoelastic point-of-care coagulation devices. Anesth Analg 2008; 106:1366-1375.

46. Rugeri L, Levrat A, David JS, Delecroix E, Floccard B, Gros A, Allaouchiche B, Negrier C. Diagnosis of early coagulation abnormalities in trauma patients by rotation thrombelastography. J Thromb Haemost 2007; 5:289-295.

47. Spalding GJ, Hartrumpf M, Sierig T, Oesberg N, Kirschke CG, Albes JM. Cost reduction of perioperative coagulation management in cardiac surgery: value of "bedside" thrombelastography (ROTEM). Eur J Cardiothorac Surg 2007; 31:1052-1057.

48. Stainsby D, MacLennan S, Thomas D, Isaac J, Hamilton PJ. Guidelines on the management of massive blood loss. Br J Haematol 2006; 135:634-641. 
49. Hellstern P, Muntean W, Schramm W, Seifried E, Solheim BG. Practical guidelines for the clinical use of plasma. Thrombosis Res 2002; 107 S $53-S_{57}$.

50. Hellstern $\mathrm{P}$, Haubelt $\mathrm{H}$. Indications for plasma in massive transfusion. Thrombosis Res 2002; 107:S19-S22.

51. Hardy JF, de Moerloose P, Samama CM. Massive transfusion and coagulopathy: pathophysiology and implications for clinical management. Can J Anaesth 2006; 53:S40-S58.

52. Hardy JF, de Moerloose $\mathrm{P}$, Samama CM. The coagulopathy of massive transfusion. Vox Sang 2005; 89:123-127.

53. American-Society-of-Anesthesiologists. Practice Guidelines for blood component therapy. Anesthesiology 1996; 84:732-747.

54. Samama CM, Djoudi R, Lecompte T, Nathan N, Schved JF. Perioperative platelet transfusion. Recommendations of the French Health Products Safety Agency (AFSSAPS) 2003. Minerva Anestesiol 2006; 72:447-452.

55. Mitra B, Mori A, Cameron PA, Fitzgerald M, Street A, Bailey M. Massive blood transfusion and trauma resuscitation. Injury 2007; 38:1023-1029.

56. Ketchum L, Hess JR, Hiippala S. Indications for early fresh frozen plasma, cryoprecipitate, and platelet transfusion in trauma. J Trauma 2006; 60:S51-S58.

57. Grottke O, Henzler D, Rossaint R. Use of blood and blood products in trauma. Best Pract Res Clin Anaesthesiol 2007; 21:257-270.

58. Hakala P, Hiippala S, Syrjala M, Randell T. Massive blood transfusion exceeding 50 units of plasma poor red cells or whole blood: the survival rate and the occurrence of leukopenia and acidosis. Injury 1999; 30:619-622.

59. Kashuk JL, Moore EE, Johnson JL, Haenel J, Wilson M, Moore JB, Cothren CC, BiffI WL, Banerjee A, Sauaia A. Postinjury life threatening coagulopathy: is 1:1 fresh frozen plasma:packed red blood cells the answer? J Trauma 2008; 65:261-270.

6o. Spinella PC. Warm fresh whole blood transfusion for severe hemorrhage: U.S. military and potent ial civilian applications. Crit Care Med 2008; 36:S340-S345.

61. Schreiber MA, Perkins J, Kiraly L, Underwood S, Wade C, Holcomb JB. Early predictors of massive transfusion in combat casualties. J Am Coll Surg 2007; 205:541-45.

62. Hess JR, Holcomb JB. Transfusion practice in military trauma. Transfus Med 2008; 18:143-150.

63. De Lorenzo C, Calatzis A, Welsch U, Heindl B. Fibrinogen concentrate reverses dilutional coagulopathy induced in vitro by saline but not by hydroxyethyl starch $6 \%$. Anesth Analg 2006; 102:1194-1200.

64. Goodnough LT, Shander AS. Recombinant factor VIla: safety and efficacy. Curr Opin Hematol 2007; 14:504-509.

65. Karkouti K, Beattie WS, Arellano R, Aye T, Bussieres JS, Callum JL, Cheng D, Heinrich L, Kent B, Lee TW, MacAdams C, Mazer CD, Muirhead B, Rochon AG, Rubens FD, Sawchuk C, Wang $S$, Waters T, Wong BI, Yau TM. Comprehensive Canadian review of the off-label use of recombinant activated factor VII in cardiac surgery. Circulation 2008; 118:331-338.

66. MacLaren R, Weber LA, Brake H, Gardner MA, Tanzi M. A multicenter assessment of recombinant factor VIla off-label usage: clinical experiences and associated outcomes. Transfusion 2005; 45:1434-1442. 


\section{Chapter 2}

67. Masud F, Bostan F, Chi E, Pass SE, Samir H, Stuebing K, Liebl MG. Recombinant factor VIla treatment of severe bleeding in cardiac surgery patients: a retrospective analysis of dosing, efficacy, and safety outcomes. J Cardiothorac Vasc Anesth 2008; 28-33.

68. Mengistu AM, Wolf MW, Boldt J, Rohm KD, Lang J, Piper SN. Evaluation of a new platelet function analyzer in cardiac surgery: a comparison of modified thromboelastography and whole-blood aggregometry. J Cardiothorac Vasc Anesth 2008; 22:40-46.

69. Rizoli SB, Boffard KD, Riou B, Warren B, lau P, Kluger $Y$, Rossaint R, Tillinger M. Recombinant activated factor VII as an adjunctive therapy for bleeding control in severe trauma patients with coagulopathy: subgroup analysis from two randomized trials. Crit Care 2006; 10:R178.

70. Zaaroor M, Soustiel JF, Brenner B, Bar-Lavie Y, Martinowitz U, Levi L. Administration off label of recombinant factor-VIla ( $\mathrm{rFVlla}$ ) to patients with blunt or penetrat ing brain injury without coagulopathy. Acta Neurochir (Wien) 2008; 150:663-668.

71. Stein DM, Dutton RP, Hess JR, Scalea TM. Low-dose recombinant factor Vlla for trauma patients with coagulopathy. Injury 2008; 39:1054-1061.

72. Fenger-Eriksen C, Midtgaard Jensen T, Kristensen BS, Jensen KM, Tonnesen E, Ingerslev J, Sorensen B. Fibrinogen substitution improves whole blood clot firmness following dilution with hydroxyethyl starch in bleeding patients undergoing radical cystectomy - a randomised placebo-controlled clinical trial. J Thromb Haemost 2009; 7:975-802.

73. Danes AF, Cuenca LG, Bueno SR, Mendarte Barrenechea L, Ronsano JB. Efficacy and tolerability of human fibrinogen concentrate administration to patients with acquired fibrinogen deficiency and active or in high-risk severe bleeding. Vox Sang 2008; 94:221-226. 


\section{Effects of plasma dilution on tissue factor- induced thrombin generation and thromboelastography: partly compensating role of platelets}

Saskia E.M. Schols, Marion A. H. Feijge, Marcus D. Lancé, Karly Hamulyák, Hugo ten Cate, Johan W. M. Heemskerk* and Elisabeth C. M. van Pampus*

Transfusion 2008; 48:2384-2394

Reprinted with permission

* Authors conrtibuted equally to this paper 
Background: Bleeding upon major surgery or severe trauma is treated by transfusion with crystalloids, colloids or plasma. This treatment however can lead to dilutional coagulopathy and impaired haemostasis. We investigated the suitability of two integrative coagulation tests to measure the haemostatic activity of diluted plasma.

Methods: Plasma from healthy donors was diluted in vitro with saline or colloid (venofundin or gelofusin). Coagulant activity in response to tissue factor was monitored by calibrated automated thrombin (CAT) generation and rotational thromboelastography (TEG), detecting formation of elastic fibrin clots. Plasma from patients receiving fluid infusion during coronary artery bypass grafting (CABG) was analyzed with the same assays.

Results: Optimal activity of CAT and TEG assays required the presence of $10 \mathrm{pmol} / \mathrm{l}$ tissue factor and $4 \mu \mathrm{mol} / /$ phospholipid vesicles or $100 \times 10^{9}$ platelets/l. Strikingly, thrombin generation and clot formation became impaired at a higher extent of dilution with platelets present ( $\leq 40 \%$ plasma) than with phospholipid vesicles present ( $\leq 60 \%$ plasma). Colloids aggravated the dilution effect on clot formation, but FFP antagonized the dilution effect on thrombin and clot formation. In contrast, fibrinogen and factor XIII only restored the impaired clot formation. In plasmas from patients undergoing CABG, CAT and TEG assay parameters were altered to an extent corresponding with the volume of fluid infusion.

Conclusion: Thrombin generation and clot formation are reduced at a plasma dilution of $>40 \%$. In either process, platelets can partly compensate for the dilution effect. In vitro dilution with colloids impaired fibrin clot elasticity compared to saline.

\section{Introduction}

Patients with massive bleeding, after severe trauma or major surgery, are usually infused with crystalloids like saline, colloids and/or fresh frozen plasma (FFP). These infusions lead to dilution of the patient's plasma and, ultimately, to a state of dilutional coagulopathy, where haemostasis is impaired and bleeding frequently occurs. ${ }^{1-3}$ At present, the haemostatic condition of such patients is controlled by conventional clotting tests, i.e. the activated partial thromboplastin time (aPTT), the prothrombin time (PT) and the international normalized ratio (INR). However, these tests are notoriously insensitive for hypocoagulant conditions, and thus may be of limited value for the detection of impaired coagulation activity upon dilution..$^{4-6}$ Hence, there is a need for better, more sensitive tests.

Surprisingly little is known of the activity and regulation of the coagulation process under conditions of overall plasma dilution. The bleeding phenotype of patients with severe thrombocytopenia or hemophilia points to the necessity of threshold amounts of both platelets and coagulation factors. Thrombin generation 
measurements demonstrate multiple interactions between platelets and coagulation factors. ${ }^{7-9}$ Thrombin plays a central role in this interplay, since it activates platelets as well as other coagulation factors and, hence, triggers potent feed-forward loops to enhance its own formation. ${ }^{10,11}$ Conversely, activated platelets provide the procoagulant membrane surface, where coagulation factors assemble, and hence support the formation of more thrombin. ${ }^{12,13}$ The calibrated automated thrombogram (CAT) method is suitable to monitor the process of thrombin generation in the presence or absence of platelets. ${ }^{14,15}$ Earlier work has shown that this assay can detect aberrations in plasmas from patients with dilutional coagulopathy. ${ }^{16}$

Upon dilution, fibrinogen may be one of the earliest plasma factors which becomes critical. ${ }^{17}$ As a thrombin substrate, the level of fibrinogen directly controls the cleavage rate to fibrin monomers and, hence, the rate of fibrin clot formation. ${ }^{18}$ Factor XIII activation (by thrombin) is needed to cross-links fibrin fibers, and provide stabilization and elasticity of the clot against contracting platelets. ${ }^{19}$ The method of rotational thromboelastography (TEG), recently improved, can measure the formation rate, strength and elasticity of fibrin clots. ${ }^{17}$ For example, with this method, it was found that colloids, i.e. modified gelatines or starches that are often infused to patients with massive blood loss during surgery, affect the process of fibrin clot formation. ${ }^{20,21}$ Although this assay is used to report on dilutional coagulopathy in whole blood samples, it is still unclear how thrombin generation and platelet activation influence the test outcome.

In this paper, we have investigated how in vitro dilution of plasma influences the kinetics and extent of thrombin and fibrin formation in parallel CAT and TEG assays. For this purpose, the assays were optimized with regard to the concentrations of tissue factor (as activating agent) and phospholipid vesicles or platelets (as procoagulant membrane surface). For comparison, plasma samples were analyzed from patients, who were subjected to blood dilution by massive infusion with crystalloids and colloids during coronary artery bypass grafting (CABG).

\section{Materials and methods}

\section{Materials}

Tissue factor (Innovin) and factor XIII (Fibrogammin P) were obtained from Dade Behring (Marburg, Germany); human fibrinogen was from Sigma (St. Louis, MO); FFP from Sanquin (Eindhoven, The Netherlands); recombinant factor VIla (NovoSeven) from Novo Nordisk Pharma (Alphen aan den Rijn, The Netherlands). The colloids gelofusin (gelatin-based) and venofundin (hydroxyethyl starch, 130/0.42) were 
obtained from Braun (Melsungen, Germany). Thrombin substrate Z-Gly-Gly-Arg aminomethyl coumarin (Z-GGR-AMC) was from Bachem (Bubendorf, Switzerland); human thrombin calibrator and thrombogram software were from Synapse (Maastricht, The Netherlands). Procoagulant phospholipid vesicles (phosphatidylserine : phosphatidylcholine : phosphatidylethanolamine, $1: 3: 1$, mol:mol) were prepared, as described. ${ }^{22}$ Thromboelastogram control was from Haemoscope (Maastricht, The Netherlands). The PT was measured using Innovin reagent, and the aPTT using an actin-FSL kit (Dade Behring). Fibrinogen levels were measured as described. ${ }^{15}$ Prothrombin was determined using a one-stage clotting assay on the Behring coagulation system (Dade Behring); antithrombin was measured in the same system using a chromogenic assay. Other reagents were from Sigma.

\section{Healthy subjects and patients}

Blood was taken from healthy volunteers, who had not received medication interfering with platelet function or coagulation. Blood was also obtained from 5 patients undergoing $C A B G$ surgery, at 30 minutes before starting the procedure; a second sample was drawn directly after protamine administration, i.e. the endpoint of the cardio-pulmonary bypass procedure. At this stage, the patients had been infused with large volumes of crystalloids (saline) and colloids (venofundin), as indicated.

Twenty-four hours before cardiothoracic surgery, all patients had stopped with oral intake of aspirin (average $100 \mathrm{mg}$ ). Patients were infused with heparin (250 IU), during the time they were on-pump; directly after surgery, this heparin was antagonized with protamine sulfate $(250 \mathrm{mg})$. No residual heparin activity could be detected in post-treatment plasma samples. None of the patients had multiple organ failure, sepsis, or renal or liver dysfunction. Standard clotting tests and factor concentrations were determined for patient care. After CABG surgery, haematocrit was reduced from $0.36 \pm 0.06$ to $0.29 \pm 0.05$, and the platelet count was reduced from $244 \pm 100$ to $197 \pm 98 \times 10^{9} / \mathrm{l}$. Remnant blood was used for thrombin generation and thromboelastographic measurements. The studies were approved by the local Medical Ethics Committee. All donors gave written informed consent.

\section{Preparation of plasma samples}

Blood from healthy donors and patients was collected into $1 / 10$ volume of $129 \mathrm{mmol} / \mathrm{l}$ trisodium citrate. Platelet-rich plasma (PRP) and platelet-free plasma (PFP) were prepared, as described. ${ }^{23}$ Platelet count was determined with a thrombocounter (Coulter Electronics, Luton, United Kingdom); it was normalized by dilution of PRP 
with autologous PFP. Washed platelets were prepared from blood collected into $1 / 6$ volume of acid-glucose solution (ACD, $80 \mathrm{mmol} / \mathrm{l}$ trisodium citrate, $52 \mathrm{mmol} / \mathrm{l}$ citric acid and $180 \mathrm{mmol} / \mathrm{l}$ glucose). ${ }^{15}$

Standard clotting tests in patient blood and plasma were determined in-hospital. Remnant plasmas were centrifuged twice at $2630 \mathrm{~g}$ for 10 minutes to obtain PFP, which was snap-frozen at $-80^{\circ} \mathrm{C}$. Reference pooled plasma from 40 healthy volunteers was prepared and stored in the same way, following guidelines of the University Hospital of Maastricht.

\section{Dilution of plasma}

PRP was used directly after isolation. PFP was thawed and reconstituted, as required, with phospholipid vesicles (standard, $4 \mu \mathrm{mol} / \mathrm{l}$ ) or washed platelets from one healthy donor (standard, $100 \times 10^{9} / \mathrm{l}$ ). Plasma samples were triggered with tissue factor (standard, $10 \mathrm{pmol} / \mathrm{l}$, f.c.) and $\mathrm{CaCl}_{2}(16.6 \mathrm{mmol} / \mathrm{l})$. With $100 \%$ citrate-anticoagulated plasma, this resulted in a free $\mathrm{Ca}^{2+}$ concentration of about $1.5 \mathrm{mmol} / \mathrm{l}$. Where indicated, plasma was diluted with saline, gelofusin or venofundin solution, after which phospholipid vesicles or washed platelets were added. Citrate concentrations were kept constant $(12.9 \mathrm{mmol} / \mathrm{l})$ in experiments with (un)diluted plasma samples. Free $\mathrm{Ca}^{2+}$ concentrations after $\mathrm{CaCl}_{2}$ addition were controlled with a $\mathrm{Ca}^{2+}$-sensitive electrode. Where indicated, plasma was mixed with FFP (Sanquin), or supplemented with fibrinogen (Sigma), factor XIII (Fibrogammin P) or recombinant factor VIla (NovoSeven). These factors were added to diluted plasma at dosages sufficient to restore the original concentration in undiluted plasma. Factor Vlla was added at a recommended concentration of $2.6 \mu \mathrm{g} / \mathrm{ml}^{24}$

\section{Thrombin generation measurements}

Thrombin formation and inactivation was continuously measured with an adapted CAT assay. ${ }^{15,25}$ Plasma from healthy donors and patients, containing phospholipid vesicles or (autologous) platelets, was supplemented with tissue factor (mostly with $10 \mathrm{pmol} / \mathrm{l}$, f.c.). Coagulation was started by addition of $\mathrm{CaCl}_{2}$ plus thrombin substrate, Z-GGR-AMC. Unless indicated otherwise, final concentrations were $16.6 \mathrm{mmol} / \mathrm{l}$ $\mathrm{CaCl}_{2}$ and $2.5 \mathrm{mmol} / \mathrm{l} \mathrm{Z-GGR-AMC}$. All samples were run at $37^{\circ} \mathrm{C}$ in triplicate. An internal calibrator was used in separate wells to give corrected and calibrated curves of thrombin generation for each plasma and each dilution. Calibrated, first-derivative traces were converted to nanomolar concentrations of thrombin. Thrombin peak height and area-under-the-curve (endogenous thrombin potential, ETP) were used as 
determining parameters of thrombin generation curves. ${ }^{23}$ In this set-up, the assay variation coefficient was 5-7\%.

\section{Thromboelastography measurements}

Rotational thromboelastography (TEG) was performed using a Model 5000 thromboelastograph from Haemoscope. This technique measures the torsion between a slowly rotating plastic cup and a stationary pin with a wire acting as a torque transducer. ${ }^{26}$ Measurements were performed under conditions equivalent to those of thrombin generation measurements. Samples of citrate-anticoagulated plasma $(340 \mu \mathrm{l})$ were supplemented with phospholipid vesicles or (autologous) platelets, followed by tissue factor (standard $10 \mathrm{pmol} / \mathrm{l}, \mathrm{f} . \mathrm{c}$.). The samples were pipetted into a cup, after which coagulation was started by addition of $\mathrm{CaCl}_{2}(16.6$ $\mathrm{mmol} / \mathrm{l}$, f.c.). Key evaluation parameters of the thromboelastograms were the $\alpha$ angle and the maximal torsion amplitude, which inform on the rate of fibrin strand formation and the elastic strength of the formed clot, respectively. Addition of Z-GGR-AMC substrate did not influence the shape of thromboelastograms under dilution conditions (not shown).

\section{Statistics}

Data are presented as means \pm SEM, unless indicated otherwise. Intervention effects were evaluated with the non-parametric Mann-Whitney test (independent samples); data from patient samples with the Wilcoxon test (related samples). SPSS 11.0 software was used for statistical analysis.

\section{Results}

\section{Contribution of platelets to thrombin generation and fibrin clot formation in undiluted plasma}

The thrombogram (CAT) assay combines high sensitivity to hypocoagulant conditions with time-dependent information of both thrombin formation and inactivation. ${ }^{25}$ This method was used to study plasma dilution effects on the kinetics of tissue factor-induced coagulation. First experiments were performed with undiluted plasma containing phospholipid vesicles $(4-8 \mu \mathrm{mol} / \mathrm{l})$ or autologous platelets $\left(50-100 \times 10^{9} / \mathrm{l}\right)$ as procoagulant surface. At a high, optimal concentration of tissue factor ( $10 \mathrm{pmol} / \mathrm{l})$, this resulted in a delayed but steeply increased generation of thrombin, followed by a decay phase due to thrombin inactivation. 


\section{CAT}
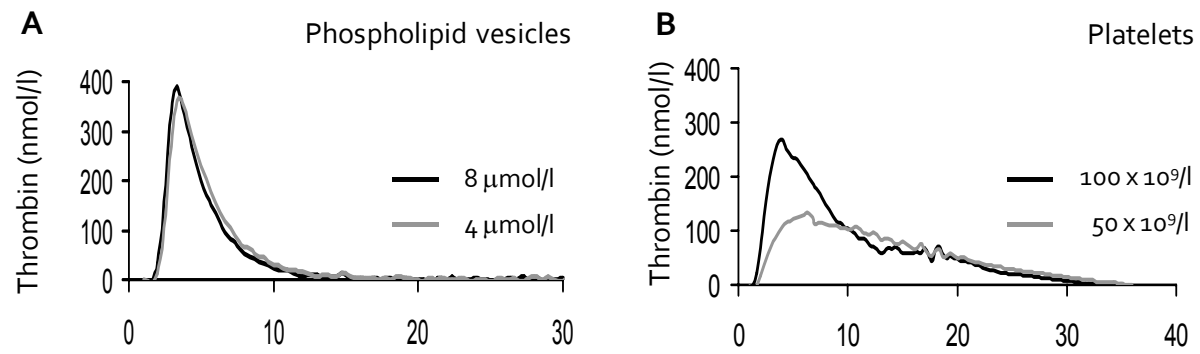

TEG
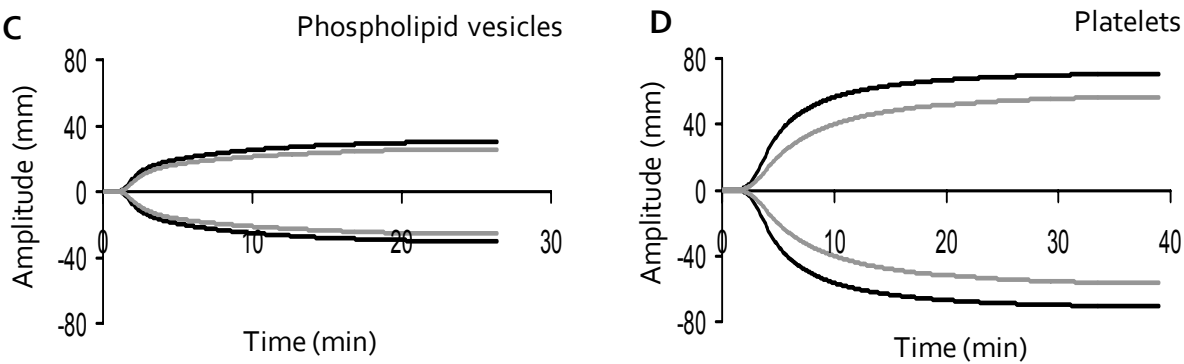

Fig. 3.1: Kinetics of thrombin generation and fibrin clot formation in undiluted normal plasma. Thrombin generation (CAT) and thromboelasticity (TEG) were measured in undiluted normal plasma, supplemented with phospholipid vesicles or autologous platelets; coagulation was induced with $10 \mathrm{pmol} / \mathrm{l}$ tissue factor. Representative curves of thrombograms with (A) phospholipid vesicles $(4-8 \mu \mathrm{mol} / \mathrm{l})$ or (B) platelets $\left(50-100 \times 10^{9} / \mathrm{l}\right)$. In addition, representative thromboelastograms at the same concentrations of (C) phospholipid vesicles or (D) platelets.

The thrombogram curves were relatively narrow with phospholipid vesicles present and broader with platelets, especially at low cell counts (Fig. 3.1A, B). This is in agreement with earlier observations, ${ }^{15}$ and likely due to the relatively slow availability of a procoagulant surface on activated platelets. ${ }^{27}$

At the same conditions of tissue factor activation, rotational thromboelastography (TEG) was used to measure fibrin clot formation and clot elasticity in plasma. Thromboelastograms showed a somewhat delayed start of clot formation with a curve amplitude that was consistently smaller with phospholipid vesicles than with platelets present (Fig. 3.1C, D). Furthermore, torsion amplitude of the curves with platelets was consistently higher even at a low platelet count, reflecting increased elasticity of the fibrin clot.

Both the CAT and TEG are integrative assays, aiming to report on the total, maximal extent of thrombin generation and fibrin clot formation, respectively. To find optimal assay conditions for both assays, phospholipid vesicles or platelets were given at various concentrations. Key thrombogram parameters, i.e. thrombin peak 
A

Phospholipid vesicles

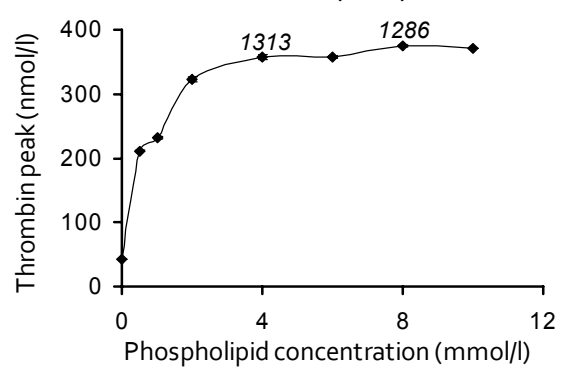

TEG

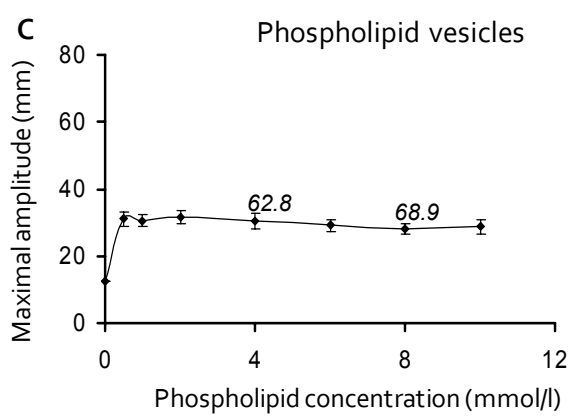

B

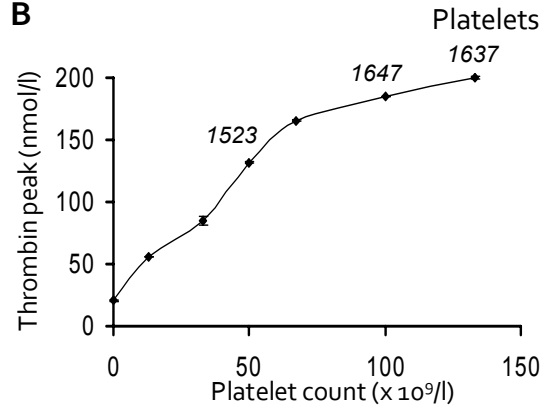

D

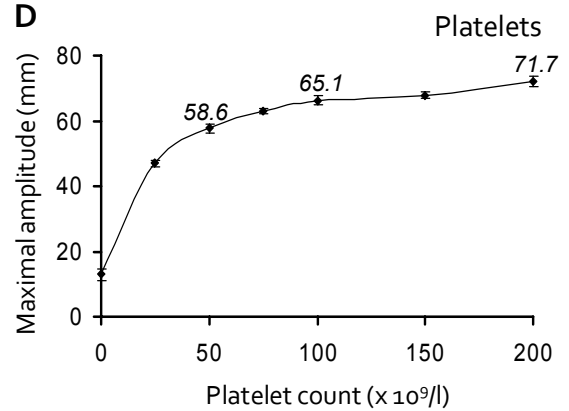

Fig. 3.2: Effect of phospholipid or platelet concentration on thrombin generation and fibrin clot formation in undiluted plasma. Thrombin generation (CAT) and thromboelasticity (TEG) were measured in tissue factor-activated plasma containing various concentrations of phospholipid vesicles $(0.5-10 \mu \mathrm{mol} / \mathrm{l})$ or autologous platelets $\left(33-133 \times 10^{9} / \mathrm{l}\right)$, as indicated. $(A, B)$ Effect on thrombin peak height in thrombograms; italic numbers represent mean ETP values $(\mathrm{nmol} \times \mathrm{min} / \mathrm{l})$. (C, D) Effect on maximal torsion amplitude in thromboelastograms; italic numbers represent mean $\alpha$-angle (mean \pm SEM). Data are representative for 5 experiments.

height and ETP, showed maximal values at $4 \mu \mathrm{mol} / \mathrm{l}$ phospholipid vesicles (Fig. 3.2A), and reached a semi-plateau value at $100 \times 10^{9}$ platelets/l (Fig. 3.2B). Main thromboelastogram parameters, $\alpha$-angle (representing the fibrin formation rate) and maximal torsion amplitude (reflecting clot elasticity) were optimal around $0.5 \mu \mathrm{mol} / \mathrm{l}$ phospholipid vesicles (Fig. 3.2C) and $100 \times 10^{9}$ platelets/l (Fig. 3.2D). Thromboelastograms with phospholipid vesicles had a similar $\alpha$-angle, but a two-fold lower amplitude in comparison to curves with platelets. Together, this points to a relatively early role of platelets in the promotion of elastic clot formation, and a slow role in the support of thrombin generation. 


\section{Effect of plasma dilution on thrombin generation and fibrin clot formation}

As coagulation under diluted conditions may require a different optimal triggering, we determined how variation in the tissue factor concentration influenced thrombin generation in plasma that was diluted with $20-80 \%$ saline. Except for the highest degree of dilution, thrombogram parameters increased with the tissue factor concentration from 1-10 pmol/l, with either phospholipid vesicles or platelets present (Fig. 3.3A, B). Importantly, at $10 \mathrm{pmol} / \mathrm{l}$ tissue factor, the thrombin peak height became sub-optimal at $\leq 60 \%$ plasma with phospholipid vesicles, and at a higher dilution of $\leq 40 \%$ plasma with platelets present.
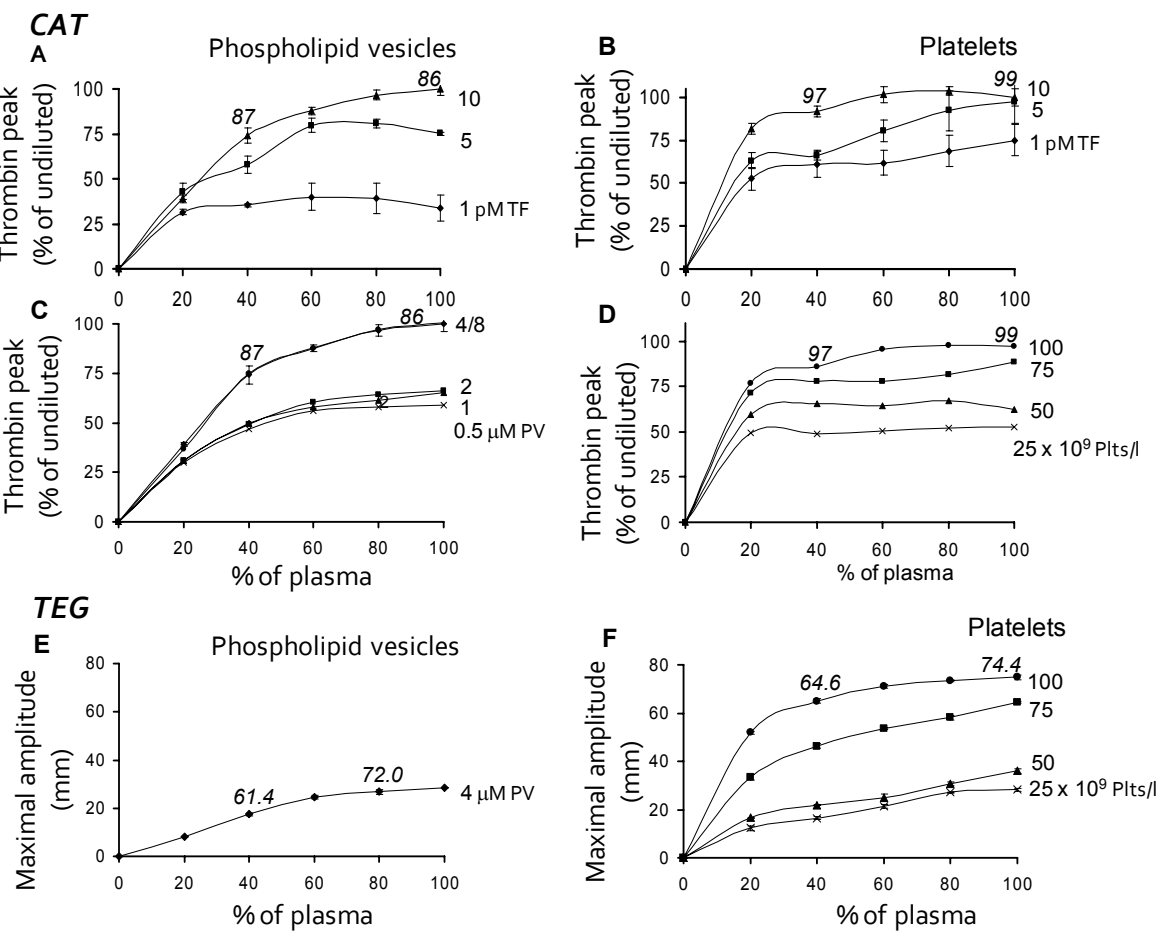

Fig. 3.3: Effect of plasma dilution on thrombin generation and fibrin clot formation. Normal plasma was diluted with saline and reconstituted with $4 \mu \mathrm{mol} / /$ phospholipid vesicles (PV) or $100 \times 10^{9} / /$ autologous platelets (Plts), unless indicated otherwise; coagulation was triggered with 1-10 pmol/l tissue factor (TF). (A, B) Effect of plasma dilution on thrombin generation with different concentrations of tissue factor. (C, D) Effect of plasma dilution on thrombin generation at different concentrations of phospholipid vesicles or platelets. Italic numbers represent corresponding ETP values. Thrombin generation values are expressed as percentages of values obtained in undiluted plasma under standard conditions ( $10 \mathrm{pmol} / \mathrm{ITF}, 4$ $\left.\mu \mathrm{mol} / \mathrm{l} \mathrm{PV}, 100 \times 10^{9} \mathrm{PLT} / \mathrm{I}\right)$. (E, F) Effect of plasma dilution on thromboelastogram (maximal torsion amplitude) with $4 \mu \mathrm{mol} / /$ phospholipid vesicles or different platelets counts (in $10^{9} / \mathrm{l}$ ), italic numbers represent mean $\alpha$-angles. Data are means $\pm \operatorname{SEM}(n=5)$. 


\section{CAT}
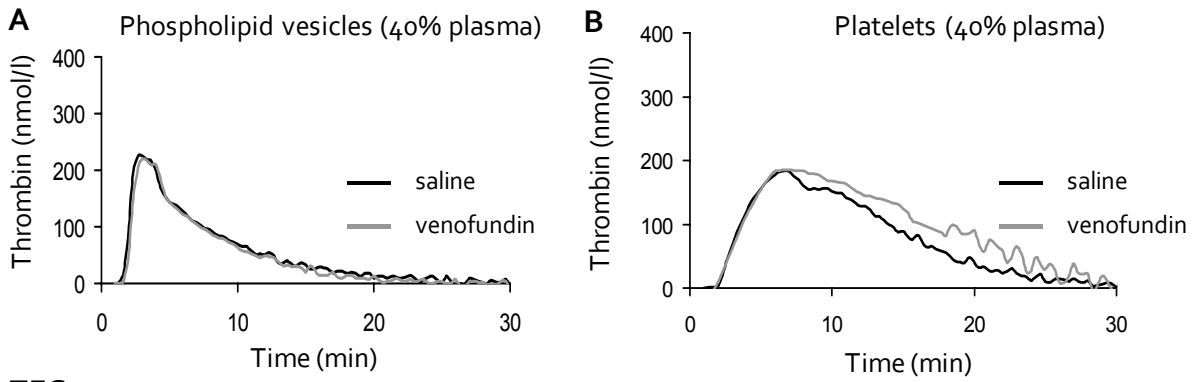

TEG
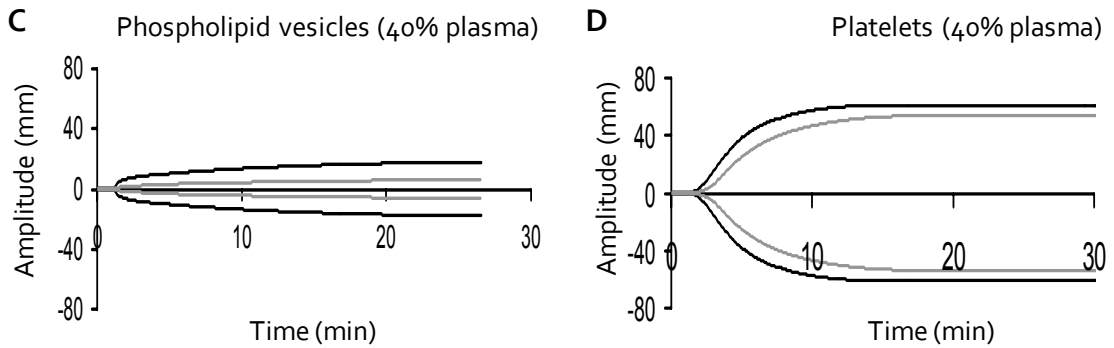

Fig. 3.4: Kinetics of thrombin generation and fibrin clot formation in diluted plasma. Representative thrombograms of plasma diluted to $40 \%$ and activated in the presence of (A) 4 $\mu \mathrm{mol} / \mathrm{l}$ phospholipid vesicles or (B) $100 \times 10^{9} / \mathrm{l}$ autologous platelets. Plasma was diluted with saline (black lines) or venofundin (grey lines), and activated with $10 \mathrm{pmol} / \mathrm{l}$ tissue factor. Corresponding thromboelastograms in the presence of (C) phospholipid vesicles or (D) platelets. Plasma again was diluted with saline (black lines) or venofundin (grey lines).

The ETP (area-under-the-curve) was less sensitive to dilution, and even tended to increase at moderate dilutions, possibly due to decreased antithrombin activity. In diluted plasma samples, concentrations of $4-8 \mu \mathrm{mol} / \mathrm{l}$ phospholipid vesicles or $100 \times 10^{9}$ platelets/l remained (near) optimal for thrombin generation (Fig. 3.3C, D). In thromboelastography measurements, the maximal torsion amplitude also started to decrease at dilutions of $\leq 60 \%$ or $\leq 40 \%$ plasma in the presence of phospholipid vesicles $(4 \mu \mathrm{mol} / \mathrm{l})$ or platelets $\left(100 \times 10^{9} / \mathrm{l}\right)$, respectively (Fig. 3.3 E, F). Together, these results indicate that, with platelets present, plasma can be diluted more in order to retain maximal levels of thrombin generation and fibrin clot formation than in the presence of phospholipid vesicles.

Knowing that commonly applied colloids may interfere with the coagulation process, ${ }^{21}$ we compared how plasma dilution with gelofusin or venofundin influenced thrombin generation and thromboelastography parameters. Even at extensive dilution of plasma $(40 \%)$, venofundin $(60 \%)$ did not influence tissue factor-induced 

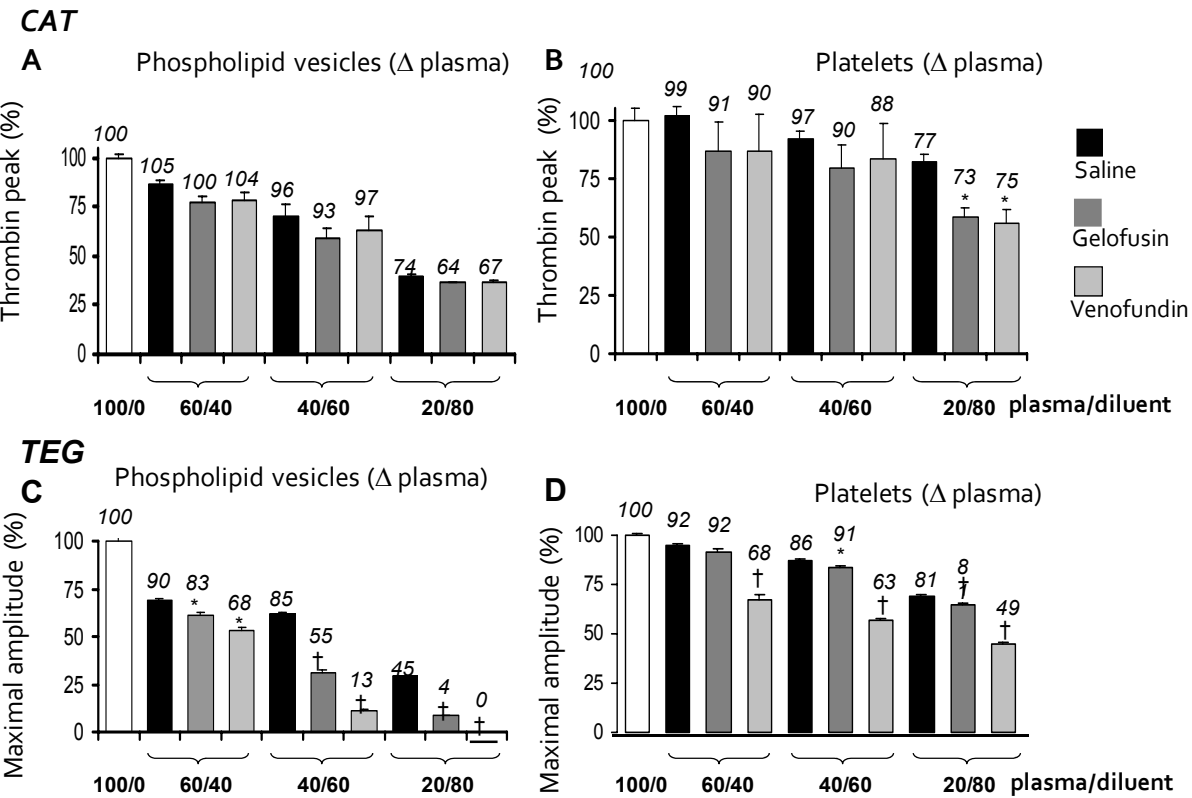

Fig. 3.5: Effect of plasma dilution with saline or colloids on thrombin generation and fibrin clot formation. Plasma was diluted to $60 \%, 40 \%$ or $20 \%$ with either saline or colloid solutions, gelofusin or venofundin. Diluted plasmas were activated with $10 \mathrm{pmol} / \mathrm{l}$ tissue factor in the presence of either phospholipid vesicles $(4 \mu \mathrm{mol} / \mathrm{l})$ or autologous platelets $\left(100 \times 10^{9} / \mathrm{l}\right)$. (A, B) Thrombogram parameters in the presence of phospholipid vesicles or platelets. Data are thrombin peak heights expressed as $\%$ of values of undiluted plasma; italic numbers above bars represent corresponding \% ETP values. (C, D) Thromboelastogram parameters in the presence of phospholipid vesicles or platelets. Data are maximal torsion amplitudes expressed as $\%$ of values of undiluted plasma; italic numbers represent $\% \alpha$-angle. Means $\pm \operatorname{SEM}(n=4) ; * p=0.05$, ${ }^{\dagger} \mathrm{p}<0.05$, compared to corresponding dilution with saline.

thrombin generation compared to dilution with saline (Fig. 3.4A, B). Venofundin, however, at this concentration did lower thromboelastograms in the presence of phospholipid vesicles or platelets (Fig. 3.4C, D). For a quantitative approach, thrombin generation was measured in plasmas diluted with increased volumes of saline, gelofusin or venofundin. With phospholipid vesicles present, thrombin peak height and ETP progressively decreased at dilutions of $\leq 60 \%$ plasma; in comparison to saline, neither of the colloids had an additional effect (Fig. 3.5A). With platelets present, thrombin peaks height and ETP remained high up to a dilution of $\leq 40 \%$ plasma; in this case gelofusin and venofundin further moderately decreased these parameters at the highest dilution with $20 \%$ plasma (Fig. 3.5B). Thromboelastography measurements demonstrated that dilution with especially 
venofundin, and to a lesser extent gelofusin, had a considerable diminishing effect on the fibrin clot formation. This was observed with both phospholipid vesicles (Fig. 3.5C) and platelets (Fig. 3.5D), irrespective of the higher clot elasticity (maximal torsion amplitude) seen in the presence of platelets. Accordingly, especially the colloid venofundin had a more marked effect on fibrin clot formation than on thrombin generation regardless of whether platelets were present or not.

\section{In vitro effects of factor concentrates on thrombin generation and fibrin clot formation in diluted plasma}

We then investigated how FFP and factor concentrates which are in clinical use could normalize the impaired thrombin generation and thromboelastography upon dilution. Combining plasma $(20-75 \%$ plasma) with FFP resulted in a moderate reduction in thrombogram parameters. Thus, at $20 \%$ plasma (80\% FFP), thrombin peak heights were $74-89 \%$ of the values in full plasma (Table 3.1). In addition, we supplemented saline-diluted plasma samples with fibrinogen or factor XIII, to reach the factor levels present in undiluted plasma. Regardless of the extent of dilution (20-75\% plasma), neither fibrinogen nor factor XIII could improve thrombin generation with phospholipid vesicles. In the presence of platelets, only fibrinogen had a small stimulatory effect when added to $20 \%$ plasma, which was borderline significant.

Thromboelastography demonstrated that replacement of plasma by FFP also caused a moderate reduction in clot formation. At $20 \%$ plasma ( $80 \% \mathrm{FFP}$ ), the maximal torsion amplitude was $79-85 \%$ of that in full plasma (Table 3.1). Addition of fibrinogen to diluted plasma markedly increased the thromboelastogram parameters both with phospholipid vesicles and platelets. Addition of factor XIII also increased the maximal torsion amplitude, but at a lesser degree. In contrast, addition of recombinant factor VIla was without effect. Taken together, in comparison to saline, the presence of FFP prevented impairment of both thrombin and fibrin clot formation. Addition of fibrinogen or factor XIII only restored the saline dilution effect on fibrin clot formation.

\section{Thrombin generation and fibrin clot elasticity in plasma from patients experiencing dilution during surgery}

Patients undergoing CABG are extensively infused with crystalloids and colloids, which leads to plasma dilution and may cause coagulation problems postoperatively. ${ }^{28}$ To compare with the findings at in vitro dilution, we analyzed pre- and post-treatment plasmas from five patients undergoing CABG surgery (Table 3.2). The 
Plasma dilution and coagulation 
patients received a variable fluid volume of $1500-4550 \mathrm{ml}$ during the surgery procedure. After the treatment, standard coagulation times were increased slightly to markedly; the mean aPTT was moderately prolonged from $30.0 \pm 2.7$ to $37.0 \pm 6.5 \mathrm{~s}$ (mean $\pm S D, n=5, p=0.043$ ), while the PT changed insignificantly from $11.1 \pm 0.7$ to $13.6 \pm 1.4 \mathrm{~s}(\mathrm{p}=0.068)$. None of the patients experienced bleeding postoperatively, or needed coagulation treatment. One of the patients (patient 1 ) was infused with a limited fluid volume of $1500 \mathrm{ml}$ crystalloid (saline and Ringer's lactate). In this patient, plasma levels of prothrombin, fibrinogen, factor $X$ and antithrombin remained at $>90 \%$ of the pretreatment values (Table 3.2 ).

Table 3.2. Dilution and plasma parameters in patients undergoing coronary artery bypass grafting (CABG). Plasma was obtained from five patients before and after CABG surgery. This procedure was accompanied by infusion with $1550 \mathrm{ml}$ crystalloids (patients no. 2-5), followed by $1000-3000 \mathrm{ml}$ crystalloids plus venofundin (patients no. 1-5). Crystalloids consisted of saline and Ringer's lactate solution. Coagulation times of plasmas before and after CABG surgery are given. Factor levels were measured after surgery, as well as parameters of CAT (thrombin peak height) and TEG (maximal amplitude), after activation with $10 \mathrm{pmol} / \mathrm{l}$ tissue factor in the presence of either $4 \mu \mathrm{mol} / /$ phospholipid vesicles (PV) or $100 \times 10^{9} / /$ platelets (PLT) from one healthy donor. Post-surgery values are given, expressed as $\%$ of pretreatment level.

\begin{tabular}{|c|c|c|c|c|c|}
\hline & \multicolumn{5}{|c|}{$\begin{array}{l}\text { Patient } \\
\text { no. }\end{array}$} \\
\hline & 1 & 2 & 3 & 4 & 5 \\
\hline \multicolumn{6}{|l|}{ Fluid transfusion $(\mathrm{ml})$} \\
\hline Crystalloids & 1000 & 2050 & 3050 & 3550 & 3550 \\
\hline Venofundin & 500 & 500 & 500 & 500 & 1000 \\
\hline Total & 1500 & 2550 & 3550 & 4050 & 4550 \\
\hline \multicolumn{6}{|c|}{ Coagulation time before / after (s) } \\
\hline aPTT & $30.3 / 31.1$ & $33.7 / 34.5$ & $28.7 / 32.7$ & $31.0 / 47.2$ & $26.3 / 39.4$ \\
\hline PT & $11.9 / 11.9$ & $10.5 / 14.4$ & $10.4 / 12.3$ & $11.6 / 14.9$ & $11.1 / 14.7$ \\
\hline \multicolumn{6}{|c|}{ Factor level (\% of pretreatment level) } \\
\hline Fibrinogen & 92 & 61 & 55 & 41 & 32 \\
\hline Prothrombin & 99 & 52 & 57 & 42 & 34 \\
\hline Factor $\mathrm{X}$ & 98 & 50 & 51 & 41 & 34 \\
\hline Antithrombin & 105 & 54 & 52 & 41 & 31 \\
\hline \multicolumn{6}{|c|}{ Coagulant activity (\% of pretreatment level) } \\
\hline Thrombin peak (PV) & 90 & 63 & 72 & 51 & 54 \\
\hline Thrombin peak (PLT) & 84 & 74 & 81 & 46 & 59 \\
\hline Maximal amplitude (PV) & 94 & 66 & 54 & 27 & 25 \\
\hline Maximal amplitude (PLT) & 95 & 98 & 88 & 84 & 81 \\
\hline
\end{tabular}




\section{CAT}

A Phospholipid vesicles

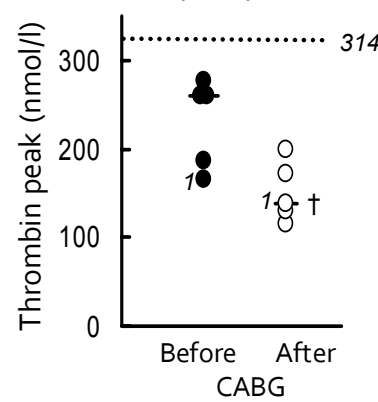

TEG

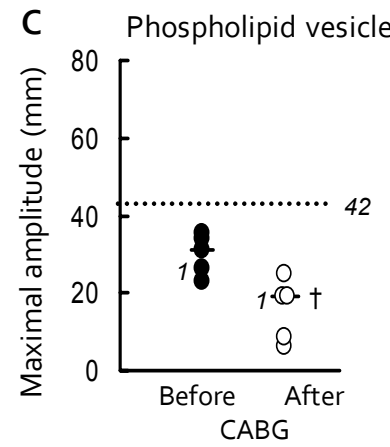

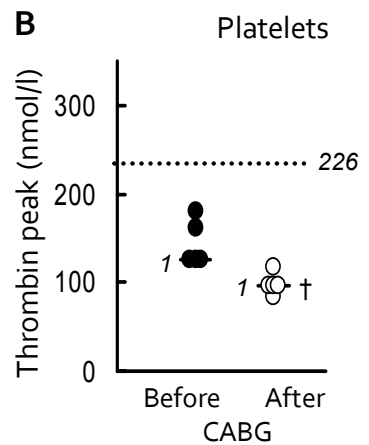

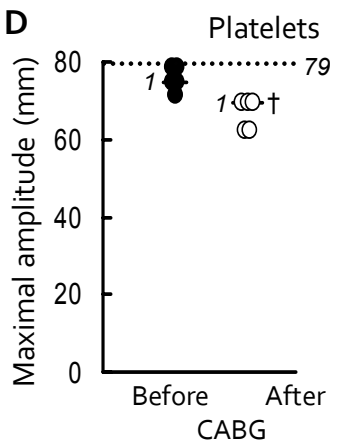

Fig. 3.6: Reduced thrombin generation and thromboelasticity in patients undergoing coronary artery bypass grafting (CABG). Plasma was obtained from five patients before and after CABG surgery, and activated with $10 \mathrm{pmol} / \mathrm{l}$ tissue factor in the presence of $4 \mu \mathrm{mol} / \mathrm{l}$ phospholipid vesicles or $100 \times 10^{9} / /$ platelets from one healthy donor (see Table 3.2). (A, B) Effect of CABG surgery on thrombin peak height in the presence of phospholipid vesicles or platelets. (C, D) Effect of CABG surgery on thromboelastogram parameter (maximal torsion amplitude). Dotted lines give values obtained with undiluted, normal pool plasma. Median values and data from patient ' 1 ' are indicated; ${ }^{\dagger} p<0.01$ compared to pre-CABG surgery.

The other four patients were infused with larger volumes of $2550-4550 \mathrm{ml}$ fluids, consisting of crystalloids (saline and Ringer's lactate) and venofundin. In these patients, coagulation factor levels post- treatment were markedly reduced to $35-65 \%$ of the values before CABG surgery.

Thrombin generation and thromboelastography were then measured in the patient plasmas. In pre-treatment plasmas, the values of CAT and TEG assays were mostly below the normal value (Fig. 3.6), which is in agreement with the relatively long aPTT (Table 3.2). In the post-treatment plasma of patient 1 , thrombin peak height and thromboelastogram torsion amplitude were no more than moderately decreased (Table 3.2). In the post-treatment plasmas from other patients, these 
assay parameters were more strongly decreased, which is in line with the larger volume of fluid infusion. For all patient plasmas together, thrombin peak height was significantly reduced after surgery (Fig. 3.6A, B). This reduction amounted to $34 \pm 9 \%$ and $31 \pm 16 \%$ (mean \pm SD) in assays with phospholipid vesicles and platelets, respectively. Thromboelastography showed a more drastic reduction in maximal torsion amplitude with phospholipid vesicles than with platelets (Fig. 3.6C, D); mean reduction was $47 \pm 29 \%$ and $11 \pm 7 \%$, respectively. Thus, in 4 out of 5 patients, fluid transfusion had led to coagulation factor dilution and a more hypocoagulant plasma condition. For thromboelastography, the dilution effect was most apparent when measured in the absence of platelets.

\section{Discussion}

In this study we compared the effects of plasma dilution with crystalloids on thrombin generation, as assayed with a modified CAT method, and on fibrin clot formation and elasticity, as detected by TEG instruments. For this purpose, we searched for test conditions to give maximal thrombogram and thromboelastogram traces in (un)diluted plasmas. This was achieved by activating the plasma with an optimal dose of $10 \mathrm{pmol} / \mathrm{l}$ tissue factor in the presence of non-rate limiting amounts of $4 \mu \mathrm{mol} / \mathrm{l}$ procoagulant phospholipid vesicles or $100 \times 10^{9} / \mathrm{l}$ autologous or donor platelets. Care was taken to keep concentrations of citrate and added $\mathrm{CaCl}_{2}$ constant at all plasma dilutions, so that the assays were carried out at the same concentrations of free $\mathrm{Ca}^{2+}(\sim 1.5 \mathrm{mmol} / \mathrm{l})$.

Without dilution, platelets had a decisive but distinct role in the formation of thrombin and of fibrin clots. Platelets prolonged the thrombin generation process when compared to procoagulant phospholipid vesicles, whereas they shortened and markedly enhanced the formation of elastic fibrin clots in TEG. An important finding was that platelets partially opposed the reduced thrombin generation and fibrin clot formation under conditions of plasma dilution. Thus, with platelets present, CAT and TEG curves remained near-maximal up to a dilution of $40 \%$ plasma, while with phospholipid vesicles these curves already decreased at $\leq 60 \%$ plasma.

Platelets need to express a procoagulant, phosphatidylserine-exposing surface before exerting their stimulatory effect on prothrombinase activity. ${ }^{13,29}$ The slower contribution of platelets to thrombin generation in comparison to phosphatidylserine-containing lipid vesicles, therefore, may be due to prior requirement of platelet activation and relatively slow availability of the procoagulant membrane surface. The compensating role of platelets in thrombin generation under diluted conditions is likely caused by: (i) the continued support of activated platelet membranes to the thrombin-generating process and, (ii) the capability of platelets to 
produce significant amounts of coagulation factors, especially fibrinogen and factors V, VIII and XIII. ${ }^{9}$

In fibrin clot formation, platelets have a different role by contributing to the elastic strength of the clot, since they generate contractile forces towards polymerized fibrin via their $\alpha$ llb $\beta 3$ receptors. ${ }^{26,30}$ Our results demonstrate that the effect on clot elasticity is platelet concentration-dependent and is prominently present in coagulating PRP. The compensating role of platelets to fibrin clot formation upon dilution is most likely related to their ability to release fibrinogen and factor XIII, which may increase the magnitude and firmness of the retracting fibrin network. $^{31}$

Colloids such as gelofusin (a gelatin) and venofundin (a hydroxyethyl starch) are known to affect clot formation by disturbing the fibrin polymerization. ${ }^{20,21}$ Our data indicate that particularly venofundin $(\geq 40 \%)$ reduces the formation of fibrin clots in comparison to saline, irrespective of the presence of platelets. In contrast, the colloids affect thrombin generation only at clinically irrelevant high concentrations (80\% volume). In the plasmas from CABG patients, who were infused with crystalloids (1000-3550 ml) and venofundin (500-1000 ml), thromboelastogram parameters in the presence of platelets remained relatively high, with suggested that the venofundin concentration was too low to influence the clot-forming process. Others have described that more extensive infusion of venofundin (up to $2000 \mathrm{ml}$ ) into patients can alter the thromboelastogram traces. ${ }^{17}$

In saline-diluted plasma samples, addition of particularly fibrinogen restored the TEG values, but not the CAT values. The relatively small effect on thrombin generation corroborates with our earlier finding that fibrinogen does not play a major role in the thrombin generation process. ${ }^{15,16}$ On the other hand, the present data indicate that, even in highly diluted (20\%) plasma, the residual thrombin formed is sufficient to cleave the extra added fibrinogen for inclusion into the fibrin clot. At all plasma dilutions, the addition of factor XIII did increase the torsion amplitude, regardless of whether platelets or phospholipid vesicles were present. This suggests that the factor XIII level is rate-limiting for maximal clot elasticity. The clot-promoting effect of fibrinogen addition to in vitro diluted plasma would favor the use of fibrinogen in the clinical practice of dilutional coagulopathy, especially because fibrinogen preparations can be infused in small fluid volumes. Evidently, clinically based studies are needed to support this.

In patient plasmas collected after CABG surgery, the CAT and TEG parameters were on average reduced, which is in line with the large fluid volume infused during the procedure. Although conventional coagulation times (aPTT and PT) were also prolonged, this effect was often but not always related to the volume of infusion (e.g., 
patient 2). In agreement with the in vitro data, TEG analysis of post-treatment plasmas showed a less severe reduction in torsion amplitude in the presence of (donor) platelets than with phospholipid vesicles. Also this finding argues for inclusion of platelets in assays determining the haemostatic activity in dilutional coagulopathy. Clearly, more patient data are needed to know the clinical consequences of these findings.

In conclusion, the present data indicate that the processes of thrombin generation and clot formation are reduced at a plasma dilution of $>40 \%$. However, they also reveal a partially compensating role of platelets in opposing the hypocoagulant effect of plasma dilution in either process. Since platelets participate in either process in a clearly different way, this suggests that a sufficient platelet count is of eminent importance for the prevention of bleeding under conditions of plasma dilution. 


\section{References}

1. Ho AM, Karmakar MK, Dion PW. Are we giving enough coagulation factors during major trauma resuscitation? Am J Surg 2005; 190:479-484.

2. Johansson PI, Hansen $\mathrm{MB}$, Sorensen $\mathrm{H}$. Transfusion practice in massively bleeding patients: time for a change? Vox Sang 2005; 89:92-96.

3. Hardy JF, de Moerloose $P$, Samama CM. The coagulopathy of massive transfusion. Vox Sang 2005; 89:123-127.

4. Mitra B, Mori A, Cameron PA, Fitzgerald M, Street A, Bailey M. Massive blood transfusion and trauma resuscitation. Injury 2007; 38:1023-1029.

5. Kamal AH, Tefferi A, Pruthi RK. How to interpret and pursue an abnormal prothrombin time, activated partial thromboplastin time, and bleeding time in adults. Mayo Clin Proc 2007; 82:864-873.

6. Holland LL, Brooks JP. Toward rational fresh frozen plasma transfusion: The effect of plasma transfusion on coagulation test results. Am J Clin Pathol 2006; 126:133-139.

7. Hemker HC, Beguin S. Phenotyping the clotting system. Thromb Haemost 2000; 84:747-751.

8. Mann KG, Brummel-Ziedins K, Orfeo T, Butenas S. Models of blood coagulation. Blood Cells Mol Dis 2006; 36:108-117.

9. Monroe DM, Hoffman M, Roberts HR. Platelets and thrombin generation. Arterioscler Thromb Vasc Biol 2002; 22:1381-1389.

10. Beguin S, Kumar R. Thrombin, fibrin and platelets: a resonance loop in which von Willebrand factor is a necessary link. Thromb Haemost 1997; 78:590-594.

11. Lane DA, Philippou H, Huntington JA. Directing thrombin. Blood 2005; 106:2605-2612.

12. Bevers EM, Comfurius $P, Z$ waal RF. The nature of the binding for prothrombinase at the platelet surface as revealed by lipolytic enzymes. Eur J Biochem 1982; 122:81-85.

13. Heemskerk JW, Bevers EM, Lindhout T. Platelet activation and blood coagulation. Thromb Haemost 2002; 88:186-193.

14. Hemker HC, Al Dieri R, Beguin S. Thrombin generation assays: accruing clinical relevance. Curr Opin Hematol 2004; 11:170-175.

15. Vanschoonbeek K, Feijge MA, Van Kampen RJ, Kenis H, Hemker HC, Giesen PL, Heemskerk JW. Initiating and potentiating role of platelets in tissue factor-induced thrombin generation in the presence of plasma: subject-dependent variation in thrombogram characteristics. J Thromb Haemost 2004; 2:476-484.

16. Schols SEM, van der Meijden PE, van Oerle R, Curvers J, Heemskerk JW, van Pampus EC. Increased thrombin generation and fibrinogen level after therapeutic plasma transfusion: relation to bleeding. Thromb Haemost 2008; 99:64-70.

17. Mittermayr M, Streif W, Haas T, Fries D, Velik-Salchner C, Klingler A, Oswald E, Bach C, Schnapka-Koepf $M$, Innerhofer P. Hemostatic changes after crystalloid or colloid fluid administration during major orthopedic surgery: the role of fibrinogen administration. Anesth Analg 2007; 105:905-917.

18. Litvinov RI, Gorkun OV, Galanakis DK, Yakovlev S, Medved L, Shuman H, Weisel JW. Polymerization of fibrin: Direct observation and quantification of individual B:b knobhole interactions. Blood 2007; 109:130-138. 
19. Craft RM, Chavez JJ, Bresee SJ, Wortham DC, Cohen E, Carroll RC. A novel modification of the Thrombelastograph assay, isolating platelet function, correlates with optical platelet aggregation. J Lab Clin Med 2004; 143:301-309.

20. De Jonge $\mathrm{E}$, Levi $\mathrm{M}$. Effects of different plasma substitutes on blood coagulation: a comparative review. Crit Care Med 2001; 29:1261-1267.

21. Innerhofer P, Fries D, Margreiter J, Klingler A, Kuhbacher G, Wachter B, Oswald E, Salner E, Frischhut B, Schobersberger W. The effects of perioperatively administered colloids and crystalloids on primary platelet-mediated hemostasis and clot formation. Anesth Analg 2002; 95:858-865.

22. Rosing J, Tans G, Govers-Riemslag JW, Zwaal RF, Hemker HC. The role of phospholipids and factor Va in the prothrombinase complex. J Biol Chem 1980; 255:274-283.

23. Van der Meijden PE, Feijge MA, Giesen PL, Huijberts M, van Raak LP, Heemskerk JW. Platelet $\mathrm{P}_{2} \mathrm{Y}_{12}$ receptors enhance signalling towards procoagulant act ivity and thrombin generation. A study with healthy subjects and patients at thrombotic risk. Thromb Haemost 2005; 93:1128-1136.

24. Altman R, Scazziota A, Lourdes Herrera MDE, Gonzalez C. Recombinant factor Vlla reverses the inhibitory effect of aspirin or aspirin plus clopidogrel on in vitro thrombin generation. J Thromb Haemost 2006; 4:2022-2027.

25. Hemker HC, Al Dieri R, de Smedt E, Beguin S. Thrombin generation, a function test of the haemostatic-thrombotic system. Thromb Haemost 2006; 96:553-561.

26. Mousa SA, Khurana S, Forsythe MS. Comparative in vitro efficacy of different platelet glycoprotein IIb/llla antagonists on platelet-mediated clot strength induced by tissue factor with use of thromboelastography: differentiation among glycoprotein Ilb/lla antagonists. Arterioscler Thromb Vasc Biol 2000; 20:1162-1167.

27. Munnix IC, Kuijpers MJ, Auger J, Thomassen CM, Panizzi P, van Zandvoort MA, Rosing J, Bock PE, Watson SP, Heemskerk JW. Segregation of Platelet Aggregatory and Procoagulant Microdomains in Thrombus Formation. Regulation by Transient Integrin Activation. Arterioscler Thromb Vasc Biol 2007; 27:2484-2490.

28. Gupta V, Grover V. Risk Assessment and Outcome after CABG. Ann Card Anaesth 2002; 5:156-158.

29. Reverter JC, Beguin S, Kessels H, Kumar R, Hemker HC, Coller BS. Inhibition of plateletmediated, tissue factor-induced thrombin generation by the mouse/human chimeric $7 \mathrm{E}_{3}$ antibody. Potential implications for the effect of $\mathrm{c}_{7} \mathrm{E}_{3} \mathrm{Fab}$ treatment on acute thrombosis and "clinical restenosis". J Clin Invest 1996; 98:863-874.

30. Chakroun T, Gerotziafas GT, Seghatchian J, Samama MM, Hatmi M, Elalamy I. The influence of fibrin polymerization and platelet-mediated contractile forces on citrated whole blood thromboelastography profile. Thromb Haemost 2006; 95:822-828.

31. Reininger AJ. Coagulation activity of platelets. Hamostaseologie 2007; 27:247-250 


\section{4}

\section{Increased thrombin generation and fibrinogen level after therapeutic plasma transfusion: relation to bleeding}

Saskia E.M. Schols, Paola E.J. van der Meijden, René van Oerle, Joyce Curvers, Johan W.M. Heemskerk, Elisabeth C.M. van Pampus

Thromb Haemost 2008; 99:64-70

Reprinted with permission 


\section{Abstract}

In a clinical setting, fresh frozen plasma (FFP) is transfused to diluted patients with complicated surgery or trauma, as guided by prolonged conventional coagulation times or low fibrinogen levels. However, the limited sensitivity of these coagulation tests may restrict their use in measuring the effect of transfusion and hence predicting the risk of perioperative bleeding. We used the more sensitive, calibrated automated thrombogram (CAT) method to evaluate the result of therapeutic FFP transfusion to 51 patients with dilutional coagulopathy. Thrombin generation was measured in pre- and post-transfusion plasma samples in the presence of either platelets or phospholipids. For all patients, the transfusion led to higher plasma coagulation factor levels, a shortened activated partial thromboplastin time, and a significant increase in thrombin generation (peak height and endogenous thrombin potential). Interestingly, thrombin generation parameters and fibrinogen levels were higher in post-transfusion plasmas from patients who stopped bleeding $(n=32)$ than for patients with ongoing bleeding $(n=19)$. Plasmas from 15 of the 19 patients with ongoing bleeding were markedly low in either thrombin generation or fibrinogen level. We conclude that the thrombin generation method detects improved haemostatic activity after plasma transfusion. Furthermore, the data suggest that thrombin generation and fibrinogen are independent determinants of the risk of perioperative bleeding in this patient group.

\section{Introduction}

Patients with severe blood loss due to complicated surgery or trauma are commonly transfused with citrate-diluted fresh frozen plasma (FFP). This intervention, usually in combination with red cell and platelet transfusions, aims to effectively replace the loss of coagulation factors in a diluted patient and then to improve the haemostasis. Hence, the FFP serves to counteract the (surgical) dilutional coagulopathy and to contribute to the halt of bleeding. However, recent papers have debated the efficacy of prophylactic FFP transfusion upon surgery and trauma. ${ }^{1,2}$ Several practical and theoretical restrictions have emerged. One of these is that the coagulant factors in plasma are likely to loose function during the freezing, storage, transportation and defrosting procedures. Another limitation is that FFP preparations are themselves diluted with citrate, implicating that transfusion may even increase dilution of patients. ${ }^{3}$ Furthermore, FFP transfusion may cause adverse side reactions such as immune responses, fluid overload and citrate toxicity. ${ }^{4}$ 
Current guidelines recommend the (prophylactic) transfusion of FFP to patients treated with crystalloids or colloids, who show overt bleeding and/or an activated thromboplastin time (aPTT) or prothrombin time (PT) that is prolonged by $>1.5$ times the normal value. ${ }^{5}$ The efficacy of the transfusion reaction is evaluated from the same conventional coagulation tests. Unfortunately, these tests are notoriously insensitive at hypocoagulant conditions, which limits their suitability for this particular group of patients. ${ }^{6}$ The practical consequence is that current decisions on the employment of FFP to treat patients with peri-operative bleeding are to a large extent based on expert opinion and personal experience, rather than on precise test outcome. It is therefore important to search for alternative, more sensitive methods to determine the need and efficacy of transfusion, and to predict the risk of ongoing bleeding in patients with dilutional coagulopathy.

One of such tests may be provided by rotational thromboelastography, which measures the extent and quality of fibrin clot formation. The test outcome is partly but not exclusively determined by the plasma fibrinogen level. ${ }^{7,8}$ Another sensitive and perhaps suitable method is the calibrated automated thrombogram (CAT) test, in which the rate and extent of thrombin generation are continuously measured, following triggering of plasma with tissue factor. Earlier work shows that this method can detect reduced coagulant activity under conditions as diverse as hemophilia, treatment with anticoagulant medication, and dietary intervention with fish oil. ${ }^{9-11}$

For this report, we analyzed plasmas from 51 patients with dilutional coagulopathy upon surgery, who received FFP to prevent ongoing bleeding. We hypothesized that bleeding in these patients can be a consequence of impaired haemostasis due to (partial) deficiency in one or two different processes: the rate/amount of thrombin generation and the extent of fibrin clot formation. To investigate this, we measured the levels of coagulation factors including fibrinogen and used the CAT test to measure thrombin generation (in the presence of phospholipids or platelets) both before and after the transfusion. By comparing the test results with the clinical outcome of the intervention (stopped or ongoing bleeding), we subsequently searched for threshold levels of these processes above which bleeding is less likely to occur.

\section{Materials and methods}

\section{Patients and blood collection}

Plasma samples were collected from 51 patients, who received transfusion with FFP in the academic hospital within a 12-months period (Table 4.1). The patients were transfused either during major surgery (abdominal or spinal bone surgery) or post- 
operatively in the intensive care unit (after cardiothoracic or aortic surgery). During or prior to surgery, all patients had previously been transfused with crystalloids and erythrocytes (at least 2 bags of each). None of the patients had multiple-organ failure, sepsis, or liver or renal dysfunction. Patients had not received medication that interfered with platelet activation or coagulation.

Most of the patients were transfused with 2 bags of $300 \mathrm{ml} \mathrm{FFP.} \mathrm{Only} \mathrm{those} \mathrm{with}$ severe bleeding received 4 bags (14 patients), as considered appropriate by the anesthesiologist. The donated FFP was prepared from normal pool plasma of healthy volunteers according to the European guidelines for quality of blood components. ${ }^{12}$ Based on international guidelines, ${ }^{13,14}$ the criteria for transfusion were: aPTT $\geq 40 \mathrm{~s}$ (31 patients), plasma fibrinogen concentration $<2.0 \mathrm{~g} / \mathrm{l}$ (32 patients), and/or massive bleeding during or after surgery (29 patients). Nineteen of the 51 patients had ongoing bleeding after FFP transfusion. Within 1 hour, these subjects were transfused again with FFP, red cell or platelet concentrates, as considered appropriate by the anesthesiologist.

Blood (10 $\mathrm{ml}$ ) was collected from the patients within 30 min before and within 30 min after the transfusion with FFP; this blood was used for the clinical assessment of haemostasis. Remnant blood, anticoagulated with sodium citrate (1/10 volume, 129 $\mathrm{mmol} / \mathrm{l})$, was used in the research laboratory to prepare platelet-free plasma by centrifugation (twice at $2630 \mathrm{~g}$ for $10 \mathrm{~min}$ ). Patient plasma was snap-frozen at $-80^{\circ} \mathrm{C}$, and was later used for analysis. The study was approved by the local Medical Ethics Committee.

\section{Materials}

Apyrase and bovine serum albumin (BSA) were from Sigma (St. Louis, MO, USA). Innovin was from Dade Behring (Marburg, Germany); Z-Gly-Gly-Arg aminomethyl coumarin (Z-GGR-AMC) from Bachem (Bubendorf, Switzerland). Human thrombin calibrator and thrombogram software were supplied by Synapse (Maastricht, the Netherlands). ${ }^{15}$ Phospholipid vesicles (phosphatidylserine : phosphatidylcholine : phosphatidylethanolamine, $1: 3: 1, \mathrm{~mol} / \mathrm{mol}$ ) were prepared, as described. ${ }^{16}$ The PT was measured using Innovin as trigger, and the aPTT was measured with the actin FSL kit (Dade Behring). Fibrinogen levels were measured as described. ${ }^{11}$ The Behring coagulation system (Dade Behring) was used to measure prothrombin levels in a onestage clotting assay; and in this system antithrombin levels were measured with a chromogenic assay. Heparin in plasma was determined as anti factor Xa activity using the Coamatic heparin test (Chromogenics, Mölndal, Sweden). 


\section{Isolation of donor platelets}

Blood from healthy donors was drawn with a 1.2- $\mathrm{mm}$ needle, dripping freely into open tubes and collected into $1 / 6$ volume of acid-glucose solution ( $A C D, 80 \mathrm{mmol} / \mathrm{l}$ trisodium citrate, $52 \mathrm{mmol} / \mathrm{l}$ citric acid and $180 \mathrm{mmol} / \mathrm{l}$ glucose). Donors gave full informed consent. Blood samples were centrifuged at $240 \mathrm{~g}$ for $15 \mathrm{~min}$ to obtain platelet-rich plasma (PRP). After addition of 10\% ACD solution and apyrase (0.1 unit/ml ADPase), PRP was centrifuged at $2100 \mathrm{~g}$ for $2 \mathrm{~min}$, and platelets were collected. Platelets were resuspended in Hepes buffer $\mathrm{pH} 7.45$ (10 mmol/l Hepes, 136 $\mathrm{mmol} / \mathrm{l} \mathrm{NaCl}, 2.7 \mathrm{mmol} / / \mathrm{KCl}, 2 \mathrm{mmol} / \mathrm{l} \mathrm{MgCl} 2,0.1 \%$ glucose and $0.1 \% \mathrm{BSA}){ }^{17}$ Platelet count was determined with a thrombocounter (Coulter Electronics, Luton, UK). Normal pooled plasma was obtained from 40 healthy donors, following guidelines of the University Hospital Maastricht.

\section{Thrombin generation measurements}

Patient platelet-free plasma was reconstituted with donor platelets $\left(100 \times 10^{9}\right.$ platelets/l) or with phospholipid vesicles $(4 \mu \mathrm{mol} / \mathrm{l})$, and then preincubated with tissue factor (10 pmol/l, all final concentrations). After an incubation time of $10 \mathrm{~min}$, coagulation was initiated with $\mathrm{CaCl}_{2}$ and thrombin substrate Z-GGR-AMC. Thrombin generation was continuously measured at $37^{\circ} \mathrm{C}$, as described. ${ }^{15,17}$ Briefly, $80 \mu \mathrm{l}$ of plasmas containing donor platelets or phospholipids were pipetted into the wells of a polystyrene 96 -wells plate. Coagulation was started by adding $20 \mu \mathrm{l}$ of Z-GGR-AMC (2.5 mmol/l), dissolved in Hepes buffer pH 7.35 (20 mmol/l Hepes, 140 mmol/l NaCl, $100 \mathrm{mmol} / / \mathrm{CaCl}_{2}$ and $60 \mathrm{mg} / \mathrm{ml} \mathrm{BSA}$ ). After shaking for $10 \mathrm{~s}$, fluorescence from cleaved AMC was measured at excitation and emission wavelengths of 368 and 460 $\mathrm{nm}$, respectively. In separate wells, human thrombin calibrator was added to each type of plasma to obtain reference thrombin curves. Samples were run at least in triplicate. First-derivative traces were directly converted into nanomolar concentrations of thrombin, as described. ${ }^{15}$ In the resulting thrombograms, thrombin peak height (a measure of the rate of thrombin formation) and endogenous thrombin potential (ETP, i.e. area-under-the-curve representing the integrated amount of thrombin activity) were used as principal parameters. ${ }^{18}$ Control experiments showed that triggering with 10 instead of $5 \mathrm{pmol} / \mathrm{l}$ resulted in a $15 \%$ higher thrombin peak height. The assay variation coefficient was 5-7\%.

\section{Statistics}

A paired sample t-test was used to compare transfusion effects; the independent sample t-test was used for comparing patients groups (SPSS 11.0 software). Data are presented as means \pm SD. 


\section{Results}

The effect was studied of plasma transfusion (FFP) to 51 patients, who were bleeding or at risk of bleeding (Table 4.1). Of the patients, 29 were transfused during abdominal or spinal back bone surgery. The 22 other patients were subjected to cardiothoracic/aortic surgery, and they received FFP while staying in the intensive care unit. Nineteen of the 51 patients experienced ongoing bleeding after the transfusion. Platelet count and haematocrit in the patient's blood were below normal, as a consequence of earlier surgery and dilution with crystalloids; these values did not increase upon FFP transfusion (Table 4.2). Further measurements were performed with isolated plasma samples. When comparing the plasmas from all 51 patients, transfusion led to shortening of the conventional coagulation times from 62 \pm 32 to $41 \pm 12 \mathrm{~s}$ (aPTT) and from $16 \pm 3$ to $13 \pm 2 \mathrm{~s}$ (PT), which agrees well with published observations. ${ }^{19}$ The levels of prothrombin and antithrombin before transfusion were $37 \%$ of normal values (Table 4.2), demonstrating the hypocoagulant state of the patients. After transfusion, these levels increased to about $50 \%$. Similarly, the low fibrinogen levels (mean $1.3 \mathrm{~g} / \mathrm{l}$ ) increased with $0.5 \mathrm{~g} / \mathrm{l}$ following FFP transfusion.

Thrombogram curves, using optimized concentrations of either procoagulant phospholipids $(4 \mu \mathrm{mol} / \mathrm{l})$ or platelets derived from one healthy donor $\left(100 \times 10^{9}\right.$ platelets/l), were measured to assess the net transfusion effect on thrombin generation. The coagulation was triggered with optimal doses of tissue factor (10 $\mathrm{pmol} / \mathrm{l})$ and $\mathrm{CaCl}_{2}(16.6 \mathrm{mM})$. Typically, the plasmas from some patients failed to increase in thrombin generation after transfusion, regardless of whether phospholipids or platelets were present (Fig. 4.1A), whilst the plasmas from other patients were markedly increased in thrombin formed (Fig. 4.1B). This suggested considerable inter-patient variation to the intervention.

To obtain normal values, thrombin generation was also measured using pooled plasma from 40 healthy donors, in the presence of the same batches of tissue factor and phospholipids and with platelets from the same donor as for patient plasmas. In normal pooled plasma, thrombin peak heights were 225 (platelets) and 352 (phospholipids) nmol/l, while ETP values were 1470 (platelets) and 1245 (phospholipids) $\mathrm{nmol} / \mathrm{l} \times \mathrm{min}$. Comparison of the 40 individual normal plasmas gave variation coefficients (SD/mean) of $14 \%$ (peak height) and $11 \%$ (ETP). 
Table 4.1: Characteristics of patients and conditions of the FFP transfusion. Means \pm SD.

\begin{tabular}{|l|l|}
\hline Patient characteristic & Variable \\
\hline Male/female $(n)$ & $26 / 25$ \\
Age (years) & $62 \pm 13$ \\
$\begin{array}{l}\text { Transfusion during surgery }(n=29) \\
\text { abdominal surgery } \\
\text { spinal back bone surgery }\end{array}$ & 24 \\
Transfusion in intensive care unit $(n=22)$ & 5 \\
cardiothoracic/aortic surgery & \\
Number of FFP bags transfused & 22 \\
\hline
\end{tabular}

Table 4.2: Hematological variables of 51 patients before and after FFP transfusion. Data are means $\pm S D ; * * * p<0.001$ compared to pre-transfusion.

\begin{tabular}{|l|l|l|l|}
\hline \multicolumn{2}{|c|}{ Before transfusion } & \multicolumn{1}{l|}{ After transfusion } & \multicolumn{1}{l|}{ Normal range } \\
\hline Platelets $\left(\times 10^{9} / \mathrm{l}\right)$ & $84 \pm 43$ & $85 \pm 29$ & $130-350$ \\
Haematocrit & $0.26 \pm 0.06$ & $0.26 \pm 0.05$ & $0.36-0.52$ \\
aPTT (s) & $62 \pm 32$ & $41 \pm 12 * * *$ & $23-32$ \\
PT (s) & $16 \pm 3$ & $13 \pm 2 * * *$ & $10-13$ \\
$\begin{array}{l}\text { Prothrombin } \\
\text { (\% control plasma) }\end{array}$ & $37 \pm 13$ & $48 \pm 14 * * *$ & 100 \\
$\begin{array}{l}\text { Antithrombin } \\
(\% \text { control plasma) }\end{array}$ & $37 \pm 10$ & $49 \pm 13 * * *$ & 100 \\
Fibrinogen (g/l) & $1.3 \pm 0.6$ & $1.8 \pm 0.9 * * *$ & $1.7-4.0$ \\
\hline
\end{tabular}

Analyzing the pre-transfusion thrombograms from all 51 patients (with platelets or phospholipids), we found mean peak heights amounting to $45-50 \%$ of the normal value, and ETP values of $77-80 \%$ of normal (Table 4.3). After transfusion, thrombin peak heights were significantly increased in the presence of both platelets $(+17 \%)$ and phospholipids $(+21 \%)$; the transfusion effects on peak height with platelets and phospholipids were strongly correlated (Fig. 4.2). Post-transfusion samples showed also higher ETP values with platelets (+15\%) and phospholipids (+13\%) (Table 4.3). The effects on thrombin generation were similar for the patients who were transfused during surgery and those recovering in the intensive care unit (Table 4.3). Typically, in post-transfusion plasmas, the aPTT correlated with neither the thrombin peak height nor the ETP $(p \geq 0.37)$. Thus, in these patients with dilutional coagulopathy, the thrombin generation method detected transfusion-mediated changes in coagulation in a likely more sensitive way than the aPTT. This in spite of the increase in procoagulant and anticoagulant factors. 
A Patient $\mathrm{A}$
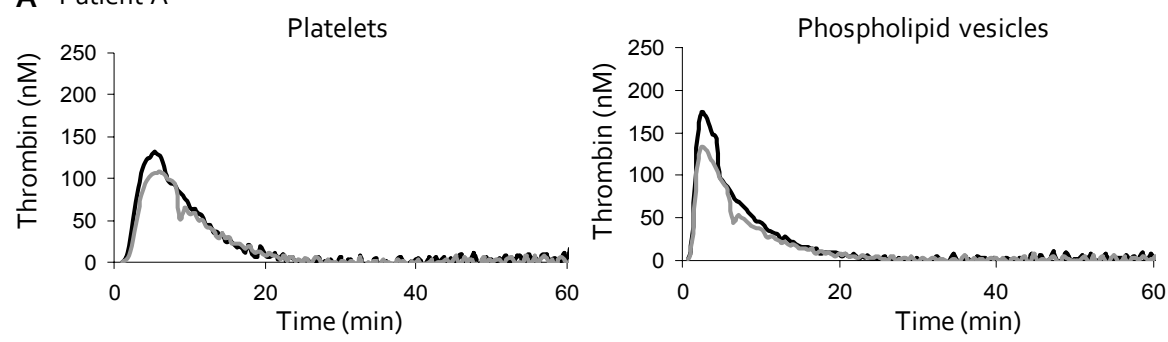

B Patient B
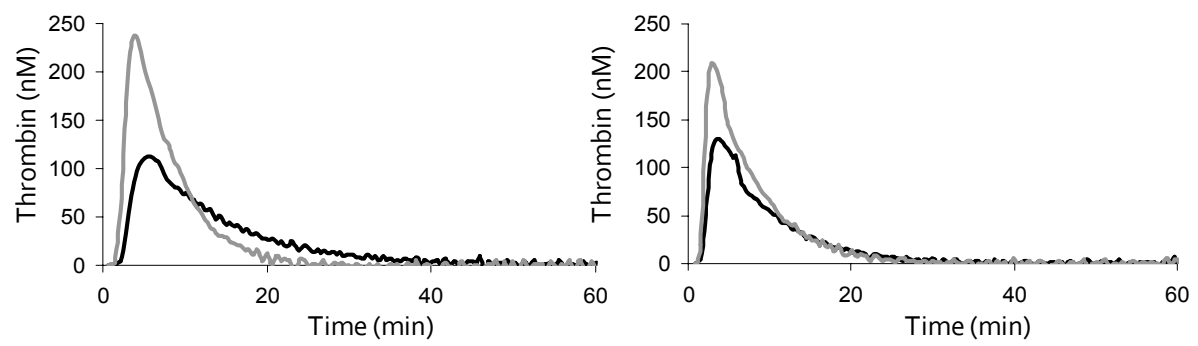

Fig. 4.1: Inter-patient difference in effect of FFP transfusion on thrombin generation. Thrombin generation was measured in plasmas of two patients, who were transfused with two bags of FFP during surgery. Pre- and post-transfusion plasma samples were supplemented with donor platelets $\left(100 \times 10^{9} / \mathrm{l}\right)$ or phospholipids $(4 \mu \mathrm{mol} / \mathrm{l})$. Coagulation was induced with 10 $\mathrm{pmol} / \mathrm{l}$ tissue factor plus $16.6 \mathrm{mmol} / \mathrm{l} \mathrm{CaCl}_{2}$ (final concentrations). Thrombin generation was measured using the CAT method. (A) Thrombogram of plasma from patient $A$ with ongoing bleeding after transfusion. Traces are given before (black) and after (grey) transfusion; aPTT was 150 and $51 \mathrm{~s}$, and fibrinogen concentration was 0.6 and $1.1 \mathrm{~g} / \mathrm{l}$, respectively. (B) Thrombogram of plasma from patient $B$, who stopped bleeding after the transfusion. Traces are given before (black) and after (grey) transfusion; aPTT was 73 and $41 \mathrm{~s}$, and fibrinogen concentration was 1.3 and $1.9 \mathrm{~g} / \mathrm{l}$, respectively.

Based on the relatively large changes in thrombin peak height relative to ETP, the former parameter was used for further analysis. Thrombogram data were compared for patients with stopped $(n=32)$ and ongoing bleeding $(n=19)$ after the FFP transfusion (Fig. 4.3). In post-transfusion plasma samples from only patients with ongoing bleeding (white dots), thrombin peak heights remained relatively low in $13 / 19$ of the cases. Using an arbitrary cut-off point of $\leq 100 \mathrm{nmol} / \mathrm{l}$ thrombin (i.e., $45 \%$ of the normal value), 8 out of 12 samples below this cut-off were patients with ongoing bleeding (Fig. 4.3). Control measurements showed that only 3 plasma samples contained heparin traces (0.23-0.47 anti-factor $\mathrm{Xa} U / \mathrm{ml}$ ), i.e. 1 pretransfusion and 2 post-transfusion samples (Fig. 4.3). 
Table 4.3: Effect of FFP transfusion on thrombin generation parameters. Thrombin generation was measured in patient plasmas in the presence of donor platelets or phospholipids (Fig. 4.1). Subjects were divided in patients transfused during surgery or when recovering in the intensive care unit (ICU). Normal values of thrombogram parameters were determined in parallel using pooled plasma from 40 healthy volunteers: thrombin peak height of 225 (platelets) and 352 (phospholipids) nmol/l; ETP of 1470 (platelets) and 1245 (phospholipids) $\mathrm{nmol} / \mathrm{l} \times \mathrm{min}$. Data are means $\pm \mathrm{SD}$ t transfusion effect (\%) is given within brackets. ${ }^{*} p<0.05, * * p<0.01, * * * p<0.001$ compared to pre-transfusion.

\begin{tabular}{|c|c|c|c|}
\hline & All patients $(n=51)$ & Surgery $(n=29)$ & $\operatorname{ICU}(n=22)$ \\
\hline \multicolumn{4}{|c|}{ Thrombogram parameters before and after transfusion } \\
\hline \multicolumn{4}{|c|}{ Peak height with platelets (nmol/l) } \\
\hline \multirow{2}{*}{$\begin{array}{l}\text { before transfusion } \\
\text { after transfusion }\end{array}$} & $112 \pm 37$ & $112 \pm 36$ & $111 \pm 38$ \\
\hline & $131 \pm 43 * * *(+17 \%)$ & $130 \pm 45 *(+16 \%)$ & $132 \pm 41 * *(+19 \%)$ \\
\hline \multicolumn{4}{|c|}{ ETP with platelets $(\mathrm{nmol} / \mathrm{l} \times \mathrm{min})$} \\
\hline \multirow{2}{*}{$\begin{array}{l}\text { before transfusion } \\
\text { after transfusion }\end{array}$} & $1136 \pm 326$ & $1208 \pm 394$ & $1196 \pm 435$ \\
\hline & $1312 \pm 377 * *(+15 \%)$ & $1323 \pm 459(+10 \%)$ & $1361 \pm 364 *(+14 \%)$ \\
\hline \multicolumn{4}{|c|}{ Thrombogram parameters before and after transfusion } \\
\hline \multicolumn{4}{|c|}{ Peak height with phospholipids (nmol/l) } \\
\hline \multirow{2}{*}{$\begin{array}{l}\text { before transfusion } \\
\text { after transfusion }\end{array}$} & $157 \pm 42$ & $151 \pm 40$ & $166 \pm 44$ \\
\hline & $190 \pm 53 * * *(+21 \%)$ & $182 \pm 48 * *(+21 \%)$ & $201 \pm 58 * * *(+21 \%)$ \\
\hline \multicolumn{4}{|c|}{ ETP with phospholipids ( $\mathrm{nmol} / \mathrm{l} \times \mathrm{min}$ ) } \\
\hline $\begin{array}{l}\text { before transfusion } \\
\text { after transfusion }\end{array}$ & $\begin{array}{l}994 \pm 248 \\
1126 \pm 267 * *(+13 \%)\end{array}$ & $\begin{array}{l}952 \pm 235 \\
1086 \pm 231(+14 \%)\end{array}$ & $\begin{array}{l}914 \pm 164 \\
1035 \pm 134(+13 \%)\end{array}$ \\
\hline
\end{tabular}

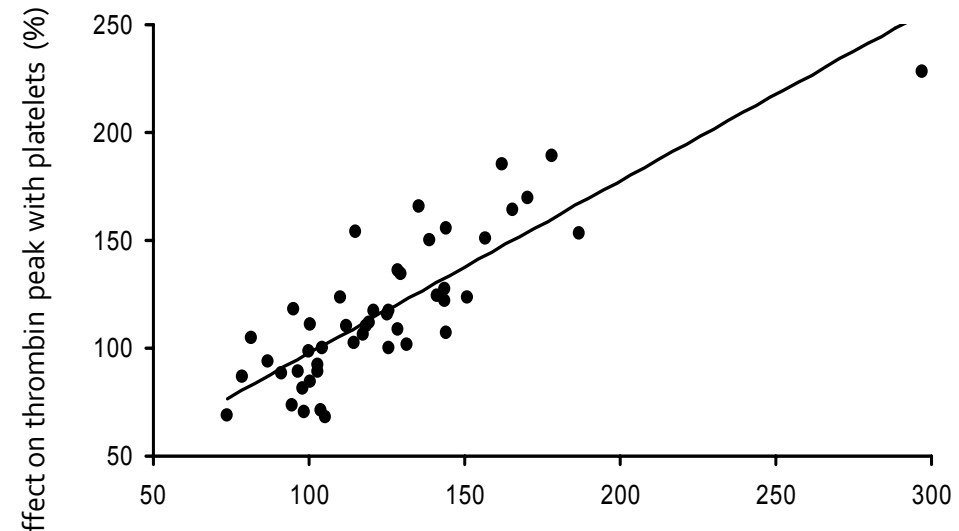

Effect on thrombin peak with phospholipid vesicles (\%)

Fig. 4.2: Correlation of effects of FFP transfusion on thrombin generation in the presence of platelets or phospholipids. Plasma samples from 51 patients were supplemented with platelets from one healthy donor $\left(100 \times 10^{9} / \mathrm{l}\right)$ or with phospholipids $(4 \mu \mathrm{mol} / \mathrm{l})$. Thrombin generation was measured as in Fig. 4.1. Shown is correlation plot of the transfusion effect on thrombin peak height in the presence of platelets or phospholipids $\left(n=51, R_{2}=0.72, p<0.01\right)$. 


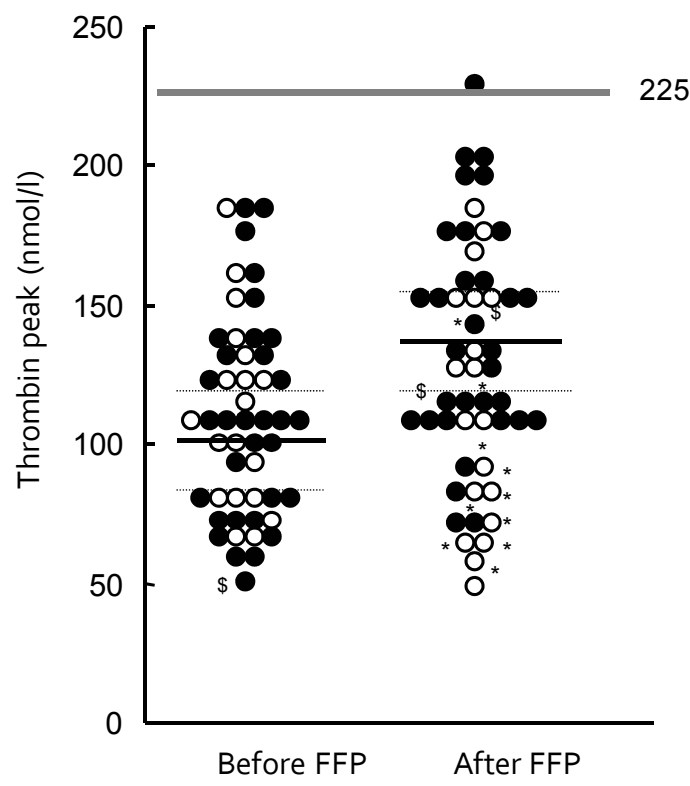

Fig. 4.3: Thrombin peak height in patient plasmas before and after FFP transfusion. Thrombin generation was measured in plasma from 51 patients before and after transfusion with FFP. Donor platelets were present, as in Fig. 4.1. Patients were characterized as experiencing stopped (black dots) or ongoing (white dots) bleeding after transfusion. Data are thrombin peak heights; reference value of normal pooled plasma is given as a horizontal bar. Dotted lines represent means \pm SD. *Plasma with post-transfusion fibrinogen level $\geq 1.05 \mathrm{~g} / \mathrm{l}_{;}$ \$plasma with heparin trace.

A

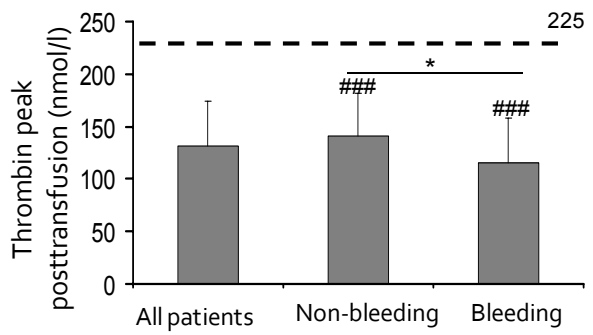

\section{$\mathrm{B}$}

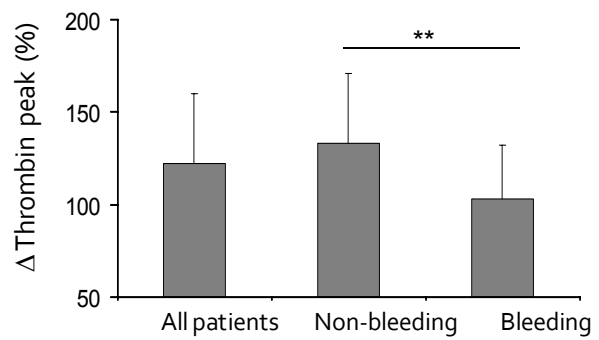

Fig. 4.4: Transfusion effect on thrombin peak height of patients with stopped or ongoing bleeding. Thrombin generation was measured in patient plasmas supplemented with platelets from one healthy donor as in Fig. 4.1. A. Thrombin peak height of post-transfusion plasmas from patients with stopped $(n=32)$ or ongoing $(n=19)$ bleeding. B. Change in thrombin peak height after transfusion. First bar shows value for normal pool plasma and the same platelet preparation is given separately. Difference between patient groups: ${ }^{\# \#} \mathrm{p}<0.001$ compared to normal pool plasma; ${ }^{*}<0.05, * * p<0.01$ inter-group comparison. Dotted line represents normal value of thrombin generation. 
In comparison to the patients with stopped bleeding, thrombin peak heights were significantly lower for the bleeding patients (Fig. 4.4A, $p<0.05$ ). In addition, the transfusion-mediated increases in peak height were smaller (Fig. 4.4B, p<0.01). In contrast, conventional coagulation times were not different for the two groups: the post-transfusion aPTT was $41 \pm 12 \mathrm{~s}$ and $49 \pm 12 \mathrm{~s}$ for patients with stopped and ongoing bleeding, respectively $(p=0.14)$.

Low plasma fibrinogen is a known risk factor for bleeding in dilutional coagulopathy. ${ }^{20}$ Theoretically, low fibrinogen levels may impair fibrin clot formation even if sufficient amounts of thrombin are generated. We found that the fibrinogen concentration after transfusion was relatively low in patients with ongoing bleeding (Fig. 4.5A). Similarly, the increase in fibrinogen upon transfusion was lower in this patient group (Fig. 4.5B). By setting an arbitrary cut-off of $\leq 1.1 \mathrm{~g}$ fibrinogen/l (i.e., $40 \%$ of the mean normal value), 7 of the 19 bleeding patients remained below this level. Strikingly, these 7 patients were non-identical to the 8 bleeding patients with low thrombin generation (Fig. 4.3). These 8 patients had a plasma fibrinogen level of $1.7 \pm 0.6 \mathrm{~g} / \mathrm{l}$, whereas the 11 other bleeding patients had a level of $0.9 \pm 0.2 \mathrm{~g} / \mathrm{l}$ $(p=0.005)$. Taking together, the data indicate that ongoing bleeding in 15 out of 19 patients was accompanied by either a low thrombin generation or a low fibrinogen concentration.

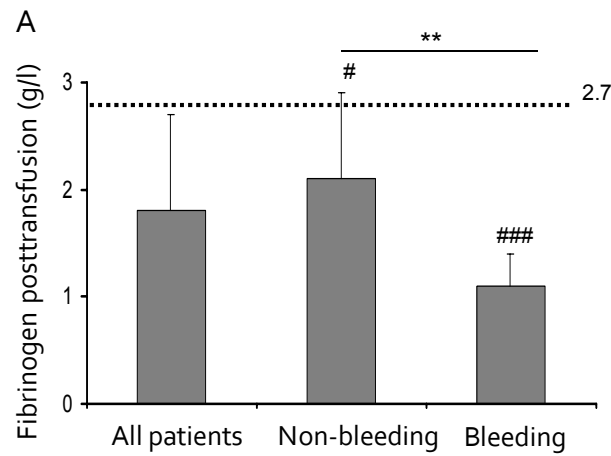

B

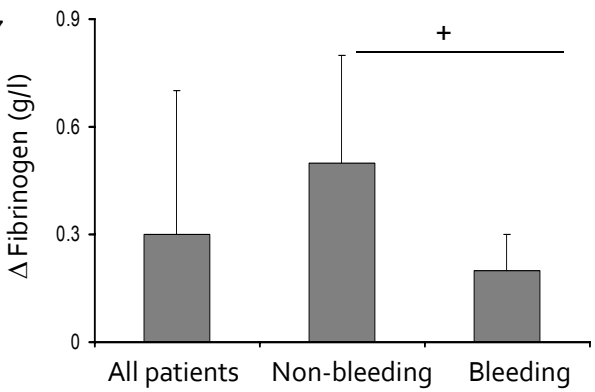

Fig. 4.5: Transfusion effect on fibrinogen concentration of patients with stopped or ongoing bleeding. A. Fibrinogen levels in post-transfusion plasmas per patient group. B. Effect of transfusion on the fibrinogen level. First bar shows value for normal pool plasma. ${ }^{\#} p<0.05$, $\# \#$ $p<0.001$ compared to normal pool plasma; ${ }^{+} p=0.05, * * p<0.01$ inter-group comparison. Dotted line represents normal value of fibrin level. 
In none of the patient groups, fibrinogen did correlate with the thrombin generation parameters ( $p>0.26)$. In agreement with earlier results, ${ }_{11}^{11}$ in vitro tests using diluted plasma samples, also showed that the fibrinogen level was of only little effect on thrombin generation; thrombin peak height increased with $10 \%$ at a $1.5 \mathrm{~g} / \mathrm{l}$ increase in fibrinogen. Thus, the outcome of the thrombin generation test was no more than moderately influenced by the fibrinogen content. Further regression analysis showed that, for all 51 patients, the fibrinogen concentration correlated, but only poorly, with the aPTT $\left(R^{2}=0.15, p<0.013\right)$. In plasmas from 9 of the 32 patients with stopped bleeding and from 5 of the 19 patients with ongoing bleeding, the aPTT was $>40 \mathrm{~S}$, which confirmed that this test is of limited use in the prediction of ongoing bleeding after transfusion.

\section{Discussion}

In this report, we used conventional and novel assays to evaluate the coagulant effect of FFP transfusion to 51 patients, who experienced dilutional coagulopathy. The transfusion resulted in a rise in procoagulant (fibrinogen, prothrombin) as well as anticoagulant (antithrombin) factors. This was accompanied by a shortening of the conventional coagulation times, particularly the aPTT, and increased thrombin generation curves. The increased thrombin generation was detected with either phospholipids or donor platelets as lipid surface; and assessed as a higher thrombin peak height and a higher ETP (area-under-the-curve). For normal undiluted plasma, it is known that prothrombin and antithrombin per-se have antagonistic effects on the coagulation process in general, and on the thrombin generation profile in particular. ${ }^{11,21}$ The present results therefore point to an overriding effect of the positive contribution of procoagulant factors (prothrombin) relative to the negative contribution of anticoagulant factors (antithrombin). The biochemical explanation for this net procoagulant transfusion effect is unclear, since no more than little is known of the kinetics of the coagulation system in the diluted plasma samples.

When comparing the patients with stopped or ongoing bleeding after transfusion, we found marked differences in thrombin generation parameters. The thrombin peak height was significantly lower in plasma samples from the patients with ongoing bleeding. The same was true for the fibrinogen level, which also increased to a lesser degree in the bleeding patients. In contrast, the aPTT was not statistically different for the two groups, suggesting this assay lacks sensitivity compared to the other tests. The marked changes in thrombin peak height are well compatible with conclusions that this thrombogram parameter is an adequate sensor of the coagulant state of plasma. ${ }^{22,23}$ 
An intriguing observation was that 8 out of 19 plasmas from patients with ongoing bleeding were markedly low in thrombin peak height ( $\leq 100 \mathrm{nmol} / \mathrm{l})$, but not in fibrinogen level (>1.2 g/l). Conversely, 7 out of 19 plasmas from different bleeding patients had higher thrombin peak heights $(>100 \mathrm{nmol} / \mathrm{l})$, but were lower in fibrinogen $(\leq 1.1 \mathrm{~g} / \mathrm{l})$. These cases were well segregated from patients where bleeding stopped, who all had thrombograms and fibrinogen levels above these cut-off levels. Jointly, $15 / 19$ (79\%) of the patients with ongoing bleeding after transfusion showed either low thrombin generation or low fibrinogen. This analysis raises the suggestion that in these patients either insufficient thrombin generation or deficient fibrinogen, likely in an independent way, contributes to the hemorrhage. However, since also the surgery in these patients has contributed to the bleeding, one needs to be careful with drawing far-reaching conclusions. Also, the examined number of patients is still limited, which points to a need for larger-scale follow-up studies.

Even taking this into account, our results do support the hypothesis that certain amounts of thrombin generation and, independently of this, certain levels of fibrinogen are required to suppress the bleeding in dilutional coagulopathy. This is further supported by recent animal studies, where supplementation of either prothrombin or fibrinogen concentrates were capable to prevent blood loss in experimental coagulopathy. ${ }^{24}$ Other support comes from thromboelastographic measurements, where fibrinogen was a key predicting variable in the assessment of clot formation in bleeding patients, independently of the outcome of the aPTT. ${ }^{25}$ This makes us conclude that both thrombin generation and fibrinogen clot formation need to be sufficiently active to ensure normal haemostasis and reduce the bleeding risk, under conditions of dilutional coagulopathy. 


\section{References}

1. Johansson $\mathrm{PI}$, Hansen $\mathrm{MB}$, Sorensen $\mathrm{H}$. Transfusion practice in massively bleeding patients: time for a change? Vox Sang 2005; 89:92-96.

2. Stanworth SJ, Brunskill SJ, Hyde CJ, McClelland DB, Murphy MF. Is fresh frozen plasma clinically effective? A systematic review of randomized controlled trials. Br J Haematol 2004; 126:139-152.

3. Hardy JF, de Moerloose P, Samama CM. The coagulopathy of massive transfusion. Vox Sang 2005; 89:123-127.

4. Bux J. Transfusion-related acute lung injury (TRALI): a serious adverse event of blood transfusion. Vox Sang 2005; 89:1-10.

5. Holland LL, Brooks JP. Toward Rational fresh frozen plasma transfusion. The Effect of Plasma Transfusion on Coagulation test results. Am J Clin Pathol 2006; 126:133-139.

6. Spahn DR, Rossaint R. Coagulopathy and blood component transfusion in trauma. $\mathrm{Br} J$ Anaesth 2005; 95:130-139.

7. Luddington RJ. Thrombelastography/thromboelastometry. Clin Lab Haematol 2005; 27:81-90.

8. Sorensen B, Ingerslev J. Tailoring haemostatic treatment to patient requirements - an update on monitoring haemostatic response using thrombelastography. Haemophilia 2005; 11:1-6.

9. Barrowcliffe TW. Factor VIII and thrombin generation assays: relevance to pharmacokinetic studies in haemophilia A. Haemophilia 2006; 12:23-29.

10. Nieuwenhuys CM, Feijge MA, Beguin S, Heemskerk JW. Monitoring hypocoagulant conditions in rat plasma: factors determining the endogenous thrombin potential of tissue factor-activated plasma. Thromb Haemost 2000; 84:1045-1051.

11. Vanschoonbeek K, Feijge MA, Paquay M, Rosing J, Saris W, Kluft C, Giesen PL, de Maat MP, Heemskerk JW. Variable hypocoagulant effect of fish oil intake in humans: modulation of fibrinogen level and thrombin generation. Arterioscler Thromb Vasc Biol 2004; 24:1734-140.

12. Matthes GA. Options and cost effectiveness of multicomponent blood collection. Transfus Apher Sci 2002; 27:115-121.

13. O'Shaughnessy DF, Atterbury C, Bolton Maggs $P$, Murphy $M$, Thomas D, Yates S, Williamson LM. Guidelines for the use of fresh-frozen plasma, cryoprecipitate and cryosupernatant. Br J Haematol 2004; 126:11-28.

14. Chowdhury P, Saayman AG, Paulus U, Findlay GP, Collins PW. Efficacy of standard dose and $30 \mathrm{ml} / \mathrm{kg}$ fresh frozen plasma in correcting laboratory parameters of haemostasis in critically ill patients. Br J Haematol 2004; 125:69-73.

15. Hemker HC, Giesen P, Al Dieri R, Regnault V, de Smedt E, Wagenvoord R, Lecompte T, Beguin S. Calibrated automated thrombin generation measurement in clotting plasma. Pathophysiol Haemost Thromb 2003; 33:4-15.

16. Rosing J, Tans G, Govers-Riemslag JW, Zwaal RF, Hemker HC. The role of phospholipids and factor Va in the prothrombinase complex. J Biol Chem 1980; 255:274-283.

17. Vanschoonbeek K, Feijge MA, Van Kampen RJ, Kenis H, Hemker HC, Giesen PL, Heemskerk JW. Initiating and potentiating role of platelets in tissue factor-induced thrombin generation in the presence of plasma: subject-dependent variation in thrombogram characteristics. J Thromb Haemost 2004; 2:476-484. 
18. Van der Meijden PE, Feijge MA, Giesen PL, Huijberts M, van Raak LP, Heemskerk JW. Platelet $\mathrm{P}_{2} \mathrm{Y}_{12}$ receptors enhance signalling towards procoagulant activity and thrombin generation. A study with healthy subjects and patients at thrombotic risk. Thromb Haemost 2005; 93:1128-1136.

19. Abdel-Wahab OI, Healy B, Dzik WH. Effect of fresh-frozen plasma transfusion on prothrombin time and bleeding in patients with mild coagulation abnormalities. Transfusion 2006; 46:1279-1285.

20. Hardy JF, de Moerloose $\mathrm{P}$, Samama CM. Massive transfusion and coagulopathy: pathophysiology and implications for clinical management. Can J Anaesth 2006; 53:S40-S58.

21. Al Dieri R, Alban S, Beguin S, Hemker HC. Thrombin generation for the control of heparin treatment, comparison with the activated partial thromboplastin time. J Thromb Haemost 2004; 2:1395-1401.

22. Hemker HC, Al Dieri R, de Smedt E, Beguin S. Thrombin generation, a function test of the haemostatic-thrombotic system. Thromb Haemost 2006; 96:553-561.

23. Heemskerk JW, Bevers EM, Lindhout T. Platelet activation and blood coagulation. Thromb Haemost 2002; 88:186-193.

24. Fries D, Haas T, Klingler A, Streif W, Klima G, Martini J, Wagner-Berger H, Innerhofer P. Efficacy of fibrinogen and prothrombin complex concentrate used to reverse dilutional coagulopathy-a porcine model. Br J Anaesth 2006; 97:460-467.

25. Kheirabadi BS, Crissey JM, Deguzman R, Holcomb JB. In vivo bleeding time and in vitro thrombelastography measurements are better indicators of dilutional hypothermic coagulopathy than prothrombin time. J Trauma 2007; 62:1352-1359. 



\section{Impaired thrombin generation and fibrin clot formation in patients with dilutional coagulopathy during major surgery}

Saskia E.M. Schols, Marcus D. Lancé, Marion A. H. Feijge, Jan Damoiseaux, Marco A. Marcus, Karly Hamulyák, Hugo ten Cate, Johan W. M. Heemskerk1* and Elisabeth C. M. van Pampus*

Thromb Haemost 2010; 103:in press

Printed with permission

* Authors contributed equally to this paper 
Background: Patients subjected to hemodilution during surgery are at increased risk of bleeding. We hypothesized that, in the acquired dilutional coagulopathy, insufficient hemostasis is due to either insufficient thrombin generation or insufficient fibrin clot formation.

Methods: In tissue factor-activated plasmas from patients with coagulation deficiency, we measured time curves of thrombin generation and fibrin clot formation (thromboelastography). Investigated were in study A: 10 patients treated with a vitamin $\mathrm{K}$ antagonist and 5 healthy subjects; in study $\mathrm{B}$ : 30 patients undergoing cardiopulmonary bypass (CPB) surgery and infused with on average $<2000 \mathrm{ml}$ crystalloids and colloids (no major bleeding); in study C: 58 patients undergoing major general surgery, and transfused with $>5000 \mathrm{ml}$ crystalloids, colloids and red cell concentrates, who experienced major bleeding and were post-transfused with fresh frozen plasma.

Results: Treatment with vitamin $\mathrm{K}$ antagonist led to a progressive reduction in thrombin generation but not fibrin clot formation. In CPB patients, plasma factor levels post-surgery were $53-60 \%$ of normal, which was accompanied by moderate reduction in both hemostatic processes. In plasmas from patients undergoing major surgery, factor levels were $38-41 \%$ of normal, and these levels increased after plasma transfusion. Taking preset thresholds for normal thrombin generation and fibrin clot formation, at least one process was low in $88-93 \%$ of the patients with (persistent) bleeding, but only in 40-53\% of the patients without bleeding.

Conclusions: The processes of thrombin generation and fibrin clot formation are independently reduced in acquired dilutional coagulopathy, while minimal levels of both seem to be required for adequate hemostasis.

\section{Introduction}

Patients undergoing major surgery or trauma are routinely treated with fluids lacking coagulation factors, which leads to an increased risk of bleeding problems due to dilutional coagulopathy. In clinical practice, the indications for impaired hemostasis are currently obtained from conventional coagulation tests, such as the prothrombin time (PT) and activated partial thromboplastin time (aPTT). However, since these single point assays are rather insensitive to coagulation insufficiencies, there is currently an increased interest in the use of integrative tests for the prediction of bleeding risks. Popular tests which provide integrated, time-dependent information on the total activity of the coagulation process include time-dependent measurements of thrombin generation and clot strength using the method of thromboelastography. ${ }^{1-5}$ It is currently discussed that these integrative measurements are valuable for not only the monitoring of coagulopathy but also the 
management of transfusion. ${ }^{6}$ However, why integrative measurements would perform better is unclear, given the still limited knowledge of the altered coagulation process under clinically relevant conditions of in vivo dilution, and in particular because of the unclear relation between the processes of thrombin generation and fibrin clot formation.

Recent data suggest that limited thrombin generation is one of the determinants of the risk of peri-operative bleeding. ${ }^{7}$ However, there is a large body of evidence that also the plasma fibrinogen level, which does not play a key role in thrombin generation, ${ }^{8}$ needs to reach threshold levels to prevent bleeding. ${ }^{9-11}$ In the present paper we hypothesized that insufficient hemostasis in dilutional coagulopathy can be due to deficiencies in either thrombin generation or fibrin clot formation. To test this, we performed a first proof-of-principle study with plasmas from patients taking a vitamin $\mathrm{K}$ antagonist and from patients experiencing peri-operative dilution with or without bleeding.

\section{Materials and methods}

\section{Materials}

Apyrase and bovine serum albumin were from Sigma (St. Louis, MO, USA). Tissue factor (Innovin) was from Dade Behring (Marburg, Germany). Thrombin substrate Z-Gly-Gly-Arg aminomethyl coumarin (Z-GGR-AMC) came from Bachem (Bubendorf, Switzerland); human thrombin calibrator and thrombogram software were from Thrombinoscope (Maastricht, The Netherlands). Procoagulant phospholipid vesicles (phosphatidylserine : phosphatidylcholine : phosphatidylethanolamine, 1:3:1, mol:mol) were prepared, as described. ${ }^{12}$ Thromboelastogram control was from Haemoscope, IPO Medical (Barendrecht, The Netherlands). Other reagents were obtained from Sigma.

\section{Clotting time and factor measurements in plasma}

Measurement of PT was with innovin reagent, of the aPTT with the actin-FSL kit (Dade Behring). Plasma fibrinogen was determined as described. ${ }^{13}$ The Behring coagulation system (Dade Behring) was used to measure levels of prothrombin, factor X and factor XIII via a one-stage clotting assay with factor-deficient plasmas. Antithrombin was measured using the same system and a chromogenic assay. Heparin in plasma was determined as anti-factor Xa activity using the Coamatic heparin test (Chromogenics, Mölndal, Sweden). Plasma levels of IgG were quantified using an Immage nephelometer and goat anti-human IgG (Beckman Coulter, Mijdrecht, The Netherlands). 


\section{Patients}

The studies were approved by the local Medical Ethics Committee. Blood was taken from patients before and after surgery for clinical determination of standard clotting tests and factor levels. Patients and healthy volunteers did not use other antithrombotic medication than indicated. None of the patients had multiple organ failure, sepsis, or renal or liver dysfunction. Remnant blood samples were used for measurements of non-standard factor levels, thrombin generation and fibrin clot formation. Healthy volunteers and patients gave full informed consent.

Study $A$. For evaluating the effects of anticoagulant treatment without plasma dilution, blood was obtained from 5 healthy volunteers and from 10 patients, who were using a vitamin $\mathrm{K}$ antagonist (acenocoumarol, 3.13 $\pm 1.8 \mathrm{mg} /$ day during $>7$ days; mean \pm SD) and were under coagulant control of the Maastricht Anticoagulation Clinic. Based on the international normalized ratio (INR) of plasma PT, the patients were divided into two groups, i.e. one with moderate anticoagulation (INR 1.8-2.6) and one with high anticoagulation (INR 3.6-4.8). Haemostatic parameters of these healthy controls and patients are given in Table 5.1.

Study $B$. Effects of non-severe dilution were investigated using remnant blood from 30 consecutive patients undergoing elective cardiopulmonary bypass (CPB) surgery, who did not experience significant blood loss and did not need plasma transfusion. A first blood sample was taken at $30 \mathrm{~min}$ before start of the surgical procedure, and a second sample was taken at 30 min after surgery and administration of protamin. Twenty-four hours before surgery, patients had stopped intake of aspirin $(83 \pm 30 \mathrm{mg} / \mathrm{day})$. During the on-pump stage of the intervention, patients received heparin $(242 \pm 53 \mathrm{IU})$, which was antagonized after surgery by administering protamin $(245 \pm 80 \mathrm{mg}$ ). During the intervention, the patients were infused with $1970 \pm 425 \mathrm{ml}$ crystalloids (saline) and colloids (venofundin). Patient characteristics are given in Table 5.2.

Study C. Effects of severe dilution were determined in remnant blood from 58 consecutive patients undergoing major surgery of various forms, e.g. vascular, abdominal or spinal back bone surgery (Table 5.2). Patients were included who suffered from massive blood loss during or after surgery and therefore needed transfusion of fresh frozen plasma (FFP). These patients had massively been transfused with crystalloids, colloids and a minimum of 10 red cell concentrates (total fluid volume $>5000 \mathrm{ml}$, corresponding to replacement of one blood volume). To stop bleeding, the patients had received on average 2.7 bags of FFP $(870 \pm 270 \mathrm{ml})$. Additional clinical criteria for transfusion of FFP: aPTT >40 s (37 patients), PT > $16 \mathrm{~s}$ (17 patients), and fibrinogen level <2.0 $\mathrm{g} / \mathrm{l}$ (41 patients), such in accordance with international guidelines. ${ }^{14,15}$ Blood samples were obtained at approximately $30 \mathrm{~min}$ 
before and 30 min after FFP transfusion (Table 5.2). If bleeding persisted, the patients were at a later stage transfused with additional red cell concentrates, FFP and/or platelets, as required. For 4 patients, insufficient remnant plasma was obtained for complete measurement sets of fibrin clot formation.

\section{Plasma preparation}

Remnant blood was used, taken by venous puncture and anticoagulated with sodium citrate (1/10 volume, $12.9 \mathrm{mmol} / \mathrm{l}$ f.c.). Platelet-poor-plasma was prepared by centrifuging twice at $2630 \mathrm{~g}$ for $10 \mathrm{~min}$ at room temperature. Plasma samples were snap-frozen at $-80^{\circ} \mathrm{C}$ until use.

\section{Thrombin generation measurement}

Thrombin generation in patient plasma was continuously measured according to the calibrated automated thrombogram assay, with slight modifications. ${ }^{13,16}$ Citrateanticoagulated plasma (12.9 mmol/l trisodium citrate) was supplemented with phospholipids $(4 \mu \mathrm{mol} / \mathrm{l})$. Coagulation was triggered with $16.6 \mathrm{mmol} / \mathrm{l} \mathrm{CaCl}_{2}$ and an optimized concentration of 10 pmol/l tissue factor. ${ }^{17}$ Thrombin activity was continuously followed at $37^{\circ} \mathrm{C}$ from the cleavage of thrombin substrate, Z-GGR-AMC $(2.5 \mathrm{mmol} / \mathrm{l})$. Samples were run in triplicate, and a calibrator was used for each plasma to give calibrated curves of thrombin activity. First-derivative traces were converted to nanomolar concentrations of thrombin, as described. ${ }^{16}$ Thrombin peak height and area-under-the-curve were used as most sensitive determining parameters describing the thrombin generation process. ${ }^{17,18}$ Intra-assay variation coefficient was $6 \%$. Normal value of the thrombin peak height was $314 \pm 24 \mathrm{nmol} / \mathrm{l}$ (mean $\pm \mathrm{SD}, \mathrm{n}=40$ healthy subjects). A cut-off level for normal thrombin generation was arbitrarily set at mean $-5 \times \mathrm{SD}$, i.e. at $194 \mathrm{nmol} / \mathrm{l}$.

\section{Thromboelastography measurement}

Thromboelastography was performed using a TEG 5000 Thrombelastograph hemostasis analyzer (Haemoscope, Niles, IL, USA), measuring the torsion between a slowly rotating plastic cup and a stationary pin. $^{19}$ Samples of $340 \mu$ l citrateanticoagulated plasma were supplemented with phospholipids $(4 \mu \mathrm{mol} / \mathrm{l}$ ), and coagulation was triggered with $10 \mathrm{pmol} / \mathrm{l}$ tissue factor and $\mathrm{CaCl}_{2}(16.6 \mathrm{mmol} / \mathrm{l})$. Key evaluation parameters of thromboelastograms were the $\alpha$-angle and the maximal amplitude, which inform on the rate of fibrin strand formation and the clot amount/strength, respectively. ${ }^{20}$ Note that experiments were carried out in the absence of platelets. Maximal amplitude was taken as measure of total fibrin clot 
formation, sensitive to plasma dilution. ${ }^{17}$ Normal value of the maximal amplitude measured in plasma from 40 healthy volunteers was $42 \pm 5.7 \mathrm{~mm}$ (mean $\pm \mathrm{SD}$ ); the cutoff level for normal fibrin clot formation was arbitrarily set at $13.5 \mathrm{~mm}$ (mean - $5 \times$ SD).

\section{Statistics}

Peri-operative effects of fluid infusion and FFP transfusion were evaluated with the paired sample t-test. Factor contributions to thrombin generation and fibrin clot formation were evaluated by multivariate regression analysis. Correlations between parameters were determined using the $\chi^{2}$ test. Patient groups were compared with a one-way ANOVA test. The statistical package for the social sciences 15.0 (SPSS, Chicago, IL, USA) was used.

\section{Results}

\section{Effect of plasma dilution on thrombin generation and fibrin clot formation after treatment with a vitamin $K$ antagonist}

To determine how anticoagulant therapy affects thrombin generation and fibrin clot formation without dilution, plasma was used from healthy subjects and patients receiving a vitamin $\mathrm{K}$ antagonist (Table 5.1). In the patient plasmas, levels of vitamin K-dependent coagulation factors were reduced to 30-43\% (INR 2.2) and 10-19\% (INR 4.2) of normal. In both patient groups, plasma antithrombin levels were in the normal range, while fibrinogen levels were relatively high i.e. on average 4.1-4.4 g/l. Coagulation activities were tested in these plasmas, either undiluted or after dilution in vitro with saline, by triggering with an optimal concentration of $10 \mathrm{pmol} / \mathrm{l}$ tissue factor in the presence of $4 \mathrm{\mu mol} / \mathrm{l}$ procoagulant phospholipids. ${ }^{17}$ Curves of thrombin generation indicated that an increase in INR from 1.0 to 2.2 was accompanied by a strong reduction in thrombin peak height, changing from about 400 to $100 \mathrm{nmol} / \mathrm{l}$ (Figure 5.1, upper panels). In plasma from patients with high anticoagulation (INR $4.2)$, thrombin generation was more delayed and reduced giving a peak height of 50 $\mathrm{nmol} / \mathrm{l}$. Fifty percent dilution of normal plasma with saline moderately reduced the thrombin peak height to $300 \mathrm{nmol} / \mathrm{l}$, but this was of little additive effect in patient plasmas (Figure 5.2a). Regression analysis of thrombin generation parameters with plasma factor levels showed that the thrombin peak height strongly correlated with prothrombin (Figure $5.2 \mathrm{~b}$ ) and factor $X\left(R_{2}=0.97, p<0.001\right)$. This supported the notion that both coagulation factors are key predictive variables of the thrombin-generating 
Table 5.1: Haemostatic parameters of healthy subjects and of patients treated with a vitamin $\mathrm{K}$ antagonist and moderate or high anticoagulation (study $\mathrm{A}$ )

\begin{tabular}{|c|c|c|c|c|}
\hline \multirow[b]{2}{*}{ Parameter } & \multicolumn{3}{|c|}{ Vitamin K antagonist } & \multirow[b]{2}{*}{ Normal range } \\
\hline & None $(n=5)$ & Moderate $(n=5)$ & High $(n=5)$ & \\
\hline INR & $1.0 \pm 0.1$ & $2.2 \pm 0.3^{* \star}$ & $4.2 \pm 0.5^{* *+}$ & $0.8-1.2$ \\
\hline aPTT (s) & $27 \pm 2.1$ & $35 \pm 5.4^{*}$ & $48 \pm 5 \cdot 7^{* * \dagger}$ & $23-32$ \\
\hline PT (s) & $12 \pm 2$ & $26 \pm 3.8^{* *}$ & $48 \pm 6^{* *+}$ & $10-13$ \\
\hline Prothrombin (\%) & $128 \pm 15$ & $43 \pm 18^{* *}$ & $19 \pm 5^{\star *}$ & 100 \\
\hline Factor $X(\%)$ & $134 \pm 10$ & $30 \pm 21^{* *}$ & $10 \pm 2^{* *}$ & 100 \\
\hline Antithrombin (\%) & $111 \pm 5$ & $102 \pm 10$ & $108 \pm 10$ & 100 \\
\hline Fibrinogen (g/l) & $2.8 \pm 0.6$ & $4.1 \pm 1.0$ & $4.4 \pm 0.5^{*}$ & $1.7-4.0$ \\
\hline
\end{tabular}

Data are means \pm SD. ${ }^{*} p<0.05$ and ${ }^{* k} p<0.001$ compared to no vitamin $K_{1}{ }^{\dagger} p<0.01$ compared to moderate vitamin $\mathrm{K}$ antagonism.
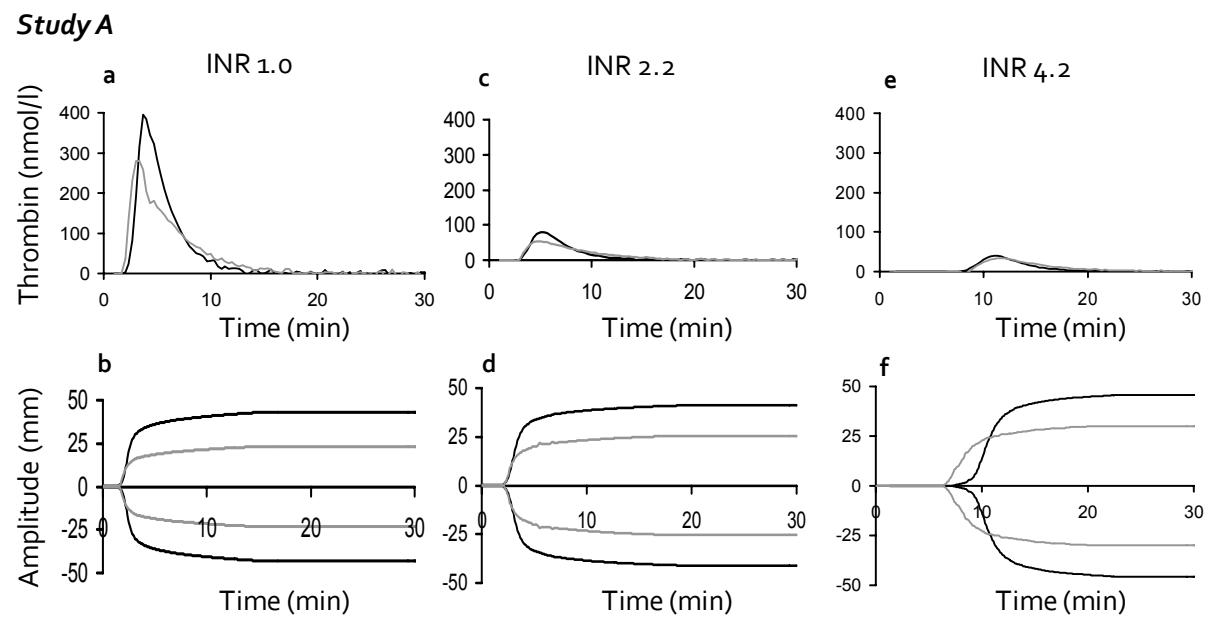

Figure 5.1: Kinetics of thrombin generation and fibrin clot formation in plasma from healthy subjects and patients treated with a vitamin $\mathrm{K}$ antagonist. Study A: plasma was used from 5 healthy volunteers ( $a, b ;$ INR 1.0); plasma was also obtained from patients treated with a vitamin $\mathrm{K}$ antagonist: 5 patients with moderate anticoagulation (c, d; INR 2.2) and 5 patients with high anticoagulation (e, $f_{;}$INR 4.2). Plasma was used either undiluted (black curves) or diluted with $50 \%$ saline containing $12.9 \mathrm{mmol} / \mathrm{l}$ citrate (grey curves). Plasma was incubated with phospholipids $(4 \mu \mathrm{mol} / \mathrm{l})$, and activated with $10 \mathrm{pmol} / \mathrm{l}$ tissue factor and 16.6 $\mathrm{mmol} / \mathrm{l} \mathrm{CaCl}$. Shown are for each patient group representative curves of thrombin generation $(a, c, e)$ and fibrin clot formation $(b, d, f)$. 
process. $^{7,21,22}$ In contrast, plasma fibrinogen levels did not correlate with thrombin generation parameters ( $p>0.20)$.

Thromboelastography was used to measure time-dependent formation of fibrin clots in these plasma samples, applying the same optimal triggering conditions of 10 pmol/l tissue factor and $4 \mu \mathrm{mol} / /$ procoagulant phospholipids (Figure 5.1, lower panels). Overall, the lag time to start of fibrin clot formation was similar to that of thrombin generation, and corresponded with the PT values. Strikingly, the rate of fibrin formation ( $\alpha$-angle of curve) and the maximal extent of fibrin formation (maximal amplitude) were not diminished in plasmas with INR of 2.2 or 4.2 , in spite of the marked reduction in thrombin generation. On the other hand, fibrin formation did substantially decrease upon 50\% dilution with saline in both control and patient plasmas (Figure 5.2C).
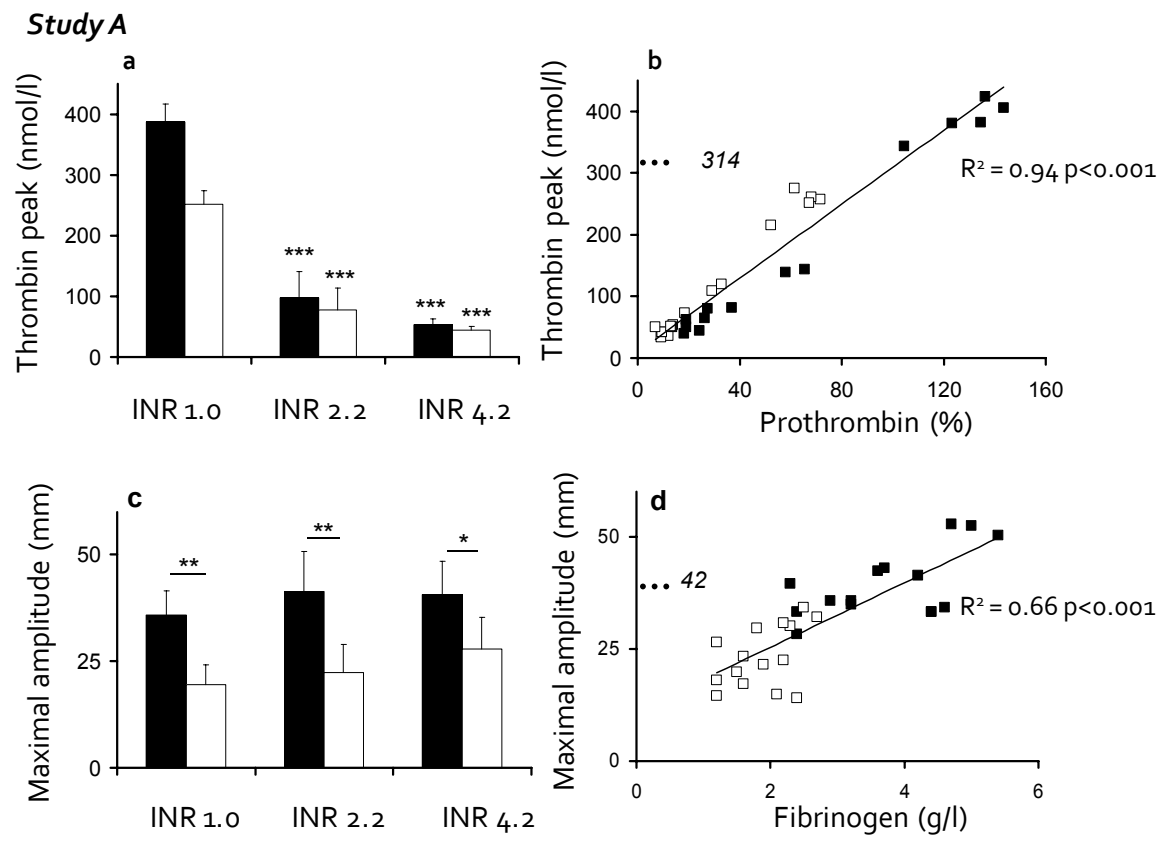

Figure 5.2: Parameters of thrombin generation and fibrin clot formation in plasma from healthy subjects and patients treated with a vitamin $\mathrm{K}$ antagonist. Plasma was used from healthy volunteers (INR 1.0) and patients with moderate (INR 2.2) or high (INR 4.2) anticoagulation (study A). Plasma was undiluted (black bars and symbols) or diluted $50 \%$ with saline (white bars and symbols), as in Figure 5.1. Thrombin generation was measured upon plasma triggering with tissue factor and $\mathrm{CaCl}_{2}$. Data give the averaged thrombin peak height (a), and correlation per sample with plasma prothrombin level (b). Fibrin clot formation was measured at the same activation conditions. It was quantified as maximal clot amplitude (c); further, correlation per sample with fibrinogen level (d). Dotted lines at $y$-axis represent values of normal pooled plasma (mean $\pm \mathrm{SD}, n=5) ;{ }^{*} p<0.05,{ }^{* *} p<0.01,{ }^{* * *} p<0.001$ compared to corresponding control group. 
The fibrinogen level was a main predictive variable of maximal amplitude in undiluted or diluted plasmas (Figure 5.2d), but the levels of prothrombin and factor $X$ failed to correlate with thromboelastography parameters $(p>0.52)$. Taken together, we find that the reduction in coagulation factor levels due to intake of vitamin $\mathrm{K}$ antagonist is accompanied by impaired thrombin generation, but not by a corresponding reduction in fibrin clot formation.

\section{Thrombin generation and fibrin clot formation in plasmas from patients with peri- operative dilution during surgery}

Two studies were performed with plasmas from surgical patients, who were undergoing in vivo plasma dilution due to fluid infusion. Study B involved 30 patients subjected to CPB surgery (Table 5.2). None of these patients showed significant bleeding during or after the intervention so that FFP transfusion was not required. In study $C$, plasmas were investigated from 58 patients subjected to major surgery of various forms. Because of the presence of major bleeding during or after surgery, these patients were transfused with FFP. In both studies B and C, the infusion of fluids during surgery resulted in a prolongation of routine clotting times and in a lowering of the plasma levels of (anti)coagulant factors. For study B, levels of prothrombin, factor $\mathrm{X}$, factor XIII, fibrinogen and antithrombin were reduced to

Table 5.2: Characteristics of patients undergoing dilution during surgery of study $B$ and $C$

\begin{tabular}{|c|c|c|}
\hline Patient characteristic & Study B & Study C \\
\hline Number of patients $(n)$ & 30 & 58 \\
\hline Male/female (n) & $27 / 3$ & $29 / 29$ \\
\hline Age (years) & $64 \pm 11$ & $62 \pm 13$ \\
\hline Cardiovascular surgery ( $n$ ) & $30^{1}$ & 21 \\
\hline Abdominal surgery (n) & 0 & 28 \\
\hline Spinal back bone surgery $(n)$ & 0 & 9 \\
\hline $\begin{array}{l}\text { Fluid volume infused during } \\
\text { surgery }(\mathrm{ml})\end{array}$ & $1970 \pm 425$ & $>5000$ \\
\hline Fluid type infused & crystalloids, colloids & $\begin{array}{l}\text { crystalloids, colloids, red cell } \\
\text { concentrates }\end{array}$ \\
\hline FFP transfused (ml) & 0 & $810 \pm 270$ \\
\hline $\begin{array}{l}\text { Medication during surgery } \\
\text { (heparin, IU) }\end{array}$ & $242 \pm 53$ & ets \\
\hline Blood sample collected & $\begin{array}{l}1^{\text {st }}: 30 \text { min before } C P B \\
2^{\text {nd }}: 30 \text { min after } C P B^{2}\end{array}$ & $\begin{array}{l}1^{\text {st }}: 30 \text { min before FFP } \\
2^{\text {nd }}: 30 \text { min after FFP }\end{array}$ \\
\hline
\end{tabular}

${ }^{1}$ Cardiopulmonary bypass (CPB); ${ }^{2}$ blood taken after administration of $245 \pm 80 \mathrm{mg}$ protamin (plasma checked for absence of heparin traces). Data are means \pm SD. 
Chapter 5

Table 5.3: Haemostatic parameters of patients in studies B and C

\begin{tabular}{|c|c|c|c|c|c|}
\hline \multirow[b]{2}{*}{ Parameter } & \multicolumn{2}{|c|}{ Study B $(n=30)$} & \multicolumn{2}{|c|}{ Study $C\left(n=5^{8}\right)$} & \multirow{2}{*}{$\begin{array}{l}\text { Normal } \\
\text { range }\end{array}$} \\
\hline & Before CPB & After CPB & Before FFP & After FFP & \\
\hline Platelets $\left(\times 10^{9} / l\right)$ & $235 \pm 82$ & $153 \pm 57^{* * *}$ & $88 \pm 43$ & $89 \pm 32$ & $130-350$ \\
\hline Haematocrit & $0.40 \pm 0.04$ & $0.27 \pm 0.04^{* * *}$ & $0.26 \pm 0.06$ & $0.26 \pm 0.05$ & $0.36-0.52$ \\
\hline aPTT (s) & $28 \pm 2.1$ & $33 \pm 2.9^{* * *}$ & $62 \pm 33$ & $40 \pm 12^{* * *}$ & $23-32$ \\
\hline PT (s) & $11 \pm 0.4$ & $14 \pm 1.2^{* * *}$ & $16 \pm 2.7$ & $13 \pm 1.6^{* * *}$ & $10-13$ \\
\hline Prothrombin (\%) & $94 \pm 16$ & $59 \pm 16^{* * *}$ & $38 \pm 13$ & $49 \pm 14^{* * *}$ & 100 \\
\hline Factor X (\%) & $83 \pm 13$ & $53 \pm 13^{* * *}$ & $40 \pm 15$ & $51 \pm 15^{* * *}$ & 100 \\
\hline Factor XIII (\%) & $91 \pm 16$ & $60 \pm 14^{* * *}$ & $41 \pm 15$ & $52 \pm 15^{* * *}$ & 100 \\
\hline Antithrombin (\%) & $82 \pm 16$ & $53 \pm 13^{* * *}$ & $38 \pm 11$ & $50 \pm 13^{* * *}$ & 100 \\
\hline Fibrinogen (g/l) & $3.5 \pm 1.0$ & $2.0 \pm 0.5^{* \star *}$ & $1.3 \pm 0.7$ & $1.7 \pm 0.8^{* * *}$ & $1.7-4.0$ \\
\hline $\lg G(g / l)$ & $7.6 \pm 1.8$ & $5.2 \pm 2.0^{* * *}$ & $3.8 \pm 1.6$ & $4.6 \pm 1.6^{* * *}$ & $7.0-16.0$ \\
\hline
\end{tabular}

Means $\pm \mathrm{SD}_{i}{ }^{* k} p<0.01,{ }^{* k} p<0.001$ compared to first plasma sample.

$53-60 \%$ of normal. In patient plasmas of study C (before FFP transfusion), these levels were more strongly reduced to $38-41 \%$ of normal (Table 5.3 ). This was also concluded from the markedly lower level of immunoglobulin $\mathrm{lgG}$, which was taken as an independent measure of plasma dilution. In this study, the transfusion of FFP resulted in a significant improvement of plasma coagulation factors and IgG.

As a consequence of the CPB procedure (study B) - in which plasmas were diluted in vivo -, the curves of thrombin generation and fibrin clot formation were markedly lowered (Figure 5.3a). In comparison to the normal range of thrombin peak height of $314 \pm 24 \mathrm{nmol} / \mathrm{l}$ (mean $\pm \mathrm{SD}, \mathrm{n}=40$ ) $(17)$, this level was within or slightly below this range in plasmas from patients prior to surgery (Figure 5.4a). After CPB surgery, the thrombin peak height dropped substantially from $284 \pm 43$ to $212 \pm 67 \mathrm{nmol} / \mathrm{l}(\mathrm{p}<0.001)$. Arbitrarily, we set a cut-off value for low thrombin generation at a peak height of $<194 \mathrm{nmol} / \mathrm{l}$ (i.e. the normal mean $-5 \times \mathrm{SD}$ ). Using this threshold, 8 out of 30 patients had a low thrombin generation profile. Similarly, thromboelastogram curves showed a significant reducing effect of the CPB procedure on fibrin clot formation (Figure $5.3 \mathrm{~b})$. Overall, the maximal amplitude decreased from $32 \pm 6.5$ to $17 \pm 8.3 \mathrm{~mm}$ $(p<0.001)$. Again, we set a cut-off value for low fibrin clot formation at a maximal amplitude of $<13.5 \mathrm{~mm}$ (i.e. normal mean - $5 \times \mathrm{SD}$ ). In this case, plasmas from 8 patients were low in clot formation after surgery (Figure $5.4 \mathrm{~b}$ ).

In study $C$ the effect of FFP transfusion could be investigated. In most patients, this transfusion increased thrombin generation as well as fibrin clot formation, as is illustrated in Figure 5.3c-d for a patient with stopped bleeding. Prior to transfusion, in the majority of patients both the thrombin peak height and the maximal clot 

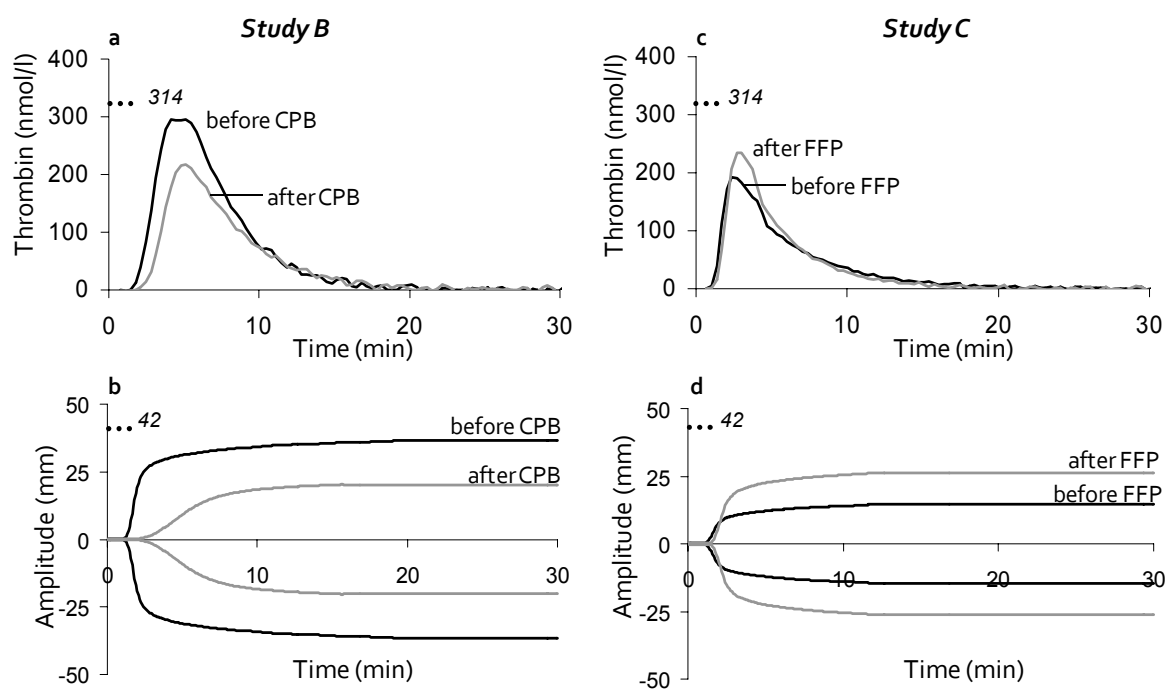

Figure 5.3: Kinetics of thrombin generation and fibrin clot formation in plasma from patients subjected to dilution during surgery. Study $B$ : plasma was obtained from patients before and after CPB surgery $(a, b)$. Study $C$ : plasma was obtained from patients undergoing major general surgery before and after FFP transfusion (c, d). Plasma was supplemented with phospholipids $(4 \mu \mathrm{mol} / \mathrm{l})$ and used for measurement of thrombin generation and fibrin clot formation, following activation with tissue factor and $\mathrm{CaCl}_{2}$ (see Figure 5.1). Shown are curves of thrombin generation $(a, c)$ and of fibrin clot formation $(b, d)$ for a representative patient before (black curves) and after (grey curves) intervention or transfusion. Dotted lines at $y$-axis represent values with normal pooled plasma.

amplitude were below the cut-off values. Thus, plasmas from 41/54 patients were low in thrombin generation and plasmas from 41/54 patients had low fibrin clot formation curves (Figure 5.4c-d). In general, transfusion with FFP significantly increased the thrombin peak height (from $159 \pm 44$ to $196 \pm 53 \mathrm{nmol} / \mathrm{l}, \mathrm{p}<0.001$ ) and the maximal amplitude of thromboelastography (from $10 \pm 7.4$ to $14 \pm 7.7 \mathrm{~mm}, \mathrm{p}<0.001$ ). Yet, even after transfusion, the plasmas from 27 and 28 patients remained below the cut-off levels for normal thrombin generation and fibrin clot formation, respectively. After FFP transfusion, bleeding stopped in 30/58 patients and continued in the other 24 patients. It was relevant to compare the assay parameters in the plasmas from patients with stopped bleeding and the plasmas from patients with continued bleeding after transfusion. Typically, these were significantly higher in the group of patients with stopped bleeding in comparison to the bleeding group: thrombin peak height of $207 \pm 51$ vs. $179 \pm 54 \mathrm{nmol} / \mathrm{l}(\mathrm{p}<0.05)$, and maximal clot amplitude of $16 \pm 7$ vs. $12 \pm 7 \mathrm{~mm}(\mathrm{p}<0.01)$, respectively. 

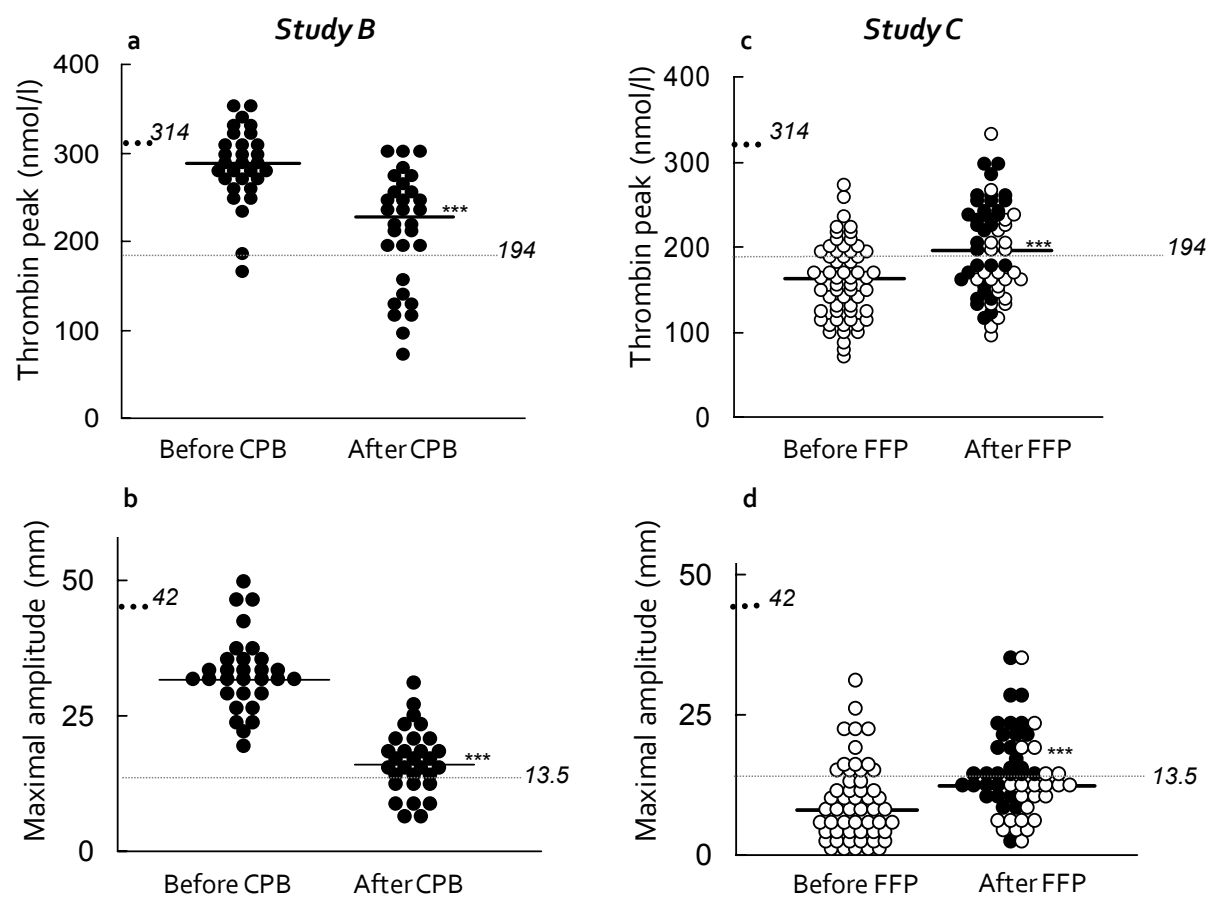

Figure 5.4. Parameters of thrombin generation and fibrin clot formation in plasma from patients subjected to dilution during surgery. Plasma was used from patients before and after CPB surgery (study B: $a, b$ ); or from patients undergoing major general surgery before and after FFP transfusion (study C: $c$, d). Measurements of thrombin generation and fibrin clot formation were as in Figure 5.3. Data are thrombin peak height before/after surgery or transfusion $(a, c)$; further, maximal amplitude of clot formation before/after surgery or transfusion $(b, d)$. White dots represent patients with bleeding before or after FFP transfusion; black dots represent patients without bleeding or with stopped bleeding. Dotted lines at $y$-axis give values with normal pooled plasma. Dotted continued lines give arbitrary cut-off values for normal thrombin or fibrin clot formation (mean $-5 \times \mathrm{SD}$ ). ${ }^{* * *} p<0.001$ compared to pre-surgery or pre-transfusion.

By combining the results of studies B and C, analysis was possible of the relations between bleeding, thrombin generation and fibrin clot formation. Therefore, thrombin peak heights and maximal amplitudes of thromboelastography were compared in regression plots (Figure 5.5a). The patients of study B with no or minor bleeding were assigned as 'non-bleeding', while those of study $C$ requiring FFP transfusion were indicated as 'bleeding'. For all patients together, the parameters of both assays were related $\left(R_{2}=0.11, p=0.002\right)$, but this was not the case for patients of only study $B(R 2=0.05, p=0.22)$ or only study $C(R 2=0.010, p=0.47)$. 
a

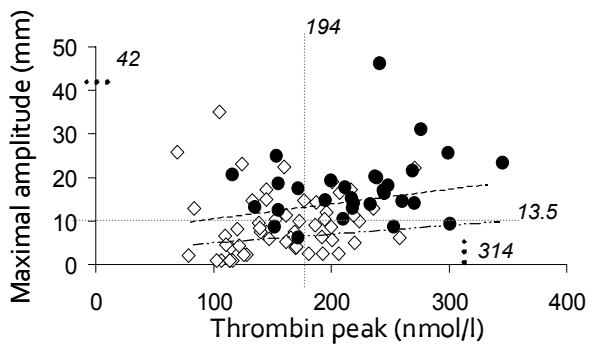

Study B (after CPB) no bleeding $(\bullet)$

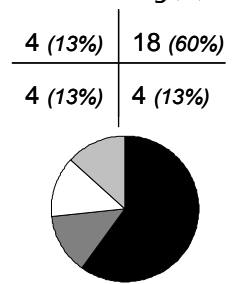

Study C (before FFP) bleeding $(\diamond)$

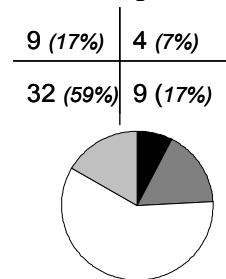

b

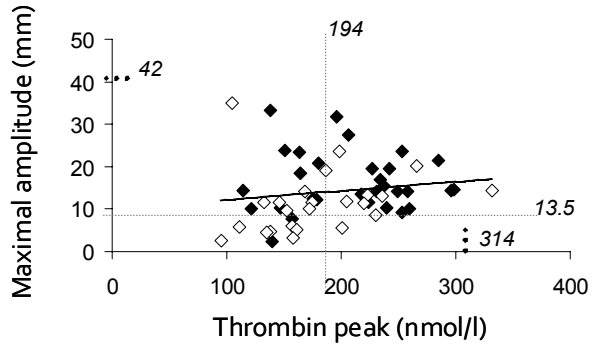

Study C (after FFP) stopped bleeding $(\diamond)$

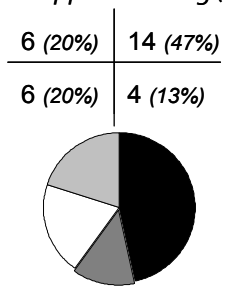

Study C (after FFP) persistent bleeding $(\diamond)$

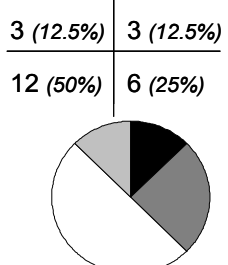

Figure 5.5: Effect of dilution during surgery on thrombin generation and fibrin clot formation. Plasma was used from patients after CPB surgery (study B) and from patients undergoing major surgery before and after FFP transfusion (study C). Measurements of thrombin generation (TG) and fibrin clot formation (FCF) were as in Figure 5.3. (a) Plasma from patients under diluted condition, i.e. patients after CPB surgery $(\bullet)$ or patients with bleeding after general surgery before FFP transfusion ( () . (b) Plasma from patients after FFP transfusion with stopped bleeding $(\diamond)$ or with persistent bleeding $(\diamond)$. Graph plots: Correlation of thrombin peak height and maximal clot formation (maximal amplitude) for individual patients. Normal and cut-off levels of thrombin generation and fibrin clot formation are set as in Figure 4. Cut-off for normal thrombin peak height was at $194 \mathrm{nmol} / \mathrm{l}$; cut-off for normal clot formation was at maximal amplitude of $13.5 \mathrm{~mm}$. Quadrants and pie-charts (clock-wise): numbers of patients (percentages) with normal TG and normal FCF (black); normal TG and low FCF (dark grey); low TG and low FCF (white); low TG and normal FCF (light grey).

When using the preset cut-off values for low thrombin generation and fibrin clot formation, the majority of non-bleeding patients $(60 \%)$ gave assay values which were both in the normal range, while this was the case for $7 \%$ of the bleeding patients. Conversely, plasmas from $13 \%$ of the non-bleeding patients, but $59 \%$ of the bleeding patients were low in both thrombin generation and fibrin clot formation $\left(\chi^{2}=0.30\right.$, $\mathrm{p}<0.001)$. Overall, $26 \%(13+13 \%)$ of the non-bleeding and $34 \%(17+17 \%)$ of the bleeding patients scored low in one of the two assays. Regarding study $\mathrm{C}$, a similar comparison was made for patients with stopped or persistent bleeding after FFP transfusion (Figure 5.5b). In this case, plasmas from $47 \%$ of the patients with stopped bleeding were normal in thrombin generation and fibrin clot formation, while this was the case for only $12.5 \%$ of the patients with persistent bleeding. 

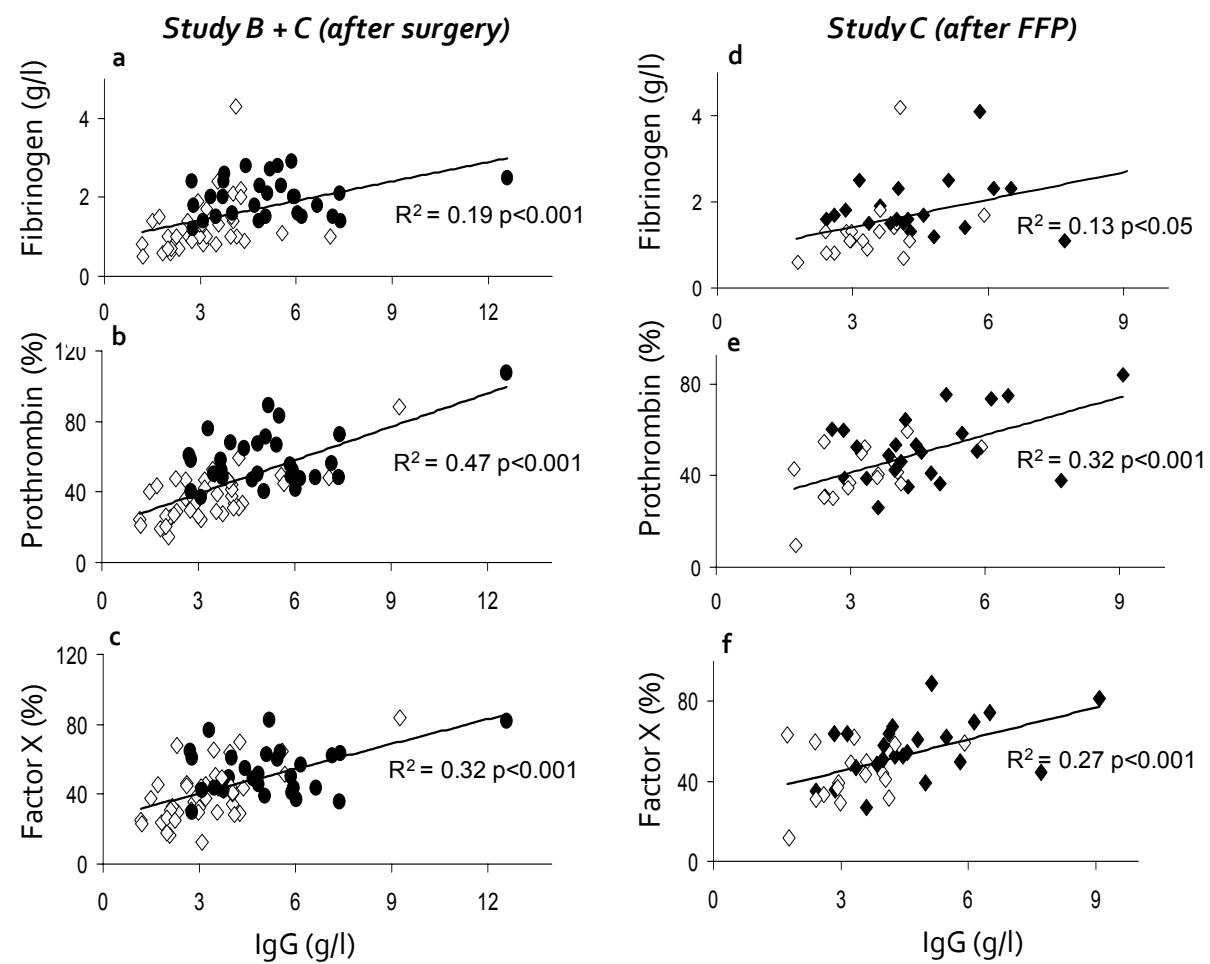

Figure 5.6: Correlation of plasma IgG and factor levels. ( $a, b, c)$ Plasmas from patients with dilution during surgery. Factor levels were measured from patients after CPB surgery (study $B$, -) and patients with bleeding after major surgery before FFP transfusion (study $C, \diamond)$. (d, e, f) Plasma from patients after FFP transfusion (study $C$ ). Dots represent patients with stopped bleeding $(\diamond)$ and persistent bleeding $(\diamond)$. Correlation of IgG level with fibrinogen $(a, d)$, prothrombin $(b, e)$ and factor $X(c, f)$.

Low values of thrombin peak height and maximal amplitude were present in $20 \%$ and $50 \%$ of the patients with stopped and persistent bleeding, respectively $\left(\chi^{2}=0.10\right.$, $p<0.05)$. Low values for one of the two assays were detected in $33 \%(20+13 \%)$ and $37.5 \%(12.5+25 \%)$ of patient plasmas. An indication for the relevance of this difference came from the observation that plasma levels of prothrombin, factor $X$, fibrinogen and IgG were significantly higher in the group with stopped bleeding than in the group with persistent bleeding $(p<0.05)$. Based on the pre-set cut-off values, it was concluded that both thrombin generation and fibrin clot formation are low in 50$59 \%$ of the patients with bleeding, but in only $13-20 \%$ of cases without or with stopped bleeding. This difference is illustrated in the pie-charts of Figure 5.5. 
Table 5.4: Predictive variables of thrombin generation and fibrin clot formation

\begin{tabular}{|c|c|c|c|c|}
\hline Variable & $\begin{array}{l}\text { Diluted } \\
(n=30)\end{array}$ & $\begin{array}{l}\text { Study B and C } \\
\text { After CPB } \\
(n=84)\end{array}$ & $\begin{array}{l}\text { Study C } \\
\text { Before FFP } \\
(n=54)\end{array}$ & $\begin{array}{l}\text { Study C } \\
\text { After FFP } \\
(n=54)\end{array}$ \\
\hline $\begin{array}{l}\text { Thrombin } \\
\text { generation }\left(R^{2}\right)\end{array}$ & $0.32^{* \star *}$ & 0.10 & $0.44^{* \star *}$ & $0.46^{\star \star \star}$ \\
\hline fibrinogen $(\beta)$ & ns & ns & $-0.33^{*}$ & ns \\
\hline prothrombin $(\beta)$ & ns & ns & $0.68^{* * *}$ & ns \\
\hline factor $X(\beta)$ & $0.32^{*}$ & + & ns & $0.97^{* * *}$ \\
\hline factor XIII ( $\beta)$ & ns & ns & ns & ns \\
\hline antithrombin ( $\beta$ ) & ns & ns & ns & $-0.45^{*}$ \\
\hline $\lg G(\beta)$ & $0.33^{*}$ & + & ns & ns \\
\hline $\begin{array}{l}\text { Fibrin clot } \\
\text { formation }\left(R^{2}\right)\end{array}$ & $0.60^{* * \pi}$ & $0.41^{* * *}$ & $0.74^{* * *}$ & $0.88^{* * *}$ \\
\hline fibrinogen $(\beta)$ & $0.78^{* * *}$ & $0.64^{* * *}$ & $0.58^{* * *}$ & $0.66^{* * *}$ \\
\hline factor $X(\beta)$ & ns & ns & ns & $0.21^{*}$ \\
\hline factor XIII ( $\beta)$ & ns & ns & $0.38^{* *}$ & ns \\
\hline antithrombin ( $\beta$ ) & ns & ns & ns & ns \\
\hline $\lg G(\beta)$ & + & + & ns & $0.26^{* *}$ \\
\hline
\end{tabular}

For multiple regression analysis of all indicated parameters, associations are indicated as $\mathrm{R}^{2}$ values. For individual parameters, values are standardized $\beta$ coefficients. ns, not significant, ${ }^{+} p<0.1$ (borderline), ${ }^{*} p<0.05,{ }^{* *} p<0.01,{ }^{* * *} p<0.001$.

\section{Predictive variables of impaired thrombin generation and fibrin clot formation in dilution}

Plasma IgG may be a useful marker of in vivo dilution which is independent of changes in coagulation. The IgG level indeed was higher in plasmas from the nonbleeding patients of study $B(5.2 \pm 2.0 \mathrm{~g} / \mathrm{l})$ than from the bleeding patients of study $C$ $(3.8 \pm 1.6 \mathrm{~g} / \mathrm{l})($ Table 5.3$)$. For both studies together, the IgG level correlated with the concentrations of fibrinogen, prothrombin and factor $X$ (Figure 5.6a-c). In addition, $\mathrm{IgG}$ correlated with the factor concentrations in post-transfusion plasmas of study $C$ (Figure $5.6 \mathrm{~d}$-f). The level of $\mathrm{IgG}$ was $<4.5 \mathrm{~g} / \mathrm{l}$ in most plasmas from patients with persistent bleeding, and it was not markedly higher in plasmas from non-bleeding patients (Figure 5.6, open and closed bullets). Correlation analysis showed significant, albeit weak correlations between $\lg$ level and thrombin peak height $\left(R_{2}=0.27\right.$, $p<0.001)$ or maximal amplitude $(R 2=0.15, p=0.001)$. Together, these results suggested that plasma IgG is a covariant of coagulant activity, rather than an independent parameter of dilution. 
Using multiple regression analysis, we analyzed correlations of key variables of both tests for plasmas of studies B and C (Table 5.4). In thrombin generation curves, the endogenous thrombin potential (area-under-the-curve) correlated strongly with the thrombin peak height in all comparisons. Similarly, in curves of fibrin clot formation, the $\alpha$-angle (rate of fibrin formation) co-varied with the maximal amplitude. Levels of factor $X$ and IgG significantly contributed to the variation in thrombin generation, while only fibrinogen explained part of the variation in fibrin clot formation. Separate regression analysis of the data from one of the studies did not yield markedly different results. Only in study C, prothrombin (in pre-FFP samples) contributed to the variation in thrombin peak height, while factor XIII contributed to the variation in maximal thromboelastography amplitude.

With respect to conventional clotting times, the prolonged aPTT in plasma samples of study B after surgery correlated with the thromboelastography assay $(\mathrm{R} 2=0.25, \mathrm{p}=0.024)$. The aPTT of plasmas from patients with stopped bleeding (study C) correlated with thrombin peak height $\left(R_{2}=0.15, p=0.022\right)$. For all patients together (studies B and C), the aPTT correlated with the assays of thrombin generation and fibrin clot formation ( $R_{2}=0.21, p<0.001$ and $R_{2}=0.14, p=0.002$, respectively); this was also the case for the PT $\left(R_{2}=0.12, p=0.007\right.$ and $R_{2}=0.15, p=0.001$, respectively). However, it is noted that correlation coefficients were low, and clotting times were not different between patients with persistent bleeding or stopped bleeding.

\section{Discussion}

This paper shows the results of a comparative study to the effects of dilution on two key processes in coagulation, namely capacity of thrombin generation and the ability of formation of fibrin clots. In study $A$, where the effect of in vitro dilution was determined of plasmas from patients treated with a vitamin $\mathrm{K}$ antagonist, reduced plasma levels of coagulation factors (prothrombin, factor VII, IX, X) were accompanied by a lower thrombin generation, but not by a reduction in fibrin clot formation. The vitamin $\mathrm{K}$ antagonist prolonged the lag-times in both tests, such in agreement with the increased INR values. This effect has also been described in another study on the influence of coumarin therapy on thrombin generation. ${ }^{23}$ The dilution of control and patient plasmas resulted in a decreased fibrin clot formation, independently of the INR value. Correspondingly, also other studies and case reports with patients undergoing fluid infusion have indicated that re-administration of fibrinogen in plasma can normalize fibrin clot formation in a way accompanied by stop of bleeding. ${ }^{10,17,24}$ Also supplementation of a fibrinogen concentrate was found to increase fibrin clot formation. ${ }^{17,25,26}$ 
The results of studies $B$ and $C$ provide further mechanistic insight into the hemostatic changes in dilutional coagulopathy. In general, it appeared that perioperative bleeding was accompanied with a low thrombin peak height (62.5-76\%) or a low thromboelastography amplitude (75-76\%). Both tests were low in 50-59\% of cases with bleeding, but in only $13-20 \%$ of non-bleeding cases. As the tests measure thrombin generation and fibrin clot formation in an optimized integrative way (e.g. triggered by high tissue factor), this suggests that the capacity of either process rather than the onset of it (lag-time) is linked to bleeding. Using thromboelastography, also other authors have been able to detect hemostatic insufficiencies in whole blood from patients undergoing surgery or with trauma. ${ }^{4,5}$ Here, especially the so-called FIBTEM test was found to be indicative for bleeding tendencies. In the FIBTEM modification, elastic clots are formed without a contribution of platelets and ${ }^{27}$ hence, this test informs on the clotting system only, which is comparable to the present measurement. On the other hand, platelets do have an important role in haemostasis, and the use of capacity coagulation tests also incorporating the function of platelets will be of additive value. Earlier work has already shown that platelets can partly compensate for the effect of moderate dilution on coagulation activity. ${ }^{17}$

An important result of studies $B$ and $C$ is that in individual patients the processes of thrombin generation and fibrin clot formation are independently reduced, and that either process can become rate-limiting separately from the other one. This refutes the suggestion from other authors that, in coagulopathy, fibrin clot formation may be merely a reflection of the thrombin generation process. ${ }^{2,28}$ In addition, our data indicate that, in diluted plasma, different coagulation factor levels control these processes, i.e. in particular factor $\mathrm{X}$ as a main determinant of thrombin generation, and fibrinogen as the key variable of fibrin clot formation. For diagnostic purposes, it will be important to have quick point-of-care versions of both assays. As long as such a thrombin generation test is not available, our results indicate that a control of the key coagulation factors, prothrombin, fibrinogen and factor $X$ is important. On the other hand, whether levels of these factors indeed are a useful clinical trigger, needs to be confirmed.

The present data show that the combined measurement of thrombin generation and fibrin clot formation provides a better evaluation of the coagulopathic profile in patients with dilutional coagulopathy than either test alone. Using preset thresholds for normal values, we found that at least one of these processes was low in 88-93\% of the patients with (persistent) bleeding, but in only $40-53 \%$ of the non-bleeding cases. We also studied whether IgG levels could be used as a coagulation-independent dilution marker. Interestingly, this measurement did not give much extra 
information, as the IgG level appeared to be highly correlated with levels of prothrombin, factor $X$ and fibrinogen.

There is a current debate on possible advantages of the use of coagulation factor concentrates in the management of peri-operative massive bleeding. ${ }^{25,29-31}$ Our data suggest that such interventions may be effective, provided they are targeted at maintaining sufficient activities of thrombin generation as well as clot formation. However, randomized clinical trials are required for establishing the real efficacy of such interventions. In summary, we conclude that, in acquired dilutional coagulopathy, the processes of thrombin generation and fibrin clot formation can be affected independently, and that sufficient activities of both are needed to prevent or stop bleeding. Both tests provide capacity-type of information and, jointly, they may be better predictors of individual increased bleeding risk than currently used routine coagulation times. 


\section{References}

1. Hemker HC, Al Dieri R, Béguin S. Thrombin generation assays: accruing clinical relevance. Curr Opin Hematol 2004; 11: 170-175.

2. Rivard GE, Brummel-Ziedins $K E$, Mann KG, et al. Evaluation of the profile of thrombin generation during the process of whole blood clotting as assessed by thrombelastography. J Thromb Haemost 2005; 3: 2039-2043.

3. Ronald A, Dunning J. Can the use of thromboelastography predict and decrease bleeding and blood and blood product requirements in adult patients undergoing cardiac surgery? Interact Cardiovasc Thorac Surg 2005; 4: 456-463.

4. Reinhofer $M$, Brauer $M$, Franke $U$, et al. The value of rotation thromboelastometry to monitor disturbed perioperative haemostasis and bleeding risk in patients with cardiopulmonary bypass. Blood Coagul Fibrinolysis 2008; 19: 212-219.

5. Rugeri L, Levrat A, David JS, et al. Diagnosis of early coagulation abnormalities in trauma patients by rotation thrombelastography. J Thromb Haemost 2007; 5: 289-295.

6. Kozek-Langenecker S. Management of massive operative blood loss. Minerva Anestesiol 2007; 73: 401-415.

7. Schols $\mathrm{SE}$, van der Meijden $\mathrm{PE}$, van Oerle $\mathrm{R}$, et al. Increased thrombin generation and fibrinogen level after therapeutic plasma transfusion: relation to bleeding. Thromb Haemost 2008; 99: 64-70.

8. Vanschoonbeek K, Feijge MA, Paquay M, et al. Variable hypocoagulant effect of fish oil intake in humans: modulation of fibrinogen level and thrombin generation. Arterioscler Thromb Vasc Biol 2004; 24: 1734-1740.

9. Hiippala ST, Myllyla GJ, Vahtera EM. Hemostatic factors and replacement of major blood loss with plasma-poor red cell concentrates. Anesth Analg 1995; 81: 360-365.

10. Fenger-Eriksen $C$, Lindberg-Larsen $M$, Christensen $A Q$, et al. Fibrinogen concentrate substitution therapy in patients with massive haemorrhage and low plasma fibrinogen concentrations. Br J Anaesth 2008; 101: 769-773.

11. Karlsson $M$, Ternstrom $L$, Hyllner $M$, et al. Plasma fibrinogen level, bleeding, and transfusion after on-pump coronary artery bypass grafting surgery: a prospective observational study. Transfusion 2008; 48: 2152-2158.

12. Rosing J, Tans G, Govers-Riemslag JW, et al. The role of phospholipids and factor Va in the prothrombinase complex. J Biol Chem 1980; 255: 274-2783.

13. Vanschoonbeek K, Feijge MA, van Kampen RJ, et al. Initiating and potentiating role of platelets in tissue factor-induced thrombin generation in the presence of plasma: subjectdependent variation in thrombogram characteristics. J Thromb Haemost 2004 i 2: 476-484.

14. O'Shaughnessy DF, Atterbury $C$, Bolton Maggs $P$, et al. Guidelines for the use of freshfrozen plasma, cryoprecipitate and cryosupernatant. Br J Haematol 2004; 126: 11-28.

15. Chowdhury P, Saayman AG, Paulus U, et al. Efficacy of standard dose and $30 \mathrm{ml} / \mathrm{kg}$ fresh frozen plasma in correcting laboratory parameters of haemostasis in critically ill patients. Br J Haematol 2004; 125: 69-73.

16. Hemker HC, Al Dieri R, De Smedt $E$, et al. Thrombin generation, a function test of the haemostatic-thrombotic system. Thromb Haemost 2006; 96: 553-561. 


\section{Chapter 5}

17. Schols SE, Feijge MA, Lancé MD, et al. Effects of plasma dilution on tissue factor-induced thrombin generation and thromboelastography: partly compensating role of platelets. Transfusion 2008; 48: 2384-2394.

18. Van der Meijden $P E$, Feijge $M A$, Giesen $P L$, et al. Platelet $P_{2} Y_{12}$ receptors enhance signalling towards procoagulant activity and thrombin generation. A study with healthy subjects and patients at thrombotic risk. Thromb Haemost 2005; 93: 1128-1136.

19. Mousa SA, Khurana S, Forsythe MS. Comparative in vitro efficacy of different platelet glycoprotein IIb/llla antagonists on platelet-mediated clot strength induced by tissue factor with use of thromboelastography: differentiation among glycoprotein $\mathrm{Ilb} / \mathrm{llla}$ antagonists. Arterioscler Thromb Vasc Biol 2000; 20: 1162-1167.

20. Luddington RJ. Thrombelastography/thromboelastometry. Clin Lab Haematol 2005 ; 27: 81-90.

21. Butenas S, van 't Veer C, Mann KG. "Normal" thrombin generation. Blood 1999 1; 94: 2169-2178.

22. Vanschoonbeek K, Feijge MA, Saris $\mathbf{W H}$, et al. Plasma triacylglycerol and coagulation factor concentrations predict the anticoagulant effect of dietary fish oil in overweight subjects. J Nutr 2007; 137: 7-13.

23. Brummel KE, Paradis SG, Branda RF, et al. Oral anticoagulation thresholds. Circulation. 2001; 104: 2311-2317.

24. Weinkove R, Rangarajan S. Fibrinogen concentrate for acquired hypofibrinogenaemic states. Transfus Med 2008; 18: 151-157.

25. Haas $T$, Fries $D$, Velik-Salchner $C$, Reif $C$, et al. The in vitro effects of fibrinogen concentrate, factor XIII and fresh frozen plasma on impaired clot formation after $60 \%$ dilution. Anesth Analg 2008; 106: 1360-1365.

26. Ganter MT, Hofer CK. Coagulation monitoring: current techniques and clinical use of viscoelastic point-of-care coagulation devices. Anesth Analg 2008; 106: 1366-1375.

27. Nielsen VG, Geary BT, Baird MS. Evaluation of the contribution of platelets to clot strength by thromboelastography in rabbits: the role of tissue factor and cytochalasin D. Anesth Analg 2000; 91: 35-39.

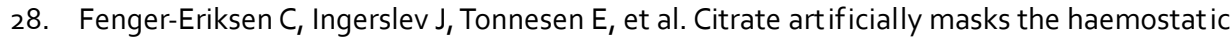
effect of recombinant factor Vlla in dilutional coagulopathy. Ann Hematol 2008; 12: 255-260.

29. Samama CM. Prothrombin complex concentrates: a brief review. Eur J Anaesthesiol 2008; 25: 784-789.

30. Yasaka M, Sakata T, Naritomi H, et al. Optimal dose of prothrombin complex concentrate for acute reversal of oral anticoagulation. Thromb Res 2005; 115: 455-459.

31. Mittermayr M, Streif W, Haas T, et al. Hemostatic changes after crystalloid or colloid fluid administration during major orthopedic surgery: the role of fibrinogen administration. Anesth Analg 2007; 105: 905-917. 


\section{6}

Novel role of glycoprotein Ib-V-IX and von Willebrand factor in platelet-dependent fibrin fiber formation at low shear flow

Saskia E.M. Schols, Judith M.E.M. Cosemans, Lucia Stefanini, Marion A. H. Feijge, Karly Hamulyák, Hans Deckmyn, Wolfgang Bergmeier and Johan W.M. Heemskerk

Submitted 


\section{Abstract}

While the role of platelets in thrombin generation is well established, little is known of the contribution of platelets to the establishment of a fibrin network and clot. We developed a procedure to study fibrin fiber formation on adherent platelets under conditions of flow and coagulation. Platelets actively formed star-like fibrin fibers at low shear rate $\left(250 \mathrm{~s}^{-1}\right)$. This focal fibrin formation was independent of the platelet morphology, was accompanied by a cytosolic $\mathrm{Ca}^{2+}$ rise and phosphatidylserine exposure, and was only slightly affected by blocking of $\alpha_{\| 1} \beta_{3}$ integrins. In contrast, fibrin formation was greatly delayed and reduced: (i) by inhibiting the interaction of von Willebrand factor (VWF) with GPIb-V-IX, (ii) in plasma or blood from patients with type 1 von Willebrand disease, and (iii) in plasma from mice deficient in VWF or the extracellular domain of GPIba. These results point to a novel role of VWF binding to GPIb-V-IX, occurring under low-shear flow, to stimulate platelet procoagulant activity and subsequent local fibrin formation. This process can be relevant to the manifestation of von Willebrand disease.

\section{Introduction}

Platelets have a prominent function in the stimulation of blood coagulation. Both in vivo and in vitro, they may activate and incorporate tissue factor to trigger the extrinsic coagulation pathway, ${ }_{1}^{1,2}$ while upon adhesion to collagen they are implicated in the intrinsic pathway of factor XII activation. ${ }^{3 / 4}$ Most well studied is the role of platelets stimulated e.g. by collagen and thrombin, that strongly support the activation of two key coagulation complexes, tenase (factor $\mathrm{X}$ activation) and prothrombinase (prothrombin activation), and hence regulate the local generation of thrombin. ${ }^{5,6}$ Such platelets expose phosphatidylserine (PS), and have been termed procoagulant or coated platelets, ${ }^{7,8}$ which refers to their property to bind coagulation factors, fibrin(ogen), von Willebrand factor (VWF) and other platelet granule-derived proteins. ${ }^{9}$ The platelet procoagulant response is stimulated not only via collagen and thrombin receptors, but also by occupancy of adhesive glycoproteins. In particular, integrin $\alpha_{\| 1 b} \beta_{3}$ appears to be involved here, since blockers of this integrin suppress the platelet procoagulant activity and the generation of thrombin in platelet-rich plasma. ${ }^{10,11}$

Glycoprotein (GP)|lb-V-IX is also abundantly expressed on the platelet surface, serving as a ligand for VWF and a variety of coagulation factors. Lack of expression of the GPIb complex (Bernard-Soulier syndrome) associates with impaired haemostasis and bleeding. ${ }^{12} \mathrm{~A}$ similar defect in hemostasis is characteristic to von Willebrand disease (VWD), where VWF, the main ligand of GPIb $\alpha$, is completely or partially absent. ${ }^{13}$ It is well established that the interaction of GPIb-V-IX with immobilized 
VWF is essential for capture and adhesion of platelets at high, arterial shear rates. However, GPIb-V-IX is also functional in the absence of high shear, for instance in supporting platelet-dependent thrombin generation, though this role is more disputed than that of $\alpha_{11 \mathrm{~b}} \beta_{3}$. Some authors report that the contribution of VWF and GPIb to thrombin generation is partly fibrin-dependent and -independent, ${ }^{14}$ while others stipulate that the role of GPIb in thrombin generation relies on factor VIla independently of VWF. ${ }^{15}$ It is also reported that thrombin binding to GPIb is essential for thrombin-induced platelet procoagulant activity, ${ }_{1}^{16}$ although this finding could not be confirmed by others. ${ }^{17}$ Another study claims that the GPIb has a procoagulant role in the presence of low-shear forces, e.g. exerted on fibrin(ogen)-bound platelets. ${ }^{18}$

How platelets interact with the thrombin product, fibrin, and thereby contribute to the formation of fibrin is even less well clarified. Early studies proposed that platelets bind to fibrin monomers via GPIb-V-IX and VWF. ${ }^{19,20}$ It was however also considered that the binding of both VWF and fibrin to platelets involves active integrin $\alpha_{111} \beta_{3}{ }^{21}$ On the other hand, a role of GPIb was suggested for platelet interaction with fibrin-bound thrombin under flow. ${ }^{22}$ These studies thus tend to place GPIb-V-IX as a central adhesive complex in the binding of VWF, thrombin and fibrin to platelets. Conversely, a potential role of GPIb-V-IX and VWF in fibrin network formation has not yet been investigated.

In the present paper, we hypothesized that platelets actively participate in fibrin formation under low-shear flow conditions. We developed a microscopic method to monitor such a role, and characterized the receptors involved in this process, including GPIb-V-IX.

\section{Materials and Methods}

\section{Materials}

Apyrase, bovine serum albumin (BSA) and prostaglandin $E_{1}\left(P_{G} E_{1}\right)$ were obtained from Sigma (St. Louis, MO); corn trypsin inhibitor from Haematologic Technologies (Essex, VT); recombinant human tissue factor (Innovin) and ristocetin from Dade Behring (Marburg, Germany). The fluorogenic thrombin substrate, Z-Gly-Gly-Arg aminomethyl coumarin (Z-GGR-AMC) came from Bachem (Bubendorf, Switzerland); thrombin substrate $\mathrm{S} 2238$ was from Chromogenics (Uppsala, Sweden). Carboxyfluorescein diacetate succinimidyl ester (CFSE), Fluo-4 and Fura-2 acetoxymethyl esters, Oregon Green (OG)488-labeled and Alexa Fluor (AF)647-labeled annexin A5 were from Invitrogen (Leiden, The Netherlands), as were OG488-labeled and AF546-labeled fibrinogen. Cathepsin $G$ was obtained from 
Calbiochem (San Diego, CA), and O-sialoglycoprotein endopeptidase from Cedarlane (Ontario, Canada).

Monoclonal antibodies (mAbs) against the N-terminal (1-289) globular domain of GPIb $\alpha$ were generated and used, as described. ${ }^{17,23,24}$ The $\mathrm{mAb}^{6 \mathrm{~B}_{4}}$ interferes with the shear- and ristocetin/botrocetin-induced binding of VWF to GPIb; $12 \mathrm{G}_{1}$ only blocks shear-induced binding of VWF to GPIb; 2D2 blocks the thrombin binding site on GPIb; $2 \mathrm{D}_{4}$ is an isotope-matched control mAb. The chimeric mAb, abciximab, directed against $\alpha_{11 \mathrm{~b}} \beta_{3}$ and $\alpha_{v} \beta_{3}$, was from Centocor (Leiden, The Netherlands); the nonpeptide $\alpha_{11 \mathrm{~b}} \beta_{3}$ antagonist, tirofiban, from Merck (Haarlem, The Netherlands); the fibrinogen $\gamma$-chain dodecapeptide, HHLGGAKQAGDV, interfering with a different fibrinogen-binding sequence on $\alpha_{\| \mathrm{lb}}$, was obtained from Anaspec (Fremont, CA).

\section{Healthy subjects and patients}

Blood was taken from healthy volunteers for the preparation of platelets and plasma. Blood was also obtained from two patients with type-1 VWD; the patient plasmas had $10-12 \%$ of normal ristocetin cofactor activity, as assessed from ristocetin-induced platelet agglutination. In both patient plasmas, TF-induced thrombin generation with procoagulant phospholipids was in the normal range. All subjects gave full informed consent. None of the subjects had taken medication interfering with coagulation or platelet function for at least two weeks.

\section{Animals}

Animal experiments were approved by the local animal experimental committees. Transgenic IL4R $\alpha / G P I b \alpha$ mice ${ }^{25}$ and mice deficient in VWF $^{26}$ were generated as described, and bred against a $\mathrm{C}_{57} \mathrm{BI} / 6$ genetic background. In the IL4R $\alpha / G P I b \alpha$ mice most of the extracellular domain of GPIb $\alpha$ was replaced by the extracellular domain of the human interleukin-4 receptor alpha. The mice were kindly provided by drs. J. Ware and D. Wagner. Platelet surface glycoproteins were in the normal range. Plasma from $\mathrm{VWF}^{-/}$mice showed normal thrombin generation in response to tissue factor, but was completely deficient in VWF oligomers and multimers.

\section{Blood collection and preparation}

Human blood was collected by freely dripping into $1 / 10$ volume of $129 \mathrm{mM}$ trisodium citrate, and used to prepare platelet-rich-plasma (PRP) and washed platelets, as described. ${ }^{4}$ Platelet-free plasma was freshly prepared by differential centrifugation of blood from healthy donors. For the preparation of pooled plasma, plasma lots from 10 donors were combined, snap frozen and stored in samples at $-80^{\circ} \mathrm{C}$ until use. 
Isolated platelets were resuspended at a concentration of $100 \times 10^{9} / \mathrm{l}$ in Hepes buffer $\mathrm{pH} 7.45$ (10 mM Hepes, $136 \mathrm{mM} \mathrm{NaCl}, 2.7 \mathrm{mM} \mathrm{KCl}, 2 \mathrm{mM} \mathrm{MgCl} 2,0.1 \%$ glucose and $0.1 \% \mathrm{BSA})$ containing apyrase $(0.1 \mathrm{U} / \mathrm{ml})$. Where indicated, platelets were pretreated with cathepsin $\mathrm{G}(400 \mathrm{nM}){ }^{27}$ or O-sialoglycoprotein endopeptidase $(0.1 \mathrm{mg} / \mathrm{ml})^{28}$ for 1 $\mathrm{h}$ at $37^{\circ} \mathrm{C}$, and washed again. Platelet count was determined with a thrombocounter (Coulter Electronics, Luton, United Kingdom). Platelets in plasma were loaded with 8 $\mu \mathrm{M}$ Fluo-4 acetoxymethyl ester and washed. ${ }^{4}$

Mouse blood was drawn from wildtype and knockout animals under anaesthesia, and collected into $1 / 10$ volume of $129 \mathrm{mM}$ trisodium citrate. ${ }^{29}$ Murine PRP and washed platelets were prepared as described, ${ }^{30}$ and the isolated platelets were resuspended at $100 \times 10^{9} / \mathrm{l}$ into Tyrode-Hepes buffer $\mathrm{pH} 7.45$ ( $5 \mathrm{mM}$ Hepes, $136 \mathrm{mM}$ $\mathrm{NaCl}, 2.7 \mathrm{mM} \mathrm{KCl}, 0.42 \mathrm{mM} \mathrm{NaH}_{2} \mathrm{PO}_{4}, 2 \mathrm{mM} \mathrm{MgCl}_{2}, 0.1 \%$ glucose and $0.1 \% \mathrm{BSA}$ ) with $0.1 \mathrm{U} / \mathrm{ml}$ apyrase. Citrate-anticoagulated platelet-free plasma from individual mice was obtained by differential centrifugation. ${ }^{31}$ Washed mouse platelets were pretreated with $\mathrm{O}$-sialoglycoprotein endopeptidase $(0.1 \mathrm{mg} / \mathrm{ml})$ for $30 \mathrm{~min}$ at $37^{\circ} \mathrm{C}$, where indicated.

\section{Platelet analysis and activation in suspension}

Expression of GPIb levels on platelets was determined by flow cytometry using FITClabeled anti-human GPIb $\alpha$ mAb M1638 (Sanquin, Amsterdam, The Netherlands) or anti-mouse GPIb $\alpha$ Mo43 mAb (Emfret, Würzburg, Germany). Agonist-induced rises in $\left[\mathrm{Ca}^{2+}\right]_{\mathrm{i}}$ in platelets in suspension were measured as before. ${ }^{4}$

\section{Microscopic measurement of fibrin formation under flow condition}

Degreased, uncoated glass coverslips were placed into a transparent parallel-plate flow chamber (dimensions: $50 \mu \mathrm{m}$ deep and $3 \mathrm{~mm}$ wide), mounted on the stage of an inverted fluorescence microscope (Diaphot 200; Nikon, Tokyo, Japan), and rinsed with Hepes buffer $\mathrm{pH} 7.45$. Coverslips in the flow chamber were then incubated for 10 min under stasis with a suspension of washed platelets $\left(100 \times 10^{9} / \mathrm{l}\right)$. This resulted in a reproducible platelet adhesion, i.e. $22 \pm 4$ platelets per microscopic field of $95 \times 95$ $\mu \mathrm{m}$. Remaining, non-bound platelets were removed by 5 -min perfusion with Hepes buffer $\mathrm{pH} 7.45$ containing 1\% BSA. The high BSA content blocked uncovered parts of the coverslip and prevented further platelet spreading. In control experiments, glass coverslips without platelets were perfused with high BSA-containing Hepes buffer. Coagulation was introduced by co-perfusing citrate-anticoagulated pooled plasma and $\mathrm{CaCl}_{2}$-Hepes buffer $\mathrm{pH} 7.45$ at a calculated total shear rate of $250 \mathrm{~s}^{-1}$ into the chamber. For the human system, 10 vol. of plasma were co-perfused with 1 vol. of 100 
$\mathrm{mM}$ Hepes, $75 \mathrm{mM} \mathrm{CaCl}_{2}$ and $37.5 \mathrm{mM} \mathrm{MgCl}_{2}$. For the mouse system, 3 vol. of plasma were co-perfused with 1 vol. of $136 \mathrm{mM}$ Hepes, $20 \mathrm{mM} \mathrm{CaCl}$ and $7 \mathrm{mM} \mathrm{MgCl}$. The fluids were mixed immediately prior to entrance of the chamber. Where indicated, citrate-anticoagulated whole blood was used instead of plasma.

(Ant)agonists and fluorescent probes were added to plasma and blood, as indicated. As a standard, at 6os after the first visual formation of fibrin fibers (lag time recorded), coverslips were super-fused with Hepes buffer $\mathrm{pH} 7.45$ supplemented with $2 \mathrm{mM} \mathrm{CaCl}$ and one or two of the following probes, OG488- or AF647-labeled annexin $A_{5}(0.5 \mu \mathrm{g} / \mathrm{ml}), O_{488}$ - or AF546-labeled fibrinogen $(100 \mu \mathrm{g} / \mathrm{ml})$. During and after the experiment, phase contrast and fluorescent images were recorded using a 100x oil immersion objective and a sensitive EM-CCD camera system (Hamamatsu, Hamamatsu City, Japan). ${ }^{32}$ Images from mouse platelets were recorded with a different microscopic system, described before. ${ }^{29}$ Dual color confocal images were recorded with a $60 \times$ oil immersion objective and a BioRad/Zeiss multiphoton laser scanning microscope system, capable to electronic zooming. ${ }^{32}$

Differential images were generated by Metamorph (Downingtown, PA) software, and analyzed for changes in pixel intensity without contrast enhancement. Fluorescence images were analyzed for integrated pixel intensities above averaged background level. Brightfield and fluorescence images from at least 8 arbitrarily chosen microscopic fields were compared for determining fractions of fluorescent platelets. For visualization purposes only, linear contrast enhancement was done with Photoshop (Corel, Ottawa, Ontario, Canada).

\section{Thrombin generation in plasma}

Thrombin generation was measured in pooled human plasma by determining the cleavage of fluorogenic Z-GGR-AMC, as described. ${ }^{33}$ Coagulation was triggered with tissue factor (1 pM) or kaolin $(1.5 \mu \mathrm{g} / \mathrm{ml})$ and $\mathrm{CaCl}_{2}$ (16.6 mM, no phospholipids added unless indicated). Lag times and peak heights of formed thrombin were recorded.

Thrombin generation was also measured in samples of plasma $(50 \mu \mathrm{l})$, collected at the outlet of the flow chamber, and mixed with stop buffer ( $50 \mathrm{mM}$ Tris, $175 \mathrm{mM} \mathrm{NaCl}$ and $10 \mathrm{mM}$ EDTA, $\mathrm{pH}$ 7.9). Thrombin activity was measured in 96-well plates by addition of substrate $S_{2238}(0.5 \mathrm{mg} / \mathrm{ml})$, and monitoring of chromogenic activity (405 $\mathrm{nm}$ absorbance).

\section{Statistics}

Significance of differences was determined with the non-parametric Mann-Whitney $\mathrm{U}$ test and the paired sample t test (intervention effects), using the statistical package for social sciences (SPSS 11.0, Chicago, IL). 


\section{Results}

\section{Platelets trigger focal fibrin fiber formation under flow}

We developed a microscopic method to investigate the role of platelets in fibrin formation under conditions of coagulation and flow. Washed human platelets were allowed to adhere to glass coverslips mounted in a flow chamber for $10 \mathrm{~min}$, after which perfusion was started with blocking buffer containing 1\% BSA to stop platelet spreading. Recalcified human pooled plasma was next flowed through the chamber to trigger coagulation. No signs of coagulation were observed at shear rates $>400 \mathrm{~s}^{-1}$, but when plasma was perfused at $250 \mathrm{~s}^{-1}$ fibrin fibers were produced on the platelets after a lag time of about 10 min (Figure 6.1A).

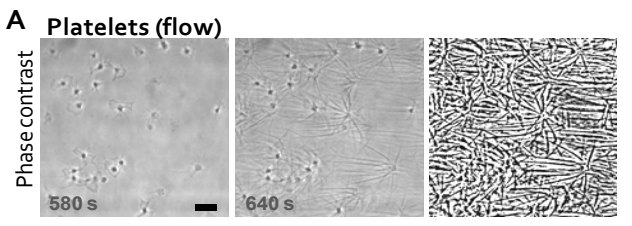

No platelets (flow)

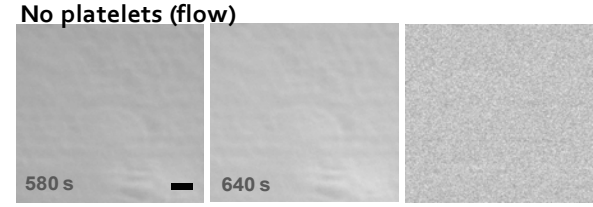

No platelets, tissue factor (flow)

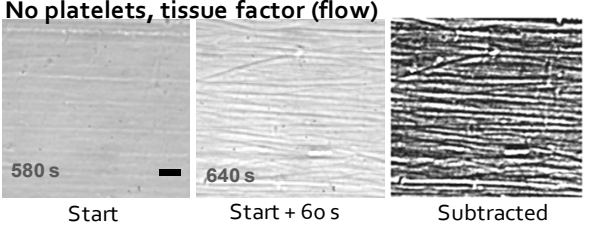

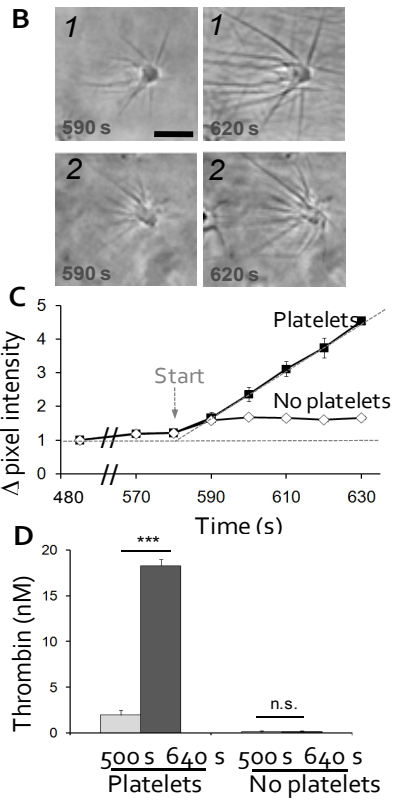

Figure 6.1: Platelet-dependent fibrin formation under flow. Recalcified pooled human plasma was perfused over a glass coverslip at a shear rate of $250 \mathrm{~s}^{-1}$ in the presence or absence of adherent platelets. Perfusion began at $\mathrm{t}=0$. $A$, Representative phase-contrast images taken at $\mathrm{t}=580 \mathrm{~s}$ (start of fibrin formation) and $\mathrm{t}=640 \mathrm{~s}$; right panels show subtracted, differential images (bars, $10 \mu \mathrm{m}$ ). Note the formation of star-like fibrin fibers originating from adherent platelets. Perfusion with tissue factor ( $1 \mathrm{pM}$ in plasma) in the absence of platelets resulted in formation of parallel fibrin fibers (lower panel). $B$, Higher magnification images of star-like fibrin formed in $30 \mathrm{~s}$ at the surface of 2 platelets. $C$, Quantification of fibrin formation. A baseline image taken at $\mathrm{t}=500 \mathrm{~s}$ was subtracted from images, taken at indicated time points. Graph shows increase in mean pixel intensity of the resulting subtracted images. $D_{1}$ Thrombin activity was measured at the indicated times in plasma samples collected at the outlet of the flow chamber. Data are from at least 3 independent experiments; means \pm SEM $(n=3-4), * * * p<0.001$ vs control. 
In control experiments without platelets, no fibrin was observed; however, when tissue factor was added, parallel fibers of fibrin did form in plasma in the direction of flow. High-magnification phase-contrast microscopic images demonstrated that upon flow platelets supported the formation of a focal, star-like network of fibrin fibers, which grew gradually in length (Figure 6.1B). By comparing series of subtraction images, the growth of individual fibers could be measured, and this was initially linear in time (Supplementary Figure 6.1A,B). Analysis of the mean pixel intensity of subtraction images allowed precise determination of the start of fibrin fiber formation, i.e. at around $580 \mathrm{~s}$ after the start of plasma flow (Figure 6.1C). Confirmation that the adherent platelets contributed to thrombin formation upon plasma perfusion came from the observation that measurements of thrombin in the eluent plasma (Figure 6.1D). Other control experiments under stasis showed high thrombin generation in the same pooled plasma only upon triggering with tissue factor (lag time, $10 \mathrm{~min}$ ) or kaolin (lag time, $19 \mathrm{~min}$ ) (Suppl. Figure 6.1C). We thus conclude that, during flow with recalcified plasma, adherent platelets are involved in the formation of thrombin and fibrin.
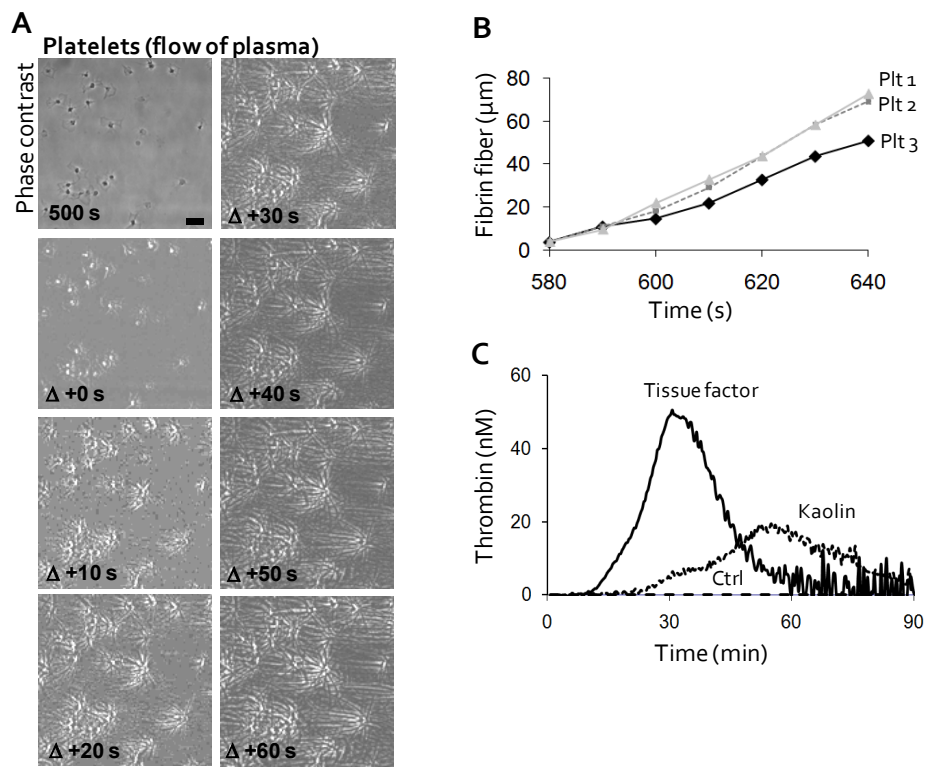

Supplementary Figure 6.1: Kinetics of fibrin formation and thrombin generation. $A$, Series of differential images taken at 580 to $640 \mathrm{~s}$, all compared to image at $500 \mathrm{~s}$, for experiments with adhered platelets perfused with recalcified pooled plasma, shown in Figure 1 (bars, 10 $\mu \mathrm{m}) . B$, Average formation rate of fibrin fibers originating from 3 representative platelets, as determined from the differential images. $C$, Kinetics of thrombin generation of recalcified pooled plasma under stasis in the presence of tissue factor $(1 \mathrm{pM})$ or kaolin $(1.5 \mu \mathrm{g} / \mathrm{ml})$; measurements by well-plate assay. No thrombin was formed in the absence of trigger (Ctrl). 
A

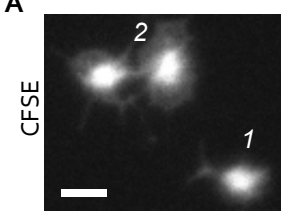

Start

B

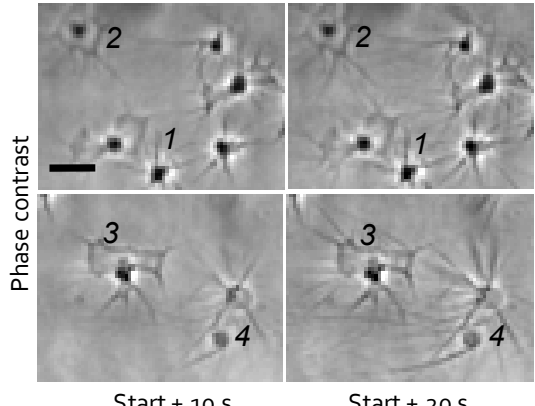

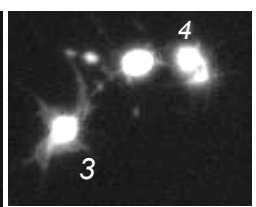

Start

Start +20

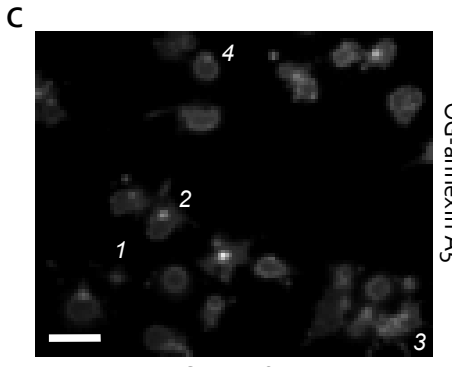

Start $+60 \mathrm{~s}$

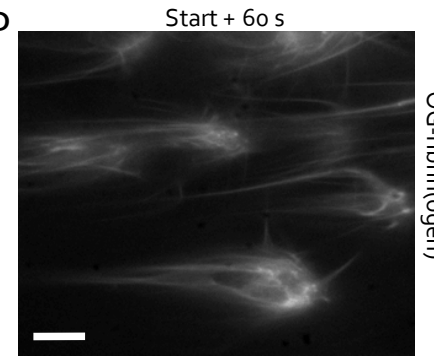

Start $+60 \mathrm{~s}$

Figure 6.2: Morphological score and fibrin formation of adhered platelets. Human platelets adhered to glass coverslips were superfused with plasma and $\mathrm{CaCl}_{2}$ at $250 \mathrm{~s}^{-1}$ (see Figure 6.1). Microscopic images were taken at the start of fibrin formation and the indicated time points thereafter. $A$, Fluorescence images of adherent platelets pre-labeled with CFSE. Numbers in italic refer to different morphologies of platelets: 1 , pseudopod(s); 2 , spread with lamellipod; 3 , spread with ruffled edge and/or shed microparticles; 4 , round blebbing platelet. $B$, Phase contrast images showing the formation of fibrin fibers induced by all four types of platelets. $C_{1}$ Staining with $\mathrm{OG}_{488} 8$-annexin $\mathrm{A}_{5}$ at $60 \mathrm{~s}$ after start of fibrin formation. $D_{1}$ Staining with OG488-labeled fibrinogen at $60 \mathrm{~s}$ after start, indicating star-like fluorescent fibrin fibers on adherent platelets. Representative images (bars, $10 \mu \mathrm{m}$ ) are shown from at least 3 independent experiments.

\section{Platelet activation is required for focal fibrin formation}

We then used high-resolution fluorescence microscopy and pre-labeling with CFSE to determine the morphology of the fibrin-forming platelets (Figure 6.2A). Four morphological forms were distinguished: platelets with pseudopods (type 1), spread platelets with lamellipods (type 2), spread platelets with ruffled edges and shed microparticles (type 3), and round blebbing platelets (type 4). The same morphological states were visible on phase-contrast images, which also demonstrated that platelets of all 4 types contributed to fibrin formation (Figure 6.2B). Post-perfusion with $\mathrm{OG}_{488}$-annexin $\mathrm{A}_{5}$ at $60 \mathrm{~s}$ after the start of fibrin formation also revealed that platelets of all types exposed PS (Figure $2 \mathrm{C}$ ). Overall, 90 $\pm 2 \%($ mean $\pm S E M, n=4)$ of the adherent platelets stained with annexin $A_{5}$, while $96 \pm$ 

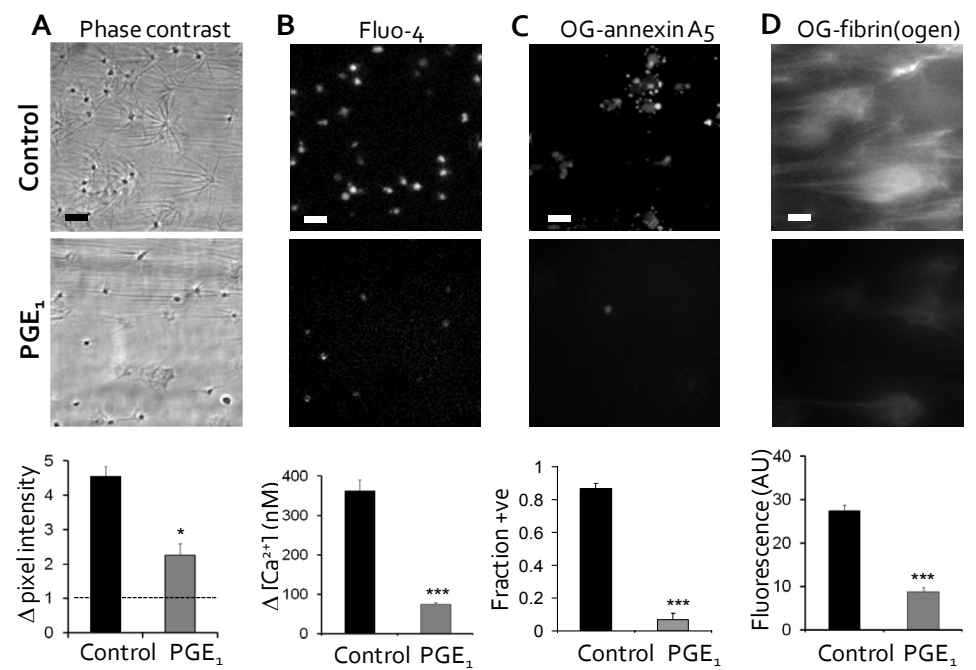

Figure 6.3: Effect of $\mathrm{PGE}_{1}$ on platelet-dependent fibrin formation under flow. Adherent platelets were superfused with plasma and $\mathrm{CaCl}_{2}$ at $250 \mathrm{~s}^{-1}$ in the absence (control) or presence $(0.5 \mu \mathrm{M})$ of $\mathrm{PGE}_{1}$. Representative images (bars, $10 \mu \mathrm{m}$ ) were taken at 60 s after start of fibrin formation; differences compared to baseline were quantified. $A$, Reduced fibrin formation after $P G E_{1}$ treatment. Subtracted images were analyzed for mean pixel intensity. $B_{1}$ Lower rises in $\left[\mathrm{Ca}^{2+}\right]_{i}$ with $\mathrm{PGE}_{1}$, measured in adhered Fluo-4-loaded platelets after $60 \mathrm{~s}$. $C_{1}$ Reduced staining for $\mathrm{OG}_{488}$-annexin $\mathrm{A}_{5}$ in the presence of $\mathrm{PGE}_{1,}$ measured after $60 \mathrm{~s}$. Graph shows fractions of adhered, annexin A5-positive platelets. $D$, Reduced $\mathrm{OG}_{488} 8$-fibrinogen staining on $\mathrm{PGE}_{1}$-treated platelets. Graph shows surface area coverage of fluorescent staining. (means $\pm \mathrm{SEM} ; n \geq 3$ experiments), $* p<0.05, * * * p<0.001$ vs control.

$4 \%$ formed fibrin fibers. The latter was confirmed by post-staining with OG488labeled fibrinogen, showing massive label incorporation into star-like fibrin fibers (Figure 6.2D). While it was reported by other authors that type 3 and 4 platelets are characterized by a procoagulant or sustained $\mathrm{Ca}^{2+}$ increase platelet (SCIP) morphology, ${ }^{9,34}$ the present data suggest that procoagulant activity (PS exposure) is a general property of adherent platelets independent of their morphology.

To demonstrate that platelet activation is required for fibrin formation, platelets adhering to the coverslip were perfused with recalcified plasma containing $0.5 \mu \mathrm{M}$ $\mathrm{PGE}_{1}$ (inhibiting platelets by elevation in intracellular cAMP). At a shear rate of $250 \mathrm{~s}^{-1}$, $\mathrm{PGE}_{1}$ significantly increased the lag time to start of fibrin formation from $9.3 \pm 0.8$ $\min$ to $12.7 \pm 2.4 \min (p<0.05, n=3)$. Furthermore, in the presence of $P G E_{1}$, only a subpopulation of the platelets formed fibrin fibers, which were few in number and no longer had a star-like appearance (Figure 6.3A). Addition of $\mathrm{PGE}_{1}$ to Fluo-4-loaded adherent resulted in a profound reduction of the $\mathrm{Ca}^{2+}$ response from 385 to $95 \mathrm{nM}$ 
Table 6.1: Effect of various treatments on platelet activation and fibrin formation under flow. Adhered platelets were co-perfused with plasma and $\mathrm{CaCl}_{2}$ at $250 \mathrm{~s}^{-1}$ (see Figure 6.1). Plasma was incubated with PGE $1(0.5 \mu \mathrm{M})$ or unlabeled annexin $\mathrm{A}_{5}(20 \mu \mathrm{g} / \mathrm{ml})$, as indicated. Alternatively, platelets were pretreated with cathepsin G (400 nM). Prior to start of fibrin formation, adhered platelets were classified as types 1-4 (containing pseudopods, lamellipods, ruffled edges or with balloon shape, respectively). Fractions of adhered platelets with type 3-4 morphology (procoagulant shape) were determined from recorded phase-contrast images. In addition, fractions of platelets staining with $\mathrm{OG}_{488}$-annexin $\mathrm{A}_{5}$ and producing fibrin fibers were determined at $60 \mathrm{~s}$ after start of initial fibrin formation. Data are means \pm SEM $(n=3-5$ experiments), $* * p<0.01, * * * p<0.001 \mathrm{vs}$ control.

\begin{tabular}{|l|l|l|l|}
\hline & \multicolumn{3}{c|}{ Fraction of aderent platelets } \\
\cline { 2 - 4 } Treatment & \multicolumn{1}{c|}{ Type $3 / 4$} & \multicolumn{1}{c|}{ PS-exposing } & \multicolumn{1}{c|}{ Fibrin forming } \\
\hline None (control) & $0.40 \pm 0.04$ & $0.90 \pm 0.02$ & $0.96 \pm 0.04$ \\
PGE1 & $0.21 \pm 0.03^{* *}$ & $0.09 \pm 0.01 * * *$ & $0.55 \pm 0.11 * *$ \\
Cathepsin G & $0.10 \pm 0.03 * * *$ & $0.16 \pm 0.09 * * *$ & $0.02 \pm 0.01 * * *$ \\
Annexin A5 & $0.08 \pm 0.01 * * *$ & n.d. $^{+}$ & $0.01 \pm 0.01 * * *$ \\
\hline
\end{tabular}

${ }^{+}$n.d., not determined

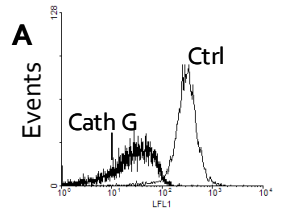

FITC $\alpha-h G P I b \alpha$

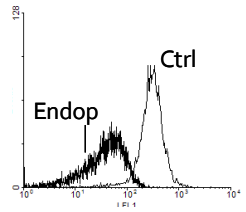

FITC $\alpha$-hGPIb $\alpha$

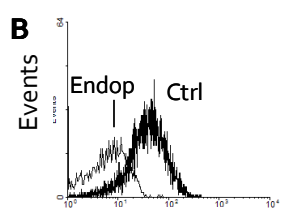

FITC $\alpha$-mGPIb $\alpha$

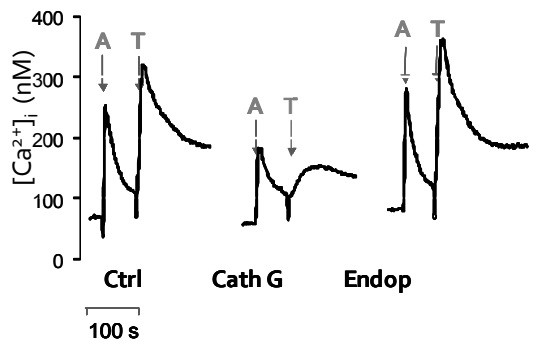

Supplementary Figure 6.2: Properties of platelets treated with cathepsin G or endopeptidase. Washed human or mouse platelets were untreated (Ctrl) or treated with cathepsin G (Cath, G, $400 \mathrm{nM}$ ) or $O$-sialoglycoprotein endopeptidase (Endop, $0.1 \mathrm{mg} / \mathrm{ml}$ ) for 1 $\mathrm{h}$ at $37^{\circ} \mathrm{C}$, and washed again. $A$, Human platelets. Upper panels: expression of GPIb after treatment. Shown are flow cytometric histograms of platelets stained with FITC anti-human GPIb $\alpha$ mAb. Lower panel: $\mathrm{Ca}^{2+}$ rises of treated, Fura-2-loaded platelets in response to ADP (A, $20 \mu \mathrm{M})$ or thrombin $(T, 4 \mathrm{nM})$. $B$, Mouse platelets. Expression of GPIb after treatment. Shown is flow cytometric histogram of platelets stained with FITC anti-mouse GPIb $\alpha$ mAb. 
(Figure 6.3B). Similarly, $\mathrm{PGE}_{1}$ treatment reduced the staining of platelets with labeled annexin $A_{5}$ and fibrinogen (Figure 6.3C,D). Detailed image analysis also showed reductions of the fractions of platelets with type 3 or 4 morphology from 40 to $21 \%$, of the PS-exposing platelets from 90 to $9 \%$, and of fibrin-forming platelets from 96 to $55 \%$ (Table 6.1).

The involvement of thrombin in platelet activation was determined by platelet pre-treatment with cathepsin $G$, which proteolytically cleaves PAR isoforms as well as GPIba. ${ }^{35-37}$ In suspensions of platelets, cathepsin $G$ treatment indeed led to a $75 \%$ reduction in thrombin-induced $\mathrm{Ca}^{2+}$ mobilization, while flow cytometry showed a major reduction in GPIb expression levels (Supplementary Figure 6.2). Cathepsin Gtreated platelets adhered normally to glass but, when perfused with plasma, only 10\% developed a type 3 or 4 morphology and a similar fraction exposed PS (Table 6.1). Markedly, only $2 \%$ of these platelets showed fibrin formation. To block procoagulant membrane surfaces, other flow experiments were performed in the presence of $20 \mu \mathrm{g} / \mathrm{ml}$ unlabeled annexin $A_{5}$, which concentration completely abrogates the generation of thrombin in tissue factor-triggered PRP. ${ }^{33}$ This treatment appeared to be as effective as cathepsin G (Table 6.1). Taken together, these data suggest that activation of platelets as well as thrombin generation on PS-exposing platelets contribute to the formation of focal, star-like fibrin fibers.

\section{Distinct contributions of integrin $\alpha_{11 b} b_{3}$ and GPIb-V-IX to fibrin formation under flow} In subsequent experiments, the contribution of common platelet adhesive receptors was studied as interaction sites for the binding and growth of fibrin. Plasma perfusions were carried out in the presence of different integrin $\alpha_{11 b} \beta_{3}$ antagonists, i.e. the chimeric $\mathrm{mAb}$ abciximab $(20 \mu \mathrm{g} / \mathrm{ml})$, the non-peptide inhibitor tirofiban $(5 \mu \mathrm{g} / \mathrm{ml})$, or blocking dodecapeptide derived from the fibrinogen $\gamma$-chain $(200 \mu \mathrm{M})$ that binds to a different epitope than RGDS in the $\alpha_{\| 1}$ chain. Surprisingly, these integrin antagonists did not abolish fibrin formation on platelets, although fibers often were no longer star-like but parallel with the direction of flow (Figure 6.4A, B). In the presence of $\alpha_{11 \mathrm{~b}} \beta_{3}$ antagonists, the time till first fibrin formation tended to be prolonged but this effect was not significant (Figure $6.4 \mathrm{C}$ ). The antagonists caused a moderate reduction in the number of fibers, as detected in subtracted phase-contrast images (Figure 6.4D) and in images of $\mathrm{OG}_{488}$-fibrinogen staining (Figure 6.4E). Also, no major effects of integrin antagonists on PS exposure were found (not shown).

The role of GPIb-V-IX was studied using a panel of mAbs directed against various epitopes on the N-terminal extracellular domain of GPIba. A non-blocking mAb 2D4 (10 $\mu \mathrm{g} / \mathrm{ml}$, control) and the $2 \mathrm{D} 2 \mathrm{mAb}$ directed against the thrombin binding site on GPIb $\alpha$, were both without significant effect on lag time or extent of fibrin formation 
A Abciximab

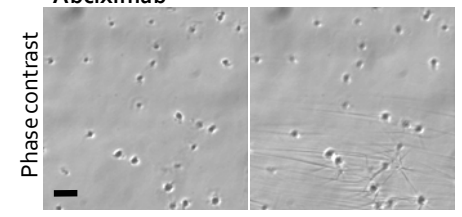

\section{Tirofiban}

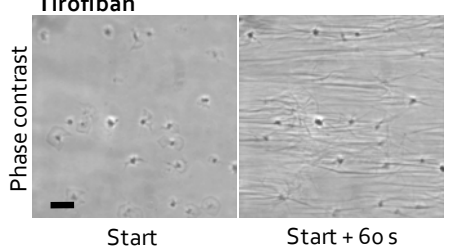

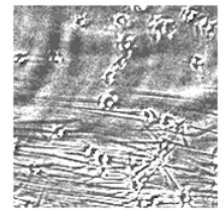

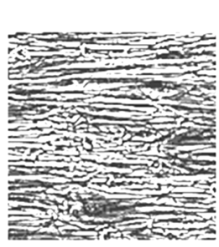

Subtracted

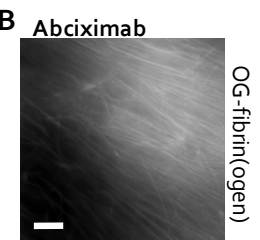

Tirofiban

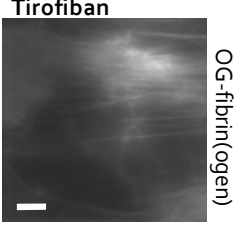

Start +60 s
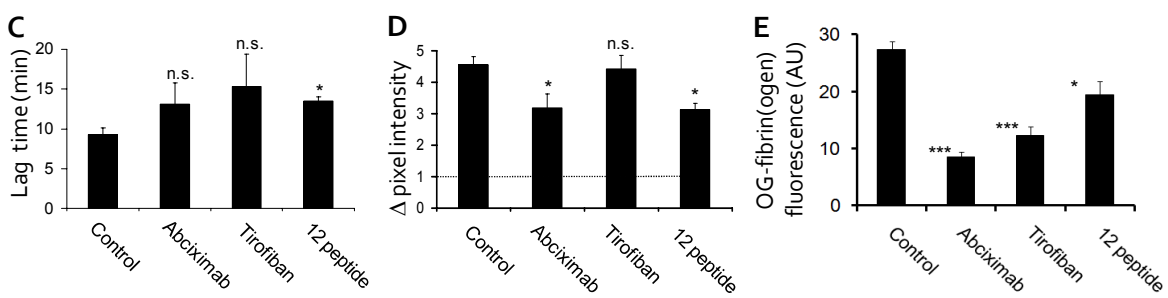

Figure 6.4: Non-essential role of platelet $\alpha_{11 b} \beta_{3}$ in fibrin formation. Adherent platelets were co-perfused with plasma and $\mathrm{CaCl}_{2}$ at $250 \mathrm{~s}^{-1}$ in the absence (control) or presence of abciximab $(20 \mu \mathrm{g} / \mathrm{ml})$, tirofiban $(5 \mu \mathrm{g} / \mathrm{ml})$ or $\gamma$-chain dodecapeptide $(200 \mu \mathrm{M})$, as indicated for Figure 6.1. $A$, Representative phase contrast and subtracted images taken at the start of fibrin formation and 60 s later (bars, $10 \mu \mathrm{m}$ ). B, Representative images for OG488-fibrinogen staining. $C_{\text {, Lag }}$ times between the start of perfusion and the start of fibrin formation. $D$, Extent of fibrin formation during $60 \mathrm{~s}$, as determined from subtracted phase-contrast images. $E$, Extent of OG 488 -fibrin(ogen) binding after $60 \mathrm{~s}$. Data are means \pm SEM ( $n=3-4$ experiments), $* p<0.05$, $* * * p<0.001$ vs control.

(Figure 6.5). In contrast, treatment with the $\mathrm{mAbs} 12 \mathrm{G}_{1}$ and $6 \mathrm{~B}_{4}$, both of which are directed against the VWF binding site on GPIb $\alpha$, resulted in marked prolongation of the lag time to fibrin formation (Figure $6.5 \mathrm{~A}-\mathrm{C}$ ). This was accompanied by a major reduction in amount of fibrin formed during the first $60 \mathrm{~s}$, as detected from subtracted contrast images and after OG-fibrinogen staining (Figure 6.5D,E). In addition, both mAbs markedly reduced PS exposure on the adherent platelets (Figure 6.5F). Further experiments showed that the combination of abciximab with 2D4, 2D2 or $6 \mathrm{~B}_{4} \mathrm{mAb}$ was not more effective than each of the anti-GPIba mAbs alone (not shown). 
A 2D2 mAb (control)
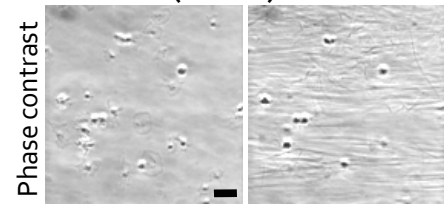

12G1 mAb

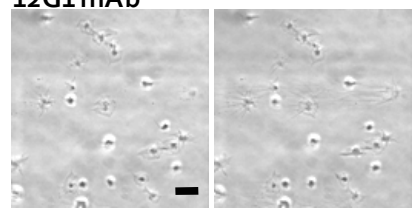

$6 \mathrm{~B}_{4} \mathrm{mAb}$

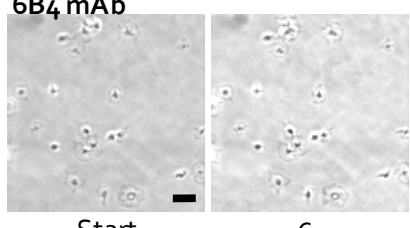

Start

$+60 s$

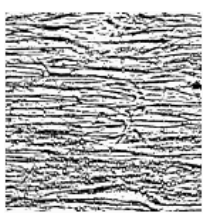

B

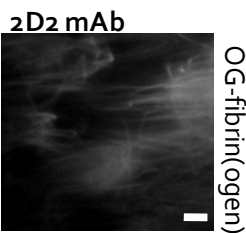

12G1 mAb

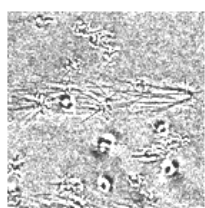

o⿰

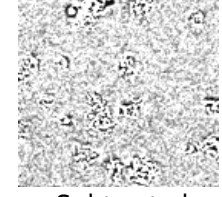

Subtracted

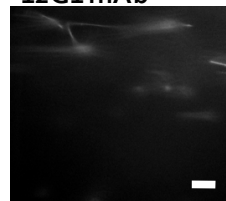

$6 \mathrm{~B}_{4} \mathrm{mAb}$

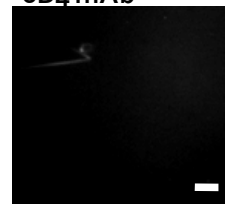

$+60 s$
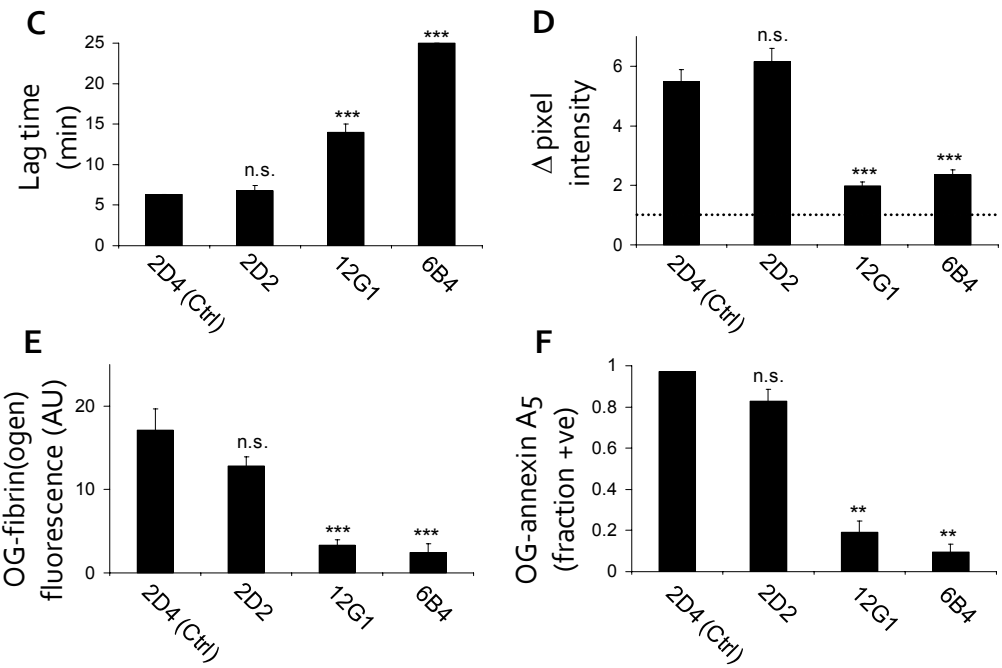

Figure 6.5: Prominent role of platelet GPIb-V-IX in fibrin formation. Adherent platelets were superfused with plasma and $\mathrm{CaCl}_{2}$ at $250 \mathrm{~s}^{-1}$ (see Figure 6.1). Plasma contained one of the following anti-GPIb $\alpha$ mAbs $(10 \mu \mathrm{g} / \mathrm{ml}): 2 D_{4}$ (control mAb), 2D2 (block of thrombin binding site), $12 \mathrm{G}_{1}$ or $6 \mathrm{~B}_{4}$ (block of VWF binding site). $A$, Representative phase contrast images at start and after $60 \mathrm{~s}$ of fibrin formation; also subtracted images (bars, $10 \mu \mathrm{m}$ ). $B$, Images after $60 \mathrm{~s}$ and staining with $\mathrm{OG}_{488} 8$-fibrinogen. $C_{1}$ Lag times to start of initial fibrin formation. $D$, Extent of fibrin formation during $60 \mathrm{~s}$, as determined from subtracted phasecontrast images. $E$, Quantification of $\mathrm{OG}_{488} 8$-fibrin(ogen) binding after $60 \mathrm{~s}$ of fibrin formation. $F$, Fraction of adhered platelets staining with $\mathrm{OG}_{488}$-annexin $\mathrm{A}_{5}$. Data are means \pm $\operatorname{SEM}(n=3-4), * * * p<0.001$ vs control mAb. 
A
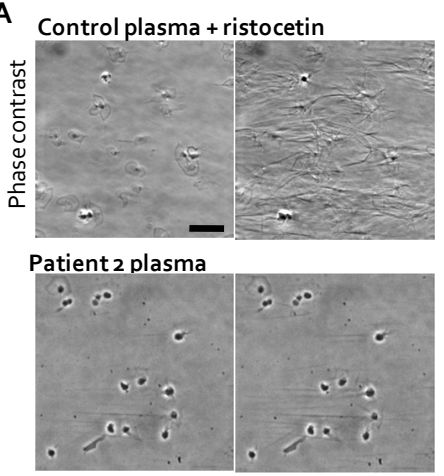

Patient 2 plasma + ristocetin

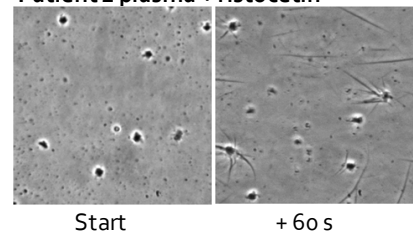

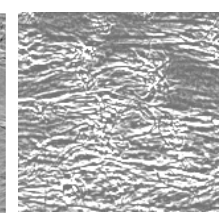
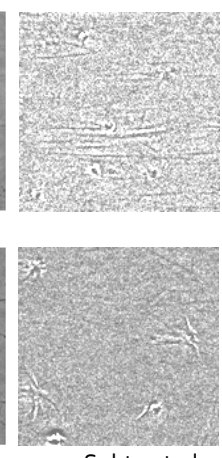

B
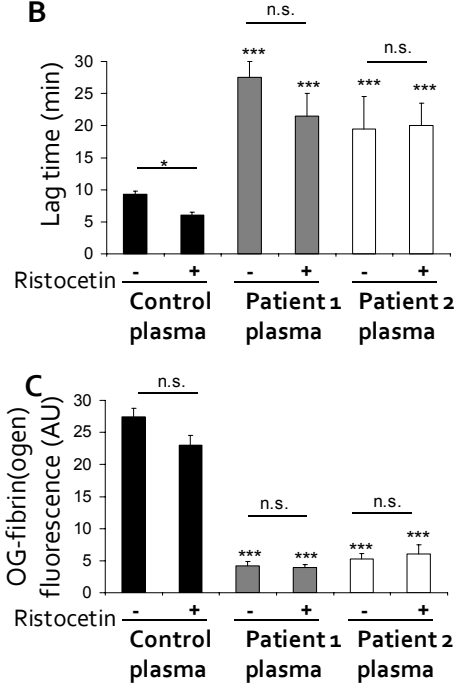

Figure 6.6: Role of VWF to platelet-dependent fibrin formation. Adherent platelets from healthy subjects were superfused with plasma and $\mathrm{CaCl}_{2}$ at $250 \mathrm{~s}^{-1}$ (see Figure 6.1). Perfusion was with pooled control plasma or with plasma from a patient with VWD. Plasmas were incubated with ristocetin $(37.5 \mu \mathrm{g} / \mathrm{ml})$, as indicated. $A$, Representative phase contrast images at start and after $60 \mathrm{~s}$ of fibrin formation; also subtracted images (bars, $10 \mu \mathrm{m}$ ). $B$, Lag times to start of fibrin formation. C, Quantification of OG488-fibrin(ogen) binding after $60 \mathrm{~s}$ of fibrin formation. Data are means \pm SEM $(n=3-4), * p<0.05, * * * p<0.001$ vs control plasma.

\section{Contribution of VWF to platelet-dependent fibrin formation}

These results so far pointed to a major role of platelet GPIb-V-IX in platelet activation and fibrin formation. A number of approaches was next used to investigate the possible involvement of VWF, the major ligand of GPIb-V-IX, in this process. First, treatment of pooled control plasma with ristocetin to activate VWF binding to GPIb resulted in a significant shortening of the lag time to fibrin formation, while the amount of fibrin formed was unchanged (Figure 6.6A,B). Second, perfusion experiments were carried out using plasma from two patients with type 1 VWD. These plasmas had $10-12 \%$ of normal ristocetin cofactor activity. With either plasma, fibrin fiber formation on control platelets was significantly delayed and diminished in comparison to control pooled plasma (Figure 6.6). Also the fraction of annexin $\mathrm{A}_{5}$ binding platelets was reduced from $76 \%$ (control plasma) to $5 \%$ (patient 1 plasma). Furthermore, ristocetin treatment of plasmas from both patients did neither shorten the lag time nor increase the fibrin formation (Figure 6.6B,C). 
A

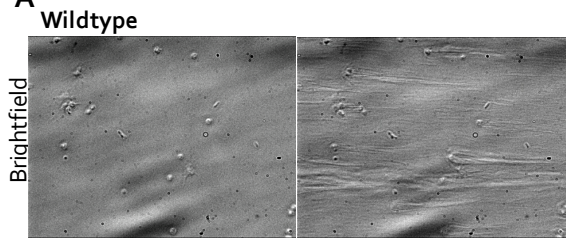

$\mathrm{GPIba}^{-1-}$

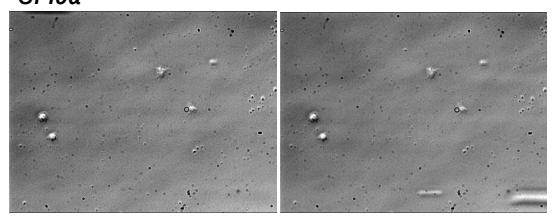

\section{$V W F^{-/-}$}

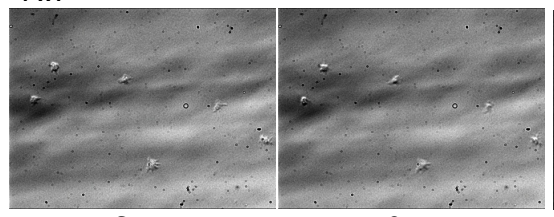

Start
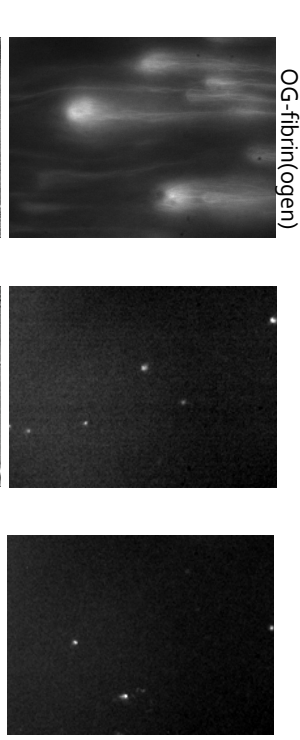

$+60 \mathrm{~s}$
B
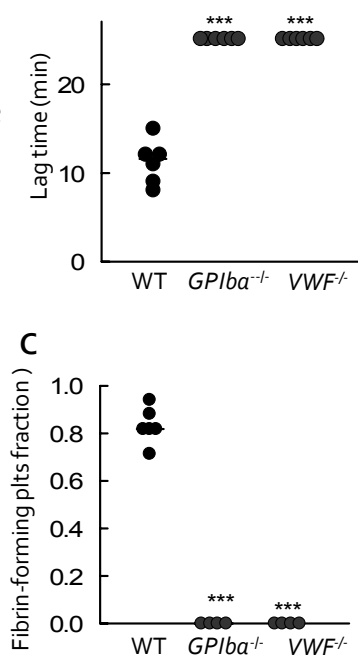

Figure 6.7: Effect of deficiency in GPIb $\alpha$ or VWF on platelet-dependent fibrin formation. Adherent platelets from wild-type mice (WT) or mice lacking the extracellular domain of GPIb $\alpha$ or deficient in VWF were superfused with autologous plasma and $\mathrm{CaCl}_{2}$ at a shear rate of $250 \mathrm{~s}^{-1}$ $A$, Representative brightfield images at start and after $60 \mathrm{~s}$ of fibrin formation, and corresponding images of $\mathrm{OG}_{488} 8$-fibrin(ogen) staining (bars, $10 \mu \mathrm{m}$ ). $B$, Lag times to start of

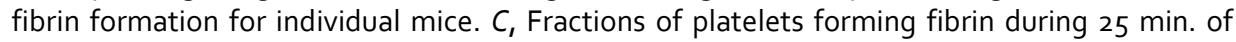
flow Data are means \pm SEM ( $n=4-6$ animals), $* * * p<0.001$ vs wildtype.

As a third approach, we studied fibrin fiber formation under flow with platelets and plasma isolated from mice, lacking the extracellular domain of GPIb $\alpha$ or deficient in VWF. Consistent with the human system, low-shear flow of recalcified wildtype plasma resulted in focal and star-like formation of fibrin fibers after a lag time of 12 min on about $80 \%$ of the adherent platelets (Figure 6.7). In marked contrast, essentially no fibrin was formed for up to $25 \mathrm{~min}$ with platelets and plasma from mice with either GPIba or VWF deficiency. To confirm the involvement of GPIb, wildtype mouse platelets were treated with O-sialoglycoprotein endopeptidase, which cleaves off the $45 \mathrm{kD} \mathrm{N}$-terminal region of mouse GPIba. ${ }^{38}$ Endopeptidase treatment resulted in platelets which had lost $>95 \%$ of their surface expressed GPIb $\alpha$ (Suppl. Figure 6.2B). With these platelets, fibrin formation during low-shear perfusion was delayed to $>25 \mathrm{~min}$, and only $3 \pm 3 \%$ of the platelets bound annexin $A_{5}$ (compared to $72 \%$ of untreated platelets). Together, these results indicate that platelet activation and 
A

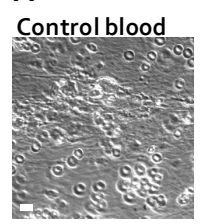

Brightfield

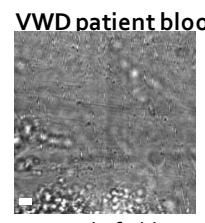

Brightfield

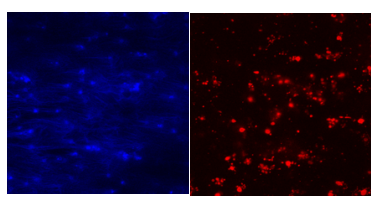

AF547fibrin(ogen)
AF647annexin $\mathrm{A}_{5}$

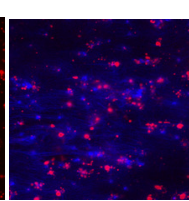

Overlay

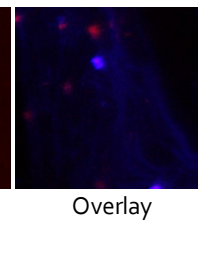

Overlay

AF647annexin $\mathrm{A}_{5}$

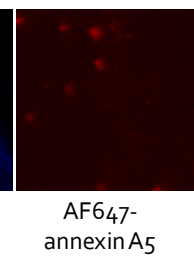

B
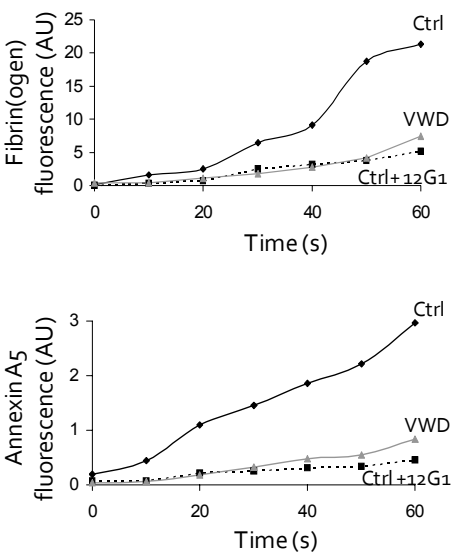

C

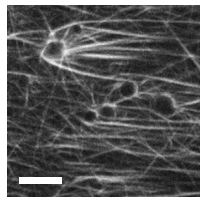

OG488-

fibrin(ogen)

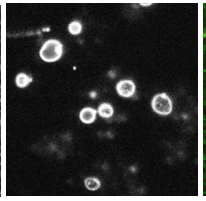

AF647-

annexin $\mathrm{A}_{5}$

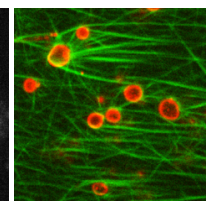

Overlay

Figure 6.8: Roles of GPIb-V-IX and VWF in fibrin formation during whole blood flow. Adhered platelets from a control subjects were co-perfused with anticoagulated whole blood and $\mathrm{CaCl}_{2}$ at a shear rate of $300 \mathrm{~s}^{-1}$ for $2.5 \mathrm{~min}$, after which the shear rate was step-wise reduced with $50 \mathrm{~s}^{-1}$ per $2.5 \mathrm{~min}$ to finally reach $125 \mathrm{~s}^{-1}$ after $10 \mathrm{~min}$. Blood was used from healthy control subjects or a type VWD patient, and was incubated with AF546-fibrinogen (150 $\mu \mathrm{g} / \mathrm{ml})$ and AF647-annexin $A_{5}(1 \mu \mathrm{g} / \mathrm{ml}) ; 12 \mathrm{G}_{1} \mathrm{mAb}(10 \mu \mathrm{g} / \mathrm{ml})$ was present where indicated. Confocal images captured after $10 \mathrm{~min}$ of flow, at a shear rate of $125 \mathrm{~s}^{-1}$ (bars, $10 \mu \mathrm{m}$ ). $A$, Representative confocal images at $60 \mathrm{~s}$ after start of image capture. $B$, Time plots of increase in surface area coverage of AF546-fibrinogen and AF647-annexin fluorescence at the optical

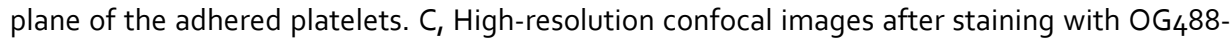
fibrin(ogen) and AF647-annexin $A_{5}$. Data are representative for 3 or more experiments.

fibrin fiber formation under low-shear flow conditions rely on the interaction of VWF with GPIb-V-IX.

\section{Role in thrombus formation at low shear flow}

To study how the GPIb-dependent fibrin formation contributes to thrombus formation, flow experiments were performed where control or patient whole blood under recalcification was perfused over adherent platelets, with stepwise reductions in wall shear rate. Addition of AF647-annexin $A_{5}$ and AF547-fibrinogen to the blood, and serial capture of confocal images from the adhered platelets allowed the detection of both PS exposure and fibrin formation in real-time. Strikingly, both 
processes were delayed and diminished, when using VWD blood or with control blood that was treated with anti-GPIb mAb $12 \mathrm{G}_{1}$ (Figure 6.8A,B). Further, high-resolution images showed that also in this whole-blood system, the PS-exposing platelets served as a focal point of fibrin formation (Figure 6.8C). These results hence pointed to a central role of platelet GPIb-V-IX and VWF in low-shear fibrin formation in whole blood.

\section{Discussion}

In this work, we have identified a novel role of platelet GPIb-V-IX interaction with VWF in low shear- and platelet activation-dependent formation of fibrin fibers, developing into a clot. Several lines of evidence demonstrated the importance of GPIb-V-IX and VWF in the fibrin-forming process on platelets, as it was: i) stimulated by ristocetin, ii) strongly antagonized by antibodies blocking the shear-dependent interaction of GPIba with VWF, iii) impaired with plasma and blood from VWD patients, and iv) absent with blood from mice deficient in the extracellular domain of GPIb $\alpha$ or in VWF. Strikingly, the flow-dependent fibrin fiber formation was no more than slightly affected by integrin $\alpha_{11 b} \beta_{3}$ inhibition. These results support the concept that platelets via the GPIb-V-IX complex and VWF directly participate in the development of a fibrin clot rather than being only trapped passively into the clot.

The role of GPIb complex in fibrin formation was independent of the spreading of platelets, as platelets at different stages of activation all were capable to produce star-like fibers at their surface. On the other hand, fiber formation was closely linked to platelet activation and expression of PS at the platelet surface. Thus, platelet inhibition with $\mathrm{PGE}_{1}$ or blocking the exposed $\mathrm{PS}$ with annexin $\mathrm{A}_{5}$ strongly delayed and suppressed the formation of fibrin. Similarly, inhibition of GPIb $\alpha$ (with 6B4 or $12 \mathrm{G} 1 \mathrm{mAb}$ ), cleavage of GPIb $\alpha$ (by cathepsin G), or reduction in VWF (VWD patients and deficient mice) suppressed platelet PS exposure along with fibrin formation. These data lead to the scheme that initial traces of thrombin together with VWF facilitate PS exposure, and that the thrombin that is generated on PS-exposing platelets then cleaves fibrinogen, which most likely is already bound (to VWF?). The first fibrin molecules may remain attached to the platelet and act as a scaffold for the growing fibrin fibers. The likely dual role of GPIb-V-IX in stimulating PS exposure and fibrin formation is well compatible with the capacity of this glycoprotein complex to bind coagulation factors, VWF and, via VWF, fibrin. ${ }^{15,24,39}$ Interestingly, while mAbs against the shear-induced binding of VWF to GPIb $\left(6 \mathrm{~B}_{4},{ }_{12} \mathrm{G}_{1}\right)$ were highly effective in reducing fibrin formation, a mAb characterized to block the binding of thrombin to GPIb (2D2) was without any effect, indicating that direct thrombin-GPIb interaction is not required for this platelet response. 
Interactions between VWF and GPIb are mostly described for high-shear flow conditions, which trigger shear-dependent conformational changes in VWF and GPIb. ${ }^{40-42}$ However, in vivo animal model studies show that a deficiency in GPIb $\alpha$ or VWF affects both arterial and venous thrombus formation, although the role of the GPIb-V-IX complex may differ from that of VWF. ${ }^{43}$ The presently described process of fibrin formation on platelets is most active at low-shear conditions, since no fibers are formed at high-shear rate (likely due to limited activity of thrombin) or in the absence of flow (fibrin ultimately forms free in plasma). This might indicate that under coagulant conditions, with thrombin present, a low shear rate can cause similar conformational changes as detected at high shear rate. For instance, thrombin may facilitate interaction of the shear-dependent binding site of GPIb $\alpha$ (blocked by $6 \mathrm{~B}_{4}$ and $12 \mathrm{G}_{1} \mathrm{mAbs}$ ) with VWF. Another possibility is that the VWF implicated in fibrin formation is secreted by the platelets themselves. However, this still needs to be determined. Under physiological conditions of haemostasis, platelets adhering to a wound more likely will sense low-shear than high-shear flow conditions, which is in agreement with the idea that the present mechanisms of platelet-dependent fibrin formation is of importance to stop bleeding events.

The studies with mouse platelets provide additional inside into the mechanism, since platelets expressing the chimeric IL-4R $\alpha / G P I b \alpha$, lacking the extracellular domain of GPIba, were unable to support fibrin formation, in spite of the fact that the intracellular domain of the glycoprotein normally interacts with filamin-1 and $14-3-3 \zeta{ }^{25}$ The severe bleeding phenotype retained in these mice may be linked to defective fibrin formation.

The flow-dependent role of platelets in fibrin formation most likely is different from the role of platelets in fibrin clot retraction, since this is potently antagonized by $\alpha_{\| 1 \mathrm{~b}} \beta_{3}$ antagonists. Indeed, semi-static thromboelastography measurements using tissue factor-activated PRP did not show an effect of anti-VWF or anti-GPIb mAbs $\left(6 B_{4}, 12 G_{1}\right)$ on clot retraction, such in contrast to the strong inhibitory effect of abciximab (S. Schols, unpublished data, 2009). On the other hand, the limited effect of $\alpha_{\| 1} \beta_{3}$ blockers on flow-dependent fibrin formation is well compatible with the finding that integrins on PS-exposing platelets are in an inactive state. ${ }^{9,32}$

In summary, the present results point to a novel role of VWF binding to GPIb-V-IX, occurring at low-shear flow, to stimulate platelet procoagulant activity and mediate local fibrin formation. This finding can be relevant to the manifestation of VWD, and it can help to better understand the action mechanism of newly developed antithrombotic drugs targeted at GPIb. 


\section{References}

1. Mackman N, Tilley RE, Key NS. Role of the extrinsic pathway of blood coagulation in hemostasis and thrombosis. Arterioscler Thromb Vasc Biol 2007; 27:1687-1693.

2. Cho J, Furie BC, Coughlin SR, Furie B. A critical role for extracellular protein disulfide isomerase during thrombus formation in mice. J Clin Invest 2008; 118:1123-1131.

3. Gailani D, Renné T. The intrinsic pathway of coagulation: a target for treating thromboembolic disease? J Thromb Haemost 2007; 5:1106-1112.

4. Van der Meijden PEJ, Schoenwaelder SM, Cosemans JMEM, Wetzker R, Heller R, Jackson $\mathrm{SP}$, Heemskerk JWM. Dual $\mathrm{P}_{2} \mathrm{Y}_{12}$ receptor signaling in thrombin-stimulated platelets: involvement of phosphoinositide 3 -kinase $\beta$ but not $\gamma$ isoforms in $\mathrm{Ca}^{2+}$ mobilization and procoagulant activity. FEBS J 2008; 275:371-385.

5. Heemskerk JWM, Kuijpers MJE, Munnix ICA, Siljander PRM. Platelet collagen receptors and coagulation. A characteristic platelet response as possible target for antithrombotic treatment. Trends Cardiovasc Med 2005; 15:86-92.

6. Monroe DM, Hoffman M. What does it take to make the perfect clot? Arterioscler Thromb Vasc Biol 2006; 26:41-48.

7. Heemskerk JWM, Bevers EM, Lindhout T. Platelet activation and blood coagulation. Thromb Haemost 2002; 88:186-193.

8. Dale GL. Coated-platelets: an emergic component of the procoagulant response. J Thromb Haemost 2005; 3:2185-2192.

9. Munnix ICA, Cosemans JMEM, Auger JM, Heemskerk JWM. Platelet response heterogeneity in thrombus formation. Thromb Haemost 2009; in press.

10. Reverter JC, Béguin S, Kessels H, Kumar R, Hemker HC, Coller BS. Inhibition of plateletmediated, tissue-factor-induced thrombin generation by the mouse/human chimeric $7 \mathrm{E}_{3}$ antibody. J Clin Invest 1996; 98:863-874.

11. Pedicord DL, Thomas BE, Mousa SA, Dicker IB. Glycoprotein IIb/IIla receptor antagonists inhibit the development of platelet procoagulant act ivity. Thromb Res 1998; 90:247-258.

12. Ruggeri ZM. The role of von Willebrand factor in thrombus formation. Thromb Res 2007; 120:S5-Sg.

13. Lillicrap D. Von Willebrand disease: phenotype versus genotype, deficiency versus disease. Thromb Res 2007; 120:S11-S16.

14. Béguin S, Kumar R, Keularts I, Seligsohn U, Coller BS, Hemker HC. Fibrin-dependent platelet procoagulant activity requires $\mathrm{GPIb}$ receptors and von Willebrand factor. Blood 1999; 93:564-570.

15. Weeterings C, De Groot PG, Adelmeijer J, Lisman T. The glycoprotein Ib-V-IX complex contributes to tissue factor-independent thrombin generation by recombinant factor VIla on the activated platelet surface. Blood 2008; 112:3227-3233.

16. Dörmann D, Clemetson KJ, Kehrel B. The GPIb thrombin-binding site is essential for thrombin-induced platelet procoagulant activity. Blood 2000; 86:2469-2478.

17. Keuren JFW, Wielders SJ, Ulrichts $H$, Hackeng $T$, Deckmyn $H$, Heemskerk JWM, Bevers $E$, Lindhout T. Synergistic effect of thrombin on collagen-induced platelet procoagulant activity is mediated through protease-act ivated receptor-1. Arterioscler Thromb Vasc Biol 2005; 25:1499-1505. 
18. Keuren JFW, Ulrichts $H$, Feijge MAH, Hamulyák K, Deckmyn H, Lindhout T, Heemskerk JWM. Integrin $\alpha$ llb $\beta 3$ and shear-dependent action of glycoprotein lb $\alpha$ st imulate plateletdependent thrombin formation in stirred plasma. J Lab Clin Med 2003; 141:350-358.

19. Parker Rl, Gralnick HR. Fibrin monomer induces binding of endogenous platelet von Willebrand factor to the glycocalicin portion of platelet glycoprotein Ib. Blood 1987; 79:1589-1594.

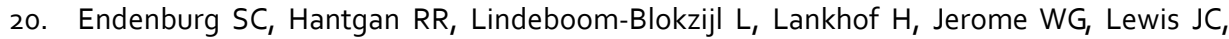
Sixma JJ, de Groot PG. On the role of von Willebrand factor in promoting platelet adhesion to fibrin in flowing blood. Blood 1995; 86:4158-4165.

21. Hantgan RR, Hindriks G, Taylor RG, Sixma JJ, de Groot PG. Glycoprotein Ib, von Willebrand factor, and glycoprotein Ilb:Illa are all involved in platelet adhesion to fibrin in flowing whole blood. Blood 1990; 76:345-353.

22. Weeterings C, Adelmeijer J, Myles T, de Groot PG, Lisman T. Glycoprotein Iba-mediated platelet adhesion and aggregation to immobilized thrombin under conditions of flow. Arterioscler Thromb Vasc Biol 2006; 26:670-675.

23. Cauwenberghs N, Vanhoorel beke K, Vauterin S, Westra DF, Romo G, Huizinga EG, Lopez JA, Berndt MC, Harsfalvi J, Deckmyn H. Epitope mapping of inhibitory ant ibodies against platelet glycoprotein Ib $\alpha$ reveals interaction between the leucine-rich repeat $\mathrm{N}$-terminal and C-terminal flanking domains of glycoprotein Ibo. Blood 2001; 98:652-66o.

24. Ulrichts $H$, Vanhoorelbeke K, Cauwenberghs S, Vauterin S, Kroll H, Santoso S, Deckmyn $\mathrm{H}$. Von Willebrand factor but not $\alpha$-thrombin binding to platelet glycoprotein Ib $\alpha$ is influenced by the HPA-2 polymorphism Arterioscler Thromb Vasc Biol 2003; 23:1302-1307.

25. Kanaji T, Russell S, Ware J. Amelioration of the macrothrombocytopenia associated with the murine Bernard-Soulier syndrome. Blood 2002; 100:2102-2107.

26. Denis C, Methia N, Frenette PS, Rayburn H, Ullman-Culleré M, Hynes RO, Wagner DD. A mouse model of severe von Willebrand disease: defects in hemostasis and thrombosis. Proc Natl Acad Sci USA 1998; 95:9524-9529.

27. Kinlough-Rathbone RL, Perry DW, Rand ML, Packham MA. Effects of cathepsin G pretreatment of platelets on their subsequent responses to aggregating agents. Thromb Res 1999; 95:315-323.

28. Bergmeier W, Rackebrandt K, Schroder W, Zirngibl H, Nieswandt B. Structural and functional characterization of the mouse von Willebrand factor receptor GPIb/IX with novel monoclonal antibodies. Blood 2000; 95:886-893.

29. Stefanini L, Roden RC, Bergmeier W. CalDAG-GEFI is at the nexus of calcium-dependent platelet activation. Bood 2009; 114:2506-2514.

30. Munnix ICA, Strehl A, Kuijpers MJE, Auger JM, van der Meijden PEJ, van Zandvoort MAMJ, oude Egbrink M, Nieswandt B, Heemskerk JWM. The glycoprotein VI-phospholipase $C_{2}$ signaling pathway controls thrombus formation induced by collagen and tissue factor in vitro and in vivo. Arterioscler Thromb Vasc Biol 2005; 25:2673-2678.

31. Vanschoonbeek K, Wouters K, van der Meijden PEJ, van Gorp PJ, Feijge MAH, Herfs M, Schurgers LJ, Hofker MH, de Maat MPM, Heemskerk JWM. Anticoagulant effect of dietary fish oil in hyperlipidemia: an mRNA expression study in APOE2 knock-in mice. Arterioscler Thromb Vasc Biol 2008; 28:2023-2029. 
32. Munnix ICA, Kuijpers MJE, Auger JM, Thomassen CMLGD, Panizzi $P$, van Zandvoort MAMJ, Rosing J, Bock PE, Watson SP, Heemskerk JWM. Segregation of platelet aggregatory and procoagulant microdomains in thrombus formation. Arterioscler Thromb Vasc Biol 2007; 27:2484-2490.

33. Vanschoonbeek K, Feijge MAH, van Kampen RJW, Kenis H, Hemker HC, Giesen PLA, Heemskerk JWM. Initiating and potentiating roles of platelets in tissue factor-induced thrombin generation in the presence of plasma. J Thromb Haemost 2004; 2:476-484.

34. Kulkarni S, Jackson SP. Platelet factor XIII and calpain negatively regulate integrin $\alpha$ llb $\beta_{3}$ adhesive function and thrombus growth. J Biol Chem; 2004. p. 30697-30706.

35. Pidard D, Renesto P, Berndt MC, Rahbi S, Clemetson KJ, Chignard M. Neutrophil proteinase cathepsin $\mathrm{G}$ is proteolytically active on the human platelet glycoprotein $\mathrm{Ib} / \mathrm{IX}$ receptor, characterization of the cleavage site within the glycoprotein Ib $\alpha$ subunit. Biochem J 1994; 303:489-498.

36. Renesto P, Si-Tahar M, Moniatte M, Balloy V, van Dorsselaer A, Pidard D, Chignard M. Specific inhibition of thrombin-induced activation by the neutrophil proteinases elastase, cathepsin G, and proteinase 3. Blood 1997; 89:1944-1953.

37. Sambrano GR, Huang W, Faruqi T, Mahrus S, Craik C, Coughlin SR. Cathepsin G activates protease-act ivated receptor-4 in human platelets. J Biol Chem 2000; 275:6819-6823.

38. Bergmeier W, Bouvard D, Eble JA, Mokhtari-Nejad R, Schulte V, Zirngibl H, Brakebusch C, Fässler R, Nieswandt B. Rhodocyt in (aggretin) activates platelets lacking $\alpha_{2} \beta_{1}$ integrin, glycoprotein $\mathrm{VI}$, and the ligand-binding domain of glycoprotein Iba. J Biol Chem 2001; 276:25121-26216.

39. Keuren JF, Baruch $D$, Legendre $P$, Denis CV, Lenting $P J$, Girma JP, Lindhout $T$. Von Willebrand factor $\mathrm{C}_{1} \mathrm{C}_{2}$ domain is involved in platelet adhesion to polymerized fibrin at high shear rate. Blood 2004; 103:1741-1746.

40. Goto S, Tamura N, Eto K, Ikeda Y, Handa S. Functional significance of adenosine 5 -diphosphate receptor $\left(\mathrm{P}_{2} \mathrm{Y}_{12}\right)$ in platelet activation initiated by binding of von Willebrand factor to platelet GPIba induced by conditions of high shear rate. Circulation 2002; 105:2531-2536.

41. Vanhoorelbeke $K$, Ulrichts $H$, Van de Walle G, Fontayne A, Deckmyn H. Inhibition of platelet glycoprotein $\mathrm{Ib}$ and its antithrombotic potential. Curr Pharm Des 2007; 13:2684-2697.

42. Ruggeri ZM, Dent JA, Saldivar E. Contribution of dist inct adhesive interactions to platelet aggregation in flowing blood. Blood 1999; 94:172-178.

43. Bergmeier W, Chauhan AK, Wagner DD. Glycoprotein Ib $\alpha$ and von Willebrand factor in primary platelet adhesion and thrombus formation: lessons from mice. Thromb Haemost 2008; 99:264-270. 


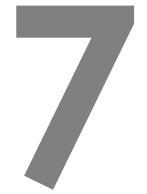

General discussion 
In spite of the many available protocols, recommendations and guidelines for transfusion therapy to patients with dilutional coagulopathy and massive bleeding, surprisingly little is known about the regulation of the coagulation mechanism in case of plasma dilution. In the present thesis, it was aimed to generate this knowledge by measuring the processes of thrombin generation and fibrin clot formation in plasma from patients with peri-operative dilutional coagulopathy. A model is proposed to predict the factors that limit the coagulation process upon dilution, which may act as a lead for using capacitive coagulation tests in this clinical situation and for development of evidence based transfusion protocols. Below, first new mechanisms are discussed how platelets, thrombin and fibrin can interact in the clotting process.

\section{Novel interactions between platelets, thrombin and fibrin(ogen)}

More than a decade ago, it was determined that positive feedback loops exist between platelet activation, thrombin generation and fibrin formation in clotting plasma. ${ }^{1,2}$ A major role was assigned to the platelet integrin $\alpha$ llb $\beta 3$, which had a surprising function in the promotion of platelet procoagulant activity and thrombin generation via binding to fibrin(ogen). ${ }^{3-5}$ Recently, it was discovered that exposure of procoagulant phosphatidylserine at the platelet surface is facilitated by both autocrine ADP release and fibrin(ogen)-dependent $\alpha$ llb $\beta 3$ outside-in signaling, which processes greatly facilitate the capability of platelets to support thrombin generation in plasma. ${ }^{6,7}$ Also another platelet adhesive receptor, the glycoprotein (GP)Ib-V-IX complex, has been reported to play a role in thrombin generation, most likely by interacting with its main ligand, von Willebrand factor (VWF). ${ }^{3,8}$ The present thesis brings in three additional ways how platelets can participate in the formation of a stable clot, namely: (i) by directly supporting fibrin formation at low shear flow rate, (ii) by increasing the strength of a fibrin clot, and (iii) by compensating for the hypocoagulant effect of plasma dilution (Figure 7.1).

Regarding the first point, Chapter 6 describes a novel role of platelets by providing a surface where star-like fibrin fibers can be formed in the presence of coagulation and flow. It is shown that both spreading and blebbing (procoagulant) platelets facilitate this star-like formation of fibrin strands. Prior activation of the platelets is required, as evidenced by the high cytosolic $\mathrm{Ca}^{2+}$-concentrations inside the cells and by the inhibitory effect of ( $\mathrm{Ca}^{2+}$-suppressing) prostaglandin $\mathrm{E}_{1}$. Interestingly, this fibrin formation is also dependent on GPIb-V-IX interaction with $V W F$, as was concluded from: the marked delay and inhibition by antibodies directed against the GPIba binding site for VWF; the delay seen in plasma from patients with VWF deficiencies (type I); and the enhanced fibrin formation in the presence of GPIb- 


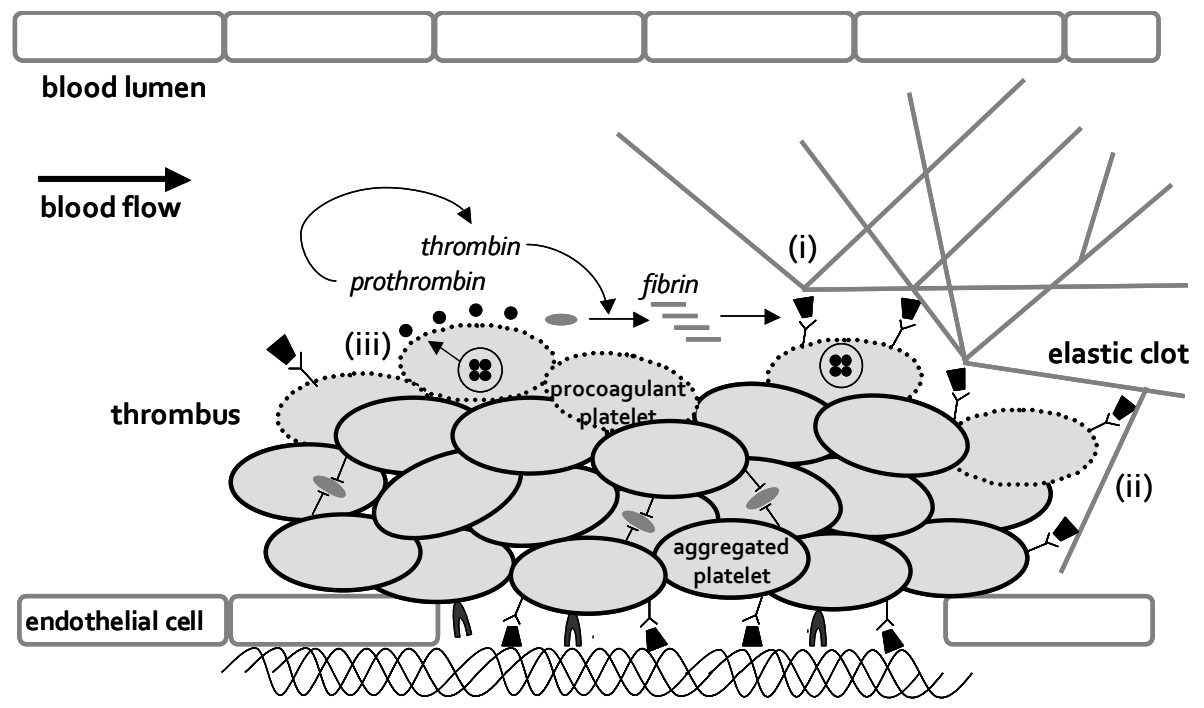

extracellular matrix

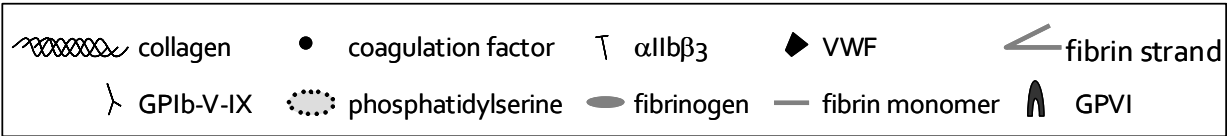

Figure 7.1: Novel roles of platelets in formation of a fibrin-containing thrombus under flow. This thesis reveals that, following vascular damage, platelets in a thrombus play a number of roles in the clotting process. (i) Activated, procoagulant platelets at the surface of a thrombus, exposing PS, mediate local conversion of prothrombin into thrombin. Thrombin converts fibrinogen into fibrin monomers, which in a flow-dependent way assemble as starlike fibres at the surface of activated ('coated') platelets via GPIb-V-IX and VWF. (ii) Contracting platelets provide elasticity to the fibrin clot. (iii) Activated platelets also release coagulation factors, which contribute to the thrombin generation, particularly under diluted conditions.

V-IX-activating ristocetin. The contribution of both GPIb-V-IX and VWF in the formation of fibrin fibers is confirmed in experiments with blood from mice lacking GPIba or VWF, in which case fibrin formation on platelets was not detected. A surprising finding is that the star-like formation of fibrin fibers is only limitedly dependent on activation of $\alpha \mathrm{llb} \beta_{3}$, which hence deviates from the marked contribution of this integrin to platelet-dependent thrombin generation. ${ }^{3}$ Together, our results provide a clear indication that phosphatidylserine exposure facilitates the GPIba/VWF-dependent assembly of fibrin fibres, although thrombin's enzymatic activity clearly is needed to cleave fibrinogen into fibrin monomers. 
In the current literature, the platelet-activating role of VWF is primarily confined to arterial thrombosis, and is considered to be a consequence of high-shear conformational changes of VWF in interaction with GPIb-V-IX..$^{9,10}$ Thus, in mouse models of experimental thrombosis, the blocking or absence of GPIb-V-IX reduces thrombus formation and downstream ischemic tissue infarction, particularly in arteries where the blood flows at high shear rate. ${ }^{11,12}$ The above results of Chapter 6 point to the existence of another role of GPIb-V-IX interaction with VWF, which is also flow-dependent but occurs at low-shear conditions. This platelet role in fibrin formation may help to stop venous bleeding, which is known to occur in patients with von Willebrand disease. Others have clarified that GPIb-V-IX interaction with VWF ${ }^{13,14}$ or thrombin ${ }^{15}$ has a procoagulant effect at low-shear or semi-static conditions, but we note that this work refers to platelet-dependent thrombin generation rather than to fibrin formation.

It has been shown that platelet binding to fibrin fibers involves VWF, and that fibrin binds with high affinity to the C domain of VWF. ${ }^{16,17}$ Furthermore, Dale and colleagues have reported that procoagulant, phosphatidylserine-exposing platelets, following stimulation with collagen and thrombin, can form a 'coat' of proteins that includes fibrin, VWF, thrombospondin and serotonin. ${ }^{18} \mathrm{~A}$ population of 'coated' platelets, partly exposing phosphatidylserine, is indeed formed during flowdependent thrombus formation on collagen under coagulant conditions. ${ }^{19}$ The present results suggest that 'coated' platelets are those activated platelets that have assembled a fibrin network via VWF binding to GPIb-V-IX, in which other plasma proteins such as thrombospondin may become integrated. While the fibrin-coated platelets may well support thrombosis, in the situation of coagulopathy they are likely also important to stop undesired bleeding.

The second point, - a supportive role of platelets in increasing the strength of a fibrin clot -, is documented in Chapter 3. Rotational thromboelastography, which method measures clot elasticity and strength, indicates that the presence of platelets greatly increases this parameter in coagulating plasma. In spite of the current popularity of thromboelastography as a clinical point-of-care test, ${ }^{20,21}$ the role of platelets in clot elasticity has obtained little attention. Some studies refer to the ability of platelets to induce clot retraction by increasing contractile forces via binding of fibrinogen to integrins that will lead to increased clot strength. ${ }^{22,23}$ On the other hand, contraction of platelets is also described under non-coagulant conditions, demonstrating that it is independent of the presence of fibrin fibers. ${ }^{24}$ Furthermore, clot retraction is known to be dependent on integrin $\alpha$ llb $\beta 3$ outside-in signalling ${ }^{25,26}$ and phosphatidylserine-exposing platelets do not express active integrins at their surface, $^{19}$ which makes it unlikely that procoagulant platelets are active in clot 
retraction. Together, this would imply that, in a clot, the population of nonprocoagulant platelets retracts and hence provides elasticity to the fibrin.

Concerning the third point - a compensating role of platelets for the hypocoagulant effect of plasma dilution -, results of Chapter 3 indicate that platelets support the processes of thrombin generation and fibrin clot formation under conditions of extensive plasma dilution. This conclusion is drawn from in vitro experiments, showing that, at moderate plasma dilution (60\%), both thrombin and fibrin formation are less impaired in the presence of platelets than in the absence of platelets. While it is important to confirm these results with platelet-rich plasma from coagulopathic patients, they are in agreement with thromboelastography data with whole patient blood, showing that the maximal fibrin clot strength is related to the levels of platelets and fibrinogen. ${ }^{27}$ The compensatory function of platelets is most likely due to the secretion of substantial amounts of coagulation factors, including fibrinogen, factors V, VIII and XIII. ${ }^{28,29}$ Particularly under diluted plasma conditions, the secreted factors may well accelerate and improve the generation of thrombin and the formation of a stable fibrin clot. However, in case of severe dilution ( $>60 \%)$, also these platelet-derived factor levels will become limiting, since Chapter 3 shows that the addition of fresh frozen plasma (FFP) to (highly) diluted plasma results in partial restoration of thrombin generation even in the presence of platelets. Similarly, supplementation of fibrinogen or factor XIII to diluted plasma can restore the impaired fibrin clot formation in the presence of platelets.

Colloids, often infused to patients to maintain intravascular pressure, are notorious for their inhibitory effect on fibrin polymerizatio..$^{30}$ Interestingly, the data in Chapter 3 indicate that the colloid effect on stable clot formation is less pronounced in the presence of platelets, likely attributable to the same functions of platelets as described above. Also for the in vivo situation, it has been reported that transfusion of fibrinogen concentrate to coagulopathic patients results in increased fibrin clot formation despite pre-infusion of colloids, $^{31}$ but the role of platelets was not examined in this study.

\section{Plasma factors limiting the coagulation process in dilutional coagulopathy}

The conventional coagulation times, i.e. the activated partial thromboplastin time and prothrombin time are based on high, saturating concentrations of coagulation triggers (kaolin and tissue factor, respectively) to assess the lag time to plasma clotting. Although they are limitedly sensitive, these routine coagulation tests are not without value for the detection of impaired hemostasis, because to a certain point they do assess the risk of bleeding in several patient groups. In the present thesis, we 
reasoned that modern capacitive measurements of fully activated plasma, where not only the lag time but also the extent and time-course of coagulant activity is determined, will provide more and better information on the coagulation potential under diluted conditions. We also anticipated that combined measurements of capacitive thrombin generation and fibrin clot formation gives better information on hemostatic activity than either measurement alone. This was investigated in the studies of Chapters 3-5.

In Chapter 3 we set to determine optimal trigger conditions for the measurement of thrombin generation, aiming to fully activate the coagulation system of normal plasma. This was achieved by triggering the extrinsic pathway with $10 \mathrm{pM}$ tissue factor. In this condition, thrombin peak heights reach maximal levels in the presence of physiologically relevant platelet counts of $100 \times 10^{9} / \mathrm{l}$, or (for measurements without platelets) at $4 \mu \mathrm{M}$ procoagulant phospholipids. ${ }^{32}$ In the optimized setting, the thrombin peak height appears to be the most consistent parameter describing the activity of the coagulation process, likely since it reflects the velocity of the generated thrombin. ${ }^{33,34}$ As capacitive measurement of fibrin clot formation, we used the method of rotational thromboelastography. Similarly to thrombin generation, maximal levels of clot strength (maximal amplitude) were reached upon triggering with $10 \mathrm{pM}$ tissue factor, a platelet count of $100 \times 10^{9} / /$ or a phospholipid concentration of $4 \mu \mathrm{M}$. An important consequence of choosing these particular conditions is that a direct comparison can be made of the capacity of thrombin generation and fibrin clot formation in a single plasma sample. ${ }^{32}$

A pilot study performed with patients taking a vitamin $\mathrm{K}$ antagonist suggests that the thrombin generation potential of undiluted plasma relies on the levels of prothrombin and factor $X$. In a recent study by Dielis et al. to the determinants of thrombin generation in plasma from normal subjects, it is reported that, at low tissue factor trigger, especially the levels of fibrinogen and factor XII correlate with this process, while the anticoagulant factors, tissue factor pathway inhibitor (TFPI) and antithrombin, show a negative correlation. ${ }^{35}$ At high tissue factor, thrombin generation is determined in addition by the levels of prothrombin, factor $\mathrm{V}$ and protein $\mathrm{S} .{ }^{35,36}$ Component analysis performed by Vanschoonbeek et al. has revealed that the levels of (anti)coagulant factors are clustered in groups, so that, for instance, fibrinogen and factor $V$ are closely correlated, and hence the fibrinogen level acts as a confounder for factor $V$ rather than being a principal determinant of thrombin generation. ${ }^{36}$ Since the concentration of TFPI is in the low nanomolar range (Chapter 1) and the active level is considerably lower, TFPI likely acts by partial inactivation of low amounts of tissue factor trigger. Thus, in case of normal undiluted plasma, this leaves prothrombin, factor $V$ and $X$, protein $S$ and antithrombin as key determinants 
of the thrombin generation. The fact that prothrombin and factor $X$ are important for this process is indeed known for many years. ${ }^{37,38}$

Chapters 4 and 5 show that, at increasing plasma dilution, the thrombin generation process becomes more and more limited and is stronger dependent on the level of factor $X$ than on the level of prothrombin. This conclusion was drawn from analysis of the thrombin generation curves of plasmas from patients with different levels of coagulopathy due to coronary artery bypass graft surgery (moderate dilution) or major general surgery (more severe dilution). In line with this, FFP transfusion to the second group of patients resulted in an increased thrombin generation. ${ }^{39}$

Others have followed the process of thrombin generation in activated, diluted whole blood by measurements of the formation of thrombin-antithrombin complex. ${ }^{40}$ Although no specific information on the contribution of platelets was obtained in this study, the results indicated that thrombin generation measurements were capable of monitoring the effect of plasma dilution on the hemostatic state in healthy individuals. Another important discussion point is the effect of plasma dilution on the anticoagulant pathway. In undiluted normal plasma, it was shown that thrombin generation becomes suppressed by activation of protein $\mathrm{S}$ and $\mathrm{C}$ in a way involving TFPI. ${ }^{41,42}$ Upon dilution, this anticoagulation pathway may loose in activity and hence increase the thrombin generation process, although this is especially reported for tissue factor concentrations in the lower range. ${ }^{43}$ These literature data thus point to a procoagulant effect of (moderate) plasma dilution. However, in the present experiments (Chapter 3), such an effect was not detected at high, saturating concentrations of tissue factor. Since in major surgery and trauma, tissue factor will massively be exposed, the high tissue factor condition is clinically most relevant for these patients. From a different point of view, transfusion of coagulopathic patients with FFP has a net pro-hemostatic effect, which implies that the positive contribution of the procoagulant factors in FFP plasma will exceed the negative effect of the anticoagulant factors.

Unlike thrombin generation, the process of fibrin clot formation was found to be primarily dependent on the plasma fibrinogen level (Chapter 5). For instance, in plasma from patients where several factor levels except fibrinogen had been lowered by intake of a vitamin $\mathrm{K}$ antagonist, the formation of elastic fibrin clots as measured by thromboelastography remained near maximal. Fibrinogen level and fibrin clot formation already decreased at moderate dilution $(\sim 40 \%)$, e.g. as in plasmas from patients undergoing coronary artery bypass graft surgery. In vitro, supplementation of moderate diluted plasmas with only fibrinogen or factor XIII had a recovering effect on fibrin clot formation. Taken together, in the setting of dilutional 
coagulopathy, our results show that jointly the processes of thrombin and fibrin formation provide better information of the impaired effect of dilution on the clotting system than the routine coagulation tests, which only report on a prolonged lag time to clotting.

\section{Use of capacitive coagulation tests to predict bleeding in dilutional coagulopathy}

An important question is how the capacitive measurements can be used to monitor the coagulation potential in patients with dilutional coagulopathy, in particular their benefit for predicting the risk of bleeding. This question is relevant since the routine tests are rather insensitive for dilution and only poorly predict the bleeding in such patients. ${ }^{44,45}$ Chapters 4 and 5 also try to give an answer to this question.

In the studies, we compared two patient groups, i.e. with a moderate degree of dilution (patients undergoing coronary artery bypass graft surgery) and with more extensive dilution (patients undergoing major surgery, receiving FFP transfusion to stop bleeding). By comparison with undiluted plasmas from healthy subjects, thresholds were set for normal values of thrombin generation and fibrin clot formation. These values were then compared to the clinical outcome of FFP transfusion, i.e. persistent or stopped bleeding. It appeared that plasmas from 88$93 \%$ of the patients with persistent bleeding were sub-threshold in at least one of the capacitive assays, whether this was the case for only $40-53 \%$ of the patients with stopped bleeding or without bleeding. It is concluded that especially the combination of the two assays is relevant for evaluation of the extent of coagulopathy in case of bleeding. These findings hence argue for use of the capacitive coagulation tests in this clinical setting. Surely, we do advice further studies to validate this.

Table 7.1 gives an overview of the various patient groups that were studied in this thesis with respect to their clinical condition, the affected hemostatic parameters and the applicable transfusion therapies. From this table, it is apparent that bleeding increases with the extent of plasma dilution and the ensuing reduction in all (anti)coagulant factors. As explained in Chapters 1-3, once peri- or post-operative bleeding occurs, a more elaborate transfusion protocol is required. It should be noted that patients with major trauma, who were not extensively studied in this thesis, are often exposed to unfavorable environmental factors that even worsen the impaired coagulation state due to dilution. This is exemplified by the fact that these patients may often have platelet dysfunction or hyperfibrinolysis or increased activity of the thrombomodulin protein $C$ pathway. ${ }^{46}$ 
Table 7.1: Possible causes and consequences of dilutional coagulopathy for patient groups discussed in this thesis

\begin{tabular}{|c|c|c|c|c|}
\hline & $\begin{array}{l}\text { Anticoagulant } \\
\text { therapy }\end{array}$ & $\begin{array}{l}\text { CABG } \\
\text { surgery } \\
\text { (no bleeding) }\end{array}$ & $\begin{array}{l}\text { Major general } \\
\text { surgery + } \\
\text { major bleeding }\end{array}$ & $\begin{array}{l}\text { Major } \\
\text { trauma }\end{array}$ \\
\hline Thesis chapters & 1,5 & 3,5 & $1,2,4,5$ & 1,2 \\
\hline \multicolumn{5}{|c|}{ Relevance for clinical condition } \\
\hline $\begin{array}{l}\text { anticoagulant } \\
\text { medication }\end{array}$ & yes & yes & (no) & (no) \\
\hline $\begin{array}{l}\text { extracorporeal } \\
\text { circulation }\end{array}$ & no & yes & no & no \\
\hline $\begin{array}{l}\text { acidosis, hypothermia } \\
\text { extent of dilution }\end{array}$ & $\begin{array}{l}\text { no } \\
\text { none }\end{array}$ & $\begin{array}{l}\text { seldom } \\
\text { moderate }\end{array}$ & $\begin{array}{l}\text { seldom } \\
\text { severe }\end{array}$ & $\begin{array}{l}\text { regular } \\
\text { severe }\end{array}$ \\
\hline \multicolumn{5}{|c|}{ Affected hemostatic parameters } \\
\hline fibrinogen & no & yes & yes & yes \\
\hline prothrombin & yes & moderate & yes & yes \\
\hline factors VII, X & yes & moderate & yes & yes \\
\hline factors XIII & no & incidental & yes & yes \\
\hline platelets & no & yes & yes & yes \\
\hline hyperfibrinolysis & no & yes & incidental & yes \\
\hline \multicolumn{5}{|c|}{ Applicable transfusion therapy } \\
\hline crystalloids/colloids & no & yes & yes & yes \\
\hline packed red cells & no & yes & yes & yes \\
\hline fresh frozen plasma & incidental & yes & yes & yes \\
\hline fresh frozen plasma & no & yes & yes & yes \\
\hline
\end{tabular}

Abbreviations: $C A B G$, coronary artery bypass grafting.

\section{A model of progressively impaired coagulation in dilutional coagulopathy}

The results of the various studies in this thesis can be integrated into a model, explaining how different degrees of plasma dilution affect clotting and the hemostatic process. Upon moderate dilution, changes in the hemostatic profile become apparent from a reduction in fibrin clot formation due to limitation in fibrinogen, whereas the thrombin generation remains sufficiently high to be not ratelimiting for clot formation (Figure 7.2A). This implicates activities of prothrombinase and tenase are above a certain threshold value. Interestingly, in normal plasma fibrinogen is one of the most abundant coagulation factors, reaching a concentration of 6100-9200 nM (Chapter 1). Upon dilution, fibrinogen is considered to be the first factor that becomes limiting for normal hemostasis ${ }_{1}^{47}$ which indicates that adequate 


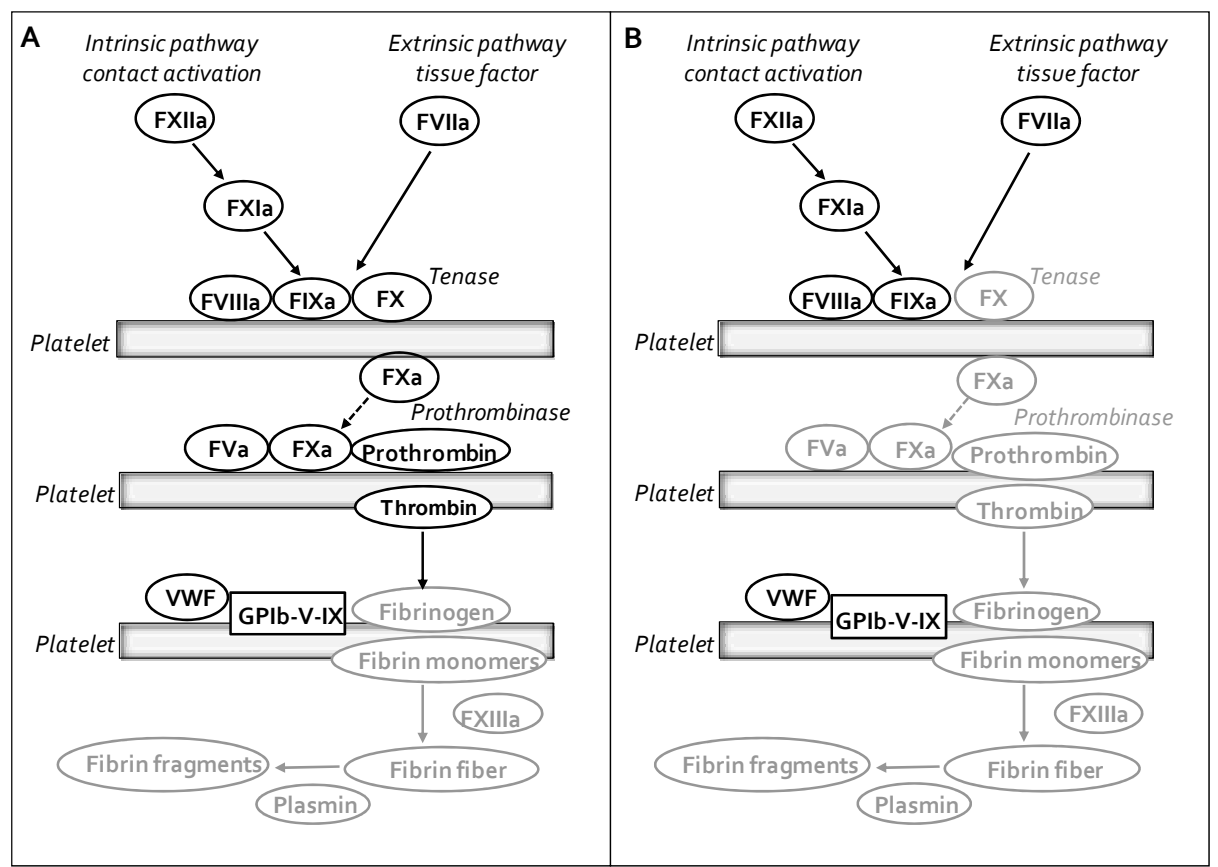

Figure 7.2: Limitations in coagulation at progressively severe dilutional coagulopathy. $A$. At moderate dilution, platelet-dependent tenase (factor $X$ activation) and prothrombinase (prothrombin activation) activities can still occur at non-limiting rates, but the fibrinogen level becomes a restrictive factor for fibrin clot formation. $B$. At more severe dilution, plasma concentrations of several coagulation factors become rate-limiting, so that at first prothrombinase and eventually tenase decrease in activities.

plasma fibrinogen concentrations are essential. In the situation of moderate dilution, platelets will also be present in non-limiting amount for supporting thrombin and fibrin formation. When the dilution is more severe, a situation can arise in which the process of thrombin generation becomes rate-limiting as a consequence of limited prothrombinase activity (Figure 7.2B). Interestingly, also prothrombin is present in normal plasma at a high concentration of $1150-1750 \mathrm{nM}$; obviously, it is a key determinant of the thrombin generation process. Low thrombin generation will have important consequences, given the multiple roles of thrombin in platelet activation and the coagulation process. For instance, this will slow down the formation of fibrin and the activation of a number of coagulation factors. In case of ongoing further dilution, it is not unlikely that a situation arises in which the formation of factor Xa by the tenase complex becomes rate-limiting, as we found that factor $X$ became the most important determinant of thrombin generation in case of severely diluted patients who required FFP transfusion (Chapter 5 ). The concentration of factor $X$ in 
undiluted plasma is $135-200 \mathrm{nM}$, indicating that lower levels of this factor than of prothrombin are sufficient for normal thrombin generation at physiological conditions.

Although this model is valuable for understanding the abnormal coagulation activities upon dilutional coagulopathy, the reality is more complex. For instance, some of the analyzed patient plasmas had normal values of thrombin generation but low fibrin clot formation; while other plasmas showed low thrombin generation and normal clot formation. Likely, the outcome of these tests is not only determined by the degree of dilution, but also by the pre-dilution values and the consumption of the various (anti)coagulation factors.

\section{Clinical implications for the transfusion practice}

The studies on thrombin generation and fibrin clot formation in peri-operative dilutional coagulopathy can provide a biochemical background for current transfusion strategies to prevent or stop massive bleeding. The following points are to be mentioned: (i) Sufficient numbers of platelets need to be present not only for aggregate formation, but also for extra delivery of coagulation factors and providing a procoagulant surface and clot retraction. (ii) Sufficient thrombin needs to be generated upon triggering, which requires the presence of minimal levels of prothrombin, factor $X$ and other coagulation factors. (iii) A threshold level of fibrinogen is required to ensure sufficient fibrin formation to produce a stable clot. Since the latter two processes are differently controlled by (anti)coagulation factors, likely the two capacitive coagulation assays need to be applied together.

The model postulated in Figure 2 predicts that, at moderate dilution, the clotforming process can be restored by administration of fibrinogen alone to restore normal hemostasis. However, at more severe dilution, additional coagulation factors implicated in prothrombinase and tenase activity likely need to be administered as well. So far, prothrombin complex concentrate has been given off-label in emergency cases or in small groups of patients undergoing specific surgical interventions, while there is already consensus about the administration of fibrinogen concentrate in massive bleeding..$^{31,48-50}$ However, application of these concentrates in large animal bleeding models has provided promising results. ${ }^{51,52}$

In the last years, the suitability of off-label use of recombinant factor VIla to stop massive bleeding in dilutional coagulopathy has been debated. ${ }^{53^{-55}}$ In the light of the findings of this thesis, it is expected that recombinant factor VIla can only restore impaired coagulation, if sufficiently high concentrations of other coagulation factors, in particular prothrombin and fibrinogen, are present to generate threshold amounts of thrombin and fibrin. Hence, a failure of recombinant factor VIla to stop bleeding 
Chapter 7

might be due to insufficient levels of other plasma factors. Hopefully, the mechanisms revealed in this thesis help in stimulating the discussion to alternative ways of transfusion practice, and in starting the necessary controlled clinical trials to test these alternative methods. If this will be the case, we have set a big step towards improvement of the treatment of acquired dilutional coagulopathy. 


\section{References}

1. Kumar R, Béguin S, Hemker HC. The effect of fibrin clots and clot-bound thrombin on the development of platelet procoagulant act ivity. Thromb Haemost 1995; 74:962-968.

2. Béguin S, Kumar R. Thrombin, fibrin and platelets: a resonance loop in which von Willebrand factor is a necessary link. Thromb Haemost 1997; 78:590-594.

3. Reverter JC, Béguin S, Kessels H, Kumar R, Hemker HC, Coller BS. Inhibition of plateletmediated, tissue factor-induced thrombin generation by the mouse/human chimeric $7 \mathrm{E}_{3}$ antibody. Potential implications for the effect of $\mathrm{C}_{7} \mathrm{E}_{3}$ Fab treatment on acute thrombosis and "clinical restenosis". J Clin Invest 1996; 98:863-874.

4. Butenas S, Cawthern KM, van't Veer C, DiLorenzo ME, Lock JB, Mann KG. Antiplatelet agents in tissue factor-induced blood coagulation. Blood 2001; 97:2314-2322.

5. Ilveskero S, Lassila R. Abciximab inhibits procoagulant activity but not the release reaction upon collagen- or clot-ad herent platelets. JThromb Haemost 2003; 1:805-813.

6. Van der Meijden PE, Feijge MA, Giesen PL, Huijberts M, van Raak LP, Heemskerk JW. Platelet $\mathrm{P}_{2} \mathrm{Y}_{12}$ receptors enhance signalling towards procoagulant activity and thrombin generation. A study with healthy subjects and patients at thrombotic risk. Thromb Haemost 2005; 93:1128-1136.

7. Van der Meijden PE. Interaction mechanisms of platelets and coagulation. Focus on $P_{2} Y_{12}$ receptor and factor XII. PhD Thesis, Maastricht University, Maastricht, The Netherlands. ISBN 978-90-5278-777-0. 2008.

8. Keularts IM, Béguin S, de Zwaan C, Hemker HC. Treatment with a GPIIb/Illa antagonist inhibits thrombin generation in platelet rich plasma from patients. Thromb Haemost 1998; 80:370-371.

9. Ruggeri ZM, Dent JA, Saldivar E. Contribution of dist inct adhesive interactions to platelet aggregation in flowing blood. Blood 1999; 94:172-178.

10. Goto S, Tamura N, Eto K, Ikeda Y, Handa S. Functional significance of adenosine 5'diphosphate receptor $\left(\mathrm{P}_{2} \mathrm{Y}_{12}\right)$ in platelet activation initiated by binding of von Willebrand factor to platelet GPIb $\alpha$ induced by conditions of high shear rate. Circulation 2002; 105:2531-2536.

11. Fontayne A, Meiring M, Lamprecht S, Roodt J, Demarsin E, Barbeaux P, Deckmyn H. The humanized anti-glycoprotein Ib monoclonal antibody h6B4-Fab is a potent and safe antithrombotic in a high shear arterial thrombosis model in baboons. Thromb Haemost 2008; 100:670-677.

12. Stoll G, Kleinschnitz C, Nieswandt B. Molecular mechanisms of thrombus formation in ischemic stroke: novel insights and targets for treatment. Blood 2008; 112:3555-3562.

13. Keuren JF, Ulrichts $H$, Feijge MA, Hamulyák $K$, Deckmyn $H$, Lindhout $T$, Heemskerk JW. Integrin $\alpha \mathrm{llb} \beta_{3}$ and shear-dependent action of glycoprotein $\mathrm{lb} \alpha$ stimulate plateletdependent thrombin formation in stirred plasma. J Lab Clin Med 2003; 141:350-358.

14. Béguin S, Keularts I, Al Dieri R, Bellucci S, Caen J, Hemker HC. Fibrin polymerization is crucial for thrombin generation in platelet-rich plasma in a VWF-GPIb-dependent process, defective in Bernard-Soulier syndrome. JThromb Haemost 2004; 2:170-176.

15. Dormann D, Clemetson KJ, Kehrel BE. The GPIb thrombin-binding site is essential for thrombin-induced platelet procoagulant activity. Blood 2000; 96:2469-2478. 
16. Keuren $J F$, Baruch $D$, Legendre $P$, Denis $C V$, Lenting $P J$, Girma JP, Lindhout $T$. von Willebrand factor $\mathrm{C}_{1} \mathrm{C}_{2}$ domain is involved in platelet adhesion to polymerized fibrin at high shear rate. Blood 2004; 103:1741-1746.

17. Endenburg SC, Hantgan RR, Lindeboom-Blokzijl L, Lankhof $H$, Jerome WG, Lewis JC, Sixma JJ, de Groot PG. On the role of von Willebrand factor in promoting platelet adhesion to fibrin in flowing blood. Blood 1995; 86:4158-4165.

18. Dale GL. Coated-platelets: an emerging component of the procoagulant response. J Thromb Haemost 2005; 3:2185-2192.

19. Munnix IC, Kuijpers MJ, Auger J, Thomassen CM, Panizzi P, van Zandvoort MA, Rosing J, Bock PE, Watson SP, Heemskerk JW. Segregation of platelet aggregatory and procoagulant microdomains in thrombus formation: regulation by transient integrin activation. Arterioscler Thromb Vasc Biol 2007; 27:2484-2490.

20. Velik-Salchner C, Haas T, Innerhofer P, Streif W, Nussbaumer W, Klingler A, Klima G, Martinowitz $U$, Fries $D$. The effect of fibrinogen concentrate on thrombocytopenia. J Thromb Haemost 2007; 5:1019-1025.

21. Rugeri L, Levrat A, David JS, Delecroix E, Floccard B, Gros A, Allaouchiche B, Negrier C. Diagnosis of early coagulation abnormalities in trauma patients by rotation thrombelastography. J Thromb Haemost 2007; 5:289-295.

22. Chakroun T, Gerotziafas GT, Seghatchian J, Samama MM, Hatmi M, Elalamy I. The influence of fibrin polymerization and platelet-mediated contractile forces on citrated whole blood thromboelastography profile. Thromb Haemost 2006; 95:822-828.

23. Mousa SA, Khurana S, Forsythe MS. Comparative in vitro efficacy of different platelet glycoprotein IIb/llla antagonists on platelet-mediated clot strength induced by tissue factor with use of thromboelastography: differentiation among glycoprotein Ilb/llla antagonists. Arterioscler Thromb Vasc Biol 2000; 20:1162-1167.

24. Ono A, Westein E, Hsiao S, Nesbitt WS, Hamilton JR, Schoenwaelder SM, Jackson SP. Identification of a fibrin-independent platelet contractile mechanism regulating primary hemostasis and thrombus growth. Blood 2008; 112:90-99.

25. Shattil SJ. Function and regulation of the $\beta_{3}$ integrins in hemostasis and vascular biology. Thromb Haemost 1995; 74:149-155.

26. Shattil SJ, Newman PJ. Integrins: dynamic scaffolds for adhesion and signaling in platelets. Blood 2004; 104:1606-1615.

27. Reinhofer M, Brauer M, Franke U, Barz D, Marx G, Losche W. The value of rotation thromboelastometry to monitor disturbed perioperative haemostasis and bleeding risk in patients with cardiopulmonary bypass. Blood Coagul Fibrinolysis 2008; 19:212-219.

28. Kaplan KL, Broekman MJ, Chernoff A, Lesznik GR, Drillings M. Platelet $\alpha$-granule proteins: studies on release and subcellular localization. Blood 1979; 53:604-618.

29. Monroe DM, Hoffman M, Roberts HR. Platelets and thrombin generation. Arterioscler Thromb Vasc Biol 2002; 22:1381-1389.

30. Innerhofer $P$, Fries D, Margreiter J, Klingler A, Kuhbacher G, Wachter B, Oswald E, Salner $E$, Frischhut $B$, Schobersberger $W$. The effects of perioperatively administered colloids and crystalloids on primary platelet-mediated hemostasis and clot formation. Anesth Analg 2002; 95:858-865. 
31. Fenger-Eriksen $C$, Jensen $T M$, Kristensen $B S$, Jensen $K M$, Tonnesen $E$, Ingerslev $J$, Sorensen B. Fibrinogen substitution improves whole blood clot firmness after dilution with hydroxyethyl starch in bleeding patients undergoing radical cystectomy: a randomized, placebo-controlled clinical trial. J Thromb Haemost 2009; 7:795-802.

32. Schols SE, Feijge MA, Lancé MD, Hamulyák $K$, ten Cate $H$, Heemskerk JW, van Pampus EC. Effects of plasma dilution on tissue-factor-induced thrombin generation and thromboelastography: partly compensating role of platelets. Transfusion 2008; 48:2384-2394.

33. Hemker HC, Al Dieri R, de Smedt E, Béguin S. Thrombin generation, a function test of the haemostatic-thrombotic system. Thromb Haemost 2006; 96:553-561.

34. Mann KG, Whelihan MF, Butenas S, Orfeo T. Citrate anticoagulation and the dynamics of thrombin generation. J Thromb Haemost 2007; 5:2055-2061.

35. Dielis AW, Castoldi E, Spronk HM, van Oerle R, Hamulyák K, ten Cate $H$, Rosing J. Coagulation factors and the protein $\mathrm{C}$ system as determinants of thrombin generation in a normal population. J Thromb Haemost 2008; 6:125-131.

36. Vanschoonbeek K, Feijge MA, van Kampen RJ, Kenis H, Hemker HC, Giesen PL, Heemskerk JW. Initiating and potentiating role of platelets in tissue factor-induced thrombin generation in the presence of plasma: subject-dependent variation in thrombogram characteristics. J Thromb Haemost 2004; 2:476-484.

37. Hemker $\mathrm{HC}$, Béguin S. Mode of action of unfractionated and low molecular weight heparins on the generation of thrombin in plasma. Haemostasis 1990; 20:81-92.

38. Butenas S, van't Veer C, Mann KG. "Normal" thrombin generation. Blood 1999; 94:2169-2178.

39. Schols SE, van der Meijden PE, van Oerle R, Curvers J, Heemskerk JW, van Pampus EC. Increased thrombin generation and fibrinogen level after therapeutic plasma transfusion: relation to bleeding. Thromb Haemost 2008; 99:64-70.

40. Brummel-Ziedins $K$, Whelihan MF, Ziedins EG, Mann KG. The resuscitative fluid you choose may potent iate bleeding. J Trauma 2006; 61:1350-1358.

41. Maurissen LF, Thomassen MC, Nicolaes GA, Dahlback B, Tans G, Rosing J, Hackeng TM. Re-evaluation of the role of the protein $\mathrm{S}-\mathrm{C}_{4} \mathrm{~b}$ binding protein complex in activated protein C-catalyzed factor Va-inactivation. Blood 2008; 111:3034-3041.

42. Rosing J, Maurissen LF, Tchaikovski SN, Tans G, Hackeng TM. Protein S is a cofactor for tissue factor pathway inhibitor. Thromb Res 2008; 122 S60-S63.

43. De Smedt $E$, Wagenvoord R, Hemker HC. The technique of measuring thrombin generation with fluorogenic substrates: 3 . The effects of sample dilution. Thromb Haemost 2009; 101:165-170.

44. Kitchens CS. To bleed or not to bleed? Is that the question for the PTT? J Thromb Haemost 2005; 3:2607-2611.

45. Martini WZ, Cortez DS, Dubick MA, Park MS, Holcomb JB. Thrombelastography is better than PT, aPTT, and activated clotting time in detecting clinically relevant clotting abnormalities after hypothermia, hemorrhagic shock and resuscitation in pigs. J Trauma 2008; 65:535-543.

46. Brohi K, Cohen MJ, Ganter MT, Schultz MJ, Levi M, Mackersie RC, Pittet JF. Acute coagulopathy of trauma: hypoperfusion induces systemic anticoagulation and hyperfibrinolysis. J Trauma 2008; 64:1211-1217. 
47. Hiippala ST, Myllyla GJ, Vahtera EM. Hemostatic factors and replacement of major blood loss with plasma-poor red cell concentrates. Anesth Analg 1995; 81:360-365.

48. Key NS, Negrier C. Coagulation factor concentrates: past, present, and future. Lancet 2007; 370:439-448.

49. Haas T, Fries D, Velik-Salchner C, Oswald E, Innerhofer P. Fibrinogen in craniosynostosis surgery. Anesth Analg 2008; 106:725-731.

50. Weinkove R, Rangarajan S. Fibrinogen concentrate for acquired hypofibrinogenaemic states. Transfus Med 2008; 18:151-157.

51. Dickneite G. Prothrombin complex concentrate versus recombinant factor VIla for reversal of coumarin anticoagulation. Thromb Res 2007; 119:643-651.

52. Dickneite G, Pragst I. Prothrombin complex concentrate vs fresh frozen plasma for reversal of dilutional coagulopathy in a porcine trauma model. $\mathrm{Br} J$ Anaesth 2009; 102:345-354.

53. Friederich PW, Henny CP, Messelink EJ, Geerdink MG, KellerT, Kurth KH, Buller HR, Levi $M$. Effect of recombinant activated factor VII on perioperative blood loss in patients undergoingretropubic prostatectomy: a double-blind placebo-controlled randomised trial. Lancet 2003; 361:201-205.

54. Williams D, McCarthy R. Recombinant activated factor VII and perioperative blood loss. Lancet 2003; 361:1745.

55. Berkhof FF, Eikenboom JC. Efficacy of recombinant activated Factor VII in patients with massive uncontrolled bleeding: a retrospective observational analysis. Transfusion 2009; 49:570-577. 
Summary 


\section{Thrombin generation in dilutional coagulopathy}

Patients, who suffer from massive blood loss during major surgery or experience severe trauma, are infused with large volumes of fluids and blood products. In the patient plasma, this inevitably leads to further dilution of the blood components and cells. Optimal hemostasis requires the presence of minimal levels of platelets and coagulation factors, since these mediate the formation of platelet aggregates, thrombin and a fibrin clot, all of which are necessary to stop a bleeding event. Massive infusion of fluids (colloids and crystalloids) and blood products (erythrocyte and platelet suspensions) often disturbs the patient's ability to form a strong fibrin clot, and increases the risk of (persistent) bleeding problems. This clinical condition is referred to as dilutional coagulopathy, and is difficult to treat. In the current clinical practice, the impaired coagulation of a patient is monitored with routine coagulation tests, i.e. the activated partial thromboplastin time, the prothrombin time and the international normalized ratio. However, these tests are notoriously insensitive for conditions of dilution. Nowadays, there is growing interest in the use of so-called capacitive coagulation tests, i.e. thrombin generation and thromboelastography, which give information not only of the lag time to coagulation, but also of the maximal capacity of plasma to generate thrombin and elastic fibrin clots, respectively. In the present thesis, it is aimed to unravel the biochemical mechanism of dilutional coagulopathy by capacity measurements of thrombin generation and fibrin clot formation.

In chapter 1, the clinical situation of dilutional coagulopathy is explained, and the conditions are described that can worsen this deficiency. Normal hemostasis upon vascular damage is the result of a complex interplay of mechanisms, where platelets become activated, form an aggregate and expose phosphatidylserine at their surface, which greatly facilitates the binding and activation of coagulation factors. Thrombin is generated and mediates the conversion of fibrinogen into fibrin, which together with red cells and platelets form a massive fibrin clot that stops a bleeding. In dilutional coagulopathy, the loss and consumption of platelets and coagulation factors and the routine fluid transfusion can lead to a vicious circle, in which coagulation becomes even more impaired, and a life-threatening situation can occur. The current treatment regime tends to increase the overall dilution.

In chapter 2, an overview is provided of current transfusion protocols for massive blood loss. There is international consensus on consecutive transfusion of fluids (crystalloids and colloids), red cell concentrates, fresh frozen plasma (FFP), and platelet concentrates. The transfusions are routinely guided by the outcome of routine coagulation tests and blood cell counts. It is argued that measurement of the processes of thrombin generation and fibrin clot formation will give better 
biochemical information on the coagulant activity in plasma from patients with dilutional coagulopathy and, likely, of the bleeding risk of the patients. Also the outcome of new transfusion protocols may better be monitored by using these two capacitive coagulation assays. However, both methods have hardly been used in this clinical setting. In the following chapters, research is described to do so.

Chapter 3 describes a study to determine the optimal conditions for measurement of thrombin generation and fibrin clot formation in plasmas from patients with dilutional coagulopathy. The most representative parameter for thrombin generation was the thrombin peak height, and for fibrin clot formation the maximal amplitude of rotational thromboelastography. Activation of plasma with a high concentration of tissue factor was required to establish the maximal capacity of plasma of thrombin generation and fibrin clot formation. This capacity was measured in the presence of platelets or phospholipids as procoagulant lipid surface. It appeared that the addition of platelets could compensate for the effect of dilution up to $60 \%$ plasma, without impairment of thrombin generation and fibrin clot formation. Dilution of plasma with colloids led to a reduced elasticity of fibrin clots, but not to altered thrombin generation. Additional investigations were performed to determine whether in vitro supplementation of factors to diluted plasma could restore the coagulation process. Combining diluted plasma with FFP resulted in an increased thrombin generation and fibrin clot formation. Supplementation of factor XIII or fibrinogen concentrate to diluted plasma led to a recovery of fibrin clot formation, but not of thrombin generation. Taken together, these results show that the two capacitive measurements report on activity of different parts of the coagulation process, and that platelets are essential to keep the clotting ability of diluted plasma at a certain minimal level.

Transfusion of FFP is a common intervention to treat dilutional coagulopathy. The effect of this transfusion on the coagulant activity of patient plasmas was studied in chapter 4 . Blood samples were obtained during or after major general surgery from patients, who experienced massive bleeding due to prior dilution. After FFP transfusion, bleeding stopped in the majority of the patients, whereas it continued in about one third of the patients. After the intervention, thrombin generation in plasma on average increased, however without fully recovering to the level measured in undiluted normal pool plasma. Coagulation variables were then compared of patients with stopped bleeding and of patients with persistent bleeding. Interestingly, after FFP transfusion, plasma from patients with persistent bleeding showed significantly lower thrombin generation and fibrinogen levels than plasma from patients in whom bleeding stopped. On the other hand, routine coagulation times were not different between the two patient groups. These results pointed to a 
possible relation between the stop of bleeding and the values of thrombin generation and fibrinogen in plasma.

In chapter 5, further research was performed to identify the coagulation problems during peri-operative dilution. In plasma from patients, who had taken a vitamin $\mathrm{K}$ antagonist, thrombin generation was markedly reduced, while fibrin clot formation was only delayed but not reduced. Hence, both assays provide information on the activity of different parts of the coagulation process. In order to discriminate between different degrees of dilutional coagulopathy, threshold levels of normal thrombin generation and fibrin clot formation were set, below which these two processes were considered to be impaired. Using these threshold values, both thrombin generation and fibrin clot formation appeared to be in the normal range for most plasmas from patients, who were subjected to moderate dilution during a cardiopulmonary surgery procedure. However, both processes were markedly impaired in plasmas from patients, who had undergone major general surgery and had experienced massive blood loss. This difference in hemostatic activity between the groups of patients with moderate and severe dilution was not detected with routine coagulation tests. The results further indicate that the determination of both thrombin generation and fibrin clot formation is of additional value in predicting the extent of peri-operative dilutional coagulopathy. Likely, measurement of both processes will better predict the risk of bleeding than the routine coagulation tests.

Platelets are essential in the formation of a thrombus following vascular damage. They are known to interact directly with fibrin via integrin $\alpha \mathrm{llb} \beta_{3}$, but in addition platelets can adhere via glycoprotein (GP)Ib-V-IX to von Willebrand factor (VWF) that is bound to fibrin. In chapter 6 a novel mechanism is described that platelets, conversely, are also involved in the formation of fibrin fibers under conditions of lowshear flow. Using high-resolution microscopic technologies, it was established that individual platelets develop a star-like network of fibrin fibers on their surface, when they are exposed to flowing plasma under conditions of thrombin generation. This fibrin formation was preceded by a rise in intracellular $\mathrm{Ca}^{2+}$-concentration, exposure of phosphatidylserine, and formation of thrombin. Blockage of the interaction of GPIb-V-IX with VWF prevented this star-like fibrin formation, whereas inhibition of integrin $\alpha$ llb $\beta_{3}$ was hardly effective. In addition, minor or no fibrin formation was seen in plasmas from patients with von Willebrand disease. Similarly, platelets from mice deficient in VWF or GPIba failed to form fibrin fibers, such in contrast to matched wildtype platelets. Together, these results point to a new function of GPIbV-IX interaction with VWF, namely to trigger the formation of fibrin fibers.

In chapter 7 the principal findings of this thesis are discussed in the light of recent literature. A central place has the discussion on new interaction mechanisms between 
platelets, thrombin and fibrin. In addition, it is concluded that thrombin generation and fibrin clot formation in the presence of platelets are important to stop persistent bleeding in case of peri-operative dilutional coagulopathy. With the new capacitive coagulation tests and the available factor concentrates, it is foreseen that improved transfusion protocols can be developed, aimed to interfere in those places of the coagulation system where the deficiency is most eminent. The results described in this thesis will hopefully contribute to this development in transfusion medicine. 

Samenvatting 


\section{Trombinegeneratie en fibrinevorming bij verdunningscoagulopathie}

Tijdens grote chirurgische ingrepen of na een ernstig trauma kunnen patiënten veel bloed verliezen. Dit bloedverlies wordt gecompenseerd door het geven van infusievloeistoffen en bloedproducten. Een nadelig gevolg van dergelijke transfusies is dat daarbij verdunning optreedt van het bloedplasma en de bloedcellen. Voor een optimale hemostase zijn minimale concentraties van bloedplaatjes en stollingsfactoren in het bloed nodig om via plaatjesactivering en trombinevorming een fibrinestolsel te maken, waarmee een bloeding gestopt kan worden. Door infusie van vloeistoffen en bloedproducten kan het vermogen van een patiënt om voldoende fibrinestolsels te maken in gevaar komen, waardoor het risico op bloedingen toeneemt en bestaande bloedingen niet gestopt kunnen worden. De ontstane klinische situatie, ook wel een verdunningscoagulopathie genoemd, is moeilijk te behandelen. In de klinische praktijk worden stollingsstoornissen geëvalueerd met behulp van routine stollingstesten, waaronder de geactiveerde partiële tromboplastinetijd, de protrombinetijd en de hiervan afgeleide internationaal genormaliseerde ratio. Het is echter gebleken dat deze stollingstijden niet nauwkeurig genoeg zijn om de stollingsstatus van patiënten die verdund zijn goed te meten. In de laatste jaren is er een toename in het gebruik van zogenaamde capacitieve stollingstesten, zoals de trombinegeneratiemeting en de tromboelastografie, die een indruk geven van het totaal vermogen van het plasma om trombine te maken en een elastisch fibrinestolsel te vormen. Door zowel trombinegeneratie als fibrinestolselvorming te meten is getracht in dit proefschrift het mechanisme te ontrafelen dat ten grondslag ligt aan de verminderde werking van het stollingssysteem tijdens verdunning. Door een beter begrip van stollingsstoornissen als gevolg van verdunning, kan hopelijk in de toekomst een meer gerichte therapie gegeven worden, waardoor de bestaande tranfusieprotocollen voor massaal bloedverlies kunnen worden verbeterd.

Het inleidende hoofdstuk 1 beschrijft het ontstaan van peri-operatieve stollingsstoornissen als gevolg van bloedverdunning en de factoren die deze situatie kunnen verergeren. Adequate hemostase na beschadiging van een vaatwand bestaat uit vele interactie-mechanismen waarbij plaatjes na adhesie aan vaatwandcomponenten geactiveerd worden, waarbij ze aggregeren en het fosfolipide fosfatidylserine (PS) op hun celoppervlak exposeren. Dit stelt stollingsfactoren in staat om een complex te vormen, waardoor de stollingscascade op gang komt. Door de vorming van trombine wordt fibrinogeen omgezet in fibrine, dat dan samen met plaatjes en rode bloedcellen een fibrinestolsel vormt, waardoor een bloeding gestopt wordt. Door een samenspel van verbruik en verlies van plaatjes en stollingsfactoren en door het massaal toedienen van transfusieproducten kan bij bloedverdunning een 
vicieuze cirkel ontstaan, waarin bestaande stollingsstoornissen kunnen verergeren. De huidige behandelingsopties om het bloedvolume te handhaven en bloedverlies te laten stoppen, hebben tot gevolg dat alleen bepaalde bloedcomponenten worden aangevuld in nog steeds verdunde vorm, met als gevolg dat de verdunning als zodanig slechts ten dele ongedaan wordt gemaakt.

Een overzicht van de meest gebruikte transfusieprotocollen bij massaal bloedverlies is gegeven in hoofdstuk 2. Het blijkt dat er een algemene consensus bestaat voor de wijze van transfusie van rode bloedcellen, plaatjes en vers ingevroren plasma (FFP). Deze is gebaseerd op het uitvoeren van routine stollingstesten en bloedceltellingen. In dit hoofdstuk wordt betoogd dat door een biochemische analyse van de stollingsstatus van patiënten met stollingsstoornissen als gevolg van verdunning, een goede inschatting gemaakt kan worden van een eventueel verhoogd risico op massaal bloedverlies. In het bijzonder kunnen metingen van de trombinegeneratie en de fibrinevorming bijdragen tot zo'n biochemische analyse. Waarschijnlijk dienen allebei de processen gemeten te worden, omdat ze gereguleerd worden door ten dele verschillende pro- en antistollingsfactoren. Door het tegelijk uitvoeren van deze capaciteitstesten kunnen nieuwe transfusieprotocollen beter geëvalueerd worden. Echter deze meetmethoden waren nog niet voldoende gevalideerd om een goede klinische toepasbaarheid te garanderen. In de volgende hoofdstukken is een start gemaakt met deze validatie.

Voor het evalueren van de stollingsstatus bij patiënten met verdunningscoagulopathie was het noodzakelijk om de optimale condities te bepalen, waaronder de trombinegeneratie en fibrinevorming in plasma gemeten kunnen worden. Het onderzoek hiernaar staat beschreven in hoofdstuk 3. De meest representatieve parameter voor trombinegeneratiemeting bleek de piekhoogte te zijn, en voor de fibrinevorming de maximale rotatie-amplitude van de trombo-elastografie. Activeren van plasma met een hoge concentratie weefselfactor was nodig om een waarde te krijgen van het maximaal stollend vermogen. Dit maximaal stollend vermogen werd gemeten in plasma dat ofwel plaatjes ofwel fosfolipiden bevatte. Gebleken is dat de aanwezigheid van plaatjes een plasmaverdunning tot $60 \%$ kon compenseren, zonder dat er een effect op de trombinegeneratie of fibrinevorming detecteerbaar was. Plasmaverdunning met colloïden resulteerde in een minder elastisch fibrinestolsel, zonder dat de trombinegeneratie verminderd werd. In dit hoofdstuk is verder beschreven hoe factorconcentraten een verminderde stolling als gevolg van verdunning kunnen herstellen. Het mengen van FFP met (patiënten)plasma leidde tot een stijging van zowel de trombinegeneratie als de fibrinevorming. Toevoeging van factor XIII of fibrinogeen aan verdund plasma resulteerde in herstel van de fibrinevorming, maar had geen invloed op de trombinegeneratie. Samengevat laten 
deze resultaten zien dat beide capacitatieve testen gevoelig zijn voor een verschillende deel van het stollingsproces, en dat plaatjes van essentieel belang zijn om bij coagulopathie het stollend vermogen van het plasma voldoende hoog te houden.

Bij de behandeling van peri-operatieve verdunningscoagulopathie worden regelmatig transfusies met FFP gegeven. Het effect hiervan op het stollend vermogen bij dergelijke patiënten is bestudeerd in hoofdstuk 4 . Hierbij is gebruik gemaakt van de geoptimaliseerde testcondities van het voorgaande hoofdstuk. Metingen werden uitgevoerd met plasmamonsters verzameld van een aantal patiënten, die tijdens of vlak na een grote chirurgische ingreep stollingsstoornissen ontwikkelden en daardoor massaal bloedverlies vertoonden. Na transfusie met FFP bleek, als verwacht, een groot deel van de patiënten gestopt te zijn met bloeden. Echter meer dan één derde van de patiënten toonde persisterend bloedverlies. Na de transfusie was er een gemiddelde stijging van de trombinegeneratie voor de hele groep patiënten, alhoewel deze meting altijd onder de normaalwaarde in onverdund plasma bleef. Vervolgens is er een vergelijkende analyse uitgevoerd van de stollingstijden in de plasmas, de factorconcentraties en de trombinegeneratiemetingen. Hieruit kwam naar voren dat de patiënten met persisterend bloedverlies na transfusie een trombinegeneratie en een plasma fibrinogeenspiegel hadden, die duidelijk lager waren dan de waarden van patiënten bij wie de bloedingen gestopt waren, terwijl de stollingstijden in beide groepen niet verschillend waren. Samengevat geven deze resultaten aan dat voldoende trombinegeneratie en voldoende fibrinogeen samen kunnen bijdragen tot het stoppen van persisterend bloedverlies bij coagulopathie.

In hoofdstuk $\mathbf{5}$ is vervolgonderzoek verricht naar stollingsstoornissen die optreden na verdunning tijdens grote chirurgische ingrepen. In het plasma van patiënten die een vitamine- $K$ antagonist gebruikten, was de trombinegeneratie sterk verlaagd, terwijl de fibrinevorming alleen verlengd was maar niet verminderd. Hieruit blijkt dat beide testen informatie geven over een verschillend deel van het stollingssysteem. Om de mate van stollingsstoornis door verdunning te kunnen bepalen zijn drempelwaarden opgesteld, waaronder de trombinegeneratie en fibrinevorming als afwijkend worden beschouwd. In het merendeel van de plasmamonsters van patiënten die matig waren verdund tijdens een cardiopulmonale chirurgische ingreep, bleek zowel de trombinegeneratie als de fibrinevorming boven deze drempelwaarden te zitten. In het overgrote deel van de plasmamonsters afkomstig van sterk verdunde patiënten met peri-operatief bloedverlies waren beide processen afwijkend. Zo'n onderscheid kon niet worden aangetoond met de routine stollingstesten. De resultaten tonen verder aan dat het vitvoeren van beide testen 
een meerwaarde heeft bij de voorspelling van de mate van verdunningscoagulopathie en uiteindelijk optredende bloeding.

Het is bekend dat plaatjes een rol spelen bij de trombusvorming als gevolg van vaatwandschade. Plaatjes kunnen rechtstreeks aan fibrine hechten via integrine $\alpha \mathrm{llb} \beta_{3}$, maar ook aan fibrine-gebonden von Willebrand factor (VWF) middels glycoproteïne (GP)Ib-V-IX. Een nieuw mechanisme hoe plaatjes betrokken zijn bij de vorming van fibrine onder stromingscondities is beschreven in hoofdstuk 6 . Door gebruik te maken van hoge resolutie microscopie is aangetoond dat individuele plaatjes op hun oppervlak een stervormige groei van fibrinevezels laten ontstaan, wanneer zij blootgesteld werden aan stromend plasma onder condities van trombinegeneratie. Deze fibrinevorming werd voorafgegaan door een stijging van de intracellulaire $\mathrm{Ca}^{2+}$-concentratie, expositie van PS, en vorming van trombine op het plaatjesoppervlak. Door het remmen van de interactie van GPIb-V-IX met VWF stopte de stervormige fibrinevorming, terwijl blokkade van integrine $\alpha$ llb $\beta_{3}$ nauwelijks effect had. Verder vond nauwelijks fibrinevorming plaats met VWF-arm plasma afkomstig van patiënten met von Willebrand ziekte. Ook bij muizen die deficiënt waren in VWF of GPIba bleken de plaatjes geen fibrine meer te vormen. Deze resultaten wijzen op een nieuwe functie van GPIb-V-IX in interactie met VWF, namelijk bij de vorming van fibrinevezels.

De algemene discussie, die in hoofdstuk 7 is gegeven, beschouwt de resultaten van dit proefschrift aan de hand van recente literatuur. Centraal hierbij staat bespreking van nieuw gevonden interactiemechanismen tussen plaatjes, trombine en fibrine. Verder is geconcludeerd dat trombinegeneratie en fibrinevorming in aanwezigheid van plaatjes van belang zijn om in het geval van peri-operatieve stollingsstoornissen, persisterend bloedverlies te laten stoppen. Aan de hand van de ontwikkelde testen, kunnen samen met de sinds kort in opkomst zijnde factorconcentraten, vernieuwde transfusieprotocollen opgesteld worden, die daar ingrijpen in het stollingssysteem waar zich de deficiëntie bevindt. De in dit proefschrift beschreven resultaten helpen mogelijkerwijs om verbetering in de transfusiegeneeskunde tot stand te brengen. 



\title{
Addendum \\ Trombo-elastografie: Een hulpmiddel bij massaal bloedverlies?
}

\author{
Saskia E.M. Schols en Elisabeth C.M. van Pampus
}

Tijdschrift voor bloedtransfusie 2009; 2:39-46

Artikel is herdrukt met toestemming van Ariez Medical Publishing 


\section{Samenvatting}

De stollingsstatus van patiënten met massaal bloedverlies na grote chirurgie en trauma wordt momenteel nog steeds geëvalueerd met de conventionele stoltesten waaronder de PT, aPTT en INR, ondanks het toenemende inzicht over de ongevoeligheid van deze testen voor het monitoren van de stollingscapaciteit tijdens massaal bloedverlies. De hernieuwde methode van de trombo-elastografie maakt het mogelijk onder viteenlopende condities kwalitatieve informatie te geven over de sterkte van fibrinestolsels. In de huidige literatuur wordt de toepassing van de trombo-elastografie vooral beschreven in beperkte observationele klinische studies betreffende cardiale chirurgie en trauma. Hieruit blijkt de zeer geringe positief voorspellende waarde voor bloedverlies van de methode. Als onderdeel van "een transfusiebeleid op maat", heeft de toepassing van de trombo-elastografie in veel gevallen tot gevolg dat zowel het aantal transfusies als het aantal bloedproducten per patiënt afneemt. Zolang er geen grote multi-center gerichte klinische studies worden verricht voor een optimale validatie van de trombo-elastografie met de huidige routine stoltesten, zal de waarde van de trombo-elastografie als diagnostisch instrument in de hematologische laboratoria en de tranfusiegeneeskunde beperkt blijven.

\section{Inleiding}

Massaal bloedverlies kan, ongeacht de oorzaak, leiden tot een verworven coagulopathie en viteindelijk zelfs tot verbloeding. Enerzijds verbetert vroegtijdige en agressieve resuscitatie met bloedproducten de prognose, anderzijds dragen bloedproducten bij aan de inflammatoire reponse met een verhoogde morbiditeit en mortaliteit. Onnodige transfusies moeten dan ook voorkomen worden. Een gericht transfusiebeleid vraagt om een eenvoudige, en snelle diagnostische test, betrouwbaar en informatief over de actuele stollingsstatus van de patiënt. Gezien het spoedeisende karakter van massaal bloedverlies is de factor tijd daarbij van zeer groot belang. Vaak is coagulopathie een klinische diagnose, waarbij het niet bekend is hoeveel "stolling" daadwerkelijk nodig is om een bloeding te laten stoppen en is deze "behoefte aan stollingsfactoren" ook niet hetzelfde voor alle situaties.

De huidige transfusie richtlijnen zijn gebaseerd op "minimale factor concentraties" (ongeveer $20 \%$ van normaal), en berusten op conventionele stoltesten zoals de protrombine tijd (PT), de geactiveerde partiële tromboplastine tijd (aPTT), en het fibrinogeen niveau. ${ }^{1}$ Deze factor percentages zijn geëxtrapoleerd uit studies met patiënten die vitamine $\mathrm{K}$-antagonisten gebruiken of aangeboren factordeficiënties hebben. De conventionele stoltesten worden uitgevoerd in gecentrifugeerd bloedplaatjes arm citraat plasma en geven daarom geen informatie 
over de interactie tussen bloedplaatjes en erytrocyten met (procoagulante- en anticoagulante) stollingsfactoren en pro- en antifibrinolyse eiwitten. Verder zijn deze testen ongevoelig voor een tekort aan factor XIII, voor fibrinolyse en niet bruikbaar tijdens toediening van hoge doses heparine. De bepalingen worden uitgevoerd bij een temperatuur van $37^{\circ} \mathrm{C}$, wat niet altijd overeenkomt met de temperatuur van de patiënt. Bovendien zijn de conventionele stoltesten ongevoelig voor verdunningen en hypocoagulante condities die optreden tijdens resuscitatie met colloïden bij massaal bloedverlies. $^{2}$

De methode van de trombo-elastografie is voor het eerst beschreven door Hartert in 1948. In eerste instantie werd deze methode toegepast in het gebied van lever transplantaties, later in het gebied van de cardiale chirurgie, waarbij vanaf de jaren 80 een hernieuwde interesse in de techniek ontstond. ${ }^{3,4}$ Dit is te verklaren door een verandering in de wijze waarop over het stollingsmechanisme gedacht wordt; van stolling als het resultaat van een opeenvolgende activatie van stollingsfactoren, naar de verandering van de trombine en fibrinevorming als resultaat van de interactie tussen cellen en stollingsfactoren. In tegenstelling tot de PT en de aPTT, waarbij op het eindpunt van de test slechts een kleine hoeveelheid trombine of fibrine is gevormd, geeft de methode van de trombo-elastografie binnen 10-30 minuten informatie over de kinetiek van de fibrine vorming en afbraak in aanwezigheid van bloedplaatjes en erytrocyten. De methode van de trombo-elastografie kan worden uitgevoerd aan het bed van de patiënt, gecorrigeerd voor pH en temperatuur. Daarbij tegemoet komend aan één van de bezwaren van de conventionele stollingstesten. Echter, ook in de methode van de trombo-elastografie blijft de invloed van bloedstroming en het effect van de interactie met de vaatwand op de bloedstolling, van essentieel belang in vivo, buiten beschouwing.

Momenteel wordt de methode van de trombo-elastografie het meest toegepast bij patiënten met massaal bloedverlies, zoals traumapatiënten, patiënten na een cardiochirurgische ingreep, patiënten die een levertransplantatie ondergaan en patiënten met een ernstige fluxus post partum. In het bijzonder in Duitsland en Oostenrijk is de methode van de trombo-elastografie in een aantal ziekenhuizen reeds ingebed in de dagelijkse routine op operatie kamers en als onderdeel van transfusiealgoritmes. ${ }^{5,6}$ In Nederland wordt deze techniek momenteel nog niet op grote schaal toegepast. Er ontbreekt duidelijkheid over de analytische vragen van de test (welke activatoren, bewaarduur en plaats van bloedafname, man-vrouw verschillen) en daaraan gekoppeld de klinische relevantie van de resultaten. In het hierna volgende beschrijven wij het basisprincipe van de methode en beogen wij een overzicht te geven van de clinical evidence in relatie tot de voorspellende waarde van de methode van trombo-elastografie als screeningstest voor coagulopathie bij 
patiënten met massaal bloedverlies en als hulpmiddel in het veld van de transfusiegeneeskunde.

\section{Tromboelastografie $\left(\right.$ TEG $^{\circledR}$ ) en Tromboelastometrie (ROTEM ${ }^{\circledR}$ )}

Het basisprincipe van de methode van de trombo-elastografie berust op het registreren van visco-elastische veranderingen die optreden tijdens het stollingsproces. De toename en later de afname van de visco-elasticiteit tijdens de stolling en fibrinolyse worden gemeten in een kleine hoeveelheid bloed aanwezig in een cup, waarin een pin hangt. Wanneer stolselvorming optreedt en de gevormde fibrinedraden zich vasthechten aan zowel de cup als aan de pin, neemt tengevolge van de toename in visco-elasticiteit van het bloed, de weerstand in de cup toe en zal dit door de pin worden geregistreerd. De veranderingen in weerstanden die de pin registreerd, worden via elektromechanische technieken omgezet naar digitale data wat door een computer vertaald wordt naar een curve, de zg. trombo-elastogram curve (zie figuur $1 \mathrm{~A}$ ). Is er geen stolling, dan wordt er geen tractie uitgeoefend op de pin en laat de curve een rechte lijn zien. Bij een sterk en stevig fibrinestolsel echter, beweegt de pin direct in fase met de cup, dat resulteert in een grote uitslag op de curve. Wanneer vervolgens het stolsel oplost (fibrinolyse) leidt dit tot afname van de visco-elasticiteit en de beweging van de pin dat zich grafisch vertaalt in een rechtevenredige afname van de amplitude van de curve. ${ }^{7}$

Tegenwoordig zijn er twee varianten van de oorspronkelijke trombo-elastograaf in gebruik:

- De tromboelastografie of de $\mathrm{TEG}^{\circledR}$ is afkomstig van Haemoscope Corporations en is gebaseerd op het oorspronkelijke meetprincipe waarbij de cup om de pin draait.

- De tromboelastometrie of de ROTEM ${ }^{\oplus}$ wordt geleverd door Pentapharm $\mathrm{GmbH}$ en is gebaseerd op een gemodificeerd principe waarbij de pin in de cup draait.

Hoewel de grafische weergaven van beide methoden grote gelijkenissen vertonen, gebruikt iedere fabrikant een eigen nomenclatuur (zie figuur $1 A, B$ en tabel 1 ) en kennen beide apparaten enkele verschillen (o.a. een verschil in oppervlaktelading en grootte van cup en pin) zodat de absolute waarden van de metingen niet met elkaar vergelijkbaar zijn. Oorspronkelijk werd onbewerkt bloed zonder toevoeging van antistolling of activatoren gebruikt. Dit houdt in dat de bepaling in minder dan 5 minuten na afname vitgevoerd moet worden en de vitslag pas na 20-30 minuten bekend is. Citraat-ontstold bloed, dat momenteel wordt gebruikt, beinvloedt de trombo-elastografie variabelen tot 90 minuten na afname. 
A

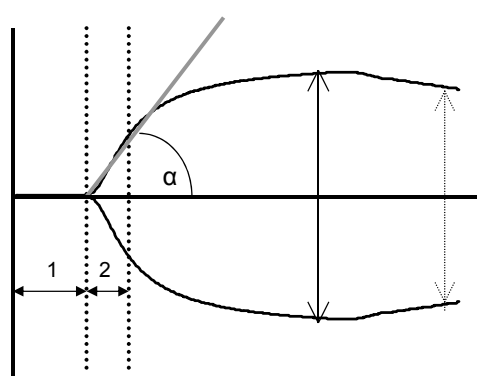

B

\begin{tabular}{|c|c|c|c|}
\hline \multicolumn{2}{|c|}{ Parameter } & \multirow{2}{*}{$\frac{\mathrm{TEG}^{\oplus}}{\mathrm{r}}$} & \multirow{2}{*}{$\frac{\text { ROTEM }^{\circledast}}{\text { CT }}$} \\
\hline 1 & $\begin{array}{l}\text { Periode tot } 2 \mathrm{~mm} \\
\text { amplitude }\end{array}$ & & \\
\hline 2 & $\begin{array}{l}\text { Periode van } 2 \text { tot } 20 \mathrm{~mm} \\
\text { amplitude }\end{array}$ & k & CFT \\
\hline$\alpha$ & Alpha hoek & $\begin{array}{l}\alpha \text { (hoek } \\
\text { tussen ren k) }\end{array}$ & $\begin{array}{l}\alpha \text { (hoek van } \\
\text { raaklijn bij } 2 \text { mm } \\
\text { amplitude) }\end{array}$ \\
\hline$\downarrow$ & $\begin{array}{l}\text { Amplitude, klont } \\
\text { stevigheid }\end{array}$ & MA & $\mathrm{MCF}$ \\
\hline 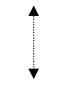 & Fibrinolyse & $\begin{array}{l}\text { CL3o, } \\
\text { CL6o }\end{array}$ & $\begin{array}{l}\mathrm{LY}_{30} \\
\text { LY6o }\end{array}$ \\
\hline
\end{tabular}

Figuur 1. Trombo-elastografie tracing met bijbehorende nomenclatuur voor de $\mathrm{TEG}^{\circledR}$ en de ROTEM ${ }^{\circledast}$. A. Representatieve trombo-elastografie curve. B. Bijbehorende nomenclatuur voor de TEG ${ }^{\oplus}$ en de ROTEM ${ }^{\oplus}$. In principe worden 5 variabelen gemeten: 1. Reactietijd: de tijd die loopt vanaf het starten van de meting tot er een uitslag op de tracing bereikt is van $2 \mathrm{~mm}$. Dit representeert de tijd die nodig is voor het initiëren van fibrinevorming, en is gerelateerd aan plasmastollingsfactoren en hun remmers (bijv. heparine). 2. Kinetische tijd: de tijd die gemeten wordt vanaf de R-waarde tot het punt waar een uitslag op de tracing van $20 \mathrm{~mm}$ wordt bereikt. Dit representeert een vaste mate van visco-elasticiteit van het gevormde stolsel. 3. Alfa-hoek: de hoek tussen de middellijn van de tracing en de lijn tangentiaal op de tracing representeert de snelheid van stolselvorming. 4. Amplitude: reflecteert de absolute sterkte van het stolsel en is afhankelijk van bloedplaatjes en fibrine. Stolling vindt plaats tot de amplitude is bereikt. (Bij stolselretractie en fibrinolyse neemt de amplitude weer af). $\mathbf{5}$. Fibrinolyse: de amplitude neemt af hetgeen wordt aangegeven als de afname t.o.v. de maximale amplitudo na 30 en 60 minuten. De gemeten fibrinolyse is mede afhankelijk van de amplitude, omdat het proces van fibrinolyse al kan worden gestart terwijl de amplitude nog niet is bereikt. Normaalwaarden zijn bij beide meetinstrumenten afhankelijk van de gebruikte activatoren en door onderlinge verschillen in de apparatuur onderling dus niet vergelijkbaar.

Deze trombo-elastografische metingen moeten derhalve na een gestandaardiseerde rustperiode worden uitgevoerd. Door het gebruik van activatoren zoals o.a. kaoline en weefsel tromboplastine zijn de testuitslagen sneller bekend (10-15 minuten na start analyse) en zou ook de variatie in deze kritische periode afnemen en wellicht deze rustperiode overbodig zijn. ${ }^{8}$ Door het gebruik van specifieke activatoren of reagentia (heparinase en aprotinine) worden meerdere fasen van de hemostase tegelijk in beeld gebracht. Door het vergelijken van de verschillende curven kan men theoretisch de oorzaak van de gemeten afwijking achterhalen. In figuur 2 staan voorbeelden van trombo-elastografie curven onder verschillende klinische condities. De nieuwste toepassing van de $\mathrm{TEG}^{\circledR}$ is de zg. "PlateletMapping"; met behulp van 
deze applicatie kan het effect van bloedplaatjesremmers als clopidogrel en acetylsalicylzuur worden gemeten. Dit gebeurt aan de hand van drie afzonderlijke metingen:

- In eerste instantie wordt de stolsel sterkte bepaald in kaoline geactiveerd bloed (100\% standaard).

- Vervolgens wordt in heparine bloed (stolsel zonder functionele bijdrage van trombine en zonder bloedplaatjesactivatie) door middel van activatie met factor XII en reptilase wederom de fibrine stolselsterkte bepaald (o\% standaard).

- Vervolgens wordt in datzelfde heparine bloed nu na bloedplaatjesactivatie met ofwel ADP ofwel arachidonzuur, een derde maal de stolselsterkte bepaald (bloedplaatjes activiteit). Deze uitslag (de (resterende bloedplaatjes functie) wordt gerelateerd aan de $100 \%$ en $0 \%$ standaard. ${ }^{9}$

Klinisch onderzoek over de waarde van deze techniek ontbreekt en belangrijk is om te vermelden dat ook in deze techniek wordt gekeken naar de functionaliteit van bloedplaatjes in afwezigheid van trombine, de belangrijkste activator in vivo.

\section{Massaal bloedverlies en coagulopathie}

Weefselschade, shock, hemodilutie, hypothermie, acidose, en inflammatie spelen allen een rol bij het optreden van coagulopathie als gevolg van massaal bloedverlies. Naast de mate van weefsel- en endotheelschade, zijn de aanwezigheid en de duur van shock, de snelheid van het bloedverlies, en bijkomende factoren zoals acidose en hypothermie bepalend voor de snelheid waarmee stollingsstoornissen optreden. Naast het verlies, verbruik en remming van stollingsfactoren en bloedplaatjes en fibrinolyse, speelt activatie van het trombomoduline- proteïne $C$ systeem een belangrijke rol bij het optreden van coagulopathie na ernstig trauma. ${ }^{10}$ De kans op overleving verslechtert door de aanwezigheid van de "lethale triade", de combinatie van acidose, coagulopathie en hypothermie. ${ }^{2}$ Naast hemodilutie en hypothermie zijn de uitgebreidheid van de ingreep, duur van de perfusie, heparine, protamine, en trombopathie als gevolg van extracorporale circulatie in combinatie met medicatie belangrijke factoren bij vooral cardiale chirurgie. Bij gecontroleerd bloedverlies zonder shock treedt in geval van een normale stollingsstatus coagulopathie pas op na verlies van 1-2 maal het bloedvolume, waarbij de fibrinogeenvoorraad als eerste beperkend wordt. ${ }^{11}$ 
Trombo-elastografie en massaal bloedverlies 

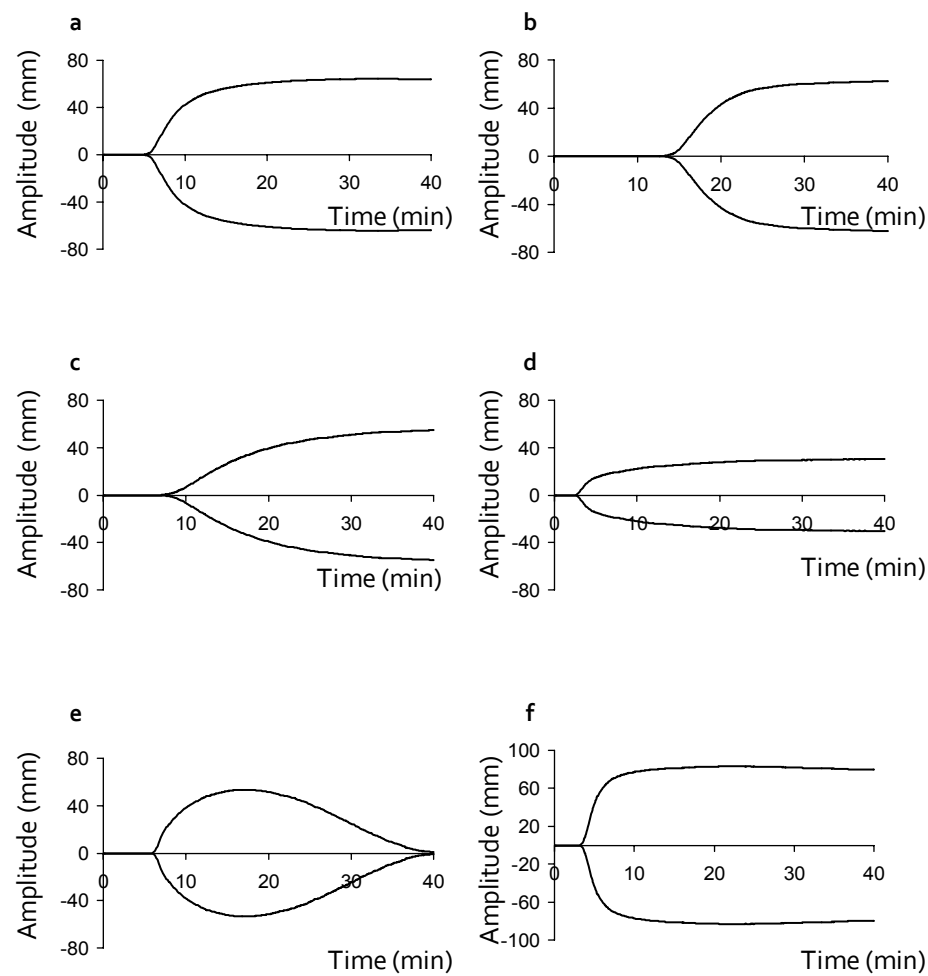

Figuur 2. Trombo-elastografie tracings van verschillende klinische condities. a) curve afkomstig van een gezonde vrijwilliger; b) curve afkomstig van een patiënt met een factor deficiëntie of heparine gebruik, waardoor het proces van fibrine vorming vertraagd wordt en dus de lagtime toeneemt ( $r$ en CT). Het vermogen om een sterke fibrine klont te maken is onveranderd en dit komt tot uiting in een overanderde maximale amplitude (MA en MCF); $c$ ) curve afkomstig van een patiënt met een lage fibrinogeen spiegel, hierdoor wordt de maximale sterkte van een fibrine klont verminderd. Dit komt tot uiting in een afname van de maximaal haalbare amplitude (MA, MCF en $\alpha$-angle); d) curve afkomstig van een patiënt met een tekort aan functionele bloedplaatjes, wat tot gevolg heeft dat er door ontbreken van een phospholipiden oppervlak en clotretractie een minder sterke fibrine stolsel gevormd wordt. Dit resulteert in een lagere maximale amplitude (MA en MCF); (e) curve afkomstig van een patiënt met een hyperfibrinolyse, hierbij wordt het gevormde fibrine stolsel na aanmaak snel weer afgebroken waardoor de amplitude van de trombo-elastografie tracing snel afneemt; en f) curve afkomstig van een patiënt met hypercoagulabiliteit, hetgeen resulteert in een overmatige stolling (korte $r$ en $\mathrm{CT}$ ) en zeer sterke fibrine stolsels (hoge maximale amplitude, MA en MCF). 


\section{Trombo-elastografie en massaal bloedverlies}

Via een search in Pubmed met als zoektermen "point of care/of point-of-care and surgery", "surgery/of trauma and massive blood loss/of bleeding", "impaired haemostasis and bleeding" en "thromboelastography and massive blood loss" in de periode van 2001-2008 zijn de meest representatieve artikelen in tabel 2 samengevat. Hieruit blijkt dat de methode van de trombo-elastografie het meest wordt toegepast in de gebieden van de trauma en cardiale chirurgie. De voorspellende waarde van de trombo-elastografie op het bloedingsrisico van patiënten die cardiale chirurgie ondergaan blijkt gering, zo niet afwezig uit prospectieve observationele studies van Cammerer, Mengistu en Ti. ${ }^{12-14}$ Reinhofer en medewerkers vonden in hun studie dat na cardiale chirurgie postoperatief de ROTEM een hogere positief voorspellende waarde had om bloedverlies te voorspellen dan de huidige conventionele stoltesten. ${ }^{15}$ Daarentegen vond Davidson en medewerkers alleen een hoge negatief voorspellende waarde voor postoperatief bloedverlies. ${ }^{16}$ Slechts een enkele studie onderzocht de relatie tussen parameters van de ROTEM met de bestaande conventionele stoltesten. ${ }^{17}$ Levrat en medewerkers hebben aangetoond dat de euglobuline lysis time (ELT) van de ROTEM in staat was om trauma patiënten met een verhoogde fibrinolyse te detecteren, waarna gerichte therapie mogelijk was. ${ }^{18}$

Het mogelijk belang van de methode van de trombo-elastografie in de transfusiegeneeskunde is onderzocht door o.a. Spalding en Anderson. ${ }^{19,20}$ Uit deze studies blijkt dat de toepassing van de trombo-elastografie de transfusie van bloedproducten waaronder rode bloedcelconcentraten (RBC), fresh frozen plasma (FFP) en bloedplaatjesconcentraten (PC) kan doen verminderen. Daarentegen vindt Avidan geen verschil in de transfusie van bloedproducten tussen groepen die enerzijds gemonitord werden met point-of-care testen of anderszijds met conventionele stoltesten. ${ }^{21}$ Uit een prospectieve studie van Westbrook bij patiënten na cardiale chirurgie werd een trend gezien van verminderd gebruik van bloedproducten postoperatief die gemonitord werden via de $\mathrm{TEG}^{\circledR}$ in vergelijking tot conventionele stoltesten. ${ }^{22}$

\section{Trombo-elastografie en factorconcentraten}

De groeiende interesse naar het gebruik van factorconcentraten bij massaal bloedverlies heeft tot gevolg dat er behoefte is aan diagnostische testen, die het effect van de factor concentraten op de hemostase beter kunnen evalueren. De huidige stoltesten waaronder de PT en aPTT die informatie geven tot het moment dat de eerste fibrinesporen ontstaan, zijn hier niet toe in staat. Het toedienen van recombinant factor VIla en protrombine complex concentraat leiden tot een verhoogde trombinegeneratie; toedienen van fibrinogeen tot meer substraat voor 
trombine om fibrine te genereren, en factor XIII tot een betere en snellere polymerizatie van fibrinemonomeren tot een fibrinenetwerk. Door de toediening van deze concentraten onstaan sterkere fibrinestolsels (gemeten met behulp van de trombo-elastografie) zonder dat de patiënt verder wordt verdund. Het toedieningsvolume van de factorconcentraten is vele male kleiner dan wanneer plasma transfusie gegeven wordt. De trombo-elastograaf wordt naast het bewaken van de hemostase bij massaal bloedverlies, ook steeds vaker toegepast om het effect van bovengenoemde factorconcentraten op de hemostase te evalueren. ${ }^{23,24}$ Gerandomiseerd klinisch onderzoek aangaande de relevantie hiervan ontbreekt nog tot op heden.

\section{Conclusies}

De huidige conventionele stoltesten waaronder de PT, aPTT en INR die gebruikt worden voor het evalueren van de stollingsstatus van patiënten, zijn niet toerijkend voor condities die optreden bij massaal bloedverlies met ernstige stollingsproblemen. De hernieuwde interesse voor het gebruik van de trombo-elastograaf verschaft nieuwe kennis over de sterkte van een fibrinestolsel, zelfs in verdund bloed afkomstig van patiënten met stollingsproblemen. Uit het overzicht van de literatuur van het gebruik van de trombo-elastograaf bij massaal bloedverlies, blijkt dat de methode vooral wordt toegepast in de cardiale chirurgie en trauma in beperkte prospectieve observationele studies. De positief voorspellende waarde van de trombo-elastograaf om het risico op ernstig bloedverlies postoperatief te voorspellen blijkt laag te zijn, met veelal hoog negatief voorspellende waarden. Opmerkelijk is dat er weinig onderzoek is verricht naar de validatie van de trombo-elastograaf ten opzichte van de huidige routine stoltesten, wat een uitgebreide toepassing van de tromboelastografie beperkt. Als onderdeel van "een transfusiebeleid op maat" heeft de toepassing van de trombo-elastograaf in veel gevallen tot gevolg dat t.o.v. historische controles zonder vast omschreven transfusieprotocol, zowel het aantal transfusies als het aantal bloedproducten per patiënt afneemt. In hoeverre zich dit vertaalt in de overige klinische uitkomst van deze patiënten wordt in de betreffende studies onvoldoende vermeld. De laatste jaren wordt de trombo-elastograaf tevens gebruikt om het effect van interventie van factorconcentraten op de stollingsstatus te evalueren. In de toekomst zal de waarde van de trombo-elastografie alleen van betekenis kunnen zijn, indien er nauwkeurige validatie van de testresultaten plaatsvindt en, in combinatie met gestandaardiseerde transfusieprotocollen, de klinische relevantie voor de verschillende settings wordt onderzocht door middel van gerandomiseerde (geblindeerde) studies tussen verschillende ziekenhuizen. 


\section{Aanwijzingen voor de praktijk}

- De huidige toepassing van de methode van de trombo-elastografie beperkt zich grotendeels tot de cardiale chirurgie en trauma.

- De trombo-elastrograaf blijkt tot dusver een lage voorspellende waarde te hebben om het risico op ernstig bloedverlies postoperatief in te schatten.

- Als onderdeel van een transfusiealgoritme bij cardiochirurgische patiënten heeft de toepassing van de trombo-elastografie in veel gevallen tot gevolg, dat zowel het aantal transfusies als het aantal bloedproducten per patiënt afneemt (t.o.v. historische controles vaak zonder vast omschreven transfusieprotocol).

- Optimale validatie en grote multi-center gerichte klinische studies in combinatie met gestandaardiseerde transfusieprotocollen zijn noodzakelijk om de waarde voor meer vitgebreider klinisch gebruik te bepalen. 
Addendum

160 
Trombo-elastografie en massaal bloedverlies

161 
Addendum

162 


\section{Referenties}

1. O'Shaughnessy DF, Atterbury C, Bolton Maggs $P$, Murphy $M$, Thomas D, Yates S, Williamson LM. Guidelines for the use of fresh-frozen plasma, cryoprecipitate and cryosupernatant. Br J Haematol 2004; 126:11-28.

2. Levy JH. Massive transfusion coagulopathy. Semin Hematol 2006; 43:S59-S63.

3. Kang YG, Mart in DJ, Marquez J, Lewis JH, Bontempo FA, Shaw BW, Jr., Starzl TE, Winter PM. Intraoperative changes in blood coagulation and thrombelastographic monitoring in liver transplantation. Anesth Analg 1985; 64:888-896.

4. Spiess BD, Gillies BS, Chandler W, Verrier E. Changes in transfusion therapy and reexploration rate after institution of a blood management program in cardiac surgical patients. J Cardiothorac Vasc Anesth 1995; 9:168-173.

5. Kozek-Langenecker S. Management of massive operative blood loss. Minerva Anestesiol 2007; 73:401-415.

6. Heindl B, Biberthaler P. [Coagulation management of severe surgical bleeding.]. Unfallchirurg 2008; 111:574-583.

7. Luddington RJ. Thrombelastography/thromboelastometry. Clin Lab Haematol 2005; 27:81-90.

8. Johansson PI, Bochsen L, Andersen S, Viuff D. Investigation of the effect of kaolin and tissue factor-activated citrated whole blood, on clot forming variables, as evaluated by thromboelastography. Transfusion 2008; 48:2377-2383.

9. Bochsen L, Wiinberg B, Kjelgaard-Hansen M, Steinbruchel DA, Johansson PI. Evaluation of the TEG platelet mapping assay in blood donors. Thromb J 2007; 5:3.

10. Cohen MJ, Brohi K, Ganter MT, Manley GT, Mackersie RC, Pittet JF. Early coagulopathy after traumatic brain injury: the role of hypoperfusion and the protein $\mathrm{C}$ pathway. $J$ Trauma 2007; 63:1254-1261.

11. Hiippala ST, Myllyla GJ, Vahtera EM. Hemostatic factors and replacement of major blood loss with plasma-poor red cell concentrates. Anesth Analg 1995; 81:360-365.

12. Cammerer U, Dietrich W, Rampf T, Braun SL, Richter JA. The predictive value of modified computerized thromboelastography and platelet function analysis for postoperative blood loss in rout ine cardiac surgery. Anesth Analg 2003; 96:51-57.

13. Mengistu AM, Wolf MW, Boldt J, Rohm KD, Lang J, Piper SN. Evaluation of a new platelet function analyzer in cardiac surgery: a comparison of modified thromboelastography and whole-blood aggregometry. J Cardiothorac Vasc Anesth 2008; 22:40-46.

14. Ti LK, Cheong KF, Chen FG. Prediction of excessive bleeding after coronary artery bypass graft surgery: the influence of timing and heparinase on thromboelastography. J Cardiothorac Vasc Anesth 2002; 16:545-550.

15. Reinhofer $M$, Brauer $M$, Franke $U$, Barz D, Marx G, Losche W. The value of rotation thromboelastometry to monitor disturbed perioperative haemostasis and bleeding risk in pat ients with cardiopulmonary bypass. Blood Coagul Fibrinolysis 2008; 19:212-219.

16. Davidson SJ, McGrowder D, Roughton M, Kelleher AA. Can ROTEM thromboelastometry predict postoperative bleeding after cardiac surgery? J Cardiothorac Vasc Anesth 2008; 22:655-661.

17. Rugeri L, Levrat A, David JS, Delecroix E, Floccard B, Gros A, Allaouchiche B, Negrier C. Diagnosis of early coagulation abnormalities in trauma patients by rotation thrombelastography. J Thromb Haemost 2007; 5:289-295. 
18. Levrat A, Gros A, Rugeri L, Inaba K, Floccard B, Negrier C, David JS. Evaluation of rotation thrombelastography for the diagnosis of hyperfibrinolysis in trauma patients. $\mathrm{Br} \mathrm{J}$ Anaesth 2008; 100:792-797.

19. Spalding GJ, Hartrumpf M, Sierig T, Oesberg N, Kirschke CG, Albes JM. Cost reduction of perioperative coagulation management in cardiac surgery: value of "bedside" thrombelastography (ROTEM). Eur J Cardiothorac Surg 2007; 31:1052-1057.

20. Anderson L, Quasim I, Soutar R, Steven M, Macfie A, Korte W. An audit of red cell and blood product use after the institution of thromboelastometry in a cardiac intensive care unit. Transfus Med 2006; 16:31-39.

21. Avidan MS, Alcock EL, Da Fonseca J, Ponte J, Desai JB, Despot is GJ, Hunt BJ. Comparison of structured use of routine laboratory tests or near-patient assessment with clinical judgement in the management of bleeding after cardiac surgery. Br J Anaesth 2004; 92:178-186.

22. Westbrook AJ, Olsen J, Bailey M, Bates J, Scully M, Salamonsen RF. Protocol Based on Thromboelastograph (TEG) Out-Performs Physician Preference Using Laboratory Coagulation Tests to Guide Blood Replacement During and After Cardiac Surgery: A Pilot Study. Heart Lung Circ 2008; in press.

23. Tanaka KA, Taketomi T, Szlam F, Calatzis A, Levy JH. Improved clot formation by combined administration of activated factor VII (NovoSeven) and fibrinogen (Haemocomplettan P). Anesth Analg 2008; 106:732-738.

24. Mittermayr M, Streif W, Haas T, Fries D, Velik-Salchner C, Klingler A, Oswald E, Bach C, Schnapka-Koepf M, Innerhofer P. Hemostatic changes after crystalloid or colloid fluid administration during major orthopedic surgery: the role of fibrinogen administration. Anesth Analg 2007; 105:905-917.

25. Plotkin AJ, Wade CE, Jenkins DH, Smith KA, Noe JC, Park MS, Perkins JG, Holcomb JB. A reduction in clot formation rate and strength assessed by thrombelastography is indicative of transfusion requirements in patients with penetrating injuries. J Trauma $2008 ; 64: \mathrm{S}_{4}-\mathrm{S} 68$. 


\section{Curriculum vitae}




\section{Curriculum Vitae}

Saskia Schols was born on the $1^{\text {st }}$ of March 1982 in Heerlen, the Netherlands. After finishing secundary school at the Eijkhagen College in Landgraaf in 2000, she moved to Maastricht to study Medicine at Maastricht University. During her study she was assigned as student assistant to the Department of Education of the Faculty of Medicine, Health and Life Sciences where she assisted the Skills Lab. In 2003 she followed the course Tropics to prepare for an internship at the Department of Paediatrics of the St. Vincentius Hospital, in Paramaribo, Suriname. In October 2004, she obtained her doctoral degree in Medicine. Subsequently, she did a research project at the Haematology Laboratory of the Maastricht University Medical Centre to develop laboratory tests for optimizing transfusion protocols for patients undergoing surgery. This was directed by dr. E.C.M. van Pampus, dr. K. Hamulyák and prof. dr. H.C. Schouten. In 2006 she received a Kootstra Fellowship for talented students from the Faculty of Health, Medicine and Life Sciences in Maastricht, to continue this research. In the same year she finished her study Medicine and started her $\mathrm{PhD}$ research described in this thesis, at the Department of Biochemistry within the Cardiovascular Research Institute of Maastricht (CARIM), under supervision of dr. J.W.M. Heemskerk, dr. E.C.M. van Pampus and prof. dr. H. ten Cate. This work was supported by an unrestricted grant from CSL Behring. During her PhD period, she gave invited talks and poster presentations at scientific conferences in Wittenberg (Germany), Geneva (Switzerland) and Boston (USA). She performed working visits in the laboratories of prof. dr. S. Jackson in Melbourne (Australia) and dr. W. Bergmeier in Philadelphia (USA). In October 2009, she started her specialisation at the Department of Internal Medicine at the Maastricht University Medical Centre. 


\section{Publications}




\section{List of publications}

\section{Papers}

- Schols SEM, van der Meijden PEJ, van Oerle R, Curvers J, Heemskerk JWM and van Pampus ECM. Increased thrombin generation and fibrinogen level after therapeutic plasma transfusion: Relation to bleeding. Thromb Haemost. 2008; 99:64-70.

- Schols SEM, Feijge MAH, Lancé MD, Hamulyák K, ten Cate H, Heemskerk JWM and van Pampus ECM. Effects of plasma dilution on tissue factor-induced thrombin generation and thromboelastography: partly compensating role of platelets. Transfusion. 2008; 48:2384-2394.

- Schols SEM and van Pampus ECM. Thrombo-elastografie: een hulpmiddel bij massaal bloedverlies? Tijdschrift voor Bloedtransfusie. 2009; 2:39-46.

- Schols SEM, Heemskerk JWM and van Pampus ECM. Correction of coagulation in dilutional coagulopathy: Use of kinetic and capacitive coagulation assays to improve hemostasis. Transfusion Medicine Reviews 2010; 24:44-52.

- Schols SEM, Lancé MD, Feijge MAH, Damoiseaux J, Marcus MA, Hamulyák K, ten Cate $\mathrm{H}$, Heemskerk JWM and van Pampus ECM. Impaired thrombin generation and fibrin clot formation in patients with dilutional coagulopathy during major surgery. Thromb Haemost 2010; 103:in press.

- Schols SEM, Cosemans JMEM, Stefanini L, Feijge MAH, Hamulyák K, Deckmyn $\mathrm{H}$, Bergmeier W and Heemskerk JWM. Novel role of glycoprotein Ib-V-IX and von Willebrand factor in platelet-dependent fibrin fibre formation at low shear flow. Submitted.

- $\quad$ Berny MA, Munnix ICA, Auger JM, Schols SEM, Cosemans JMEM, Panizzi P, Bock PE, Watson SP, McCarthy OJT and Heemskerk JWM. Location of coagulation factors in shear flow dependent thrombus formation. Submitted. 


\section{Abstracts}

- Schols SEM, van der Meijden PEJ, Curvers J, Heemskerk JWM and van Pampus ECM. Detection of anti-haemostatic effect of plasma dilution via thrombin generation. Proceedings of the $\mathrm{XX}_{1}{ }^{\text {st }}$ European Platelet Meeting. 2007, Wittenberg, Germany.

- $\quad$ Schols SEM, van der Meijden PEJ, Cuvers J, Heemskerk JWM and van Pampus ECM. Detection of anti-haemostatic effect of plasma transfusion via thrombin generation. J Thromb Haemost. 2007; 5: supplement 2.

- Schols SEM, Lancé MD, Feijge MAH, Damoiseaux J, Marcus MA, Hamulyák K, ten Cate $\mathrm{H}$, Heemskerk JWM and van Pampus ECM. Impaired thrombin generation and fibrin clot formation in patients with dilutional coagulopathy in major surgery. J Thromb Haemost. 2009; supplement.

- Schols SEM, Berny MA, Cosemans JMEM, Gilio K, Feijge MAH, Deckmyn H and Heemskerk JWM. New role of platelets in inducing fibrin formation under flow. J Thromb Haemost. 2009; supplement.

- $\quad$ Berny MA, Munnix ICA, Schols SEM, Bock PE, McCarthy OJ and Heemskerk JWM. Heterogeneous localization of coagulation factors in an ex vivo model of thrombus formation. J Thromb Haemost. 2009; supplement. 


\section{Oral presentations}

- Detection of anti-haemostatic effect of plasma dilution via thrombin generation. European Platelet Meeting. 2007, Wittenberg, Germany.

- Detection of haemostatic effect of FFP transfusion and role of platelets in diluted plasma - an in vitro assay and a patient study. Department of Internal Medicine, Maastricht University Medical Centre. 2008, Maastricht, the Netherlands.

- Monitoring dilutional coagulopathy in patients with peri/post-operative massive bleeding problems. Department of Cardiothoracic Surgery, Maastricht University Medical Centre. 2008, Maastricht, the Netherlands.

- Can combined measurement of thrombin potential and thromboelastography predicts the risk of severe bleeding in surgery and trauma? First results. Maastricht Acquired Bleeding Investigators Group (MABIG) and CSL Behring R\&D. 2007, Maastricht, the Netherlands.

\section{Awards}

- Kootstra Fellowship talented student, Faculty of Healthy, Medicine and Life Sciences, University of Maastricht, intended for the period between graduation of study medicine and the appointment of medical specialization.

- Poster award, XXII ${ }^{\text {nd }}$ Congress of the International Society on Thrombosis and Haemostasis, Boston, USA 2009.

- PhD student of August 2009 of newsletter Vascular Medicine. 
Dankwoord 


\section{Mijn promotieteam}

Mijn wetenschappelijke carrière begon op een voorjaarsdag in maart 2005. Voor mijn wetenschapsstage had ik een afspraak met prof. dr. Schouten. Hij wist op dat moment wel iemand die op zoek was naar een student om onderzoek te doen. Niet veel later verscheen jij, Lizzy, in de kamer van professor Schouten, met een brede glimlach! Ik zal die ontmoeting niet snel vergeten. Je legde uit wat het onderzoek inhield en voor ik het wist was ik een complete collectie van artikelen over trombocyten transfusies rijker. Je nam me direct mee naar de afdeling biochemie waar je een meeting had met een bloedplaatjes expert. En dat bleek jij te zijn Johan. Je kreeg te horen dat een student onderzoek bij je zou komen gaan doen naar de invloed van plasmatransfusie op de stollingscapaciteit. Volgens jou kon dat het beste met trombinegeneratiemetingen in PPP of PRP. "In wat?" dacht ik. Oei, dat zouden nog weleens een paar lastige weken kunnen worden... Het bleken de meest memorabele weken van mijn studie geneeskunde. Ik werd meteen in het lab gezet voor trombinegeneratiemetingen. De eerste pipet die ik in mijn handen kreeg heeft het weliswaar niet lang uitgehouden, maar de resultaten gaven aanleiding tot mooie discussies.

Uiteindelijk heb ik na mijn wetenschapsstage de Kootstra Fellowship beurs gekregen om verder te kunnen gaan met onderzoek na de studie. Ik leerde Hugo en Karly kennen die ook onderzoek deden naar bloedstolling. Met z'n vijven vormden we de MABIG groep (waar stond dat ook alweer voor?), en zijn we op de meest stormachtige avond in de winter van 2006 naar Marburg vertrokken om bij CSL Behring geld te krijgen voor mijn onderzoek. Uiteindelijk heeft dit bezoek er toe geleid dat ik nog 2 jaar financiering kreeg om van mijn onderzoek een echt promotie traject te maken! Roger Nuijtinck, ik wil je heel erg bedanken voor alle moeite die je als vertegenwoordiger van CSL Behring hebt gedaan om het mogelijk te maken dat ik mijn onderzoek kon voltooien.

Johan, bedankt voor de kans die je mij gegeven hebt om dit promotieonderzoek te doen, en het geloof dat je in me had om toch iets extra's te doen naast trombinegeneratiemetingen. Dat extra bleek te FIMS te zijn, ik heb daar menige dagen in het donker gezeten en gestaard naar die bloedplaatjes en de fibrinevorming. Je hebt de afgelopen jaren heel wat teksten van mij gecorrigeerd (van artikelen tot subsidie-aanvragen), maar dit is dan de enige "lange lap tekst" die niet ingekort gaat worden! Lizzy, jij ook heel erg bedankt, met woorden is het haast niet te beschrijven hoeveel enthousiasme jij uitstraalde tijdens mijn hele promotieonderzoek. Zonder jou zou ik nooit in de afgelopen drie jaar het onderzoek afgerond kunnen hebben. Zelfs buiten kantooruren verzamelde jij nog bloedmonsters. Nu ik begonnen ben in de kliniek bij interne geneeskunde hoop ik nog veel van je te leren! Hugo en Karly, 
bedankt voor de fijne discussies over mijn project en alle keren dat ik mijn artikelen door jullie kon laten nakijken. Ik heb er veel van geleerd. Hugo, als supervisor van de afdeling waar ik nu sta, blijven we samenwerken!

\section{Het ondersteunende lab}

Om aan alle bloedmonsters te komen die ik de afgelopen drie jaar verzameld heb, was een samenwerking met het lab hematologie onontbeerlijk. Yvonne Henskens en je hele team aan analisten, heel erg bedankt voor jullie gastvrijheid als ik weer eens langskwam om laboratoriumuitslagen op te vragen of bloedmonsters te halen. Marcus Lancé, zonder jou als anesthesist op de plek waar direct bloed werd afgenomen van de patiënten, had ik natuurlijk nooit mijn patiëntenstudies kunnen voltooien. Je bent zelf ook druk bezig met je promotieonderzoek, waarbij ik je heel veel succes wil wensen. Met jouw enthousiasme gaat het je zeker lukken om het goed af te ronden! René en Carina, ook jullie wil ik graag bedanken voor het regelmatig doormeten van de vele patiëntenmonsters wanneer ik weer eens stoltijden of factorconcentraties nodig had voor mijn artikelen.

\section{Mijn bloedplaatjes collega's}

De afgelopen jaren zouden lang niet zo succesvol zijn geweest als ik niet zo'n fijne groep collega's zou hebben gehad. Ik wil jullie daar heel erg voor bedanken. Ook al had ik een andere studie achtergrond dan jullie en heb ik mij vooral op mijn eigen onderzoek geconcentreerd, ik heb genoten van jullie als collega's, ieder met zijn eigen unieke persoonlijkheid. Imke, vanaf het eerste contact dat ik met je had tijdens mijn wetenschapsstage hebben we veel lol gehad samen. We hebben wat afgekletst en privémomenten besproken in het lab, op het terras van niveau 4, in de altijd donkere FIMS ruimte, in Australië en op je oude kamer, wat later mijn plekje werd. Je zit nu al een tijdje in het Atrium ziekenhuis in Heerlen bij de klinische chemie, en hebt je plekje helemaal gevonden. Ik wil je heel erg bedanken dat je mijn paranimf wilt zijn en voor de gezellige momenten bij de biochemie! Karen, mijn andere paranimf, we zijn samen begonnen als AIO bij de plaatjesgroep. Je was mijn buurmeisje op de kamer voor de eerste 2 jaar. Ik heb alle voorbereidingen meegemaakt van je bruiloft en de bouw van je nieuwe stulpje. Je bent een echte multi-tasker (behalve op de fiets(:) en in tegenstelling tot mij ben je betrokken bij zowat alle lopende projecten van onze groep! Ik heb een super leuke tijd met je gehad bij de biochemie (en natuurlijk ons eerste avontuur in Wittenberg!). Ik weet zeker dat je een heel mooi boekje zult krijgen en ben erg benieuwd waar je hierna terecht komt. Bedankt dat je mijn paranimf wilt zijn! Judith, jij bent de rasechte wetenschapper van ons groepje. Je was mijn kamergenootje voor de eerste twee jaar, en toen ik naar een andere kamer 
ging ben je mij snel gevolgd $: ;$ ! Ik heb veel van je geleerd, en vond het fijn dat je geen geneeskunde hebt gestudeerd zodat ik jou ook af en toe wat kon uitleggen! We hebben leuke avonturen beleefd samen in Australië en Philadelphia (dat eerste ontbijt was echt een topper hè). Je bent een ontzettend harde werker en zult een mooie carrière tegemoet gaan, waar je ook voor zult kiezen.

Paola, je hebt me tijdens mijn wetenschapsstage veel geholpen om een brug te slaan tussen mijn klinische blik en de wetenschappelijke betekenis van de eerste resultaten. Je hebt na je promotie niet voor niets gekozen voor een plekje bij de meest klinisch georiënteerde groep van de biochemie. Ik wens je veel succes met het verdere beloop van je carrière. Marion en Marijke, als langstzittende collega's van de plaatjesgroep heb ik veel van jullie geleerd in het lab, tijdens de werkbespreking en wanneer ik weer eens hulp nodig had bij het uitvoeren van statistiek! Reyhan, je zit nu al enige tijd bij ons en hebt het druk naast je baan als AIO met het leren van de Nederlandse taal. Ik wens je veel succes met de afronding van je proefschrift en heb heel veel bewondering voor de manier waarop jij je staande houdt in een ander land, ver weg van je man, je familie en je vrienden! Monique en Roger, jullie zijn pas begonnen aan het AIO-avontuur en ik wens jullie veel succes met alle projecten die op jullie pad komen en natuurlijk de vele leuke uitstapjes en congressen. Marissa, jij was mijn enige student tijdens mijn AIO-tijd die ik begeleid heb. Je bent ongelooflijk fanatiek in het inzamelen van bloedmonsters en het vitvoeren van trombinegeneratie- en trombo-elastografie metingen. Ik wil je hiervoor erg bedanken! Sandra je bent nu al enige tijd werkzaam in Aken. Je was mijn directe begeleidster toen ik nog student was. Bedankt voor je behulpzaamheid om mij trombinegeneratiemeringen te leren.

Jan Rosing, ik wil je bedanken voor de inhoudelijke discussies die volgden op mijn presentaties tijdens de werkbesprekingen. Ik heb er veel van geleerd. Trees, onze gezamenlijke secretaresse van biochemie, ik wil je bedanken voor de vele leuke en afwisselende gesprekken die we hadden bij het koffiezetapparaat. En natuurlijk alle keren dat ik weer eens binnenviel en iets nodig had en niet wist hoe ik een document naar het buitenland moest faxen. Waar ik ook voor kwam, je was er altijd om me te helpen. Niko, je bent een jaar lang mijn kamergenoot geweest. Ik wil je graag bedanken voor de vele gezellige momenten op de kamer. We hebben wat afgekletst en je beurde me altijd weer op als er iets tegenzat! Heel erg veel geluk gewenst met je gezinnetje.

During my PhD period, I had the opportunity to visit and work in laboratories abroad. In 2007, I visited the laboratory of Shaun Jackson in Melbourne, Australia, for flow- 
dependent experiments. Although, by that time I hadn't have the experience with this type of experiments, I'd learned a lot. The second time abroad, I visited the laboratory of Wolfgang Bergmeier in Philadelpia, USA. We had to perform a lot of experiments in a very short time. I want to thank you, Wolfgang and Lucia for your intensive help during my stay. We had a lot of problems with the experiments during the first three days, however, finally we managed to succeed!

Ik wil graag alle leden van de leescommissie bedanken voor het lezen en vooral goedkeuren van mijn manuscript: prof. dr. J.W. Cohen Tervaert (voorzitter), dr. H.C.J Eikenboom (Leids Universitair Medisch Centrum), prof. dr. T. Hackeng, prof. dr. K. van Hoorelbeke (Katholieke Universiteit Leuven, België) en prof. dr. H. Schouten.

\section{Mijn vrienden en familie}

Miesje, Marieke, Elleke, Ilse, en Eda, we zijn vriendinnen geworden tijdens onze studie geneeskunde. Ondanks het feit dat we verspreid over het land terecht zijn gekomen, blijven we elkaar regelmatig zien wat altijd weer erg gezellig is! Tijdens de studie waren er de feestjes, nu doen we meer cultureel verantwoorde uitjes, en hebben we alweer een bruiloft samen meegemaakt, is er een kleine op komst en een andere bruiloft in aantocht.... Ik wil jullie bedanken voor alle gezellige momenten tijdens de afgelopen jaren dat een super afleiding was naast mijn onderzoek. Jullie waren altijd geïnteresseerd in wat ik nu precies deed en dat voelde erg fijn!

Lieve papa en mama, woorden schieten natuurlijk tekort om jullie te bedanken voor de steun tijdens mijn onderzoek. Dat de afgelopen jaren met ups en downs zijn verlopen is natuurlijk een understatement voor jullie. Ook al is het moeilijk uit te leggen waar ik nu precies onderzoek naar deed, jullie voelden me als geen ander aan of het goed ging of niet. De treinreis van Maastricht naar Eindhoven was een stuk korter als ik weer eens iets te vertellen had... Ik weet dat jullie me onvoorwaardelijk steunen, in alles wat ik doe, en dat geeft me ontzettend veel doorzettingsvermogen. Dank je wel, voor alles. Lieve Suzanne en Ruben, het is altijd weer enorm gezellig om bij jullie te zijn. Het wordt voor jullie een spannende tijd met de kleine op komst. Maar jullie weten dat er altijd een oppasplekje voor de kleine is in Eindhoven wanneer jullie favoriete PSV thuis speelt! Daarnaast wil ik mijn schoonfamilie, Jacintha, Hans, Manon en Martin bedanken voor de gezellige momenten als wij op bezoek komen.

En dan als laatste, mijn lieve Leon. Zonder jouw steun zou het mij nooit gelukt zijn om dit proefschrift te voltooien. Je bent voor mij verhuisd van Breda waar je werkte naar Eindhoven, zodat we konden gaan samenwonen en nu allebei iedere dag 
moeten reizen naar het werk. Ik vind het heerlijk na elke werkdag weer naar Eindhoven te reizen en de avond met jou door te brengen. Ik ben al snel gestopt om je uit te leggen waar ik nu precies onderzoek naar deed. Bij het horen van de termen bloedplaatjes, stolling en fibrine haakte jij snel af, en gelukkig maar, want bij jou kon ik tenminste aan iets anders denken. Dank je wel Leon, voor alle mooie jaren die we samen nu al hebben meegemaakt, en natuurlijk hoop ik op vele mooie jaren die zullen volgen. Ik weet dat ik altijd op jou kan rekenen, bedankt schat! 